\title{
Zinc supplementation for preventing mortality, morbidity, and growth failure in children aged 6 months to 12 years of age (Review)
}

Mayo-Wilson E, Junior JA, Imdad A, Dean S, Chan XHS, Chan ES, Jaswal A, Bhutta ZA

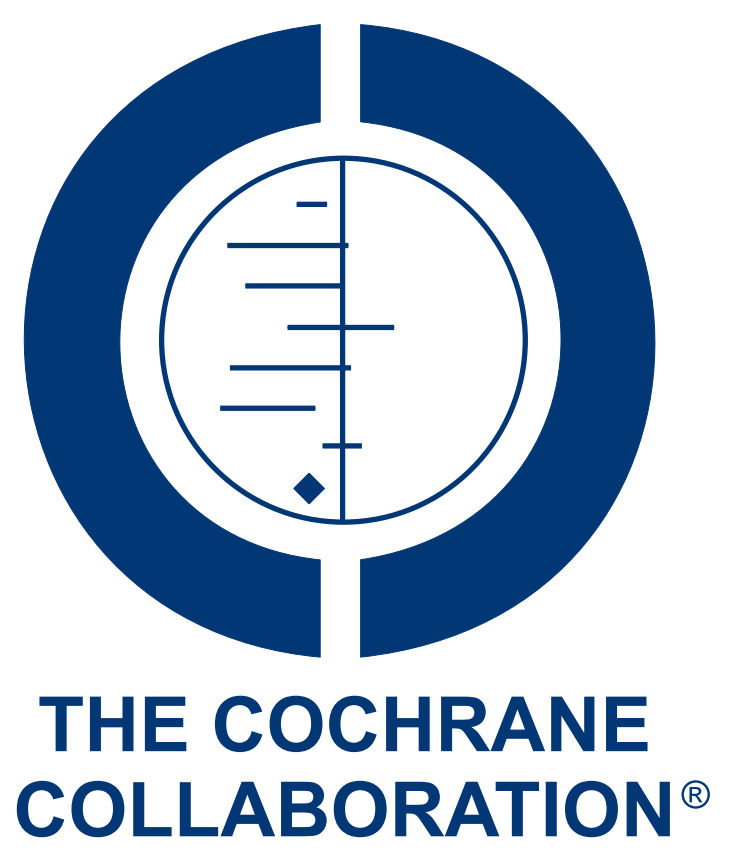

This is a reprint of a Cochrane review, prepared and maintained by The Cochrane Collaboration and published in The Cochrane Library 2014, Issue 5

http://www.thecochranelibrary.com

\section{WILEY}

Zinc supplementation for preventing mortality, morbidity, and growth failure in children aged 6 months to 12 years of age (Review) Copyright $\odot 2014$ The Cochrane Collaboration. Published by John Wiley \& Sons, Ltd. 
TABLE OF CONTENTS

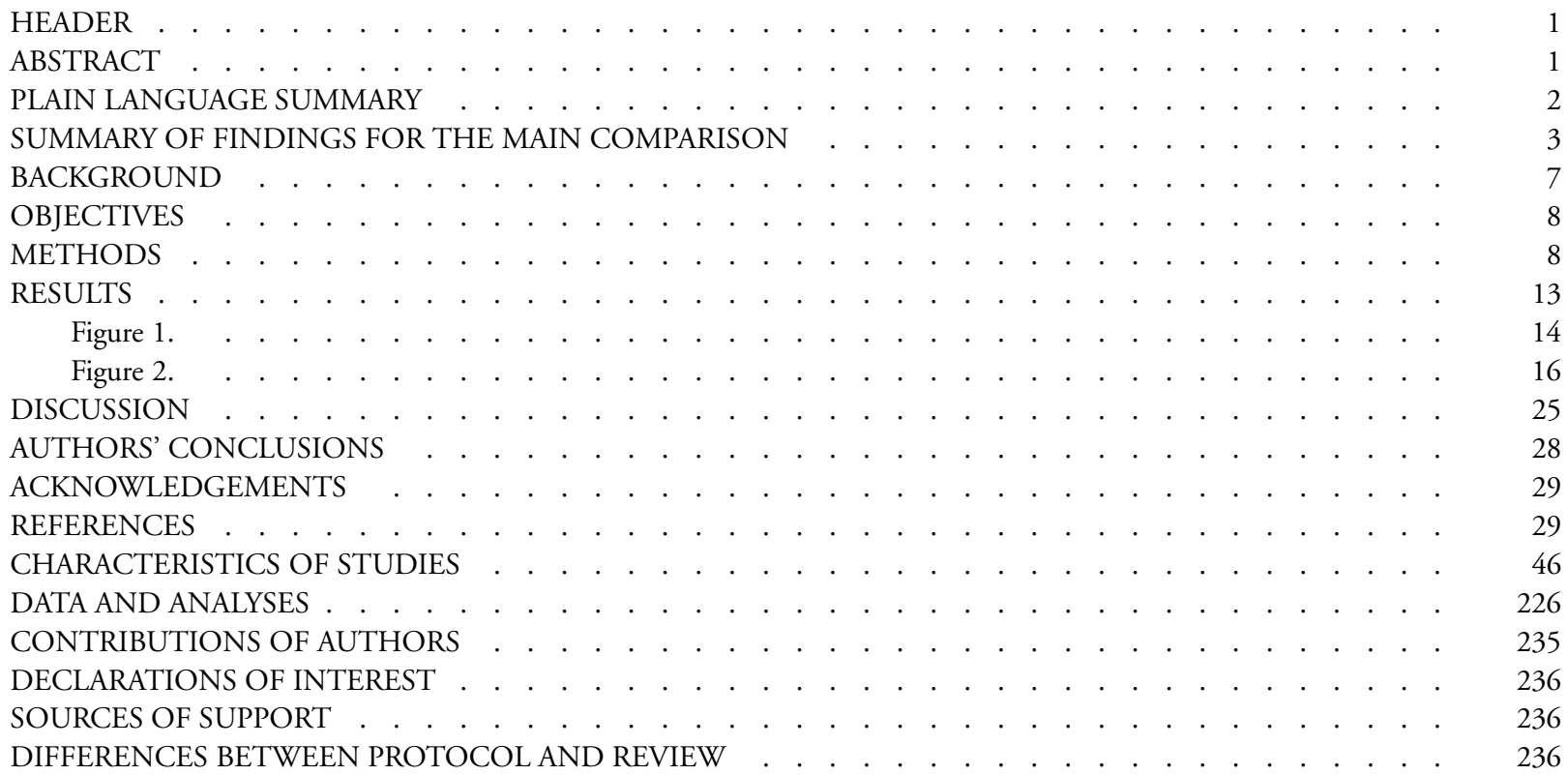

Zinc supplementation for preventing mortality, morbidity, and growth failure in children aged 6 months to 12 years of age (Review)

Copyright $\odot 2014$ The Cochrane Collaboration. Published by John Wiley \& Sons, Ltd. 


\title{
[Intervention Review]
}

\section{Zinc supplementation for preventing mortality, morbidity, and growth failure in children aged 6 months to $I 2$ years of age}

\author{
Evan Mayo-Wilson ${ }^{1}$, Jean A Junior ${ }^{2}$, Aamer Imdad ${ }^{3}$, Sohni Dean ${ }^{4}$, Xin Hui S Chan ${ }^{5}$, Evelyn S Chan ${ }^{6}$, Aneil Jaswal ${ }^{7}$, Zulfiqar A \\ Bhutta $^{8,9}$ \\ ${ }^{1}$ Department of Epidemiology, Johns Hopkins University Bloomberg School of Public Health, Baltimore MD, MD, USA. ${ }^{2}$ Harvard \\ Medical School, Boston, MA, USA. ${ }^{3}$ Department of Pediatrics, SUNY Upstate Medical University, Syracuse, New York, USA. ${ }^{4}$ Division \\ of Women and Child Health, Aga Khan University Hospital, Karachi, Pakistan. ${ }^{5}$ John Radcliffe Hospital, Oxford, UK. ${ }^{6}$ Department \\ of Public Health, National Perinatal Epidemiology Unit, University of Oxford, Oxford, UK. ${ }^{7}$ Nuffield Department of Population \\ Health, University of Oxford, Oxford, UK. ${ }^{8}$ Center for Global Child Health, Hospital for Sick Children, Toronto, Canada. ${ }^{9}$ Centre \\ for Excellence in Women and Child Health, Aga Khan University Hospital, Karachi, Pakistan
}

Contact address: Zulfiqar A Bhutta, zulfiqar.bhutta@aku.edu.

Editorial group: Cochrane Developmental, Psychosocial and Learning Problems Group.

Publication status and date: New, published in Issue 5, 2014.

Review content assessed as up-to-date: 29 June 2013.

Citation: Mayo-Wilson E, Junior JA, Imdad A, Dean S, Chan XHS, Chan ES, Jaswal A, Bhutta ZA. Zinc supplementation for preventing mortality, morbidity, and growth failure in children aged 6 months to 12 years of age. Cochrane Database of Systematic Reviews 2014, Issue 5. Art. No.: CD009384. DOI: 10.1002/14651858.CD009384.pub2.

Copyright (C) 2014 The Cochrane Collaboration. Published by John Wiley \& Sons, Ltd.

\begin{abstract}
A B S T R A C T
Background

Zinc deficiency is prevalent in low- and middle-income countries, and contributes to significant diarrhoea-, pneumonia-, and malariarelated morbidity and mortality among young children. Zinc deficiency also impairs growth.
\end{abstract}

Objectives

To assess the effects of zinc supplementation for preventing mortality and morbidity, and for promoting growth, in children aged six months to 12 years of age.

\section{Search methods}

Between December 2012 and January 2013, we searched CENTRAL, MEDLINE, MEDLINE In-Process and Other Non-Indexed Citations, Embase, African Index Medicus, Conference Proceedings Citation Index, Dissertation Abstracts, Global Health, IndMED, LILACS, WHOLIS, metaRegister of Controlled Trials, and WHO ICTRP.

\section{Selection criteria}

Randomised controlled trials of preventive zinc supplementation in children aged six months to 12 years compared with no intervention, a placebo, or a waiting list control. We excluded hospitalised children and children with chronic diseases or conditions. We excluded food fortification or intake, sprinkles, and therapeutic interventions.

Data collection and analysis

Two authors screened studies, extracted data, and assessed risk of bias. We contacted trial authors for missing information.

Zinc supplementation for preventing mortality, morbidity, and growth failure in children aged 6 months to 12 years of age (Review)

Copyright @ 2014 The Cochrane Collaboration. Published by John Wiley \& Sons, Ltd. 


\section{Main results}

We included 80 randomised controlled trials with 205,401 eligible participants. We did not consider that the evidence for the key analyses of morbidity and mortality outcomes were affected by risk of bias. The risk ratio (RR) for all-cause mortality was compatible with a reduction and a small increased risk of death with zinc supplementation (RR 0.95, 95\% confidence interval (CI) 0.86 to 1.05 , 14 studies, high-quality evidence), and also for cause-specific mortality due to diarrhoea (RR $0.95,95 \%$ CI 0.69 to 1.31 , four studies, moderate-quality evidence), lower respiratory tract infection (LRTI) (RR 0.86, 95\% CI 0.64 to 1.15, three studies, moderate-quality evidence), or malaria (RR $0.90,95 \%$ CI 0.77 to 1.06 , two studies, moderate-quality evidence).

Supplementation reduced diarrhoea morbidity, including the incidence of all-cause diarrhoea (RR 0.87, 95\% CI 0.85 to $0.89,26$ studies, moderate-quality evidence), but the results for LRTI and malaria were imprecise: LRTI (RR 1, 95\% CI 0.94 to 1.07, 12 studies, moderate-quality evidence); malaria (RR 1.05, 95\% 0.95 to 1.15 , four studies, moderate-quality evidence).

There was moderate-quality evidence of a very small improvement in height with supplementation (standardised mean difference (SMD) $-0.09,95 \%$ CI -0.13 to $-0.06 ; 50$ studies), but the size of this effect might not be clinically important. There was a medium to large positive effect on zinc status.

Supplementation was associated with an increase in the number of participants with at least one vomiting episode (RR $1.29,95 \%$ CI 1.14 to 1.46 , five studies, high-quality evidence). We found no clear evidence of benefit or harm of supplementation with regard to haemoglobin or iron status. Supplementation had a negative effect on copper status.

\section{Authors' conclusions}

In our opinion, the benefits of preventive zinc supplementation outweigh the harms in areas where the risk of zinc deficiency is relatively high. Further research should determine optimal intervention characteristics such as supplement dose.

\section{PLAIN LANGUAGE SUMMARY}

\section{Zinc supplementation for preventing death and disease, and for growth, in children aged six months to 12 years of age}

\section{Review question}

This review investigated the effectiveness of zinc supplementation for preventing illness and mortality, and for promoting growth, in children between six months and 12 years of age.

\section{Background}

Zinc is an essential micronutrient and zinc deficiency is an important public health problem in low- and middle-income countries. Zinc deficiency impairs growth and contributes to numerous child deaths per year due to diarrhoea, pneumonia, and malaria. This review aimed to determine if giving children zinc supplements would help prevent child death, disease, and growth deficits.

\section{Study characteristics}

We searched a wide range of electronic databases for studies that randomly assigned children aged six months to 12 years to either zinc supplementation or a control group that did not receive zinc. Eighty randomised studies with 205,401 eligible participants were included in this review. The evidence is current to December 2012.

\section{Key results and the quality of the evidence}

Giving children zinc supplements might reduce their risk of death in general, and their risk of death due to diarrhoea, lower respiratory tract infection (LRTI), or malaria. The quality of evidence for overall mortality was high, though evidence for other critical outcomes was only moderate. Children given zinc experience less diarrhoeal disease than children not given zinc; however, zinc does not seem to reduce children's risk of respiratory infection or malaria. Zinc supplementation may have a very small effect on growth, but eating more calories would probably have a larger effect for many malnourished children. Children who take zinc supplements may experience vomiting as a side effect.

Zinc supplementation for preventing mortality, morbidity, and growth failure in children aged 6 months to 12 years of age (Review) 


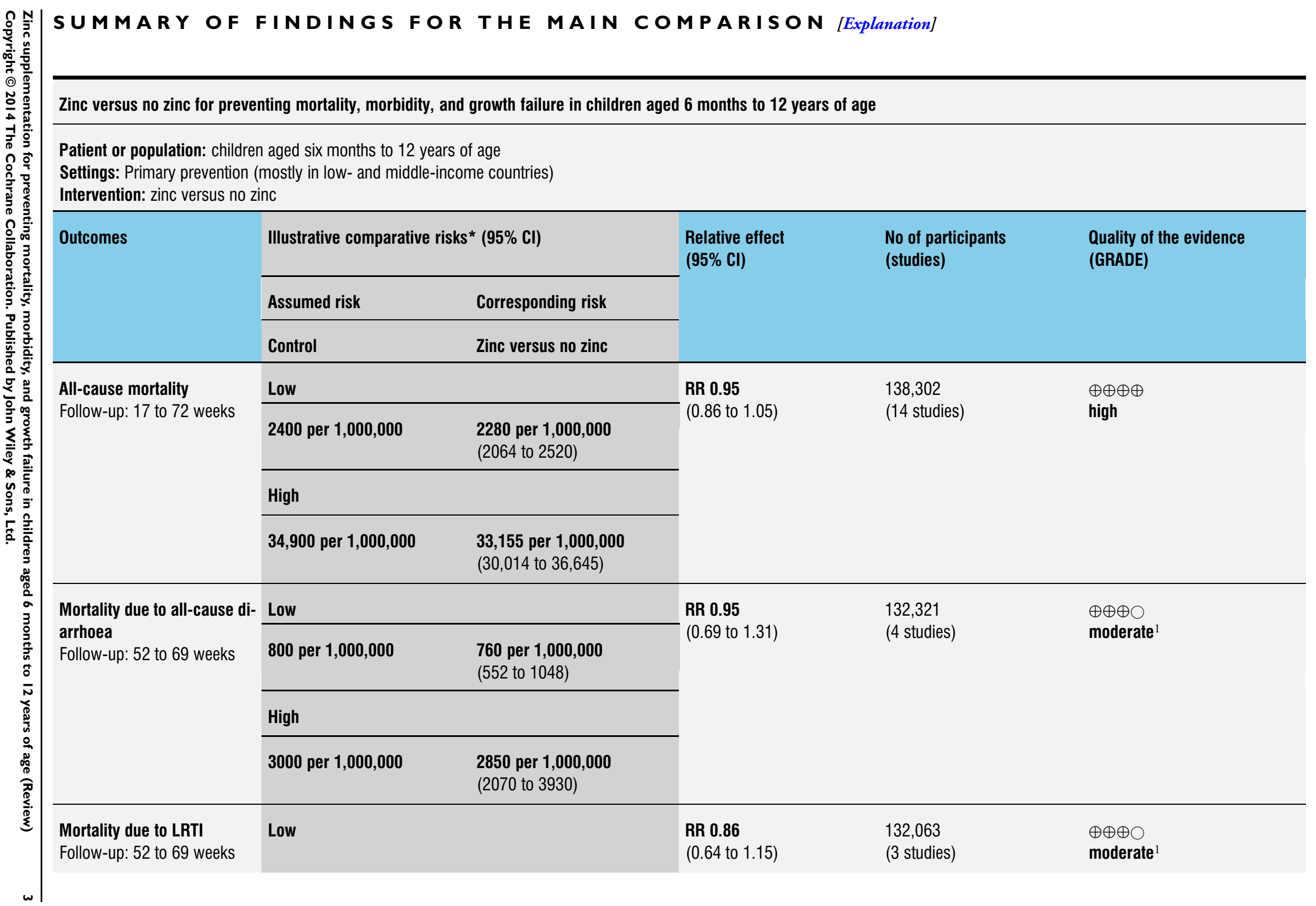




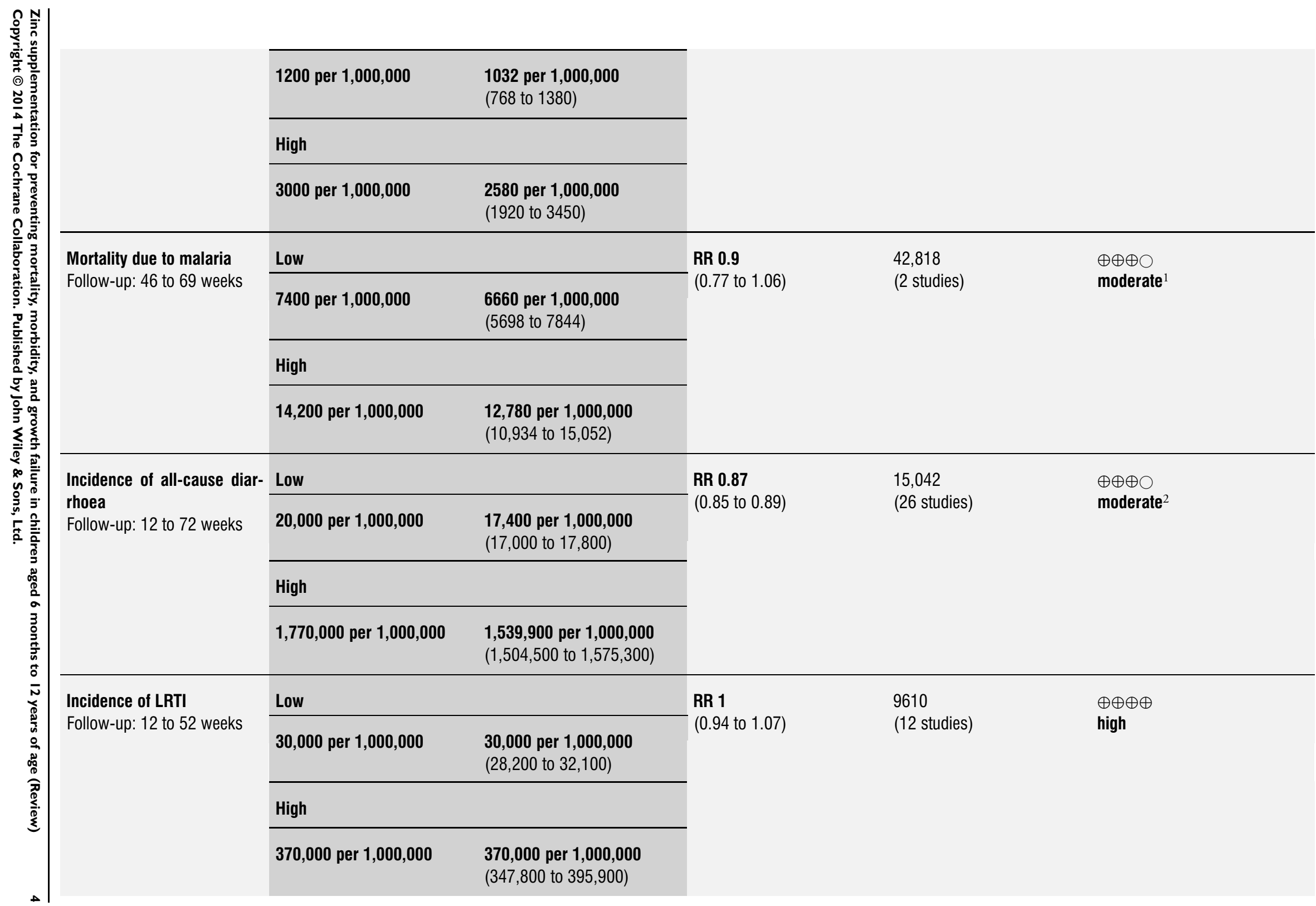




\begin{tabular}{|c|c|c|c|c|c|}
\hline & 140,000 per $1,000,000$ & $\begin{array}{l}\mathbf{1 4 7 , 0 0 0} \text { per } \mathbf{1 , 0 0 0 , 0 0 0} \\
(133,000 \text { to } 161,000)\end{array}$ & \multirow{3}{*}{$\begin{array}{l}\text { RR } 1.05 \\
-(0.95 \text { to } 1.15)\end{array}$} & \multirow{3}{*}{$\begin{array}{l}2407 \\
\text { (4 studies) }\end{array}$} & \multirow{3}{*}{$\begin{array}{l}\oplus \oplus \oplus \bigcirc \\
\text { moderate }^{3}\end{array}$} \\
\hline & \multicolumn{2}{|l|}{ High } & & & \\
\hline & $2,950,000$ per $1,000,000$ & $\begin{array}{l}3,097,500 \text { per } 1,000,000 \\
(2,802,500 \text { to } 3,392,500)\end{array}$ & & & \\
\hline 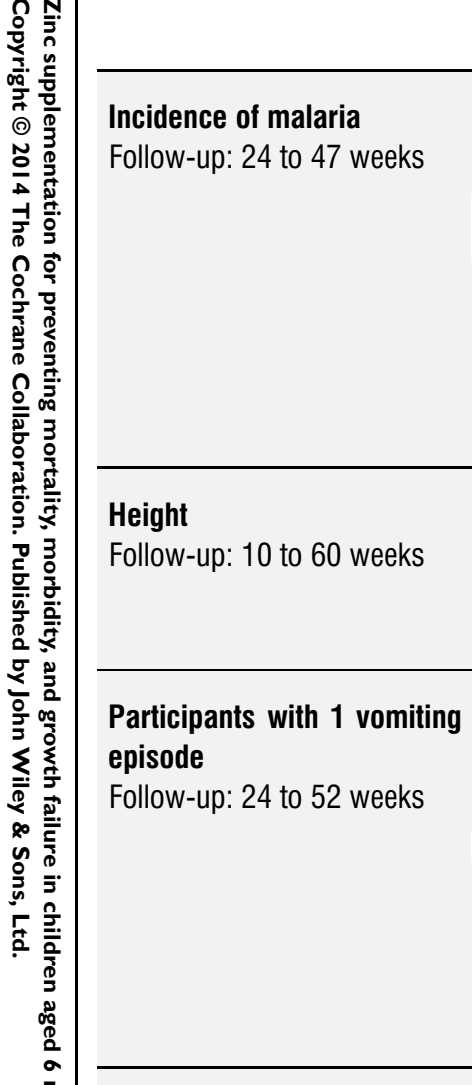 & $\begin{array}{l}\text { The mean height in the control } \\
\text { groups was } \\
-1 \text { HAZ }\end{array}$ & $\begin{array}{l}\text { The mean height in the inter- } \\
\text { vention groups was } \\
0.1 \text { HAZ better } \\
\text { ( } 0 \text { to } 0.2 \text { better) }\end{array}$ & $\begin{array}{l}\text { SMD }-\mathbf{0 . 0 9} \\
(-0.13 \text { to }-0.06)\end{array}$ & $\begin{array}{l}13,669 \\
\text { (50 studies) }\end{array}$ & $\begin{array}{l}\oplus \oplus \oplus \bigcirc \\
\text { moderate }\end{array}$ \\
\hline \multirow{3}{*}{$\begin{array}{l}\text { Participants with } 1 \text { vomiting } \\
\text { episode } \\
\text { Follow-up: } 24 \text { to } 52 \text { weeks }\end{array}$} & Low & & \multirow{3}{*}{$\begin{array}{l}\text { RR } 1.29 \\
-(1.14 \text { to } 1.46)\end{array}$} & \multirow{3}{*}{$\begin{array}{l}35,192 \\
\text { (5 studies) }\end{array}$} & \multirow{3}{*}{$\begin{array}{l}\oplus \oplus \oplus \oplus \\
\text { high }\end{array}$} \\
\hline & \multicolumn{2}{|l|}{ High } & & & \\
\hline & 300,600 per $1,000,000$ & $\begin{array}{l}\mathbf{3 8 7 , 7 7 4} \text { per } \mathbf{1 , 0 0 0 , 0 0 0} \\
\text { (342,684 to } 438,876)\end{array}$ & & & \\
\hline
\end{tabular}

*The basis for the assumed risk (e.g. the median control group risk across studies) is provided in footnotes. The corresponding risk (and its $95 \%$ confidence interval) is based on the assumed risk in the comparison group and the relative effect of the intervention (and its $95 \% \mathrm{Cl}$ ).

CI: confidence interval; HAZ: height-for-age z-score; LRTI: lower respiratory tract infection; RR: risk ratio; SMD: standardised mean difference

GRADE Working Group grades of evidence

High quality: Further research is very unlikely to change our confidence in the estimate of effect.

Moderate quality: Further research is likely to have an important impact on our confidence in the estimate of effect and may change the estimate.

Low quality: Further research is very likely to have an important impact on our confidence in the estimate of effect and is likely to change the estimate.

Very low quality: We are very uncertain about the estimate.

${ }^{1}$ Few deaths observed overall.

${ }^{2} \mathrm{P}^{2}=88 \%$.

ज) ${ }^{3} P^{2}=44 \%$. 


$$
\mid
$$




\section{B A C K G R O U N D}

\section{Description of the condition}

Zinc is an essential micronutrient. Regular dietary intake of zinc is necessary because the human body cannot produce zinc and does not have an adequate mechanism for storing or releasing it (Hotz 2004; Maggini 2010). Severe zinc deficiency affects numerous organ systems, including the immune, gastrointestinal, skeletal, reproductive, and central nervous systems (Tuerk 2009). Even marginal deficiency may be associated with immune system dysfunction and restricted physical development (Prasad 1963; Shankar 1998). Children are especially vulnerable to deficiency because their periods of rapid growth create increased zinc needs that may remain unmet (Gibson 2006).

In 2011 , about 116,000 deaths in children under five years of age were attributable to zinc deficiency $(1.7 \%$ of all mortalities in this group) (Black 2013). Intervention studies suggest that deficiency leads to deaths due to diarrhoea, pneumonia, and malaria, which are leading causes of mortality in this age group (Bryce 2005; Fischer Walker 2008; WHO 2009; Black 2010; Wazny 2013). Zinc deficiency may also impair growth and contribute to childhood stunting (Williams 1970; Hess 2009b; Prasad 2009); high stunting prevalence is used as an indicator of population-level zinc deficiency (Engle-Stone 2007; Hess 2009b).

The global prevalence of zinc deficiency is approximately $17 \%$ (Wessells 2012a), and rates of deficiency approach $73 \%$ in some regions (Caulfield 2004; Black 2008). Countries in most of South and Southeast Asia, sub-Saharan Africa, and parts of Latin America have relatively high rates of deficiency (Caulfield 2004; Hotz 2004; Black 2008).

At both national and individual levels, zinc deficiency and its consequences are linked to poverty. Firstly, foods from animal sources, which are rich in zinc, are often expensive. Particularly in low- and middle-income countries, poor individuals may primarily eat foods such as cereals, grains, and legumes (Hotz 2004). These foods have relatively low concentrations of zinc; they also have relatively high concentrations of fibre and phytate molecules, which reduce zinc absorption by the intestine (Sandstead 1991; Hotz 2004). Secondly, in resource-scarce settings, poor water and sanitation systems lead to frequent exposure to gastrointestinal pathogens and high rates of infectious disease and diarrhoea (Hotz 2004). Finally, factors such as poverty, poor nutrition and sanitation, and infectious morbidity exacerbate one another. For instance, diarrhoea can compromise intestinal function and damage the gastrointestinal tract lining, thereby causing increased zinc excretion via the intestine (Aggarwal 2007; Maggini 2010). Damage to the gastrointestinal tract lining can hinder the absorption of zinc and other nutrients (Fagundes-Neto 1984; Salazar-Lindo 2004; McKay 2010). Thus, a cycle of zinc deficiency can develop, leading to infectious morbidity, in turn leading to further zinc deficiency. Similarly, since morbidity and mortality contribute to reduced economic productivity (Behrman 2004), a cycle can develop in which poverty contributes to zinc-related morbidity and mortality, which contribute to further poverty.

\section{Description of the intervention}

Zinc supplementation is a relatively easily implemented and inexpensive intervention that could help address zinc deficiency (Shrimpton 2005). Zinc supplements come in various physical forms, including liquid solutions, syrups, pills, tablets, capsules, powders, and pastes (Hotz 2004). Supplements also come in various chemical forms, such as zinc sulfate and zinc acetate, with water soluble compounds often preferred because they may be more efficiently absorbed (Hotz 2004; Brown 2009). In addition, zinc is sometimes administered with other micronutrients such as vitamin A or iron (Brown 2009). Zinc supplements have been provided at various doses, daily and weekly, for a few weeks to over a year (Brown 2009).

Recommendations for normal zinc consumption among children range between $2 \mathrm{mg}$ and $11 \mathrm{mg}$ per day, depending on age and diet (Institute of Medicine 2001; Hotz 2004; WHO/FAO 2004). The World Health Organization (WHO) recommends a supplemental dose of $20 \mathrm{mg}$ per day for 10 to 14 days to treat diarrhoea in children six to 59 months of age (WHO/UNICEF 2004). A dose of $10 \mathrm{mg}$ per day for six months may significantly reduce stunting (Imdad 2011), and $5 \mathrm{mg}$ or $10 \mathrm{mg}$ per day may be appropriate for preventive supplementation among children under 14 years of age (Hotz 2004). However, there are no standard recommendations for dose, frequency, and duration of preventive zinc supplementation (Boy 2009).

\section{How the intervention might work}

Zinc is in every cell of the human body and is required for normal functioning (Fisher 1975; Fischer Walker 2004). It plays critical catalytic, structural, and regulatory roles (Cousins 1994; Tuerk 2009). Zinc enables hundreds of enzymes to function, facilitates protein synthesis and folding, and regulates processes such as gene expression and apoptosis (MacDonald 2000; Hotz 2004; Stefanidou 2006; Aggarwal 2007; Hambidge 2007; Tuerk 2009). Zinc is also important for DNA and RNA metabolism, as well as cellular replication, differentiation, and growth (MacDonald 2000; Stefanidou 2006). Zinc is involved in both non-specific and specific immune system processes, including phagocytosis, maintenance of gastrointestinal and respiratory tract linings, and development and function of T- and B-cells (Shankar 1998). Zinc is also involved in bone development, growth hormone function, taste acuity, and appetite (Salgueiro 2002). By increasing the availability of zinc for these biological processes, supplementation may improve health outcomes. 
Most importantly, zinc supplementation may reduce all-cause mortality among children by reducing mortality due to diarrhoea, lower respiratory tract infection (LRTI), and malaria. Trials show that preventive supplementation may reduce the incidence of these three morbidities (Bhutta 1999; Brown 2009). Trials also show that therapeutic supplementation reduces the duration of acute and persistent diarrhoea (Lazzerini 2008). In addition, some trials indicate that zinc supplementation promotes linear growth and weight gain (Brown 2009).

However, not all trials have found zinc supplementation to be effective for certain outcomes (Brown 2009; Ramakrishnan 2009). In addition, the effects of zinc may be influenced and complicated by several factors. For example, children with more severe deficiency, such as those who are stunted, may benefit more from supplementation than children with less severe deficiency. Children with certain chronic diseases and severe protein-energy malnutrition may have different zinc requirements and growth trajectories than children without these comorbidities (Brown 2002). Supplementation might also affect children with non-chronic illnesses and healthy children differently. For instance, presence of infection generally causes zinc to be sequestered in the liver, and conditions that affect intestinal function and integrity can influence zinc homeostasis (Hotz 2004). Despite such complications, it has been proposed that short-term therapeutic zinc supplementation, such as the kind recommended by the WHO for diarrhoea, might also result in some long-term preventive effects (Haider 2009).

Another set of factors influencing the effects of zinc supplementation are interactions between zinc, iron, and copper. Iron supplementation may interfere with the absorption of zinc, and zinc may interfere with iron and copper absorption (Sandstrom 1985; Allen 1998; Sandstrom 2001; Maret 2006); however, the evidence is mixed as to whether supplemental zinc contributes to anaemia, iron deficiency, and/or copper deficiency (Fosmire 1990; Brown 2009). Other potential adverse effects of zinc occur primarily when it is given in very high doses (such as $225 \mathrm{mg}$ to $450 \mathrm{mg}$ ) (Fosmire 1990). These adverse effects include abdominal pain, nausea, vomiting, and diarrhoea (Fosmire 1990; Larson 2008).

\section{Why it is important to do this review}

Zinc supplementation in children has been investigated in several non-Cochrane reviews, some of which have had conflicting results (Bhutta 1999; Brown 2002; Aggarwal 2007; Brown 2009; Ramakrishnan 2009; Dekker 2010; Roth 2010; Imdad 2011; Patel 2011; Yakoob 2011). For example, some reviews have found that zinc supplementation has a significant effect on height (Brown 2002; Brown 2009; Imdad 2011) and weight gain (Brown 2002; Brown 2009). However, another review found that zinc did not significantly affect these outcomes (Ramakrishnan 2009). This review seeks to resolve such discrepancies.

Zinc supplementation has also been investigated in several Cochrane Reviews. There are reviews of zinc supplementation as an adjunct to diarrhoea treatment (Lazzerini 2008), pneumonia treatment (Haider 2011), and for mental and motor development in children (Gogia 2012). There are reviews of zinc supplementation in populations with HIV (Humphreys 2010; Irlam 2010). Reviews have also focused on zinc supplementation for pregnancy and infant outcomes (Mahomed 2007), the common cold (Singh 2011), otitis media (Abba 2010), and pneumonia prevention (Lassi 2010). However, zinc supplementation may have multiple and complex effects, and no Cochrane Review has investigated its impact on all-cause mortality as well as the illnesses responsible for a plurality of child deaths worldwide.

\section{O B JE C T IVES}

To assess the effects of zinc supplementation for preventing mortality and morbidity, and for promoting growth, in children aged six months to 12 years of age.

\section{METHODS}

\section{Criteria for considering studies for this review}

\section{Types of studies}

Randomised controlled trials (RCTs) and cluster-RCTs with a parallel-group design, in which intervention and control groups were enrolled concurrently. We excluded quasi-RCTs such as trials in which allocation was determined by alternation or date of birth.

\section{Types of participants}

Children of six months to 12 years of age (inclusive) at the baseline time point of a study.

We excluded the following:

- children less than six months of age (the WHO recommends exclusive breastfeeding for children less than six months of age, and trials assessing zinc for lactating mothers were excluded);

- hospitalised children;

- children with any of the following: severe protein-energy malnutrition; HIV; chronic diseases, such as cystic fibrosis and sickle cell disease, or conditions, such as Down syndrome, that could affect growth.

If some, but not all, of a study's participants were eligible for our review, then we asked the study authors for disaggregated data. If we were unable to obtain the appropriate disaggregated data, then we included a study if the majority (at least $51 \%$ ) of its participants were eligible for our review. If we were unable to determine the 
exact per cent of a study's participants who were eligible, then we included the study if its participants were eligible on average (for example, the mean participant age was less than 13 years).

\section{Types of interventions}

\section{Intervention}

Orally administered zinc given as a supplement, regardless of compound, formulation, dose, duration, or frequency.

We excluded the following:

- food fortification or intake;

- studies of mixed micronutrients that did not isolate zinc (for example, a review has already been conducted on micronutrient sprinkles (De-Regil 2011));

- trials evaluating the therapeutic effects of zinc (that is, trials in which children received zinc while they were ill with diarrhoea, LRTI, or malaria, but stopped receiving zinc after recovering from illness).

\section{Comparisons}

Placebo, no intervention, and waiting list controls. A control comparison group could have been administered a non-zinc co-intervention (such as a vitamin A supplement), as long as the intervention group to which it was being compared was administered the same co-intervention. Comparisons between two different dosages of zinc (that is a high dose and a low dose) were not eligible; nor were comparisons between different zinc compounds, durations of supplementation, or frequencies at which doses were given. To evaluate the effect of providing zinc and iron simultaneously, we also included comparisons of iron plus zinc versus zinc alone.

\section{Types of outcome measures}

We assessed the preventive effects of zinc supplementation by extracting data for the following outcomes. In studies reporting more than one measure of an outcome, we extracted measures for meta-analysis using the methods described below (see Measures of treatment effect).

\section{Primary outcomes}

1. All-cause mortality

2. Cause-specific mortality

2.1 Mortality due to all-cause diarrhoea

2.2 Mortality due to lower respiratory tract infection (LRTI, including pneumonia)

2.3 Mortality due to malaria

\section{Secondary outcomes}

3. All-cause hospitalisation

4. Diarrhoea

4.1 Incidence of all-cause diarrhoea

4.2 Prevalence of all-cause diarrhoea

4.3 Hospitalisation due to all-cause diarrhoea

4.4 Incidence of severe diarrhoea

4.5 Prevalence of severe diarrhoea

4.6 Incidence of persistent diarrhoea

4.7 Prevalence of persistent diarrhoea

4.8 Hospitalisation due to persistent diarrhoea

5. Lower respiratory tract infection (LRTI)

5.1 Incidence of LRTI (including pneumonia)

5.2 Prevalence of LRTI

5.3 Hospitalisation due to LRTI

6. Malaria

6.1 Incidence of malaria

6.2 Prevalence of malaria

6.3 Hospitalisation due to malaria

7. Growth

7.1 Height

7.2 Weight

7.3 Weight-to-height ratio

7.4 Prevalence of stunting

8. Zinc status

8.1 Serum or plasma zinc concentration

8.2 Prevalence of zinc deficiency

\section{Adverse events}

9. Side effects

9.1 Study withdrawal

9.2 Participants with one or more side effect

9.3 Vomiting episodes

9.4 Participants with one or more vomiting episode

10. Haemoglobin status

10.1 Blood haemoglobin concentration

10.2 Prevalence of anaemia

11. Iron status

11.1 Serum or plasma ferritin concentration

11.2 Prevalence of iron deficiency

12. Copper status

12.1 Serum or plasma copper concentration

12.2 Prevalence of copper deficiency

We included the following outcomes in the Summary of findings for the main comparison: all-cause mortality, mortality due to allcause diarrhoea, mortality due to LRTI, mortality due to malaria, incidence of all-cause diarrhoea, incidence of severe diarrhoea, incidence of persistent diarrhoea, incidence of LRTI, incidence of malaria, height, and participants with one or more vomiting episode. Measures of treatment effect describes the measures reported in the 'Summary of findings for the main comparison'. 


\section{Search methods for identification of studies}

We conducted the initial searches in August and September 2011. The searches were updated between 29 December 2012 and 15 January 2013.

\section{Electronic searches}

We searched the following databases without date or language restrictions. Appendix 1 provides details of the search strategy for each database.

- Cochrane Central Register of Controlled Trials (CENTRAL), part of The Cochrane Library, searched 29

December 2012

- Ovid MEDLINE, searched 29 December 2012

- Ovid MEDLINE In-Process \& Other Non-Indexed

Citations, searched 29 December 2012

- Embase, searched 29 December 2012

- African Index Medicus, searched December 2012

- Global Health, searched 29 December 2012

- IndMED, searched 29 December 2012

- Latin American Caribbean Health Sciences Literature

(LILACS), searched 15 January 2013

- WHO Library \& Information Networks for Knowledge

Database (WHOLIS), searched 15 January 2013

- metaRegister of Controlled Trials (controlled-trials.com/ mrct/), searched 15 January 2013

- WHO International Clinical Trials Registry Platform

(ICTRP) (apps.who.int/trialsearch/), searched 15 January 2013

- Conference Proceedings Citation Index -Science (Web of Science), searched 15 January 2013

- ProQuest Dissertations \& Theses Database, searched 29

December 2012

\section{Searching other resources}

\section{Reference lists}

We searched the reference lists of relevant review articles and included studies to identify additional studies in the published or unpublished literature.

\section{Correspondence}

We contacted the authors of included studies to identify additional studies that were ongoing or unpublished.

\section{Data collection and analysis}

\section{Selection of studies}

Two review authors (from JJ, AI, EMW, EC, AJ) independently screened the titles and abstracts of all reports yielded by the search to determine which were eligible for inclusion in the review. We then obtained and independently screened the full text of all potentially relevant studies to determine whether or not they met the inclusion criteria. If the authors disagreed about the eligibility of a study, then they discussed the disagreement between themselves and with a third author in order to reach a consensus about the study's eligibility. We sought additional information from study authors to help clarify any uncertainties about eligibility. During the study selection process, we were not blinded to study authors, institutions, journal of publication, or results.

\section{Data extraction and management}

We drafted a data extraction form to capture the following characteristics of each study.

General

- Year of study

- Country

- Setting (that is urban or rural, specific region or city if provided)

- Unit of analysis (for example, individual or cluster randomisation)

Participants

- Total number of study participants and clusters

- Number of study participants and clusters randomised to each included group

- Age

- Gender

- Inclusion and exclusion criteria

- Comorbidities

For each intervention or comparison group of interest

- Dose of zinc supplement

- Duration of zinc supplementation

- Frequency of zinc supplementation

- Co-interventions (if any)

For each outcome of interest

- Time points (i) collected and (ii) reported

- Missing data (exclusion of participants, attrition)

For each study, we also rated risk of bias (see Assessment of risk of bias in included studies).

Two review authors (JJ and SD) independently piloted the data extraction form on several studies included in the review and revised the form (with EMW and AI). Two authors (from JJ, EMW, AI, SD, XHSC, AJ) used the revised form to independently extract data from the rest of the studies. If a disagreement arose about the data extracted, then they discussed the disagreement between themselves and with a third author in order to reach a consensus. Details of the data extracted for each study are provided in a Characteristics of included studies table. 


\section{Assessment of risk of bias in included studies}

Two authors (EMW or JJ and either SD, AI, XHSC, or AJ) coded each included study using The Cochrane Collaboration's tool for assessing risk of bias (Higgins 2011). We used this tool to judge whether each study was at low, high, or unclear risk of bias relating to sequence generation, allocation concealment, blinding of study participants, blinding of personnel, blinding of outcome assessors, incomplete outcome data, selective outcome reporting, and other sources of bias. If a disagreement arose concerning a 'Risk of bias' assessment, then the authors discussed the disagreement between themselves and with another author (EMW or JJ) in order to reach a consensus. We were not blinded to study authors, institutions, journal of publication, or results. Details are provided in a 'Risk of bias' table.

\section{Measures of treatment effect}

\section{Multiple outcomes}

Studies often report outcomes using multiple definitions and outcome measures. When studies reported outcomes, we did the following:

\section{Diarrhoea}

If a trial presented data on diarrhoea overall, undifferentiated by severity level, then we included these data in meta-analyses for allcause diarrhoea outcomes. We did the same for outcomes that trial authors defined as acute diarrhoea. We defined persistent diarrhoea as lasting 14 or more days. We defined diarrhoea as severe if it was defined this way by trial authors.

\section{LRTI}

Several systematic reviews have found that LRTI is often defined inconsistently across studies (Bhutta 1999; Imdad 2010; Roth 2010). To deal with this inconsistency, we only included LRTI data from a study if the study's LRTI definition matched any of the following definitions. The first two of these definitions could have been diagnosed by someone who was not a medical professional (for example, a field worker). The third definition must have been diagnosed by a medical professional (for example, a physician).

- Difficulty breathing or rapid breathing, or both.

- Difficulty breathing or cough, along with one or more of the following: age-specific rapid breathing rates, lower chest wall indrawing, chest auscultation signs of pneumonia (decreased breath sounds, bronchial breath sounds, crackles, abnormal voice resonance, pleural rub), nasal flaring, grunting, fever, central cyanosis, inability to breastfeed or drink, vomiting everything, convulsions, lethargy, unconsciousness, or severe respiratory distress (for example, head nodding) (WHO 2000; WHO/UNICEF 2005).
- Clinical evidence of LRTI based on chest auscultation (decreased breath sounds, bronchial breath sounds, crackles, abnormal voice resonance, pleural rub) or chest radiograph.

We gave preference to more severe or rigorously diagnosed LRTI outcome data. For example, if a study provided LRTI data based on rapid breathing and LRTI data based on both rapid breathing and symptoms such as chest indrawing, then we extracted the latter. If a study provided data from caregivers of children and from study field workers, then we extracted the latter. If a study provided fieldworker-reported and physician-reported data, we extracted the latter. If a trial reported LRTI outcomes and pneumonia outcomes separately, then we used the LRTI outcomes. We did not include upper respiratory tract infection data.

\section{Malaria}

As with LRTI, we gave preference to more virulent forms of malaria (for example, preference was given to Plasmodium falciparum rather than Plasmodium vivax) if it was not possible to extract all forms.

\section{Growth}

Height data could be described in terms of raw lengths (for example, in units of centimetre $(\mathrm{cm})$ ), or in terms of height-for-age z-scores. Z-scores describe a child's height as a standard deviation score in a height distribution from a reference population of children of similar ages. If a study reported height outcomes as both raw lengths and height-for-age $\mathrm{z}$-scores, then we preferentially extracted the height-for-age z-scores. However, if a study only reported raw lengths, then we extracted these. We did the same for raw weights and weight-for-age z-scores.

\section{Zinc and other micronutrient status and adverse events}

We included measures of zinc deficiency, anaemia, iron deficiency, or copper deficiency, as defined by trial authors. If authors reported more than one measure for a particular outcome, then we gave preference to the one defined as most severe.

\section{Multiple outcome measures}

To avoid review author bias, we predetermined the order of preference for extracting outcomes when data were available in several formats.

For studies that randomised individuals, we gave preference to data that required the least manipulation by authors or inference by review authors. We extracted raw values (for example, means and standard deviations) rather than calculated effect sizes (for example, Cohen's d). If outcomes were reported as both final values and changes from baseline, then we preferentially extracted the final values. In the case of cluster-RCTs, we (i) used adjusted estimates reported by the authors, or (ii) used raw data and inflated the standard error (SE) using the procedures described below. 
For mortality data, we gave preference to denominators in the following order: number with definite outcome known (or imputed, as described in Dealing with missing data), number randomised, and child-years. For other dichotomous outcomes to which both survivors and non-survivors may have contributed data, we gave preference to child-years, number with definite outcome known, and number randomised.

\section{Summary measures}

Whenever possible, we used a risk ratio (RR) as the effect measure for each outcome for which there was dichotomous data. For incidence data, we combined risk ratios (events per child) and rate ratios (events per child year), because these ratios used the same scale and could be interpreted in the same way for these studies. Since we expected the duration of studies to be short, we did not anticipate interaction between the intervention and time at risk. We estimated time at risk if appropriate, as when authors reported incidence rate, study duration, and number of children in a group. We used Hedges' (adjusted) $g$ (a standardised mean difference) for each outcome for which there was continuous data. We report all outcomes with a $95 \%$ confidence interval.

\section{Unit of analysis issues}

\section{Cluster-randomised trials}

Cluster-randomised trials randomise groups of people rather than individuals. For each cluster-randomised trial, we first determined whether or not its data incorporated sufficient controls for clustering (such as robust standard errors or hierarchical linear models). If the data did not have proper controls, then we attempted to obtain an appropriate estimate of the data's intracluster correlation coefficient (ICC). If we could not find an estimate in the report of the trial, then we requested an estimate from the trial report authors. If the authors did not provide an estimate, then we obtained one from a similar study and conducted a sensitivity analysis to determine if the results were robust when different values were imputed. We used the ICC estimate to control the trial's data for clustering, according to procedures described in Higgins 2011.

\section{Cross-over trials}

For cross-over trials, we extracted and analysed data from the first period only.

\section{Studies with multiple treatment groups}

For factorial studies, we included all comparisons that differed only in the presence or absence of zinc. For example, in a $2 \times 2$ factorial study of zinc and vitamin A supplementation, we included two comparisons: (1) zinc versus placebo and (2) zinc and vitamin A versus vitamin A alone. For other studies, multiple eligible intervention groups were combined.

\section{Outcomes measured at multiple time points}

For outcomes measured at multiple time points, we only included the time point that occurred the most days after randomisation in our meta-analyses.

\section{Dealing with missing data}

Missing data, and methods for imputing such data, may affect the magnitude and direction of a point estimate and its standard error. For all analyses, we attempted to include all randomised study participants. When analyses were reported for completers as well as controlling for dropout (for example, imputed using regression methods), we extracted the latter. If data were missing for some cases, or if reasons for dropout were not reported, then we contacted study authors to request missing data and further information on dropouts.

For the primary outcome, data were likely to be missing at random. Secondary outcome data may have been missing for reasons related to group assignment (for example, early mortality in the comparison group). We reported reasons for missing data, including reasons for dropout and number of dropouts. The potential impact of missing data on review findings is discussed below.

\section{Assessment of heterogeneity}

We discussed the similarities and differences between included studies in terms of their participants, interventions, outcomes, and methods. For each meta-analysis, we used three methods to identify statistical heterogeneity: visually inspecting forest plots to see if the confidence intervals of individual studies have poor overlap - a rough indication of statistical heterogeneity, conducting a Chi ${ }^{2}$ test, and calculating an $\mathrm{I}^{2}$ statistic. We deemed a metaanalysis to have substantial heterogeneity if its $\mathrm{Chi}^{2} \mathrm{P}$ value is less than 0.10 and its $\mathrm{I}^{2}$ statistic is greater than $50 \%$.

\section{Assessment of reporting biases}

We created a funnel plot for each meta-analysis that included 10 or more studies and looked to see if any funnel plot appeared asymmetrical. We judged a meta-analysis with an asymmetrical funnel plot to be potentially biased by small-study effects or reporting bias.

\section{Data synthesis}

We used Review Manager (RevMan) Version 5.2 software (Review Manager 2013) to conduct all meta-analyses. We used MantelHaenszel methods to meta-analyse dichotomous data that could be combined directly in RevMan. If studies reported dichotomous data in multiple formats that could not be combined in RevMan, we used Comprehensive Meta-Analysis Version 2 software (Borenstein 2005) to calculate log risk ratios and standard errors for the data, enter these log risk ratios and standard errors 
into RevMan, and then meta-analyse these using inverse-variance methods. We also used the inverse-variance method to meta-analyse continuous data. We used fixed-effect methods for all metaanalyses. Although there may have been some differences across trials (for example, dose and population), the biological mechanism should have been similar across trials. However, we conducted a sensitivity analysis in which random-effects methods were used (see Sensitivity analysis).

\section{Subgroup analysis and investigation of heterogeneity}

We planned to conduct the following subgroup analyses for outcomes with at least 10 studies measuring the relevant characteristic. We report a $\mathrm{Chi}^{2}$ test for each analysis to determine whether or not the effects of zinc are statistically significantly different for different subgroups.

1. Country income level: low- and middle-income countries versus high-income countries, as defined by the World Bank's country income classification system (World Bank 2011).

2. Age: children six months to under one year, versus one to under five years, versus five years to under 13 years.

3. Stunting: children with a height-for-age $z$-score of $<-2$ versus children with a height-for-age $z$-score $\geq-2$.

4. Dose: daily dose equivalent less than $5 \mathrm{mg}$ per day, versus 5 $\mathrm{mg}$ to under $10 \mathrm{mg}$, versus $10 \mathrm{mg}$ to under $15 \mathrm{mg}$, versus $15 \mathrm{mg}$ to under $20 \mathrm{mg}$, versus $20 \mathrm{mg}$ or more per day.

5. Duration: supplementation lasting zero to five months, versus six to 11 months, versus 12 months or more.

6. Iron co-interventions: iron + zinc versus iron alone, zinc versus no supplementation.
7. Formulation: solution versus pill and/or tablet versus capsule versus powder.

\section{Sensitivity analysis}

We had planned to conduct the following sensitivity analyses to examine whether or not our findings were robust to certain decisions we made while conducting the review; however, only the first of these was possible.

1. We repeated the analyses using random-effects methods.

2. We had planned to repeat the primary meta-analysis excluding studies at high risk of bias due to incomplete outcome data.

3. We had planned to repeat the primary meta-analysis if it included one or more cluster-randomised trials for which we had to impute the ICC. We planned to repeat the meta-analysis using an ICC value at least as large as the largest observed ICC.

\section{RES U L T S}

\section{Description of studies}

\section{Results of the search}

We screened 6384 records and 326 full-text trial reports (Figure 1). 
Figure I. Study flow diagram.

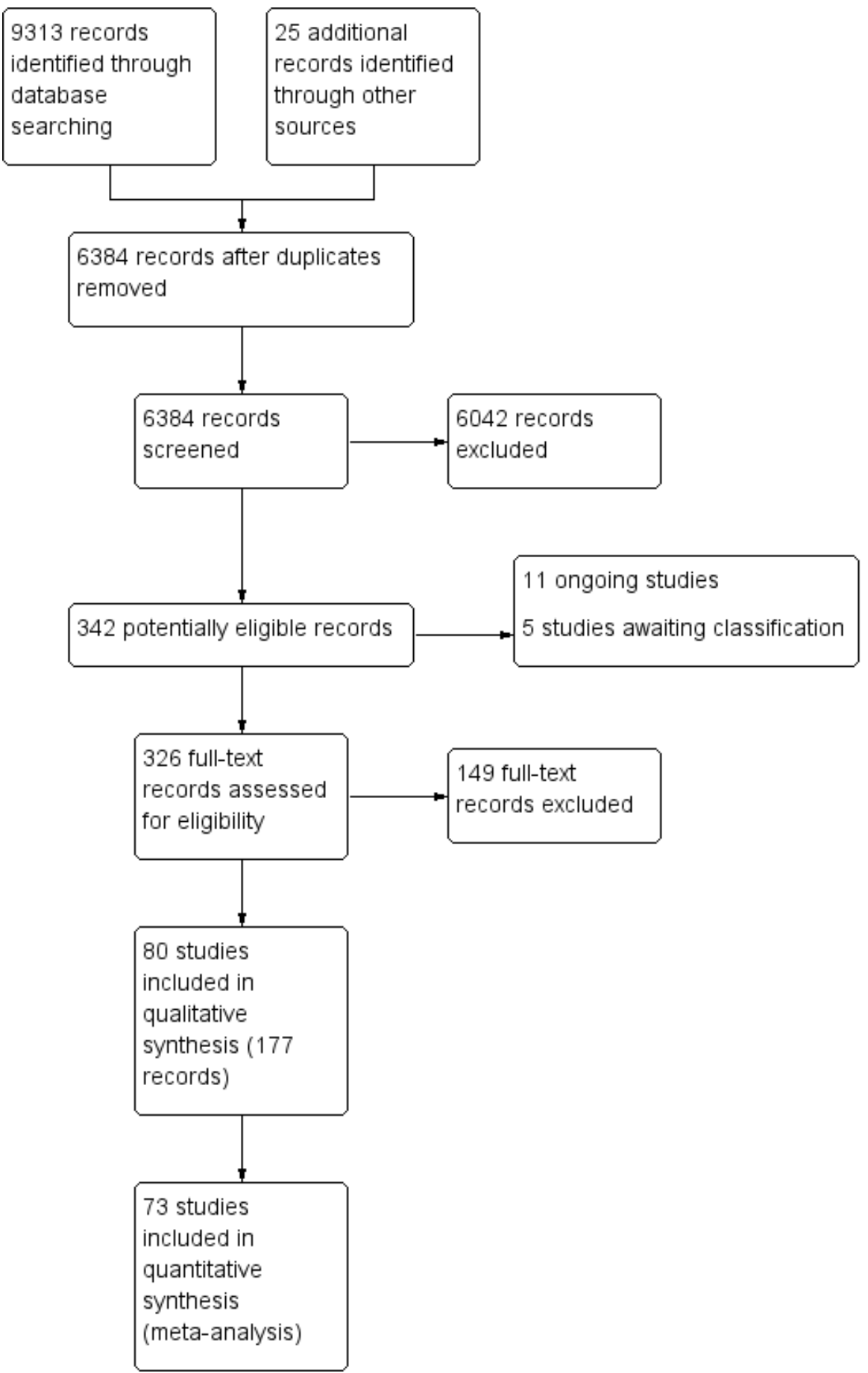




\section{Included studies}

Eighty eligible studies, reported in 177 trial reports, compared zinc versus placebo or zinc with a co-intervention versus the cointervention alone. Thirty-six studies were reported in more than one publication or paper. Five studies were published in nonEnglish languages: two studies written in Spanish, one in Chinese, and two in Portuguese. Seven studies did not contribute to any meta-analysis because they did not report any outcomes of interest to this review or because they did not report sufficient data ( Sanjur 1990; Marinho 1991; Sandstead 1998; Castillo-Durán 2002; Ahmed 2009a; Vakili 2009; Shah 2011). A Characteristics of included studies table describes each included study in greater detail.

\section{Design}

There were two cross-over trials, for which data from the first period only were analysed (Hong 1982; Garcia 1998).

Nine studies were cluster-RCTs (Sandstead 1998; Sazawal 2006; Tielsch 2006; Bhandari 2007; Gupta 2007; Hettiarachchi 2008; Tupe 2009; Chen 2012; Soofi 2013). Sazawal 2006 and Bhandari 2007 randomised households and had average cluster sizes of fewer than two children. The other meta-analysed cluster-RCTs randomised by school class or community health worker surveillance area, and had cluster sizes ranging from approximately eight to 116 individuals. Sazawal 2006 and Tielsch 2006 reported design effects, and unpublished ICCs were obtained for the Bhandari 2007 and Tupe 2009 studies. An ICC was calculated based on the design effect from Tielsch 2006. ICCs from Tielsch 2006 and Tupe 2009 were then averaged, and the average (0.014) was used to adjust data from Gupta 2007 and Hettiarachchi 2008 for clustering. Results of the meta-analyses of which Gupta 2007 and Hettiarachchi 2008 were a part were robust regardless of whether an ICC of $0.014,0$, or 1 was assumed from these studies.

\section{Sample sizes}

This review includes approximately 205,923 eligible participants from the 80 included studies. The 73 studies (91\%) that contributed to at least one meta-analysis had approximately 205,401 participants (more than $99 \%$ of those randomised). Sample sizes of included studies ranged from 21 to 72,438 eligible participants, with a median sample size of 200 . The three largest studies in this review accounted for $88 \%$ of the eligible participants (Sazawal 2006; Tielsch 2006; Bhandari 2007). Participants were approximately evenly split between zinc and control groups.

\section{Setting}

Thirty-two countries are represented amongst the studies included in this review. Seventy-three studies (91\%) were conducted in low- or middle-income countries: 37 in Asia, 26 in Latin America and the Caribbean, and 10 in sub-Saharan Africa. Seven were conducted in North America or Europe. The countries where the most studies were conducted were Bangladesh and India, with seven and eight studies, respectively. The three largest trials took place in India, Nepal, and Zanzibar (a semi-autonomous region of Tanzania). Among the 72 studies that described their setting, 46 were conducted in urban or peri-urban areas, 21 in rural areas, and five in both urban and rural areas.

\section{Participants}

Sixty-one studies reported mean participant age at baseline. The median of these mean ages was 28 months. Most participants in this review were under five years of age. Of the 76 trials that could be classified in an age subgroup, only 24 were in the five to 13 years of age category. The gender of participants was reported in 73 studies, which was usually equally divided.

Forty-eight studies reported the mean height-for-age z-score of their participants at baseline. The median of these mean scores was -1.6 , with scores ranging from -2.9 to 0.10 . Both stunted and nonstunted children were included in 42 studies; five included only stunted children, five included only non-stunted children, and 28 did not specify whether or not their participants were stunted. Forty-six studies reported the mean baseline plasma or serum zinc concentration of their participants. The median of these mean concentrations was $72.5 \mu \mathrm{g} / \mathrm{dL}$.

\section{Interventions}

Studies reporting the formulation of their zinc supplements provided zinc as a solution or syrup (46), pill or tablet (17), capsule (6), or powder (2). One trial provided zinc as a syrup to one study group and as a tablet to another study group (Wessells 2012b). Studies reporting the chemical compound of their zinc supplements provided zinc as sulfate (45), gluconate (12), acetate (six), and other compounds (eight).

Studies provided zinc for less than two months (eight), two to less than six months (22), six to less than 12 months (33), and 11 months or more (16). Twenty-five studies provided zinc for six months and 11 provided zinc for 12 months. Studies reporting the frequency of zinc supplementation had frequencies ranging from daily to weekly. Zinc was provided daily in 48 studies and 11 provided zinc weekly. Studies that could be classified based on zinc dose administered daily dose equivalents of less than $5 \mathrm{mg}$

Zinc supplementation for preventing mortality, morbidity, and growth failure in children aged 6 months to 12 years of age (Review) 
(five), $5 \mathrm{mg}$ to less than $10 \mathrm{mg}$ (19), $10 \mathrm{mg}$ to less than $15 \mathrm{mg}$ (30), $15 \mathrm{mg}$ to less than $20 \mathrm{mg}$ (eight), and $20 \mathrm{mg}$ or more (12). Twenty trials were factorial. Among both factorial and non-factorial trials in this review, there were 100 eligible comparisons. Of these eligible comparisons, 51 (49\%) included a co-intervention that both the zinc and the control groups received. Common cointerventions were iron, vitamin $\mathrm{A}$, or multivitamin supplements.

\section{Duration}

Outcomes were observed at a median time period of 26 weeks after randomisation, with follow-up periods ranging between two and 80 weeks.

\section{Excluded studies}

We excluded 149 full-text records, including 28 studies that came close to meeting this review's inclusion criteria but were ultimately excluded (see Characteristics of excluded studies table).

\section{Ongoing studies}

Eleven likely eligible ongoing or completed studies were identified (CTRI/2010/091/001417; NCT00133406; NCT00228254;
NCT00374023;

NCT00944359;

NCT00421668;

NCT00589264;

NCT01306097; NCT01616693). We contacted the authors and asked them to supply data. These studies are described in a Characteristics of ongoing studies table.

\section{Studies awaiting classification}

Five potentially eligible studies could not be definitively classified as eligible or ineligible (Smith 1985; Jimenez 2000; Chicourel 2001; Mitter 2009; Arabaci 2010). For these studies, no full-text trial records could be obtained, or records obtained did not report sufficient information concerning inclusion criteria such as participant age. These studies are described in a Characteristics of studies awaiting classification table.

\section{Risk of bias in included studies}

We used The Cochrane Collaboration's tool for assessing risk of bias (Higgins 2011) to judge each included study as being at low, high, or unclear risk of bias in five domains. These judgements are summarised in Figure 2 and detailed justifications for each judgement are listed in the Characteristics of included studies table.

Figure 2. 'Risk of bias' graph: review authors' judgements about each risk of bias item presented as percentages across all included studies.

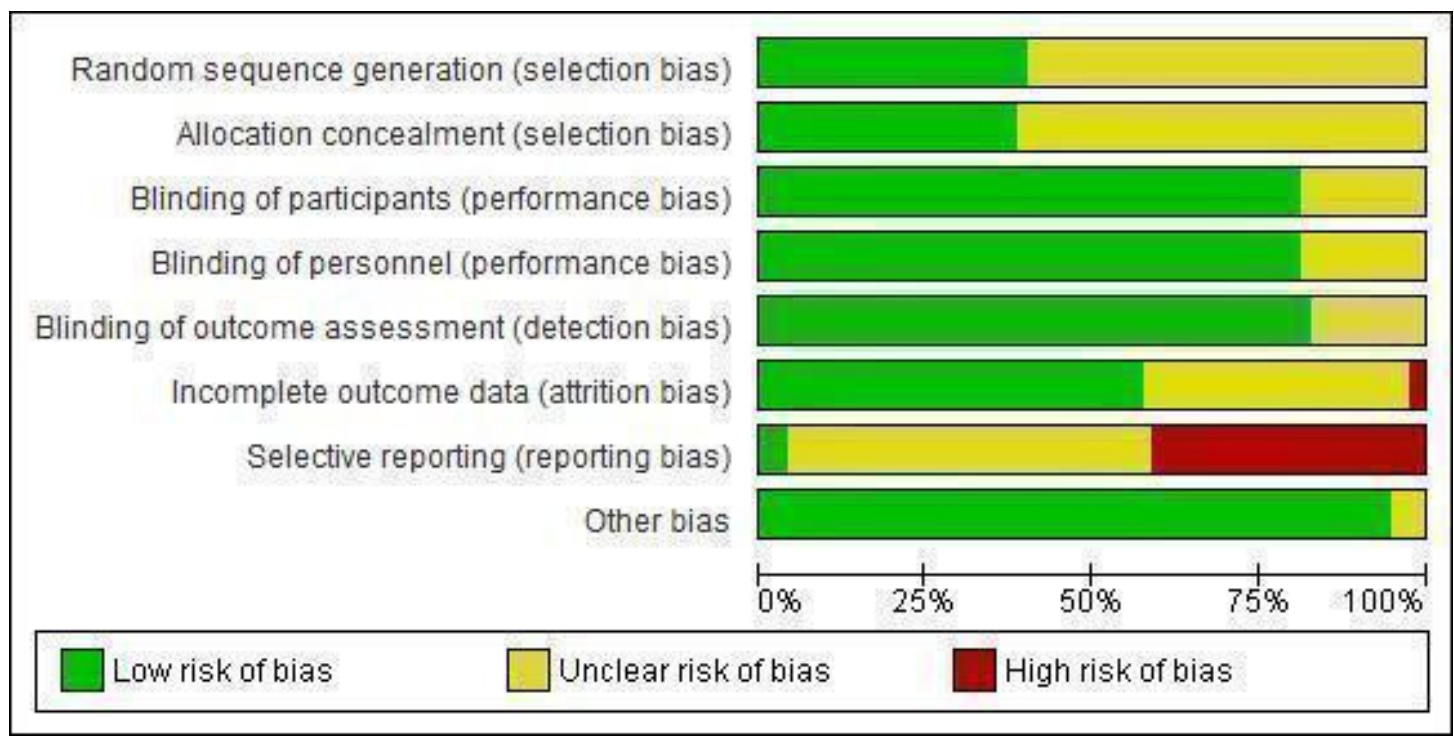

Zinc supplementation for preventing mortality, morbidity, and growth failure in children aged 6 months to 12 years of age (Review) 


\section{Allocation}

\section{Random sequence generation}

For the random sequence generation domain, 34 studies were at low risk of bias and 46 were at unclear risk. Of the 34 studies at low risk of bias, 18 used a computer random number generator to randomise participants, eight used a random number table, three used drawing of lots, and one tossed a coin. Four of these 34 studies did not refer explicitly to any of these sequence generation methods, but did report the use of permuted blocks.

\section{Allocation concealment}

For allocation concealment, 32 studies were at low risk of bias and 48 were at unclear risk. Among studies at low risk, methods such as central randomisation (that is randomisation by someone not involved with enrolling participants) were used to conceal allocation. Furthermore, though allocation concealment and blinding are distinct bias domains, some have argued that "blinded trials of drugs are very likely to be concealed" (Devereaux 2004; Guyatt $2011 \mathrm{~b}$ ). In this review, risk of bias related to blinding did not seem substantial, nor did risk of bias related to allocation concealment.

\section{Blinding}

For blinding of participants and for blinding of personnel, 63 studies were at low risk of bias and 15 were at unclear risk. For blinding of outcome assessment, 65 studies were at low risk of bias and 15 were at unclear risk. To ensure blinding, trials used strategies such as providing the control group a placebo of identical appearance and taste to that of zinc. Strategies such as these make blinding an intervention, such as zinc supplementation, easier than blinding more complex, interactive interventions. Furthermore, the primary outcome of this review is mortality and this outcome is less vulnerable to bias related to blinding than other, more subjective, outcomes (Altman 2001).

\section{Incomplete outcome data}

For incomplete outcome data, 47 studies were at low risk of bias, 31 were at unclear risk, and two were at high risk. For 70 studies, it was possible to calculate an approximate percentage of study participants with missing data for non-mortality outcomes. Of these, 35 studies had less than $10 \%$ missing data, 23 had $10 \%$ to less than $20 \%$ missing data, and 12 had at least $20 \%$ missing data. Amounts of and reasons for missing data were generally balanced between groups.

\section{Selective reporting}

For selective reporting, three studies were at low risk of bias, 44 were at unclear risk, and 32 were at high risk. For 31 of the studies at unclear risk, a trial protocol could not be obtained and it was not possible to confirm whether their outcomes were reported as planned in their protocols. Among many studies at high risk of bias, trial reports stated that certain outcomes were measured but no numerical data disaggregated by study group were reported for these outcomes, or insufficient data were reported to include them in a meta-analysis. Many missing outcomes were biochemical, growth, and side effect outcomes.

\section{Other potential sources of bias}

Other potential sources of bias appeared to be minimal and unlikely to impact the results of this review.

\section{Effects of interventions}

See: Summary of findings for the main comparison Zinc versus no zinc for preventing mortality, morbidity, and growth failure in children aged 6 months to 12 years of age

This section describes the results of the meta-analysis of each outcome in this review. Results are presented as the pooled effect estimate followed by the lower and upper limits of its $95 \%$ confidence interval $(\mathrm{CI})$ in brackets. For all analyses, smaller or more negative effect estimates (risk ratio $(\mathrm{RR})<1$; standardised mean difference $(\mathrm{SMD})<0$ ) favour intervention. Within forest plots, outcome data for each eligible comparison are in a separate row. For instance, in a factorial trial, the zinc versus placebo comparison would be in one row of a forest plot, and the zinc and vitamin A versus vitamin A comparison would be in another row. Within the Data and analyses tables, each eligible comparison is counted as a separate study.

No studies reported the prevalence of severe diarrhoea or hospitalisation due to malaria, so these outcomes do not appear below. As per the protocol, we did not conduct subgroup analyses for analyses with fewer than 10 comparisons. Specifically, we did not conduct analyses for country income for outcomes that did not include any studies conducted in high-income countries. We did not conduct stunting subgroup analyses for outcomes when no study reported separate data on that outcome for stunted or nonstunted children. When country income and stunting subgroup analyses were conducted, one group often contained few studies. In some subgroup analyses, one or more subgroups contained no study data and effects are reported for all subgroups except those without data.

One sensitivity analysis was to repeat the primary meta-analysis excluding studies at high risk of bias due to incomplete outcome data. We did not undertake this analysis because only two studies were at high risk of bias due to incomplete outcome data and these studies did not report any of the primary outcomes for this review (Gupta 2007; Ba Lo 2011). Another sensitivity analysis was to repeat the primary meta-analysis to test if the results from it were robust to assumptions about imputed intracluster correlation co- 
efficients (ICCs) for cluster-randomised controlled trials (RCTs). We did not undertake this analysis because neither of the two studies for which ICCs were imputed reported any of the primary outcomes for this review. Finally, we conducted a random-effects sensitivity analysis for all meta-analyses. We report the pooled estimate from the random-effects model when heterogeneity is potentially important (that is $\mathrm{I}^{2}>25 \%$ ).

\section{Comparison I: Zinc versus no zinc}

\section{Primary outcomes}

\section{(1) All-cause mortality}

Thirteen studies, one of which included two comparisons (total number of comparisons $=14$ ), comprising 138,302 participants (67\% of participants in the review), were included in the analysis of all-cause mortality (see Analysis 1.1). Other studies included no deaths in either group. Zinc supplementation did not have a statistically significant effect on all-cause mortality (RR 0.95, 95\% CI 0.86 to 1.05$)$ and there was no statistical heterogeneity $\left(\mathrm{Chi}^{2}\right.$ $=10.57, \mathrm{df}=13(\mathrm{P}$ value $\left.=0.65) ; \mathrm{I}^{2}=0 \%\right)$, but the results were consistent with a small reduction in mortality.

A funnel plot, which we created to explore the possibility of smallstudy effects or reporting bias further, appeared symmetrical.

\section{Subgroup analyses}

Effects did not differ significantly among age $($ P value $=0.11)$, dose $(\mathrm{P}$ value $=0.45)$, duration $(\mathrm{P}$ value $=0.55)$, iron co-intervention $(\mathrm{P}$ value $=0.25)$, or formulation $(\mathrm{P}$ value $=0.91)$ subgroups .

\section{(2) Cause-specific mortality}

\section{(2.1) Mortality due to all-cause diarrhoea}

Four studies, involving 132,321 participants (64\% of participants in the review), reported no significant effect on mortality due to diarrhoea (RR 0.95, 95\% CI 0.69 to 1.31) (see Analysis 1.2) and no heterogeneity $\left(\mathrm{Chi}^{2}=0.82, \mathrm{df}=3(\mathrm{P}\right.$ value $\left.=0.84) ; \mathrm{I}^{2}=0 \%\right)$.

\section{(2.2) Mortality due to lower respiratory tract infection} (LRTI)

In three studies including 132,063 participants (64\% of participants in the review), zinc supplementation did not have a statistically significant effect on mortality due to LRTI (RR 0.86, 95\% CI 0.64 to 1.15$)$ and there was no heterogeneity $\left(\mathrm{Chi}^{2}=0.07 \mathrm{df}\right.$ $=2(\mathrm{P}$ value $\left.=0.96) ; \mathrm{I}^{2}=0 \%\right)($ see Analysis 1.3 $)$.

\section{(2.3) Mortality due to malaria}

Two studies (Shankar 2000; Sazawal 2006), including 42,818 participants ( $21 \%$ of participants in the review), reported mortality due to malaria (see Analysis 1.4). Zinc supplementation did not have a statistically significant effect (RR $0.90,95 \%$ CI 0.77 to
1.06) and there was no heterogeneity $\left(\mathrm{Chi}^{2}=0.01, \mathrm{df}=1(\mathrm{P}\right.$ value $\left.=0.94) ; \mathrm{I}^{2}=0 \%\right)$.

\section{Secondary outcomes}

\section{(3) All-cause hospitalisation}

Seven trials, two of which contributed two comparisons (total number of comparisons $=$ nine), included 92,872 participants ( $45 \%$ of participants in the review) and reported no overall effect on all-cause hospitalisation (RR 1.04, 95\% CI 0.97 to 1.11 ); heterogeneity was moderate $\left(\mathrm{Chi}^{2}=14.41, \mathrm{df}=8(\mathrm{P}\right.$ value $=0.07)$; $\mathrm{I}^{2}=44 \%$ ) (Analysis 1.5).

Three studies reported hospitalisation data as the number of participants ever hospitalised rather than as the number of hospitalisations (Meeks Gardner 1998; Bhandari 2002; Chhagan 2009). Excluding these from the analysis did not change the result (RR $1.04,95 \%$ CI 0.97 to 1.12 ). The result also remained insignificant when calculated using a random-effects model (RR 0.98, 95\% CI 0.83 to 1.14 ).

\section{(4) Diarrhoea}

\section{(4.1) Incidence of all-cause diarrhoea}

In 26 studies (nine of which included two comparisons; total number of comparisons $=35)$ involving 15,042 participants $(7 \%$ of participants in the review), there was a combined $13 \%$ reduction in the incidence of all-cause diarrhoea (RR $0.87,95 \% \mathrm{CI} 0.85$ to $0.89)$, though heterogeneity was substantial $\left(\mathrm{Chi}^{2}=295.56, \mathrm{df}=\right.$ 34 ( $\mathrm{P}<0.00001) ; \mathrm{I}^{2}=88 \%$ ) (Analysis 1.6). Three studies in this meta-analysis reported data as medians, but excluding these from the analysis did not change the result (RR $0.87,95 \%$ CI 0.86 to 0.89) (Ruel 1997; Meeks Gardner 1998; Meeks Gardner 2005). There was some evidence of funnel plot asymmetry, with several smaller studies reporting unusually large reductions in all-cause diarrhoea incidence. However, the result of this meta-analysis was similar when we used a random-effects model (RR 0.84, 95\% CI 0.78 to 0.91 ), which suggests that the result was not strongly influenced by small-study effects.

\section{Subgroup analyses}

Effects did not differ significantly by duration of supplementation $(\mathrm{P}$ value $=0.56)$ or age $(\mathrm{P}$ value $=0.85)$.

Dose subgroups were significantly different $(\mathrm{P}<0.00001)$, but there did not appear to be a coherent pattern of increasing or decreasing effect across doses: $0 \mathrm{mg}$ to $5 \mathrm{mg}$ (RR 0.95, 95\% CI 0.89 to 1.01 ); $5 \mathrm{mg}$ to $10 \mathrm{mg}$ (RR $0.73,95 \%$ CI 0.64 to 0.83 ); $10 \mathrm{mg}$ to $15 \mathrm{mg}$ (RR $0.96,95 \%$ CI 0.92 to 0.99 ); $15 \mathrm{mg}$ to 20 $\mathrm{mg}$ (RR $0.61,95 \%$ CI 0.58 to 0.65 ); $20 \mathrm{mg}$ or more (RR 0.90 , $95 \%$ CI 0.87 to 0.94$)$.

Formulation subgroups were significantly different $(\mathrm{P}<0.00001)$, but most studies used a solution and effects generally favoured 
intervention for solution (RR $0.84,95 \%$ CI 0.82 to 0.86 ), pill and/or tablet (RR $0.90,95 \%$ CI 0.81 to 0.99 ), and capsule (RR $0.78,95 \%$ CI 0.60 to 1.01 ); there was no significant effect in two studies using micronutrient powder (RR 1.04, 95\% CI 0.98 to 1.09).

Iron co-intervention subgroups were significantly different $(\mathrm{P}<$ $0.00001)$, with no benefit for the group that received iron (RR $1.00,95 \%$ CI 0.96 to 1.05 ) and a significant benefit for the group that did not receive iron (RR $0.82,95 \%$ CI 0.80 to 0.84 ).

\section{(4.2) Prevalence of all-cause diarrhoea}

In 13 studies (two of which included two comparisons; total number of comparisons $=15$ ) including 8519 participants ( $4 \%$ of participants in the review), there was a $12 \%$ reduction in the prevalence all-cause diarrhoea (RR $0.88,95 \%$ CI 0.86 to 0.90 ), though heterogeneity was considerable $\left(\mathrm{Chi}^{2}=118.88, \mathrm{df}=14(\mathrm{P}\right.$ $<0.00001$ ); $\mathrm{I}^{2}=88 \%$ ) (Analysis 1.7 ). Two studies in this metaanalysis reported data as medians, but excluding these from the analysis had no effect on the result (RR $0.88,95 \%$ CI 0.87 to 0.90) (Ruel 1997; Chhagan 2009). The result was robust when we used random-effects (RR 0.87, 95\% CI 0.81 to 0.93 ). We created a funnel plot, which appeared symmetrical.

\section{Subgroup analyses}

Age subgroups were significantly different $(\mathrm{P}<0.00001)$, with greater benefit in the older age group, but both effects favoured intervention: between six and 12 months (RR 0.96, 95\% CI 0.93 to 1.00 ); between one and five years (RR $0.85,95 \%$ CI 0.83 to $0.87)$.

Dose subgroups were significantly different $(\mathrm{P}<0.0001)$, with potentially larger effects at higher doses: $0 \mathrm{mg}$ to $5 \mathrm{mg}$ (RR 1.00, $95 \%$ CI 0.92 to 1.08 ); $5 \mathrm{mg}$ to $10 \mathrm{mg}$ (RR $1.17,95 \%$ CI 0.60 to 2.28); $10 \mathrm{mg}$ to $15 \mathrm{mg}$ (RR $0.93,95 \%$ CI 0.90 to 0.96 ); $15 \mathrm{mg}$ to $20 \mathrm{mg}$ (RR $0.61,95 \% \mathrm{CI} 0.54$ to 069$), 20 \mathrm{mg}$ or more (RR $0.85,95 \%$ CI 0.82 to 0.87 ).

Duration subgroups were significantly different $(\mathrm{P}$ value $=$ 0.00009), but there did not appear to be a coherent pattern of results: between zero and six months (RR $0.85,95 \% \mathrm{CI} 0.82$ to 0.87 ); between six and 12 months (RR $0.92,95 \%$ CI 0.89 to 0.95 ); 12 months or more (RR 0.88 , $95 \%$ CI 0.74 to 1.03 ).

Formulation subgroups were significantly different $(\mathrm{P}$ value $=$ $0.00009)$, but most studies used a solution and effects generally favoured intervention for solution (RR $0.88,95 \%$ CI 0.85 to 0.90 ) and pill and/or tablet (RR $0.86,95 \%$ CI 0.81 to 0.92 ); there was no significant effect in one study using micronutrient powder (RR $1.03,95 \%$ CI 0.95 to 1.12 ). The solution and tablet groups were consistent when the powder study was removed from the analysis. Iron co-intervention subgroups were significantly different $(\mathrm{P}$ value $=0.05$ ), with no clear benefit for the group that received iron (RR $0.96,95 \%$ CI 0.88 to 1.05 ) and a significant benefit for the group that did not receive iron (RR $0.88,95 \%$ CI 0.86 to 0.90 ), but only three studies contributed to the first group.

\section{(4.3) Hospitalisation due to all-cause diarrhoea}

Four trials, one of which reported two comparisons (total number of comparisons $=$ five $)$, including 74,039 participants $(36 \%$ of participants in the review) found no significant combined effect on hospitalisation due to all-cause diarrhoea (RR 1.03, 95\% CI 0.87 to 1.22$)$, but there was moderate heterogeneity $\left(\mathrm{Chi}^{2}=6.91\right.$, $\mathrm{df}=4(\mathrm{P}$ value $\left.=0.14) ; \mathrm{I}^{2}=42 \%\right)$ (Analysis 1.8). Excluding data from one study that reported hospitalisation data as the number of participants ever hospitalised (Chhagan 2009) did not change the result (RR $1.03,95 \%$ CI 0.87 to 1.22 ), but the effect changed when calculated using random-effects (RR $0.90,95 \%$ CI 0.65 to 1.24).

\section{(4.4) Incidence of severe diarrhoea}

Six trials, one of which reported two comparisons (total number of comparisons $=$ seven $)$, included 4982 participants $(2 \%$ of participants in the review) and found a significant combined effect on incidence of severe diarrhoea (RR 0.89 , 95\% CI 0.84 to $0.95)$. However, heterogeneity was substantial $\left(\mathrm{Chi}^{2}=13.54, \mathrm{df}=\right.$ $6(\mathrm{P}$ value $\left.=0.04) ; \mathrm{I}^{2}=56 \%\right)$ (Analysis 1.9$)$. The estimated effect was not importantly different, though it was no longer significant when calculated using random-effects (RR $0.92,95 \%$ CI 0.82 to 1.03).

\section{(4.5) Incidence of persistent diarrhoea}

Seven trials, two of which reported two comparisons each (total number of comparisons = nine), including 6216 participants $(3 \%$ of participants in the review), found that zinc supplementation was associated with a $27 \%$ decrease in the incidence of persistent diarrhoea (RR $0.73,95 \%$ CI 0.62 to 0.85 ), with substantial heterogeneity $\left(\mathrm{Chi}^{2}=20.47, \mathrm{df}=8(\mathrm{P}\right.$ value $\left.=0.009) ; \mathrm{I}^{2}=61 \%\right)$ (Analysis 1.10). The estimated effect was not importantly different when calculated using random-effects (RR 0.72, 95\% CI 0.54 to 0.96$)$.

\section{(4.6) Prevalence of persistent diarrhoea}

Only one trial, which made two comparisons (Rahman 2001/ Rahman 2001 (2); total number of comparisons = two), with 665 participants (<1\% of participants in this review), reported a $30 \%$ reduction in the prevalence of persistent diarrhoea (RR 0.70, $95 \%$ CI 0.64 to 0.76 ) (Analysis 1.11 ).

\section{(5) LRTI}

\section{(5.1) Incidence of LRTI}

One trial reported no LRTI in either group (Sempertegui 1996). Twelve trials, six of which made two comparisons (total number of comparisons $=18$ ), contributed 9610 participants ( $5 \%$ of participants in this review) to a meta-analysis that found no effect on LRTI incidence (RR 1.00, 95\% CI 0.94 to 1.07 ) and had no im- 
portant heterogeneity $\left(\mathrm{Chi}^{2}=17.16, \mathrm{df}=17(\mathrm{P}\right.$ value $=0.44) ; \mathrm{I}^{2}=$ 1\%) (Analysis 1.12). A funnel plot did not appear asymmetrical.

\section{Subgroup analyses}

Effects were not significantly heterogeneous across different age $(P$ value $=0.47)$, dose $(P$ value $=0.74)$, duration $(P$ value $=0.67)$, iron co-intervention $(\mathrm{P}$ value $=0.80)$, or formulation $(\mathrm{P}$ value $=$ $0.29)$ subgroups.

\section{(5.2) Prevalence of LRTI}

Three trials, one reporting two comparisons (total number of comparisons $=$ four $)$, included 1955 participants $(1 \%$ of participants in the review) and found that zinc supplementation was associated with a $20 \%$ increase in the prevalence of LRTI (RR 1.20, 95\% CI 1.10 to 1.30$)$, though heterogeneity was considerable $\left(\mathrm{Chi}^{2}=\right.$ 89.87, df = $\left.3(\mathrm{P}<0.00001) ; \mathrm{I}^{2}=97 \%\right)$ (Analysis 1.13).

This increase in prevalence was not significant when a randomeffects model was used (RR 1.13, 95\% CI 0.71 to 1.81 ). However, given that the three studies in this meta-analysis had sample sizes of 603,666 , and 686, it seems unlikely that small-study effects influenced the results. LRTI outcome criteria were similar across these studies, so LRTI criteria would not likely explain the difference between the random-effects and fixed-effect models. One possible explanation for this difference is that baseline population characteristics were different among the studies included in this meta-analysis, and some results were the result of chance. For example, Rahman 2001/Rahman 2001 (2) had a lower average baseline height-for-age z-score (-2.41) than that of Muller 2001 (1.6). Baseline risk of LRTI was different across the studies: Sazawal 1996 (2.11 days per child-year), Muller 2001 (1.56 days per childyear), Rahman 2001 (2.94 days per child-year), Rahman 2001 (2) (3.58 days per child-year).

\section{(5.3) Hospitalisation due to LRTI}

Three trials, one making two comparisons (total number of comparisons = four) (Bhandari 2007; Chang 2010/Chang 2010 (2); Soofi 2013), included 74,743 participants (36\% of participants in this review) and found no statistically significant effect on hospitalisation due to LRTI (RR $1.10,95 \%$ CI 0.93 to 1.30 ). There was no heterogeneity $\left(\mathrm{Chi}^{2}=0.35, \mathrm{df}=3(\mathrm{P}\right.$ value $=0.95) ; \mathrm{I}^{2}=$ 0\%) (Analysis 1.14).

\section{(6) Malaria}

\section{(6.1) Incidence of malaria}

Four trials, two of which made two comparisons (total number of comparisons = six), included 2407 participants ( $1 \%$ of participants in this review) and found no statistically significant effect on malaria incidence (RR $1.05,95 \%$ CI 0.95 to 1.15$)$; heterogeneity was not significant $\left(\mathrm{Chi}^{2}=2.04, \mathrm{df}=5(\mathrm{P}\right.$ value $\left.=0.84) ; \mathrm{I}^{2}=0 \%\right)$ (Analysis 1.15). The effect was not importantly different when analysed using random-effects (RR $0.99,95 \%$ CI 0.83 to 1.18 ).

\section{(6.2) Prevalence of malaria}

One study (Muller 2001) with 661 participants (< 1\% of participants in this review) reported no significant effect on malaria prevalence (RR 0.88, 95\% CI, 0.47 to 1.64 ) (Analysis 1.16).

\section{(7) Growth}

\section{(7.1) Height}

Fifty studies, nine of which made two comparisons (total number of comparisons $=59)$, reported height for 13,669 participants (7\% of participants in this review) (see Analysis 1.17). As explained in Measures of treatment effect, some studies measured height in units of $\mathrm{cm}$; other studies measured height as height-for-age zscores. We combined these height measures for this analysis. In all but one study (Sazawal 2006/Sazawal 2006 (2)), height was measured at, or after, the end of the supplementation period. Zinc supplementation was associated with a small, but significant, increase in height (SMD -0.09, 95\% CI -0.13 to -0.06), but heterogeneity was considerable $\left(\mathrm{Chi}^{2}=407.92, \mathrm{df}=58(\mathrm{P}<0.00001)\right.$; $\left.\mathrm{I}^{2}=86 \%\right)$. The result was not importantly different when analysed using random-effects (SMD $-0.10,95 \% \mathrm{CI}-0.20$ to -0.00 ). A funnel plot appeared generally symmetrical.

\section{Subgroup analyses}

Studies were not significantly different in the subgroup analyses for country income level $(\mathrm{P}$ value $=0.50)$ or stunting $(\mathrm{P}$ value $=$ 0.32).

Age subgroups were significantly heterogeneous $(\mathrm{P}<0.00001)$, with greater benefit in older age groups: between six and 12 months (SMD $0.26,95 \%$ CI 0.19 to 0.33 ); between one and five years (SMD $-0.09,95 \%$ CI -0.14 to -0.04 ); between five and 13 years (SMD -0.25, 95\% CI -0.32 to -0.18).

Dose subgroups were significantly different $(\mathrm{P}<0.00001)$. There did not appear to be a coherent pattern of increasing or decreasing effect across increasing doses: $0 \mathrm{mg}$ to $5 \mathrm{mg}$ (SMD - $0.02,95 \% \mathrm{CI}$ -0.13 to 0.10$) ; 5 \mathrm{mg}$ to $10 \mathrm{mg}(\mathrm{SMD}-0.29,95 \% \mathrm{CI}-0.37$ to 0.22 ); $10 \mathrm{mg}$ to $15 \mathrm{mg}$ (SMD $-0.06,95 \% \mathrm{CI}-0.12$ to -0.00$) ; 15$ $\mathrm{mg}$ to $20 \mathrm{mg}$ (SMD $0.01,95 \% \mathrm{CI}-0.24$ to 0.26 ); $20 \mathrm{mg}$ or more (SMD 0.01, 95\% CI -0.05 to 0.07).

Duration subgroups were significantly different $(\mathrm{P}<0.0001)$. There did not appear to be a coherent pattern of increasing or decreasing effect across increasing durations: between zero and six months (SMD 0.01, 95\% CI -0.04 to 0.07); between six and 12 months (SMD -0.17, 95\% CI -0.22 to -0.12); 12 months or more (SMD -0.10, 95\% CI -0.17 to -0.02).

Iron co-intervention subgroups were significantly different (P value $=0.01$, with a significant benefit in the group without iron (SMD - $0.12,95 \%$ CI -0.16 to -0.08 ) and no difference in the group with iron (SMD -0.01, 95\% CI -0.08 to 0.07).

Formulation subgroups were significantly different $(\mathrm{P}$ value $=$ 0.02). There were larger benefits in the solution and capsule sub- 
groups than the pill/tablet subgroup: solution (SMD -0.12, 95\% CI -0.16 to -0.07); pill and/or tablet (SMD -0.02, 95\% CI -0.09 to 0.04 ); capsule (SMD $-0.31,95 \%$ CI -0.59 to -0.03 ).

\section{(7.2) Weight}

Forty-four trials, eight of which reported two comparisons (total number of comparisons $=52$ ), included 12,305 participants $(6 \%$ of participants in this review) and found that zinc was associated with a small increase in weight (SMD -0.10, 95\% CI -0.14 to $-0.07)$, but heterogeneity was substantial $\left(\mathrm{Chi}^{2}=216.64, \mathrm{df}=\right.$ $\left.51(\mathrm{P}<0.00001) ; \mathrm{I}^{2}=76 \%\right)$ (Analysis 1.18). The result was not different when analysed using random-effects (SMD -0.10, 95\% CI -0.18 to - 0.02 ). However, there was some visual asymmetry in the funnel plot for this analysis, suggesting that small-study effects or reporting bias might have influenced the result.

\section{Subgroup analyses}

Effects did not differ significantly among country income level (P value $=0.62)$, stunting $(\mathrm{P}$ value $=0.13)$, or iron co-intervention (P value $=0.22)$ subgroups.

Age subgroups were significantly heterogeneous $(\mathrm{P}<0.00001)$, with greater benefit in older age groups: between six and 12 months (SMD 0.31, 95\% CI 0.25 to 0.38 ); between one and five years (SMD - $0.06,95 \%$ CI -0.11 to -0.01 ); between five and 13 years (SMD - $0.28,95 \%$ CI -0.36 to -0.20). The apparent harmful effect in the youngest subgroup is explained by the result of a subgroup analysis from one study (Bhandari 2002).

Dose subgroups were significantly different $(\mathrm{P}<0.00001)$, but there did not appear to be a coherent pattern of increasing or decreasing effect across increasing doses: $0 \mathrm{mg}$ to $5 \mathrm{mg}$ (SMD $0.00,95 \%$ CI -0.12 to 0.11 ); $5 \mathrm{mg}$ to $10 \mathrm{mg}$ (SMD $-0.27,95 \%$ CI -0.35 to -0.20 ); $10 \mathrm{mg}$ to $15 \mathrm{mg}$ (SMD $-0.11,95 \% \mathrm{CI}-0.17$ to -0.04 ); $15 \mathrm{mg}$ to $20 \mathrm{mg}$ (SMD $0.20,95 \% \mathrm{CI}-0.06$ to 0.45 ); $20 \mathrm{mg}$ or more (SMD $-0.01,95 \%$ CI -0.08 to 0.05 ).

Duration subgroups were significantly different $(\mathrm{P}<0.00001)$, but there did not appear to be a coherent pattern of increasing or decreasing effect across increasing durations: between zero and six months (SMD -0.05, 95\% CI -0.11 to 0.00 ); between six and 12 months (SMD $-0.20,95 \%$ CI -0.26 to -0.15 ); 12 months or more (SMD $0.01,95 \%$ CI -0.07 to 0.09 ).

Formulation subgroups were significantly different $(\mathrm{P}$ value $=$ $0.0004)$. There were statistically significant benefits in the solution and capsule subgroups and no statistically significant effect in the pill/tablet subgroup: solution (SMD -0.14, 95\% CI -0.19 to -0.10); pill and/or tablet (SMD -0.01, 95\% CI -0.08 to 0.06); capsule (SMD -0.41, 95\% CI -0.71 to -0.12).

\section{(7.3) Weight-to-height ratio}

Twenty-four trials, five of which reported two comparisons (total number of comparisons $=29)$, included 7901 participants $(4 \%$ of participants in this review) and found that zinc supplementation was associated with a small increase in weight-to-height ratio
(SMD $-0.05,95 \%$ CI -0.10 to -0.01 ). There was no heterogeneity $\left(\mathrm{Chi}^{2}=34.96, \mathrm{df}=28(\mathrm{P}\right.$ value $\left.=0.17) ; \mathrm{I}^{2}=20 \%\right)($ Analysis 1.19) . The funnel plot appeared symmetrical.

\section{Subgroup analyses}

Studies were not significantly different in the subgroup analyses for country income level $(\mathrm{P}$ value $=0.66)$, age $(\mathrm{P}$ value $=0.75)$, dose $(\mathrm{P}$ value $=0.34)$, duration $(\mathrm{P}$ value $=0.29)$, iron co-interventions $(\mathrm{P}$ value $=0.06)$, or formulation $(\mathrm{P}$ value $=0.16)$.

\section{(7.4) Prevalence of stunting}

Six trials, three of which included two comparisons (total number of comparisons $=$ nine $)$, included 3838 participants $(2 \%$ of participants in this review) and found no significant effect on the prevalence of stunting (RR $0.94,95 \% \mathrm{CI}, 0.86$ to 1.02 ), but heterogeneity was substantial $\left(\mathrm{Chi}^{2}=19.43, \mathrm{df}=8(\mathrm{P}\right.$ value $=0.01)$; $\mathrm{I}^{2}=59 \%$ ) (Analysis 1.20). The average effect was not importantly different when calculated using random-effects (RR 0.90, 95\% CI 0.72 to 1.12 ).

\section{(8) Zinc status}

\section{(8.1) Serum or plasma zinc concentration}

Forty-six studies, 10 of which made two comparisons (total number of comparisons $=56$ ), included 9810 participants ( $5 \%$ of participants randomised) and found that zinc supplementation was associated with a medium to large increase in zinc concentration (SMD -0.62, 95\% CI -0.67 to -0.58$)$, though heterogeneity was considerable $\left(\mathrm{Chi}^{2}=582.45, \mathrm{df}=55(\mathrm{P}<0.00001) ; \mathrm{I}^{2}=91 \%\right)$ (Analysis 1.21). The result was not different when analysed using random-effects (SMD -0.62, 95\% CI -0.77 to -0.48). The funnel plot did not appear to have any substantive asymmetry.

\section{Subgroup analyses}

Age subgroups were significantly heterogeneous $(\mathrm{P}<0.0001)$ with the greatest benefit in the one to five year age group: between six and 12 months (SMD - $0.46,95 \%$ CI -0.55 to -0.37 ); between one and five years (SMD $-0.75,95 \% \mathrm{CI}-0.81$ to -0.69 ); between five and 13 years (SMD $-0.47,95 \%$ CI -0.55 to -0.38 ).

Country income level subgroups were significantly different (P value $=0.003$ ), with statistically significant benefit only in the lowand middle-income subgroups (SMD -0.63, 95\% CI -0.68 to $0.59)$, which contained most of the data, and no difference in the high-income subgroup (SMD -0.23, 95\% CI, -0.49 to 0.03 ).

Dose subgroups were significantly different $(\mathrm{P}<0.00001)$ with larger doses associated with larger increases in zinc concentration: $0 \mathrm{mg}$ to $5 \mathrm{mg}$ (SMD $-0.35,95 \% \mathrm{CI}-0.49$ to -0.21 ); $5 \mathrm{mg}$ to 10 $\mathrm{mg}$ (SMD $-0.49,95 \% \mathrm{CI}-0.59$ to -0.40$) ; 10 \mathrm{mg}$ to $15 \mathrm{mg}$ (SMD $-0.62,95 \%$ CI -0.68 to -0.56 ); $15 \mathrm{mg}$ to $20 \mathrm{mg}$ (SMD $-0.76,95 \%$ CI -0.94 to -0.58$) ; 20 \mathrm{mg}$ or more (SMD $-0.88,95 \%$ CI -0.98 to $-0.78)$. 
Duration subgroups were significantly different $(\mathrm{P}<0.0001)$. Shorter durations were associated with larger increases in zinc concentration: between zero and six months (SMD -0.81, 95\% CI 0.88 to -0.73 ); between six and 12 months (SMD $-0.52,95 \% \mathrm{CI}$ -0.58 to -0.46 ); 12 months or more (SMD $-0.59,95 \%$ CI -0.67 to -0.50$)$.

Formulation subgroups were significantly different $(\mathrm{P}<0.00001)$, with greatest benefit in the capsule subgroup (SMD -1.07, 95\% CI -1.21 to -0.94 ), then the solution group (SMD - $0.78,95 \% \mathrm{CI}$ -0.84 to -0.72 ), and least benefit in the pill and/or tablet subgroup (SMD $-0.42,95 \%$ CI -0.49 to -0.35 ).

Iron co-intervention subgroups were significantly different $(\mathrm{P}<$ $0.00001)$, with greater benefit in the subgroup not given iron: no iron (SMD - $0.70,95 \%$ CI - 0.75 to -0.65); iron (SMD - $0.47,95 \%$ CI -0.54 to -0.39 ).

\section{(8.2) Prevalence of zinc deficiency}

Fifteen trials, six of which reported two comparisons each (total number of comparisons $=21$ ), included 5434 participants (3\% of participants in this review) and found that zinc supplementation was associated with a $51 \%$ reduction in the prevalence of zinc deficiency (RR 0.49 , 95\% CI 0.45 to 0.53 ), but heterogeneity was substantial $\left(\mathrm{Chi}^{2}=144.77, \mathrm{df}=20(\mathrm{P}<0.00001) ; \mathrm{I}^{2}=86 \%\right)$ (Analysis 1.22). There was a larger effect when calculated using random-effects (RR $0.36,95 \%$ CI 0.27 to 0.48 ) and the funnel plot appeared to be skewed.

\section{Subgroup analyses}

Age subgroups were significantly different $(\mathrm{P}<0.00001)$, with greater benefit in older age groups: between six and 12 months (RR 0.62, 95\% CI 0.54 to 0.70 ); between one and five years (RR $0.41,95 \%$ CI 0.37 to 0.47 ); between five and 13 years (RR 0.31 , $95 \%$ CI 0.20 to 0.49 ).

Dose subgroups were significantly different $(\mathrm{P}<0.00001)$. There did not appear to be a coherent pattern of increasing or decreasing effect across increasing doses: $5 \mathrm{mg}$ to $10 \mathrm{mg}$ (RR 0.34, 95\% CI 0.27 to 0.44 ); $10 \mathrm{mg}$ to $15 \mathrm{mg}$ (RR $0.57,95 \% \mathrm{CI} 0.52$ to 0.63 ); $15 \mathrm{mg}$ to $20 \mathrm{mg}$ (RR $0.46,95 \%$ CI 0.24 to 0.89 ); $20 \mathrm{mg}$ or more (RR $0.14,95 \%$ CI 0.10 to 0.19 ).

Duration subgroups were significantly different $(\mathrm{P}<0.00001)$. There did not appear to be a coherent pattern of increasing or decreasing effect across increasing durations: between zero and six months (RR 0.22 , 95\% CI 0.18 to 0.27 ); between six and 12 months (RR $0.59,95 \%$ CI 0.53 to 0.67 ); 12 months or more (RR $0.55,95 \%$ CI 0.48 to 0.64 ).

Iron co-intervention subgroups were significantly different $(\mathrm{P}<$ $0.00001)$, with greater benefit in the subgroup not given iron ( $R R$ $0.37,95 \%$ CI 0.33 to 0.42 ) compared with the group given iron (RR 0.62, 95\% CI 0.55, 0.69).

Formulation subgroups were significantly different $(\mathrm{P}<0.0001)$, with greatest benefit in the capsule subgroup (RR 0.29, 95\% CI
0.23 to 0.37 ), then the solution group (RR $0.49,95 \%$ CI 0.44 to 0.54 ), and then the pill and/or tablet group (RR $0.59,95 \% \mathrm{CI}$ 0.50 to 0.68 ).

\section{Adverse events}

\section{(9) Side effects}

Two trials (Alarcon 2004; Mazariegos 2010) reported no adverse events, including vomiting, in either group.

\section{(9.1) Study withdrawal}

Six trials, which included data for 4263 participants (1\% of participants in this review), found no significant effect on study withdrawal (RR $1.75,95 \%$ CI 0.93 to 3.32 ) and heterogeneity was not significant $\left(\mathrm{Chi}^{2}=5.07, \mathrm{df}=4(\mathrm{P}\right.$ value $\left.=0.28) ; \mathrm{I}^{2}=21 \%\right)$ (Analysis 1.23). There were only 37 events in total.

This meta-analysis included 3437 participants in five trials. There was no significant effect on study withdrawal.

\section{(9.2) Participants with more than one side effect}

Three trials, including data for 850 participants $(<1 \%$ of participants in this review), found some evidence of increased side effects (RR 1.13, 95\% CI 1.00 to 1.27$)$ with no heterogeneity $\left(\mathrm{Chi}^{2}=\right.$ $0.49, \mathrm{df}=2(\mathrm{P}$ value $\left.=0.78) ; \mathrm{I}^{2}=0 \%\right)($ Analysis 1.24$)$.

\section{(9.3) Vomiting episodes}

Five trials, one of which made two comparisons (total number of comparisons $=$ six), included 4095 participants ( $2 \%$ of participants in this review) and suggest that zinc supplementation was associated with an increase in vomiting episodes (RR 1.68, 95\% CI 1.61 to 1.75$)$, though heterogeneity was considerable $\left(\mathrm{Chi}^{2}=\right.$ $\left.34.28, \mathrm{df}=5(\mathrm{P}<0.00001) ; \mathrm{I}^{2}=85 \%\right)$ (Analysis 1.25). This effect appears to be slightly larger when analysed using random-effects (RR $1.85,95 \%$ CI 1.30 to 2.63 ).

\section{(9.4) Participants with more than one vomiting episode}

Five trials, including data for 35,192 participants ( $<17 \%$ of participants in this review) found some evidence of increased vomiting associated with supplementation (RR 1.29, 95\% CI 1.14 to $1.46)$, with some heterogeneity $\left(\mathrm{Chi}^{2}=6.31, \mathrm{df}=4(\mathrm{P}\right.$ value $=$ $0.18) ; \mathrm{I}^{2}=37 \%$ ) (see Analysis 1.26).

\section{(10) Haemoglobin status}

\section{(10.1) Blood haemoglobin concentration}

Twenty-six trials, 10 of which made two comparisons (total number of comparisons $=36$ ), included 6024 participants ( $3 \%$ of participants in the review) and reported a very small difference in blood haemoglobin concentration (SMD 0.05, 95\% CI -0.00 to $0.10)$; heterogeneity was moderate $\left(\mathrm{Chi}^{2}=63.96, \mathrm{df}=35(\mathrm{P}<\right.$ 0.002); $\mathrm{I}^{2}=45 \%$ ) (Analysis 1.27). This effect estimate remained 
trivial when estimated using random-effects (SMD 0.05, 95\% CI -0.03 to 0.12 ). The funnel plot was generally symmetrical.

\section{Subgroup analyses}

Studies did not differ significantly in the subgroup analyses for age $(\mathrm{P}$ value $=0.46)$, dose $(\mathrm{P}$ value $=0.71)$, duration $(\mathrm{P}$ value $=0.12)$, iron co-interventions $(\mathrm{P}$ value $=0.40)$, or formulation $(\mathrm{P}$ value $=$ $0.71)$.

\section{(10.2) Prevalence of anaemia}

Thirteen trials, six of which made two comparisons (total number of comparisons $=19$ ), included 4287 participants ( $2 \%$ of participants in this review) and found no overall effect on the prevalence of anaemia (RR $1.00,95 \%$ CI 0.95 to 1.06 ); heterogeneity was moderate $\left(\mathrm{Chi}^{2}=28.52, \mathrm{df}=18(\mathrm{P}\right.$ value $\left.=0.05) ; \mathrm{I}^{2}=37 \%\right)$ (Analysis 1.28). The estimate was not importantly different when estimated using random-effects methods (RR 0.98, 95\% CI 0.89 to 1.07 ), but there was evidence of some funnel plot asymmetry.

\section{Subgroup analyses}

Effects were not significantly different across age (P value $=0.34)$, iron co-intervention $(\mathrm{P}$ value $=0.93)$, or formulation $(\mathrm{P}$ value $=$ 0.36) subgroups.

Dose subgroups were significantly different $(\mathrm{P}$ value $=0.01)$, though this was explained by one high-dose study that reported a large effect (Alarcon 2004). There did not appear to be a coherent pattern otherwise: $0 \mathrm{mg}$ to $5 \mathrm{mg}$ (RR 1.01, 95\% CI 0.94 to 1.09); $5 \mathrm{mg}$ to $10 \mathrm{mg}$ (RR $0.94,95 \% \mathrm{CI} 0.47$ to 1.87 ); $10 \mathrm{mg}$ to 15 $\mathrm{mg}$ (RR $1.01,95 \%$ CI 0.92 to 1.11 ); $15 \mathrm{mg}$ to $20 \mathrm{mg}$ (RR 0.76, $95 \%$ CI 0.40 to 1.46 ); $20 \mathrm{mg}$ or more (RR $0.17,95 \%$ CI 0.06 to $0.46)$.

Duration subgroups were significantly different $(\mathrm{P}$ value $=0.003)$, but this was also a consequence of one trial (Alarcon 2004): between zero and six months (RR $0.18,95 \%$ CI 0.06 to 0.48 ); between six and 12 months (RR 1.01, 95\% CI 0.94 to 1.08 ); 12 months or more (RR $1.00,95 \%$ CI 0.90 to 1.12 ).

\section{(11) Iron status}

\section{(11.1) Serum or plasma ferritin concentration}

Twenty studies, five of which made two comparisons (total number of comparisons $=25$ ), included 4474 participants ( $2 \%$ of participants in this review) and found that zinc supplementation was associated with a small increase in ferritin concentration (SMD $0.07,95 \%$ CI -0.13 to -0.00$)$, though heterogeneity was considerable $\left(\mathrm{Chi}^{2}=480.50, \mathrm{df}=24(\mathrm{P}<0.00001) ; \mathrm{I}^{2}=95 \%\right)$ (Analysis 1.29). One study in this meta-analysis reported data as medians, but excluding this study from the analysis did not affect the result importantly (SMD -0.11, 95\% CI -0.17 to 0.04) (Tielsch 2006 (2)). The average effect was not importantly different when calcu- lated using random-effects (SMD - $0.13,95 \% \mathrm{CI}-0.42$ to 0.15 ), but there was evidence of some funnel plot asymmetry.

\section{Subgroup analyses}

Studies did not differ significantly in the subgroup analyses for age $(\mathrm{P}$ value $=0.60)$.

Country income level subgroups were significantly different (P value $=0.01$ ), but only one trial in a high-income country reported the outcome (Sandstead 2008), and it was inconsistent with the others (SMD 0.88, 95\% CI 0.29 to 1.47 ).

Dose subgroups were significantly different $(\mathrm{P}$ value $=0.00009)$. There did not appear to be a coherent pattern of results: $0 \mathrm{mg}$ to $5 \mathrm{mg}$ (SMD $0.07,95 \% \mathrm{CI}-0.14$ to 0.28 ); $5 \mathrm{mg}$ to $10 \mathrm{mg}$ (SMD $0.15,95 \% \mathrm{CI}-0.34$ to 0.63 ); $10 \mathrm{mg}$ to $15 \mathrm{mg}$ (SMD $0.20,95 \%$ CI 0.13 to 0.28 ); $15 \mathrm{mg}$ to $20 \mathrm{mg}$ (SMD $0.14,95 \% \mathrm{CI}-0.08$ to 0.36 ); $20 \mathrm{mg}$ or more (SMD $-0.17,95 \% \mathrm{CI}-0.33$ to -0.02$)$.

Duration subgroups were significantly different $(\mathrm{P}<0.00001)$, with some evidence of harm at increasing doses: between zero and six months (SMD $-0.06,95 \%$ CI -0.20 to 0.07 ); between six and 12 months (SMD 0.07 , 95\% CI -0.03 to 0.17 ); 12 months or more (SMD $0.34,95 \%$ CI 0.24 to 0.45 ).

Iron co-intervention subgroups were significantly different (P value $=0.0009)$. There was statistically significant harm in the subgroup without iron (SMD 0.27, 95\% CI 0.17 to 0.38 ) and no statistically significant effect in the subgroup with iron (SMD $0.05,95 \%$ CI -0.02 to 0.13 ).

Formulation subgroups were significantly different $(\mathrm{P}<0.00001)$ due to the inclusion of one outlier in the capsule group (Veenemans 2011; Veenemans 2011 (2))

\section{(11.2) Prevalence of iron deficiency}

Ten trials (comprising a total of 15 comparisons) included 3149 participants ( $2 \%$ of those included in the review) and found that there was no significant effect on the prevalence of iron deficiency (RR $0.99,95 \%$ CI 0.89 to 1.10 ), with no significant heterogeneity $\left(\mathrm{Chi}^{2}=16.44, \mathrm{df}=14(\mathrm{P}\right.$ value $\left.=0.29) ; \mathrm{I}^{2}=15 \%\right)($ Analysis 1.30 $)$. The funnel plot appeared generally symmetrical.

\section{Subgroup analyses}

Effects were not significantly different across age ( $\mathrm{P}$ value $=0.17$ ), dose $(\mathrm{P}$ value $=0.12)$, duration $(\mathrm{P}$ value $=0.13)$, iron co-intervention $(\mathrm{P}$ value $=0.48)$, or formulation $(\mathrm{P}$ value $=0.39)$ subgroups .

\section{(12) Copper status}

\section{(12.1) Serum or plasma copper concentration}

Eleven trials (comprising a total of 13 comparisons), reported data for 3071 participants ( $1 \%$ of participants in this review) and suggested that zinc supplementation was associated with a small decrease in copper concentration (SMD 0.22, 95\% CI 0.14 to 0.29), though there was substantial heterogeneity $\left(\mathrm{Chi}^{2}=37.47, \mathrm{df}=12\right.$ 
$(\mathrm{P}$ value $\left.=0.0002) ; \mathrm{I}^{2}=68 \%\right)($ Analysis 1.31) . This estimate was reduced when calculated using random-effects (SMD 0.11, 95\% CI -0.03 to 0.25 ) and there was evidence of funnel plot asymmetry.

\section{Subgroup analyses}

Effects did not differ significantly among country income level $(\mathrm{P}$ value $=0.06)$, age $(\mathrm{P}$ value $=0.06)$, or iron co-intervention $(\mathrm{P}$ value $=0.09)$ subgroups.

Dose subgroups were significantly heterogeneous $(\mathrm{P}<0.00001)$, but there was not a coherent pattern of results: $0 \mathrm{mg}$ to $5 \mathrm{mg}$ (SMD 0.08, 95\% CI -0.12 to 0.27); $5 \mathrm{mg}$ to $10 \mathrm{mg}$ (SMD 0.31, $95 \% \mathrm{CI} 0.13$ to 0.49 ); $10 \mathrm{mg}$ to $15 \mathrm{mg}$ (SMD $0.01,95 \% \mathrm{CI}-$ 0.10 to 0.12 ); $20 \mathrm{mg}$ or more (SMD $0.46,95 \%$ CI 0.33 to 0.59 ). Duration subgroups were significantly heterogeneous $(\mathrm{P}<$ 0.00001). There was statistically significant harm when zinc was given for between zero and six months, and no statistically significant effect when zinc was given for longer durations: between zero and six months (SMD 0.44, 95\% CI 0.33 to 0.55 ); between six and 12 months (SMD $0.08,95 \%$ CI -0.04 to 0.20 ); 12 months or more (SMD -0.06, 95\% CI -0.24 to 0.11). However, few studies were included in each group.

Formulation subgroups were significantly different $(\mathrm{P}<0.00001)$, with greater harm in the pill/tablet subgroup: solution (SMD 0.37, $95 \%$ CI 0.29 to 0.46 ); pill and/or tablet (SMD 0.83, 95\% CI 0.65 to 1.01$)$.

\section{(12.2) Prevalence of copper deficiency}

Three trials including 1337 participants (1\% of participants in this review) reported that zinc supplementation was associated with an increase in the prevalence of copper deficiency (RR 2.64, 95\% CI 1.28 to 5.42$)$, though heterogeneity was substantial $\left(\mathrm{Chi}^{2}=4.94\right.$, $\mathrm{df}=2(\mathrm{P}$ value $\left.=0.08) ; \mathrm{I}^{2}=59 \%\right)$ (Analysis 1.32$)$. The estimate was not significant when analysed using random-effects (RR 2.72, $95 \%$ CI 0.73 to 10.18$)$.

\section{Comparison 2: Zinc plus iron versus zinc alone}

In addition to comparing zinc to no intervention, several trials compared zinc with iron versus zinc alone. Post hoc, we conducted additional analyses of key outcomes to test the hypothesis that delivering zinc with iron would reduce the effect of zinc.

\section{Primary outcomes}

\section{(1) All-cause mortality}

One trial reported all-cause mortality for 323 participants and the difference was not significant (RR 0.33 , 95\% CI 0.01 to 8.39 ) (Analysis 2.1).

\section{Secondary outcomes}

\section{(2) Hospitalisation}

One trial reported all-cause hospitalisation for 399 participants and the difference was not significant (RR $0.92,95 \%$ CI 0.45 to 1.89) (Analysis 2.2).

\section{(3) Diarrhoea}

\section{(3.1) Incidence of all-cause diarrhoea}

Five trials reported the incidence of all-cause diarrhoea for 1530 participants and the difference favoured zinc alone (RR 1.10, 95\% CI 1.03 to 1.18$)$, but there was considerable heterogeneity $\left(\mathrm{Chi}^{2}=\right.$ $16.92, \mathrm{df}=4(\mathrm{P}$ value $\left.=0.002) ; \mathrm{I}^{2}=76 \%\right)$ (Analysis 2.3$)$, and there was no difference between groups when analysed using randomeffects (RR $1.07,95 \%$ CI 0.91 to 1.25 ).

\section{(3.2) Prevalence of all-cause diarrhoea}

One trial reported the prevalence of all-cause diarrhoea for 399 participants and the difference was not significant (RR 0.90, 95\% CI 0.76 to 1.06 ) (Analysis 2.4).

\section{(3.3) Incidence of severe diarrhoea}

One trial reported the incidence of severe diarrhoea for 323 participants and the difference was not significant (RR 0.78, 95\% CI 0.59 to 1.04 ) (Analysis 2.5).

\section{(3.4) Hospitalisation due to all-cause diarrhoea}

One trial reported hospitalisation due to diarrhoea for 399 participants and the difference was not significant (RR 0.99, 95\% CI 0.25 to 3.88 ) (Analysis 2.6).

\section{(4) Incidence of LRTI}

Three trials reported the prevalence of all-cause diarrhoea for 1065 participants and the difference was not significant (RR 0.93, CI 0.83 to 1.04$)$, with no important heterogeneity $\left(\mathrm{Chi}^{2}=2.52 \mathrm{df}\right.$ $=2(\mathrm{P}$ value $\left.=0.28) ; \mathrm{I}^{2}=21 \%\right)($ Analysis 2.7$)$.

\section{(5) Incidence of malaria}

One trial reported the incidence of malaria for 419 participants and the difference was not significant (RR $0.86,95 \%$ CI 0.59 to 1.24) (Analysis 2.8).

\section{(6) Growth}

\section{(6.1) Height}

Five trials reported height for 1517 participants and the difference was not significant (SMD 0.06, 95\% CI -0.04 to 0.16 ), with no heterogeneity $\left(\mathrm{Chi}^{2}=3.54, \mathrm{df}=4(\mathrm{P}\right.$ value $\left.=0.47) ; \mathrm{I}^{2}=0 \%\right)$ (Analysis 2.9). 


\section{(6.2) Weight}

Four trials reported weight for 910 participants and the difference was not significant (SMD 0.12, 95\% CI -0.01 to 0.25 ), with no important heterogeneity $\left(\mathrm{Chi}^{2}=2.29, \mathrm{df}=3(\mathrm{P}\right.$ value $=0.51) ; \mathrm{I}^{2}$ $=0 \%$ ) (Analysis 2.10).

\section{(6.3) Weight-to-height ratio}

Four trials reported weight-to-height ratio for 933 participants and the difference was not significant (SMD 0.06, 95\% CI -0.07 to 0.19$)$, with no heterogeneity $\left(\mathrm{Chi}^{2}=1.36, \mathrm{df}=3(\mathrm{P}\right.$ value $=$ $\left.0.71) ; \mathrm{I}^{2}=0 \%\right)($ Analysis 2.11$)$

\section{(6.4) Prevalence of stunting}

Two trials reported stunting for 462 participants (RR 0.92, 95\% CI 0.85 to 0.99$)$ but the studies appeared to be inconsistent $\left(\mathrm{Chi}^{2}\right.$ $=1.82, \mathrm{df}=1(\mathrm{P}$ value $\left.=0.18) ; \mathrm{I}^{2}=45 \%\right)($ Analysis 2.12$)$.

\section{(7) Zinc status}

\section{(7.1) Serum or plasma zinc concentration}

Eight trials reported serum zinc concentration for 1337 participants and the difference favoured zinc alone (SMD 0.16, 95\% CI 0.05 to 0.27$)$, but there was considerable heterogeneity $\left(\mathrm{Chi}^{2}=\right.$ 17.84, $\mathrm{df}=7$ (P value $=0.01) ; \mathrm{I}^{2}=61 \%$ ) (Analysis 2.13), and the difference between groups was no longer significant when analysed using random-effects (SMD 0.14, 95\% CI -0.05 to 0.33).

\section{(7.2) Prevalence of zinc deficiency}

Three trials reported the prevalence of zinc deficiency for 350 participants and the difference was not significant (RR 1.42, 95\% CI 0.75 to 2.68) (Analysis 2.14).

\section{Adverse events}

\section{(8) Study withdrawal}

Two trials reported study withdrawal for 557 participants and the difference was not significant (RR 1.41, 95\% CI 0.91 to 2.18) (Analysis 2.15).

\section{(9) Haemoglobin status}

Eight trials reported blood haemoglobin concentration for 1341 participants and the difference favoured zinc with iron (SMD $0.23,95 \% \mathrm{CI}-0.34$ to -0.12$)$, but there was considerable heterogeneity $\left(\mathrm{Chi}^{2}=33.53, \mathrm{df}=7(\mathrm{P}<0.00001) ; \mathrm{I}^{2}=79 \%\right)$ (Analysis 2.16), and the difference between groups was no longer significant when analysed using random-effects (SMD - $0.21,95 \%$ CI -0.47 to 0.05 ).

\section{(10) Iron status}

\section{(10.1) Serum or plasma ferritin concentration}

Six trials reported serum ferritin concentration for 945 participants and the difference favoured zinc with iron (SMD -1.78, 95\% CI -1.99 to -1.56$)$; there was considerable heterogeneity $\left(\mathrm{Chi}^{2}=\right.$ 927.92, $\left.\mathrm{df}=5(\mathrm{P}<0.00001) ; \mathrm{I}^{2}=99 \%\right)$ (Analysis 2.17), and the range of possible effects appears wider (less certain) when analysed using random-effects (SMD -3.28, 95\% CI -6.27 to -0.30).

(10.2) Prevalence of iron deficiency

Two trials reported the prevalence of iron deficiency for 248 participants and the difference favoured zinc with iron (RR 0.12, 95\% CI 0.04 to 0.32 ) (Analysis 2.18).

\section{(11) Copper status}

Two trials reported serum copper concentration for 353 participants and the difference was not significant (SMD 0.06, 95\% CI -0.15 to 0.27 , with no heterogeneity $\left(\mathrm{Chi}^{2}=0.11, \mathrm{df}=1\right.$ (P value $=0.74) ; \mathrm{I}^{2}=0 \%$ ) (Analysis 2.20).

\section{I SCUSSION}

\section{Summary of main results}

See Summary of findings for the main comparison for an overview of the main results and quality of the evidence.

\section{Primary outcomes}

The effect of preventive zinc supplementation on all-cause mortality was not statistically significant, but these results are consistent with a small reduction in mortality. Cause-specific mortality due to diarrhoea, lower respiratory tract infection (LRTI), and malaria are thought to be key pathways through which zinc deficiency leads to increased overall mortality. This review's pooled estimates for mortality due to diarrhoea, LRTI, and malaria were not statistically significant; however, all of these estimates were consistent with a previous review suggesting that there are small benefits of zinc supplementation (Black 2013). To change the conclusions of this review, additional studies would need to be extremely large and very precise. It seems unlikely that further research will affect the primary outcome.

\section{Secondary outcomes}

Zinc supplementation was associated with significant reductions in diarrhoea incidence and prevalence. Supplementation resulted in very small, but statistically significant, improvements in most growth-related outcomes; however, these may be too small to be clinically significant. Zinc status also reflects significant, medium to large improvements as a result of supplementation. Supplementation did not significantly affect reported hospitalisation outcomes. There were no significant effects on LRTI, and malaria incidence and prevalence. 


\section{Adverse events}

Supplementation may be associated with increased vomiting. Supplementation had no important effect on haemoglobin or iron status, but it may have a negative effect on copper status. Most studies provided supplements as zinc sulfate and it is unclear if the chemical formulation may relate to side effects.

\section{Overall completeness and applicability of evidence}

Overall, the external validity of this review is strong. This review included 80 studies conducted in a large number of countries. Almost all outcomes of interest were reported in multiple trials and almost all meta-analyses included over 1000 participants. Nonstunted and stunted children of both genders and all eligible ages were represented in the included trials and numerous types of preventive zinc supplementation characteristics are represented. Clinical outcomes were investigated, as well as side effects and biochemical outcomes (such as zinc status). Furthermore, there was no important heterogeneity among studies for the primary outcomes of this review. Given these strengths, there may be no need for further placebo-controlled trials of the effects of preventive zinc supplementation for the population and outcomes of this review.

\section{Setting}

Most of the studies in this review were conducted in low- or middle-income countries, and a wide range of such countries are represented. The evidence of this review may not be as applicable in high-income countries, as the risk of zinc deficiency is a greater problem in low- and middle-income countries.

Among low- and middle-income countries, there is inter- and intra-country variation. For instance, zinc supplementation may be more effective in settings with relatively low levels of meat intake, high levels of undernutrition, and high population-level risk of zinc deficiency. The impact of supplementation may also vary with varying levels of fibre and phytate consumption.

The effectiveness of zinc might also be influenced by differing disease prevalence and pathogen profiles among low- and middleincome countries. For instance, particular micronutrient supplementation interventions may have differing levels of benefit or harm when delivered in malaria endemic versus non-endemic areas (Sazawal 2006). The impact of supplementation might also be influenced by the particular infectious, disease-causing pathogens in a given area (Patel 2011).

\section{Participant characteristics}

The full range of eligible ages was represented among participants in this review. However, the majority of studies - including the largest three trials - did not include children over five years of age. Most of the age subgroup analyses, including the analysis for all-cause mortality, did not indicate that the effects of zinc supplementation were significantly different for different age groups. However, of those that did indicate a difference, supplementation was generally more effective in the one to five years age group than the six to 12 months group. This possible association must be interpreted with caution; trials may be more likely to report disaggregated data for participant subgroups when these groups are significantly different, and subgroup analyses in systematic reviews often yield false positive results (Guyatt 2008; Guyatt 2011a). Stunted children were also represented in this review, as illustrated by the number of studies that included stunted children and the median baseline height-for-age $\mathrm{z}$-scores across trials. Most stunting subgroup analyses indicated that the effects of supplementation for stunted children were similar to those for non-stunted children. However, due to a lack of data reported separately for stunted versus non-stunted children, this review might have been underpowered to detect any meaningful effect modification by stunting status.

\section{Intervention implementation}

The evidence from this review seems applicable to preventive zinc supplementation programmes with a variety of doses, durations, co-interventions, and formulations. Furthermore, there was not strong evidence of meaningful effect modification based on dose, duration, presence or absence of an iron co-intervention, or formulation. Significant subgroup differences were generally inconsistent across outcomes, heterogeneity was often high even within individual subgroups, and subgroup differences often lacked a coherent directionality (for example, higher doses leading to greater effects).

For many subgroup analyses, a few studies contributed most of the weight and the tests for subgroup differences were underpowered. Furthermore, certain types of effect modification, such as a gradient of effectiveness based on dose, might be more conducive to meta-regression analysis than categorical subgroup analysis. There could have been a relationship between effect estimates and dose or effect estimates and duration that the subgroup analyses in this review were unable to detect.

Furthermore, though we analysed studies of zinc with an iron cointervention versus those without an iron co-intervention, this review was not primarily designed to explore this relationship fully. It has been shown previously that co-supplementation of iron and zinc may reduce the efficacy of zinc for growth (Imdad 2011). This aspect is very important as there are existing programmes of iron supplementation for prevention of anaemia using multiple micronutrients or additional zinc and co-supplementation with iron might decrease the desired preventive effect of zinc supplementation. Our subgroup analyses identified few statistically significant differences between subgroups receiving an iron co-intervention versus subgroups not receiving an iron co-intervention; however, there were relatively few studies in most analyses. Within trials 
that made multiple comparisons, effects for groups receiving an iron co-intervention were not consistently different from effects for groups without an iron co-intervention (Comparison 2: Zinc versus zinc plus iron).

\section{Quality of the evidence}

This review included 80 studies with approximately 205,923 children, who were evaluated for mortality, morbidity, growth, and adverse event outcomes. We used the GRADE framework to assess the quality of evidence for outcomes in this review based on the following factors: indirectness of evidence, unexplained heterogeneity, publication bias, risk of bias due to study design limitations, and imprecision of results (Balshem 2011).

The meta-analysis of all-cause mortality included outcomes for 138,302 participants in 14 studies. For all-cause and cause-specific mortality outcomes, the quality of evidence was moderate to high. Thus, there may be no need for further placebo-controlled trials analysing the effects of preventive zinc supplementation on mortality in the population of this review. As discussed above, indirectness of evidence did not seem to be a significant problem for this review, because it did not have to use proxies for its populations, interventions, and outcomes of interest. There was no significant heterogeneity among studies in the mortality metaanalyses. Though it is difficult to evaluate the probability of publication bias accurately, no such bias was detected for the primary outcomes through funnel plot inspections.

The three largest studies in this review, which accounted for almost all of the effects in each mortality meta-analysis, were at low risk of bias for sequence generation, allocation concealment, blinding, and incomplete outcome data. Many studies in this review were at high risk of bias due to selective outcome reporting. However, it seems unlikely that selective reporting substantially biased the results of the mortality meta-analyses given that the three largest studies in this review all reported mortality outcomes. Thus, even if mortality outcome data were selectively withheld from the trial reports of certain studies, these studies would not likely be numerous or large enough to influence the results of the primary analysis. In terms of imprecision, the $95 \%$ confidence interval for all-cause mortality suggests that the intervention is highly unlikely to cause appreciable harm. The confidence intervals for mortality due to diarrhoea or LRTI included the possibility of harm and there were also few cause-specific deaths observed due to diarrhoea, LRTI, or malaria. We thus downgraded the latter outcomes and considered them to be moderate rather than high-quality evidence.

Compared to the primary outcomes of this review, the quality of evidence for the secondary outcomes and adverse events was more mixed. Heterogeneity was significant for some of these outcomes and this heterogeneity remained largely unexplained even after subgroup analyses were undertaken. Due to unexplained heterogeneity, we downgraded incidence of all-cause diarrhoea, inci- dence of malaria, and height from high to moderate quality. Selective reporting was also more likely to influence secondary outcomes with meta-analyses involving relatively small numbers of participants.

Inverse variance methods may give biased results for rare events, but the overall effects are small and many are not significant; small biases in the methods may have minimal consequences for the results and interpretation.

\section{Potential biases in the review process}

This review had several strengths in terms of preventing bias. Its search was comprehensive and yielded both unpublished and nonEnglish language trial reports. Two independent review authors extracted data to reduce the possibility of errors and bias being introduced by a single extractor. Numerous trials presented at least some baseline, outcome, or risk of bias data that were unclear, incomplete, discrepant, or reported for some trial participants outside of the age range of this review. Whenever the relevant contact information could be obtained, we contacted the authors of such trials at least twice to obtain clarification or disaggregated data (or both). This comprehensive process of contacting authors improved the completeness of data in this review.

However, as with any systematic review, subjective judgements and decisions had to be made during the research process. We made attempts to be transparent about any such judgement calls in the text of this review, and in the Characteristics of included studies and Characteristics of excluded studies tables.

In areas of research with less evidence or areas with rapid publication, our searches could be considered outdated. However, large trials are unlikely to change the main conclusions of this review, so it may not be necessary to update the searches and analyses for several years.

\section{Agreements and disagreements with other studies or reviews}

The results of this review were generally consistent with those of past systematic reviews of zinc supplementation. This was true of mortality outcomes (previously investigated by Brown 2009, Patel 2011 and Yakoob 2011) and diarrhoea morbidity outcomes (previously investigated by Bhutta 1999, Aggarwal 2007, Brown 2009, Patel 2011 and Yakoob 2011).

Previously, reviews have generally found a beneficial impact of zinc supplementation on LRTI (Bhutta 1999; Aggarwal 2007; Brown 2009; Lassi 2010; Roth 2010; Yakoob 2011). The results of this review do not support this finding. However, this discrepancy might be due to slightly differing inclusion criteria and eligible LRTI outcome definitions. For example, Lassi 2010 included studies with children infected with HIV, while we excluded them. Similarly, Brown 2009 included studies with children younger than six months of age while we excluded them; however, differing age criteria did not seem to account for all of the differences in results. 
Zinc supplementation may be more beneficial for severe LRTI or LRTI that meets more specifically defined clinical criteria (Roth 2010). While this review indicates a slight, statistically insignificant harm in terms of malaria incidence, one other review indicated a statistically insignificant benefit (Yakoob 2011).

Previously reviews have disagreed on whether supplementation has a significant positive effect on growth outcomes (Brown 2002; Brown 2009; Imdad 2011) or not (Ramakrishnan 2009). Though this review does not fully explain this disagreement, it does support the hypothesis that supplementation may have a very small but positive effect on growth. As shown by the age subgroup analysis for height and weight, zinc may be more effective at improving growth outcomes in the five to 13 years of age subgroup. Thus, one potential reason for the disagreement between previous reviews is the fact that Brown 2002 and Brown 2009 included participants older than five years of age and Ramakrishnan 2009 did not.

The results of this review are also generally consistent with past investigations of zinc (Brown 2002; Brown 2009), haemoglobin (Brown 2009; Dekker 2010), and iron status (Brown 2009). However, while this review indicates that supplementation has a negative effect on copper status, one past review indicated no effect (Brown 2009).

Finally, previous reviews have attempted to explain heterogeneity related to the impact of zinc supplementation. Two reviews have suggested that age may modify the impact of supplementation, with benefits limited to children one year of age or older (Brown 2009; Patel 2011). Subgroup analyses for some outcomes in this review were consistent with this hypothesis. However, this potential association could be spurious; indeed, Patel 2011 notes that studies in their review with higher age groups also appeared to be at higher risk of bias.

\section{AUTHORS' CONCLUSIONS}

\section{Implications for practice}

The benefits, harms, and costs of preventive zinc supplementation should be carefully considered when deciding whether or not to use this intervention. On the one hand, supplementation positively impacted zinc status and diarrhoea morbidity. There were statistically significant effects for growth outcomes, but these may not be clinically important. Supplementation may have had a small positive impact on all-cause mortality, though the effects of zinc on this outcome, and on most hospitalisation, lower respiratory tract infection (LRTI), and malaria outcomes, were not statistically significant. On the other hand, supplementation was associated with increased vomiting and worsened copper status, though it was not associated with any important effect on haemoglobin or iron status. Balancing these factors, the benefits of zinc supplementation would outweigh the harms in low- and middle-income countries where the risk of zinc deficiency is relatively high.
It has been argued that zinc supplementation, as part of a package of interventions to reduce undernutrition among preschoolers, is among the most cost-effective interventions for advancing human welfare (Horton 2009).

However, preventive zinc supplementation is not a sufficient or long-term solution to the nutrition and health challenges facing children in resource-scarce settings. Children ultimately need wellbalanced diets, and poverty is often a risk factor for undernutrition and pathogen exposure. Unfortunately, until these issues are effectively addressed, zinc deficiency (and the mortality, morbidity, and growth deficits associated with it) will likely remain. The evidence suggests that preventive zinc supplementation offers a short-term intervention to help alleviate these problems in resource-scarce settings. It may also be pragmatic and effective to deliver zinc supplementation along with other public health interventions such as growth monitoring. Furthermore, fortification may be beneficial in areas where food production and processing systems could enrich foods with zinc (Hotz 2004; Hess 2009a).

On the basis of our review findings, policymakers may wish to consider preventive zinc supplementation as one of the public health and nutrition interventions offered to children at risk in low- and middle-income countries. Where zinc supplements are locally available, clinicians in such settings could provide them to children under their care who likely lack sufficient dietary zinc intake. However, the evidence also suggests that monitoring for side effects, such as vomiting, may be required. Finally, families can be encouraged to recognise the importance of adequate dietary zinc for their children.

\section{Implications for research}

\section{Populations}

Finding ways to improve the delivery of zinc to hard to reach populations (for example, the poorest of the poor) is one of the most important priorities to reduce mortality and morbidity due to childhood diarrhoeal disease (Wazny 2013).

Children with severe protein-energy malnutrition were excluded from this review, as well as children with chronic diseases such as cystic fibrosis and sickle cell disease. The effects of zinc in populations with co-morbidities such as these could be examined in future systematic reviews. As mentioned above, two Cochrane reviews have already addressed the effects of zinc supplementation in populations with HIV (Humphreys 2010; Irlam 2010).

\section{Interventions}

Although zinc is an apparently simple intervention, a large study of vitamin A supplementation (Awasthi 2013), which is inconsistent with a large body of previous research (Mayo-Wilson 2011), demonstrates that interventions with proven effectiveness may fail 
to scale-up if they are not implemented with fidelity. Further research is needed to determine the best way to ensure the effective delivery of zinc supplementation on a large scale (Wazny 2013). This review has not confirmed the optimal range of doses, durations, frequencies, or formulations necessary for zinc supplementation to achieve clinically meaningful improvements in mortality, morbidity, or growth outcomes. Future studies could try to specify these optimal intervention characteristics better. In addition, the timing of when preventive supplementation should be initiated in children could be further investigated. For instance, a few studies in this review started several months of preventive supplementation immediately after participants received therapeutic supplementation for an episode of diarrhoea (Sazawal 1996; Larson 2010). In addition, future studies could further evaluate fortification and dietary change interventions as alternative means of addressing zinc deficiency. These could be compared to a zinc supplementation intervention.

\section{Outcomes}

Overall, this review presents strong evidence for the effectiveness of preventive zinc supplementation on most of the outcomes analysed. Many of the conclusions of this review would be robust to the results of further preventive zinc supplementation trials. Further updates of this review are unlikely to come to different conclusions in the absence of extremely large trials with importantly different results.

\section{ACKNOWLEDGEMENTS}

We thank the Cochrane Developmental Psychosocial and Learning Problems Group (especially Margaret Anderson, Laura MacDonald, and Geraldine Macdonald) for help with the preparation of the protocol and review, the Cochrane Methods Group for statistical advice and assistance, and anonymous peer reviewers for their feedback. Chris Champion generously extracted one study in Portuguese. We would also like to thank Dr Jai Das, who helped with double data extraction for additional analysis of zinc plus iron.

\section{R E F E R E N C E S}

\section{References to studies included in this review}

Ahmed 2009a \{published data only (unpublished sought but not used)\} Ahmed T, Arifuzzaman M, Lebens M, Qadri F, Lundgren

A. CD4+ T-cell responses to an oral inactivated cholera vaccine in young children in a cholera endemic country and the enhancing effect of zinc supplementation. Vaccine 2009;28(2):422-9.

Akramuzzaman 1994 \{published data only (unpublished sought but not used)\}

Akramuzzaman SM, Mahalanabis D, Mitra AK, Rahman

MM. Effect of long-term supplementation of zinc in undernourished young children of a poor peri urban community in Bangladesh. Journal of Gastroenterology and Hepatology 1994;9(6):A132 (Abstract 6.5).

Alarcon 2004 \{published and unpublished data\}

Alarcon K, Kolsteren PW, Prada AM, Chian AM, Velarde RE, Pecho IL, et al.Effects of separate delivery of zinc or zinc and vitamin $\mathrm{A}$ on hemoglobin response, growth, and diarrhea in young Peruvian children receiving iron therapy for anemia. American Journal of Clinical Nutrition 2004;80 (5):1276-82.

Albert 2003 \{published data only (unpublished sought but not used)\} * Albert MJ, Qadri F, Wahed MA, Ahmed T, Rahman ASMH, Ahmed F, et al.Supplementation with zinc, but not vitamin $\mathrm{A}$, improves seroconversion to vibriocidal antibody in children given an oral cholera vaccine. Journal of Infectious Diseases 2003;187(6):909-13.

Qadri F, Ahmed T, Wahed MA, Ahmed F, Bhuiyan NA, Rahman ASMH, et al.Suppressive effect of zinc on antibody response to cholera toxin in children given the killed, B subunit-whole cell, oral cholera vaccine. Vaccine 2004;22

(3-4):416-21.

Albert 2003 (2) \{published data only (unpublished sought but not used)\}

* Albert MJ, Qadri F, Wahed MA, Ahmed T, Rahman ASMH, Ahmed F, et al.Supplementation with zinc, but not vitamin $\mathrm{A}$, improves seroconversion to vibriocidal antibody in children given an oral cholera vaccine. Journal of Infectious Diseases 2003;187(6):909-13.

Qadri F, Ahmed T, Wahed MA, Ahmed F, Bhuiyan NA, Rahman ASMH, et al.Suppressive effect of zinc on antibody response to cholera toxin in children given the killed, B subunit-whole cell, oral cholera vaccine. Vaccine 2004;22 (3-4):416-21.

Ba Lo 2011 \{published and unpublished data\} Ba Lo N, Aaron GJ, Hess SY, Dossou NI, Guiro AT, Wade $S$, et al.Plasma zinc concentration responds to short-term zinc supplementation, but not zinc fortification, in young children in Senegal. American Journal of Clinical Nutrition 2011;93(6):1348-55.

Baqui 2003 \{published data only (unpublished sought but not used)\} Baqui AH, Fischer Walker CL, Zaman K, El Arifeen S, Chowdhury HR, Wahed MA, et al.Weekly iron supplementation does not block increases in serum zinc due to weekly zinc supplementation in Bangladeshi infants. Journal of Nutrition 2005;135(9):2187-91.

* Baqui AH, Zaman K, Persson LA, El Arifeen S, Yunus $\mathrm{M}$, Begum N, et al.Simultaneous weekly supplementation of iron and zinc is associated with lower morbidity due to 
diarrhea and acute lower respiratory infection in Bangladeshi infants. Journal of Nutrition 2003;133(12):4150-7. Black MM, Baqui AH, Zaman K, Ake Persson L, El Arifeen $\mathrm{S}$, Le K, et al.Iron and zinc supplementation promote motor development and exploratory behavior among Bangladeshi infants. American Journal of Clinical Nutrition 2004;80(4): 903-10.

Fischer Walker CL, Baqui AH, Ahmed S, Zaman K, El Arifeen S, Begum N, et al.Low-dose weekly supplementation of iron and/or zinc does not affect growth among Bangladeshi infants. European Journal of Clinical Nutrition 2009;63(1):87-92.

\section{Baqui 2003 (2) \{published data only (unpublished sought but not} used)\}

Baqui AH, Fischer Walker CL, Zaman K, El Arifeen $S$, Chowdhury HR, Wahed MA, et al.Weekly iron supplementation does not block increases in serum zinc due to weekly zinc supplementation in Bangladeshi infants. Journal of Nutrition 2005;135(9):2187-91.

* Baqui AH, Zaman K, Persson LA, El Arifeen S, Yunus $\mathrm{M}$, Begum N, et al.Simultaneous weekly supplementation of iron and zinc is associated with lower morbidity due to diarrhea and acute lower respiratory infection in Bangladeshi infants. Journal of Nutrition 2003;133(12):4150-7.

Black MM, Baqui AH, Zaman K, Ake Persson L, El Arifeen $S$, Le K, et al.Iron and zinc supplementation promote motor development and exploratory behavior among Bangladeshi infants. American Journal of Clinical Nutrition 2004;80(4): 903-10.

Fischer Walker CL, Baqui AH, Ahmed S, Zaman K, El Arifeen S, Begum N, et al.Low-dose weekly supplementation of iron and/or zinc does not affect growth among Bangladeshi infants. European Journal of Clinical Nutrition 2009;63(1):87-92.

Bhandari 2002 \{published and unpublished data\}

* Bhandari N, Bahl R, Taneja S, Strand T, Molbak K, Ulvik $\mathrm{RJ}$, et al.Substantial reduction in severe diarrheal morbidity by daily zinc supplementation in young north Indian children. Pediatrics 2002;109(6):e86.

Bhandari N, Bahl R, Taneja S, Strand T, Mølbak K, Ulvik RJ, et al.Effect of routine zinc supplementation on pneumonia in children aged 6 months to 3 years: randomised controlled trial in an urban slum. BMJ 2002; 324:1358.

Manger MS, Strand TA, Taneja S, Refsum H, Ueland PM, Nygard O, et al.Cobalamin status modifies the effect of zinc supplementation on the incidence of prolonged diarrhea in 6- to 30-month-old North Indian children. Journal of Nutrition 2011;141(6):1108-13.

Manger MS, Taneja S, Strand TA, Ueland PM, Refsum $\mathrm{H}$, Schneede J, et al.Poor folate status predicts persistent diarrhea in 6- to 30-month-old north Indian children. Journal of Nutrition 2011;141(12):2226-32.

Taneja S, Bhandari N, Bahl R, Bhan MK. Impact of zinc supplementation on mental and psychomotor scores of children aged 12 to 18 months: a randomized, double-blind trial. Journal of Pediatrics 2005;146(4):506-11.

Taneja S, Bhandari N, Strand TA, Sommerfelt H, Refsum

$\mathrm{H}$, Ueland PM, et al.Cobalamin and folate status in infants and young children in a low-to-middle income community in India. American Journal of Clinical Nutrition 2007;86(5): 1302-9.

Taneja S, Strand TA, Sommerfelt H, Bahl R, Bhandari N. Zinc supplementation for four months does not affect growth in young north Indian children. Journal of Nutrition 2010;140(3):630-4.

\section{Bhandari 2007 \{published and unpublished data\}}

Bhan G, Bhandari N, Taneja S, Mazumder S, Bahl R. The effect of maternal education on gender bias in care-seeking for common childhood illnesses. Social Science and Medicine 2005;60(4):715-24.

* Bhandari N, Taneja S, Mazumder S, Bahl R, Fontaine O, Bhan MK, et al.Adding zinc to supplemental iron and folic acid does not affect mortality and severe morbidity in young children. Journal of Nutrition 2007;137(1):112-7.

Brown 2007 \{published and unpublished data\} Arsenault JE. Dietary Zinc Intake of Young Children in Peru and the United States, and Effects of Supplemental Zinc on Energy Intake, Appetite, Body Composition, and Plasma Leptin, Ghrelin, and Insulin Concentrations of Peruvian Infants. Davis, California, US: University of California, Davis, 2006.

Arsenault JE, Havel PJ, Lopez de Romana D, Penny ME, Van Loan MD, Brown KH. Longitudinal measures of circulating leptin and ghrelin concentrations are associated with the growth of young Peruvian children but are not affected by zinc supplementation. American Journal of Clinical Nutrition 2007;86(4):1111-9.

Arsenault JE, Lopez de Romana D, Penny ME, Van Loan $\mathrm{MD}$, Brown $\mathrm{KH}$. Additional zinc delivered in a liquid supplement, but not in a fortified porridge, increased fatfree mass accrual among young Peruvian children with mild-to-moderate stunting. Journal of Nutrition 2008;138 (1):108-14.

* Brown KH, Lopez de Romana D, Arsenault JE, Peerson JM, Penny ME. Comparison of the effects of zinc delivered in a fortified food or a liquid supplement on the growth, morbidity, and plasma zinc concentrations of young Peruvian children. American Journal of Clinical Nutrition 2007;85(2):538-47.

Castillo-Durán 1994 \{published data only (unpublished sought but not used)\}

Castillo-Durán C, Garcia H, Venegas P, Torrealba I, Panteon

$\mathrm{E}$, Concha $\mathrm{N}$, et al.Zinc supplementation increases growth velocity of male children and adolescents with short stature. Acta Paediatrica 1994;83(8):833-7.

Castillo-Durán 2002 \{published data only (unpublished sought but not used)\}

Castillo-Duran C, Hertrampf ED, Ruz MO, Torrejon CS, Salazar G. Controlled trial of zinc supplementation on growth and body composition in Chilean children from low income groups. Pediatric Research 2002;51(4):188A (Abstract 1097). 


\section{Cavan 1993 \{published and unpublished data\}}

Cavan KR. The Assessment of the Zinc Status of a Group of School Children from a Peri-Urban Area of Guatemala City, Guatemala. Guelph, Canada: University of Guelph, 1991. Cavan KR, Gibson RS, Grazioso CF, Isalgue AM, Ruz M, Solomons NW. Growth and body composition of periurban Guatemalan children in relation to zinc status: a crosssectional study. American Journal of Clinical Nutrition 1993; 57(3):334-43

* Cavan KR, Gibson RS, Grazioso CF, Isalgue AM, Ruz M, Solomons NW. Growth and body composition of periurban Guatemalan children in relation to zinc status: a longitudinal zinc intervention trial. American Journal of Clinical Nutrition 1993;57(3):344-52.

Grazioso CF, Isalgue M, De Ramirez I, Ruz M, Solomons NW. The effect of zinc supplementation on parasitic reinfestation of Guatemalan schoolchildren. American Journal of Clinical Nutrition 1993;57(5):673-8.

\section{Chang 2010 \{published and unpublished data\}}

Chang S, El Arifeen S, Bari S, Wahed MA, Rahman KM, Rahman MT, et al.Supplementing iron and zinc: double blind, randomized evaluation of separate or combined delivery. European Journal of Clinical Nutrition 2010;64(2): 153-60.

Chang 2010 (2) \{published and unpublished data\} Chang S, El Arifeen S, Bari S, Wahed MA, Rahman KM, Rahman MT, et al.Supplementing iron and zinc: double blind, randomized evaluation of separate or combined delivery. European Journal of Clinical Nutrition 2010;64(2): 153-60.

\section{Chen 2012 \{published data only\}}

Chen L, Liu YF, Gong M, Jiang W, Fan Z, Qu P, et al.Effects of vitamin A, vitamin A plus zinc, and multiple micronutrients on anemia in preschool children in Chongqing, China. Asia Pacific Journal of Clinical Nutrition 2012;21(1):3-11

Chhagan 2009 \{published and unpublished data\} Chhagan M. The Effect of Micronutrient Supplementation on Morbidity and Growth in South African Children. Boston, MA: Tufts University, Gerald J. and Dorothy R. Friedman School of Nutrition Science and Policy, 2009. Chhagan MK, Van den Broeck J, Luabeya K-KA, Mpontshane N, Tomkins A, Bennish ML. Effect on longitudinal growth and anemia of zinc or multiple micronutrients added to vitamin A: a randomized controlled trial in children aged 6-24 months. BMC Public Health 2010;10:145.

* Chhagan MK, Van den Broeck J, Luabeya K-KA, Mpontshane N, Tucker KL, Bennish ML. Effect of micronutrient supplementation on diarrhoeal disease among stunted children in rural South Africa. European Journal of Clinical Nutrition 2009;63(7):850-7. Luabeya K-KA, Mpontshane N, Mackay M, Ward H, Elson I, Chhagan M, et al.Zinc or multiple micronutrient supplementation to reduce diarrhea and respiratory disease in South African children: a randomized controlled trial. PLoS One 2007;2(6):e541.

Van den Broeck J, Mackay M, Mpontshane N, Luabeya KKA, Chhagan M, Bennish ML. Maintaining data integrity in a rural clinical trial. Clinical Trials 2007;4(5):572-82.

Clark 1999 \{published data only (unpublished sought but not used)\} Clark PJ, Eastell R, Barker ME. Zinc supplementation and bone growth in pubertal girls. Lancet 1999;354(9177):485.

Cole 2012 \{unpublished data only\} Sampaio DLB, De Mattos P, Ribeiro TCM, De Q. Leite ME, Cole CR, Costa-Ribeiro H Jr. Zinc and other micronutrients supplementation through the use of sprinkles: impact on the occurrence of diarrhea and respiratory infections in institutionalized children [Suplementação de zinco e outros micronutrientes através do uso de sprinkles: impacto na ocorrência de doença diarreica e infecçōes respiratórias em crianças institucionalizadas]. Unpublished manuscript.

De Fonseca 2002 \{unpublished data only\} De Fonseca APP. Impacto Antropométrico da Suplementação Semanal de Zinco em Escolares com Déficit de Crescimento: Ensaio Randomizado Duplo-Cego. São Paulo, Brazil: Universidade Federal de São Paulo, 2002.

Dehbozorgi 2007 \{published data only\} Dehbozorgi P, Mohseni P, Mazloom Z. The influence of zinc sulfate supplementation on the growth of school age children in villages around Shiraz 2002, 2003. Journal of Medical Sciences 2007;7(4):690-3.

DiGirolamo 2010 \{published data only (unpublished sought but not used)\}

Bui VQ, DiGirolamo AM, Stein AD, Ramakrishnan U, Ramirez-Zea M, Flores-Ayala RC, et al.No effect of 6month zinc supplementation on anthropometric measures in 6-11 year-old urban school children in Guatemala. FASEB Journal 2009;23(Meeting abstract supplement): 917.14 .

* DiGirolamo AM, Ramirez-Zea M, Wang M, Flores-Ayala R, Martorell R, Neufeld LM, et al.Randomized trial of the effect of zinc supplementation on the mental health of school-age children in Guatemala. American Journal of Clinical Nutrition 2010;92(5):1241-50.

Ebrahimi 2006 \{published data only\} Ebrahimi S, Pormahmodi A, Kamkar A. Study of zinc supplementation on growth of schoolchildren in Yasuj, Southwest of Iran. Pakistan Journal of Nutrition 2006;5(4): $341-2$.

Fallahi 2007 \{published data only (unpublished sought but not used)\} Fallahi E, Kimiagar M, Nazari A, Hasanvand MA, Seifi M. Effect of zinc and iron supplementation on indicators of iron, zinc and vitamin A status of primary school children. Pakistan Journal of Biological Sciences 2007;10(7):1088-92.

Friis 1997 \{published and unpublished data\}

Friis H, Ndhlovu P, Mduluza T, Kaondera K, Sandstrom B, Michaelsen KF, et al.The impact of zinc supplementation on Schistosoma mansoni reinfection rate and intensities: a randomized, controlled trial among rural Zimbabwean 
schoolchildren. European Journal of Clinical Nutrition 1997; 51(1):33-7.

* Friis H, Ndhlovu P, Mduluza T, Kaondera K, Sandstrom $\mathrm{B}$, Michaelsen KF, et al.The impact of zinc supplementation on growth and body composition: a randomized, controlled trial among rural Zimbabwean schoolchildren. European Journal of Clinical Nutrition 1997;51(1):38-45.

Garcia 1998 \{published data only (unpublished sought but not used)\} Garcia H, Ugarte F, Henriquez C, Iniquez G, Salazar T, Pizarro F, et al.Lack of effect of zinc supplementation on growth and somatothrophic axis in children with idiopathic short stature and diminished growth velocity [Ausencia de efecto de la suplementacion con cinc sobre el crecimiento y el eje somatotrofico en ninos con talla baja idiopatica y velocidad de crecimiento disminuida]. Endocrinologia 1998; 45(5):183-7.

Gibson 1989 \{published and unpublished data\} Gibson RS, Vanderkooy PDS, MacDonald AC, Goldman A, Ryan BA, Berry M. A growth-limiting, mild zinc-deficiency syndrome in some Southern Ontario boys with low height percentiles. American Journal of Clinical Nutrition 1989;49 (6):1266-73.

Gracia 2005 \{published data only (unpublished sought but not used)\} Gracia B, De Plata C, Rueda A, Mosquera M, Suarez MF, Pradilla A. Effect of zinc supplementation on growth velocity of preschool children [Efecto de la complementación con zinc en la velocidad de crecimiento en niños preescolares]. Colombia Medica 2005;36(4 Suppl 3):31-40.

Gupta 2003 \{published data only (unpublished sought but not used)\} Gupta DN, Mondal SK, Ghosh S, Rajendran K, Sur D, Manna B. Impact of zinc supplementation on diarrhoeal morbidity in rural children of West Bengal, India. Acta Paediatrica 2003;92(5):531-6.

Gupta 2007 \{published data only (unpublished sought but not used)\} Gupta DN, Rajendran K, Mondal SK, Ghosh S, Bhattacharya SK. Operational feasibility of implementing community-based zinc supplementation: impact on childhood diarrheal morbidity. Pediatric Infectious Disease Journal 2007;26(4):306-10.

Hambidge 1978 \{published and unpublished data\}

* Hambidge KM, Chavez MN, Brown RM, Walravens PA. Zinc supplementation of low-income pre-school children. Trace Element Metabolism in Man and Animals 1978;3: 296-9.

Hambidge KM, Krebs NF, Walravens PA. Growth velocity of young children receiving a dietary zinc supplement. Nutrition Research 1985;5(Suppl 1):S306-16.

Han 2002 \{published data only (unpublished sought but not used)\} * Han JH, Yang YX, Shao XP, He M, Bian LH, Wang Z. Effect of micronutrient supplementation on the growth of preschool children in China. Nutritional Sciences 2002;5(3): 155-60.

Yang YX, Han JH, Shao XP, He M, Bian LH, Wang Z, et al.Effect of micronutrient supplementation on the growth of preschool children in China. Biomedical and Environmental Sciences 2002;15(3):196-202.
Han 2002 (2) \{published data only (unpublished sought but not used)\}

* Han JH, Yang YX, Shao XP, He M, Bian LH, Wang Z.

Effect of micronutrient supplementation on the growth of preschool children in China. Nutritional Sciences 2002;5(3): 155-60.

Yang YX, Han JH, Shao XP, He M, Bian LH, Wang Z, et al.Effect of micronutrient supplementation on the growth of preschool children in China. Biomedical and Environmental Sciences 2002;15(3):196-202.

Hettiarachchi 2008 \{published and unpublished data\} Hettiarachchi M, Liyanage C, Wickremasinghe R, Hilmers DC, Abrams SA. The efficacy of micronutrient supplementation in reducing the prevalence of anaemia and deficiencies of zinc and iron among adolescents in Sri Lanka. European Journal of Clinical Nutrition 2008;62(7):856-65.

Hettiarachchi 2008 (2) \{published and unpublished data\} Hettiarachchi M, Liyanage C, Wickremasinghe R, Hilmers DC, Abrams SA. The efficacy of micronutrient supplementation in reducing the prevalence of anaemia and deficiencies of zinc and iron among adolescents in Sri Lanka. European Journal of Clinical Nutrition 2008;62(7):856-65.

Hong 1982 \{published data only\}

Hong ZY. Observation on the therapeutic effect of zinc on underweight children. Zhonghua Yi Xue Za Zhi 1982;62 (7):415-9.

Ince 1995 \{published and unpublished data\} Ince E, Kemahli S, Uysal Z, Akar N, Cin S, Arcasoy A. Mild zinc deficiency in preschool children. Journal of Trace Elements in Experimental Medicine 1995;7(4):135-41.

Kartasurya 2012 \{published data only\} Kartasurya MI, Ahmed F, Subagio HW, Rahfiludin MZ, Marks GC. Zinc combined with vitamin A reduces upper respiratory tract infection morbidity in a randomised trial in preschool children in Indonesia. British Journal of Nutrition 2012;108(12):2251-60.

Kikafunda 1998 \{published data only (unpublished sought but not used)\}

* Kikafunda JK, Walker AF, Allan EF, Tumwine JK. Effect of zinc supplementation on growth and body composition of Ugandan preschool children: a randomized, controlled, intervention trial. American Journal of Clinical Nutrition 1998;68(6):1261-6.

Sandstead HH. Improving study design. American Journal of Clinical Nutrition 1999;70(1):110.

Solomons NW, Ruz M, Gibson RS. Single-nutrient interventions with zinc. American Journal of Clinical Nutrition 1999;70(1):111-2.

Walker AF. Reply to HH Sandstead. American Journal of Clinical Nutrition 1999;70(1):110a-1.

Walker AF. Reply to NW Solomons et al. American Journal of Clinical Nutrition 1999;70(1):112-3.

Kurugöl 2006 \{published data only (unpublished sought but not used)\} Kurugöl Z, Akilli M, Bayram N, Koturoglu G. The prophylactic and therapeutic effectiveness of zinc sulphate on common cold in children. Acta Paediatrica 2006;95(10): 1175-81. 
Larson 2010 \{published data only (unpublished sought but not used)\}

* Larson CP, Nasrin D, Saha A, Chowdhury MI, Qadri

F. The added benefit of zinc supplementation after zinc treatment of acute childhood diarrhoea: a randomized, double-blind field trial. Tropical Medicine and International Health 2010;15(6):754-61.

Sheikh A, Shamsuzzaman S, Ahmad SM, Nasrin D, Nahar $S$, Alam MM, et al.Zinc influences innate immune responses in children with enterotoxigenic Escherichia coli-induced diarrhea. Journal of Nutrition 2010;140(5):1049-56.

\section{Lind 2003 \{published and unpublished data\}}

Lind T. Iron and Zinc in Infancy: Results from Experimental Trials in Sweden and Indonesia. Umeå, Sweden: Umeå Universitet, 2004.

Lind T, Lonnerdal B, Stenlund H, Gamayanti IL, Ismail $\mathrm{D}$, Seswandhana R, et al.A community-based randomized controlled trial of iron and zinc supplementation in Indonesian infants: effects on growth and development. American Journal of Clinical Nutrition 2004;80(3):729-36.

* Lind T, Lonnerdal B, Stenlund H, Ismail D, Seswandhana R, Ekstrom EC, et al.A community-based randomized controlled trial of iron and zinc supplementation in Indonesian infants: interactions between iron and zinc. American Journal of Clinical Nutrition 2003;77(4):883-90. Lind T, Seswandhana R, Persson LA, Lonnerdal B. Iron supplementation of iron-replete Indonesian infants is associated with reduced weight-for-age. Acta Paediatrica 2008;97(6):770-5.

Lind 2003 (2) \{published and unpublished data\} Lind T. Iron and Zinc in Infancy: Results from Experimental Trials in Sweden and Indonesia. Umeå, Sweden: Umeå Universitet, 2004.

Lind T, Lonnerdal B, Stenlund H, Gamayanti IL, Ismail $\mathrm{D}$, Seswandhana R, et al.A community-based randomized controlled trial of iron and zinc supplementation in Indonesian infants: effects on growth and development. American Journal of Clinical Nutrition 2004;80(3):729-36.

* Lind T, Lonnerdal B, Stenlund H, Ismail D, Seswandhana R, Ekstrom EC, et al.A community-based randomized controlled trial of iron and zinc supplementation in Indonesian infants: interactions between iron and zinc. American Journal of Clinical Nutrition 2003;77(4):883-90. Lind T, Seswandhana R, Persson LA, Lonnerdal B. Iron supplementation of iron-replete Indonesian infants is associated with reduced weight-for-age. Acta Paediatrica 2008;97(6):770-5.

Long 2006 \{published and unpublished data\}

* Long KZ, Montoya Y, Hertzmark E, Santos JI, Rosado JL. A double-blind, randomized, clinical trial of the effect of vitamin $A$ and zinc supplementation on diarrheal disease and respiratory tract infections in children in Mexico City, Mexico. American Journal of Clinical Nutrition 2006;83(3): 693-700.

Long KZ, Rosado JL, Montoya Y, De Lourdes Solano M, Hertzmark E, DuPont HL, et al.Effect of vitamin A and zinc supplementation on gastrointestinal parasitic infections among Mexican children. Pediatrics 2007;120(4):e846-55. Rosado JL, Caamano MC, Montoya YA, De Lourdes Solano M, Santos JI, Long KZ. Interaction of zinc or vitamin A supplementation and specific parasite infections on Mexican infants' growth: a randomized clinical trial. European Journal of Clinical Nutrition 2009;63(10):1176-84.

Sanchez-Hernandez JJ, Long K, Al Mamun A, Rosado JL, Del Carmen Caamano M, Marks G. Nutritional status as a modifier of the effect of vitamin a or zinc supplementation on gastrointestinal parasite infections in Mexican children. FASEB Journal 2011;25(Meeting abstract supplement): 343.1 .

Long 2006 (2) \{published and unpublished data\}

${ }^{*}$ Long KZ, Montoya Y, Hertzmark E, Santos JI, Rosado JL. A double-blind, randomized, clinical trial of the effect of vitamin $A$ and zinc supplementation on diarrheal disease and respiratory tract infections in children in Mexico City, Mexico. American Journal of Clinical Nutrition 2006;83(3): 693-700.

Long KZ, Rosado JL, Montoya Y, De Lourdes Solano M, Hertzmark E, DuPont HL, et al.Effect of vitamin A and zinc supplementation on gastrointestinal parasitic infections among Mexican children. Pediatrics 2007;120(4):e846-55. Rosado JL, Caamano MC, Montoya YA, De Lourdes Solano M, Santos JI, Long KZ. Interaction of zinc or vitamin A supplementation and specific parasite infections on Mexican infants' growth: a randomized clinical trial. European Journal of Clinical Nutrition 2009;63(10):1176-84. Sanchez-Hernandez JJ, Long K, Al Mamun A, Rosado JL, Del Carmen Caamano M, Marks G. Nutritional status as a modifier of the effect of vitamin a or zinc supplementation on gastrointestinal parasite infections in Mexican children. FASEB Journal 2011;25(Meeting abstract supplement): 343.1 .

Mahloudji 1975 \{published data only\} Mahloudji M, Reinhold JG, Haghshenass M, Ronaghy HA, Fox MR, Halsted JA. Combined zinc and iron compared with iron supplementation of diets of 6-to 12 -year old village schoolchildren in southern Iran. American Journal of Clinical Nutrition 1975;28(7):721-5.

Malik 2013 \{published data only\}

Malik A, Taneja S. Report on the trial for effect of short course prophylactic zinc supplementation of 2 weeks on diarrhea morbidity in infants of 6-11 months of age. Unpublished data.

Marinho 1991 \{published data only\}

Marinho HA, Shrimpton R, Giugliano R, Burini RC. Influence of enteral parasites on the blood vitamin A levels in preschool children orally supplemented with retinol and/ or zinc. European Journal of Clinical Nutrition 1991;45(11): $539-44$.

Mazariegos 2010 \{published and unpublished data\} Mazariegos M, Hambidge KM, Westcott JE, Solomons NW, Raboy V, Das A, et al.Neither a zinc supplement nor phytate-reduced maize nor their combination enhance 
growth of 6- to 12-month-old Guatemalan infants. Journal of Nutrition 2010;140(5):1041-8.

Meeks Gardner 1998 \{published data only (unpublished sought but not used)\}

Meeks Gardner J, Witter M, Ramdath D. Zinc

supplementation morbidity and growth in stunted Jamaican

children. West Indian Medical Journal 1998;47(2 Suppl):

28-9 (Abstract 0-27).

* Meeks Gardner J, Witter MM, Ramdath DD. Zinc

supplementation: effects on the growth and morbidity of undernourished Jamaican children. European Journal of

Clinical Nutrition 1998;52(1):34-9.

Meeks Gardner 2005 \{published data only (unpublished sought but not used)\}

Meeks Gardner J, Powell CA, Baker-Henningham H,

Walker SP, Cole TJ, Grantham-McGregor SM. Zinc supplementation and psychosocial stimulation: effects on the development of undernourished Jamaican children. American Journal of Clinical Nutrition 2005;82(2):399-405.

Mozaffari-Khosravi 2009 \{published and unpublished data\}

* Mozaffari-Khosravi H, Shakiba M, Eftekhari MH, Fatehi

F. Effects of zinc supplementation on physical growth in 25-year-old children. Biological Trace Element Research 2009; 128(2):118-27.

Mozaffari-Khosravi H, Shakiba M, Eftekhari MH, Vahidi AR. Effects of zinc supplementation on the physical growth of 2-5 years old children. Iranian Journal of Endocrinology and Metabolism 2008;10(4):363-71.

Muller 2001 \{published and unpublished data\}

Garenne M, Becher H, Ye Y, Kouyate B, Muller O. Sexspecific responses to zinc supplementation in Nouna, Burkina Faso. Journal of Pediatric Gastroenterology and Nutrition 2007;44(5):619-28.

* Muller O, Becher H, Van Zweeden AB, Ye Y, Diallo DA, Konate AT, et al.Effect of zinc supplementation on malaria and other causes of morbidity in west African children: randomised double blind placebo controlled trial. $B M J$ 2001;322(7302):1567.

Muller O, Garenne M, Reitmaier P, Van Zweeden AB, Kouyate B, Becher H. Effect of zinc supplementation on growth in West African children: a randomized doubleblind placebo-controlled trial in rural Burkina Faso. International Journal of Epidemiology 2003;32(6):1098-102.

Nakamura 1993 \{published data only\} Graham GG. Effect of zinc on growth in short children. Journal of Pediatrics 1994;124(1):163-4.

Nakamura T. Letter. Journal of Pediatrics 1994;124(1):164. * Nakamura T, Nishiyama S, Futagoishi-Suginohara Y, Matsuda I, Higashi A. Mild to moderate zinc deficiency in short children: effect of zinc supplementation on linear growth velocity. Journal of Pediatrics 1993;123(1):65-9.

Ninh 1996 \{published data only (unpublished sought but not used)\} Ninh NX, Thissen JP, Collette L, Gerard G, Khoi HH, Ketelslegers JM. Zinc supplementation increases growth and circulating insulin-like growth factor I (IGF-I) in growth- retarded Vietnamese children. American Journal of Clinical Nutrition 1996;63(4):514-9.

Penny 2004 \{published data only (unpublished sought but not used)\} * Penny ME, Marin RM, Duran A, Peerson JM, Lanata CF, Lonnerdal B, et al.Randomized controlled trial of the effect of daily supplementation with zinc or multiple micronutrients on the morbidity, growth, and micronutrient status of young Peruvian children. American Journal of Clinical Nutrition 2004;79(3):457-65.

Penny ME, Peerson JM, Marin RM, Duran A, Lanata CF, Lonnerdal B, et al.Randomized, community-based trial of the effect of zinc supplementation, with and without other micronutrients, on the duration of persistent childhood diarrhea in Lima, Peru. Journal of Pediatrics 1999;135(2): 208-17.

\section{Rahman 2001 \{published and unpublished data\}}

Rahman MM. Effect of Simultaneous Zinc and Vitamin A Supplementation on the Biochemical Indices of Vitamin A Nutriture, Morbidity, and Growth in Bangladeshi Children: A Randomized, Double Blind, Placebo Controlled Trial. Birmingham, Alabama: The University of Alabama at Birmingham, School of Public Health, 1999. Rahman MM, Tofail F, Wahed MA, Fuchs GJ, Baqui $\mathrm{AH}$, Alvarez JO. Short-term supplementation with zinc and vitamin A has no significant effect on the growth of undernourished Bangladeshi children. American Journal of Clinical Nutrition 2002;75(1):87-91.

* Rahman MM, Vermund SH, Wahed MA, Fuchs GJ, Baqui AH, Alvarez JO. Simultaneous zinc and vitamin A supplementation in Bangladeshi children: randomised double blind controlled trial. BMJ 2001;323(7308):314-8. Rahman MM, Wahed MA, Fuchs GJ, Baqui AH, Alvarez JO. Synergistic effect of zinc and vitamin A on the biochemical indexes of vitamin A nutrition in children. American Journal of Clinical Nutrition 2002;75(1):92-8.

\section{Rahman 2001 (2) \{published and unpublished data\}}

Rahman MM. Effect of Simultaneous Zinc and Vitamin A Supplementation on the Biochemical Indices of Vitamin A Nutriture, Morbidity, and Growth in Bangladeshi Children: A Randomized, Double Blind, Placebo Controlled Trial. Birmingham, Alabama: The University of Alabama at Birmingham, School of Public Health, 1999.

Rahman MM, Tofail F, Wahed MA, Fuchs GJ, Baqui $\mathrm{AH}$, Alvarez JO. Short-term supplementation with zinc and vitamin A has no significant effect on the growth of undernourished Bangladeshi children. American Journal of Clinical Nutrition 2002;75(1):87-91.

* Rahman MM, Vermund SH, Wahed MA, Fuchs GJ, Baqui AH, Alvarez JO. Simultaneous zinc and vitamin A supplementation in Bangladeshi children: randomised double blind controlled trial. BMJ 2001;323(7308):314-8. Rahman MM, Wahed MA, Fuchs GJ, Baqui AH, Alvarez JO. Synergistic effect of zinc and vitamin $A$ on the biochemical indexes of vitamin A nutrition in children. American Journal of Clinical Nutrition 2002;75(1):92-8. 
Richard 2006 \{published data only (unpublished sought but not used)\} Richard SA, Zavaleta N, Caulfield LE, Black RE, Witzig RS, Shankar AH. Zinc and iron supplementation and malaria, diarrhea, and respiratory infections in children in the Peruvian Amazon. American Journal of Tropical Medicine and Hygiene 2006;75(1):126-32.

Richard 2006 (2) \{published data only (unpublished sought but not used)\}

Richard SA, Zavaleta N, Caulfield LE, Black RE, Witzig

RS, Shankar AH. Zinc and iron supplementation and malaria, diarrhea, and respiratory infections in children in the Peruvian Amazon. American Journal of Tropical Medicine and Hygiene 2006;75(1):126-32.

Rosado 1997 \{published and unpublished data\} Allen LH, Rosado JL, Casterline JE, Lopez P, Muñoz E, Garcia OP, et al.Lack of hemoglobin response to iron supplementation in anemic mexican preschoolers with multiple micronutrient deficiencies. American Journal of Clinical Nutrition 2000;71(6):1485-94.

Muñoz EC, Rosado JL, Lopez P, Furr HC, Allen LH. Iron and zinc supplementation improves indicators of vitamin $\mathrm{A}$ status of Mexican preschoolers. American Journal of Clinical Nutrition 2000;71(3):789-94.

* Rosado JL, Lopez P, Muñoz E, Martinez H, Allen LH. Zinc supplementation reduced morbidity, but neither zinc nor iron supplementation affected growth or body composition of Mexican preschoolers. American Journal of Clinical Nutrition 1997;65(1):13-9.

Rosado 1997 (2) \{published and unpublished data\} Allen LH, Rosado JL, Casterline JE, Lopez P, Muñoz E, Garcia OP, et al.Lack of hemoglobin response to iron supplementation in anemic Mexican preschoolers with multiple micronutrient deficiencies. American Journal of Clinical Nutrition 2000;71(6):1485-94.

Muñoz EC, Rosado JL, Lopez P, Furr HC, Allen LH. Iron and zinc supplementation improves indicators of vitamin $\mathrm{A}$ status of Mexican preschoolers. American Journal of Clinical Nutrition 2000;71(3):789-94.

* Rosado JL, Lopez P, Muñoz E, Martinez H, Allen LH. Zinc supplementation reduced morbidity, but neither zinc nor iron supplementation affected growth or body composition of Mexican preschoolers. American Journal of Clinical Nutrition 1997;65(1):13-9.

Rosales 2004 \{published and unpublished data\} Rosales FJ, Kang Y, Pfeiffer B, Rau A, Romero-Abal ME, Erhardt JG, et al.Twice the recommended daily allowance of iron is associated with an increase in plasma alpha-1 antichymotrypsin concentrations in Guatemalan schoolaged children. Nutrition Research 2004;24(11):875-87.

Rosales 2004 (2) \{published and unpublished data\} Rosales FJ, Kang Y, Pfeiffer B, Rau A, Romero-Abal ME, Erhardt JG, et al.Twice the recommended daily allowance of iron is associated with an increase in plasma alpha-1 antichymotrypsin concentrations in Guatemalan schoolaged children. Nutrition Research 2004;24(11):875-87.
Ruel 1997 \{published data only (unpublished sought but not used)\} Bentley ME, Caulfield LE, Ram M, Santizo MC, Hurtado E, Rivera JA, et al.Zinc supplementation affects the activity patterns of rural Guatemalan infants. Journal of Nutrition 1997;127(7):1333-8.

Rivera JA, Ruel MT, Santizo MC, Lonnerdal B, Brown $\mathrm{KH}$. Zinc supplementation improves the growth of stunted rural Guatemalan infants. Journal of Nutrition 1998;128 (3):556-62.

* Ruel MT, Rivera JA, Santizo MC, Lonnerdal B, Brown $\mathrm{KH}$. Impact of zinc supplementation on morbidity from diarrhea and respiratory infections among rural Guatemalan children. Pediatrics 1997;99(6):808-13.

Ruz 1997 \{published data only (unpublished sought but not used)\} Ruz M, Castillo-Duran C, Lara X, Codoceo J, Rebolledo A, Alalah E. A 14-mo zinc-supplementation trial in apparently healthy Chilean preschool children. American Journal of Clinical Nutrition 1997;66(6):1406-13.

Sandstead 1998 \{published data only (unpublished sought but not used)\}

Penland JG, Sandstead HH, Alcock NW, Dayal HH, Chen $\mathrm{XC}, \mathrm{Li}$ JS, et al.A preliminary report: effects of zinc and micronutrient repletion on growth and neuropsychological function of urban Chinese children. Journal of the American College of Nutrition 1997;16(3):268-72.

* Sandstead HH, Penland JG, Alcock NW, Dayal HH, Chen XC, Li JS, et al.Effects of repletion with zinc and other micronutrients on neuropsychologic performance and growth of Chinese children. American Journal of Clinical Nutrition 1998;68(2 Suppl):470-5S.

Sandstead 2008 \{published data only (unpublished sought but not used)\}

Sandstead HH, Prasad AS, Penland JG, Beck FWJ, Kaplan J, Egger NG. Zinc deficiency in Mexican American children: influence of zinc and other micronutrients on $\mathrm{T}$ cells, cytokines, and antiinflammatory plasma proteins. American Journal of Clinical Nutrition 2008;88(4):1067-73.

Sanjur 1990 \{published data only\}

Sanjur D, Garcia A, Aguilar R, Furumoto R, Mort M. Dietary patterns and nutrient intakes of toddlers from low-income families in Denver, Colorado. Journal of the American Dietetic Association 1990;90(6):823-9.

Sayeg Porto 2000 \{published data only (unpublished sought but not used)\}

Sayeg Porto MA, Oliveira HP, Cunha AJ, Miranda G, Guimaraes MM, Oliveira WA, et al.Linear growth and zinc supplementation in children with short stature. Journal of Pediatric Endocrinology 2000;13(8):1121-8.

Sazawal 1996 \{published and unpublished data\} Chugh K. Zinc therapy in acute diarrhea. Indian Pediatrics 1996;33(4):352.

Dhingra U, Hiremath G, Menon VP, Dhingra P, Sarkar A, Sazawal S. Zinc deficiency: descriptive epidemiology and morbidity among preschool children in peri-urban 
population in Delhi, India. Journal of Health, Population and Nutrition 2009;27(5):632-9.

Sazawal S. Effect of Zinc Supplementation on Diarrheal Morbidity among Urban Slum Children in India. Baltimore, MD: The Johns Hopkins University, 1996.

Sazawal S, Bentley M, Black RE, Dhingra P, George S, Bhan MK. Effect of zinc supplementation on observed activity in low socioeconomic Indian preschool children. Pediatrics 1996;98(6):1132-7.

Sazawal S, Black RE, Bhan MK, Bhandari N, Sinha A, Jalla $S$. Zinc supplementation in young children with acute diarrhea in India. New England Journal of Medicine 1995; 333(13):839-44.

* Sazawal S, Black RE, Bhan MK, Jalla S, Bhandari N, Sinha $A$, et al.Zinc supplementation reduces the incidence of persistent diarrhea and dysentery among low socioeconomic children in India. Journal of Nutrition 1996;126(2):443-50. Sazawal S, Black RE, Bhan MK, Jalla S, Sinha A, Bhandari $\mathrm{N}$. Efficacy of zinc supplementation in reducing the incidence and prevalence of acute diarrhea - a communitybased, double-blind, controlled trial. American Journal of Clinical Nutrition 1997;66(2):413-8.

Sazawal S, Black RE, Jalla S, Mazumdar S, Sinha A, Bhan MK. Zinc supplementation reduces the incidence of acute lower respiratory infections in infants and preschool children: a double-blind, controlled trial. Pediatrics 1998; 102(1): $1-5$.

Sazawal S, Jalla S, Mazumder S, Sinha A, Black RE, Bhan MK. Effect of zinc supplementation on cell-mediated immunity and lymphocyte subsets in preschool children. Indian Pediatrics 1997;34(7):589-97.

Sazawal S, Malik P, Jalla S, Krebs N, Bhan MK, Black RE. Zinc supplementation for four months does not affect plasma copper concentration in infants. Acta Paediatrica 2004;93(5):599-602.

Sazawal S, Usha D, Saikat D, Bhan MK, Menon VP, Black RE. Effect of zinc added to multi-vitamin supplementation containing low-dose vitamin A on plasma retinol level in children - a double-blind randomized, controlled trial. Journal of Health, Population and Nutrition 2007;25(1): 62-6.

\section{Sazawal 2006 \{published and unpublished data\}}

De Benoist B, Darnton-Hill I, Lynch S, Allen L, Savioli

L. Zinc and iron supplementation trials in Nepal and Tanzania. Lancet 2006;367(9513):816.

Kariger PK, Stoltzfus RJ, Olney D, Sazawal S, Black R, Tielsch JM, et al.Iron deficiency and physical growth predict attainment of walking but not crawling in poorly nourished Zanzibari infants. Journal of Nutrition 2005;135(4):814-9. Kordas K, Siegel EH, Olney DK, Katz J, Tielsch JM, Chwaya HM, et al.Maternal reports of sleep in 6-18 monthold infants from Nepal and Zanzibar: association with iron deficiency anemia and stunting. Early Human Development 2008;84(6):389-98.

Kordas K, Siegel EH, Olney DK, Katz J, Tielsch JM, Kariger $\mathrm{PK}$, et al.The effects of iron and/or zinc supplementation on maternal reports of sleep in infants from Nepal and
Zanzibar. Journal of Developmental and Behavioral Pediatrics 2009;30(2):131-9.

Olney DK. Modeling the Effects of Anemia, Malaria, Growth and Micronutrient Supplementation on Development of Young Zanzibari Children. Davis, CA: University of California,

Davis, 2006.

Olney DK, Kariger PK, Stoltzfus RJ, Khalfan SS, Ali NS, Tielsch JM, et al.Development of nutritionally at-risk young children is predicted by malaria, anemia, and stunting in Pemba, Zanzibar. Journal of Nutrition 2009;139(4): 763-72.

Olney DK, Pollitt E, Kariger PK, Khalfan SS, Ali

NS, Tielsch JM, et al.Combined iron and folic acid supplementation with or without zinc reduces time to walking unassisted among Zanzibari infants 5- to 11-mo old. Journal of Nutrition 2006;136(9):2427-34.

Olney DK, Pollitt E, Kariger PK, Khalfan SS, Ali NS, Tielsch JM, et al.Young Zanzibari children with iron deficiency, iron deficiency anemia, stunting, or malaria have lower motor activity scores and spend less time in locomotion. Journal of Nutrition 2007;137(12):2756-62. Sazawal S, Black RE, Ramsan M, Chwaya HM, Dutta A, Dhingra U, et al.Effect of zinc supplementation on mortality in children aged 1-48 months: a communitybased randomised placebo-controlled trial. Lancet 2007; 369(9565):927-34.

* Sazawal S, Black RE, Ramsan M, Chwaya HM, Stoltzfus RJ, Dutta A, et al.Effects of routine prophylactic supplementation with iron and folic acid on admission to hospital and mortality in preschool children in a high malaria transmission setting: community-based, randomised, placebo-controlled trial. Lancet 2006;367 (9505):133-43.

\section{Sazawal 2006 (2) \{published and unpublished data\}}

De Benoist B, Darnton-Hill I, Lynch S, Allen L, Savioli L. Zinc and iron supplementation trials in Nepal and Tanzania. Lancet 2006;367(9513):816.

Kariger PK, Stoltzfus RJ, Olney D, Sazawal S, Black R, Tielsch JM, et al.Iron deficiency and physical growth predict attainment of walking but not crawling in poorly nourished Zanzibari infants. Journal of Nutrition 2005;135(4):814-9. Kordas K, Siegel EH, Olney DK, Katz J, Tielsch JM, Chwaya HM, et al.Maternal reports of sleep in 6-18 monthold infants from Nepal and Zanzibar: association with iron deficiency anemia and stunting. Early Human Development 2008;84(6):389-98.

Kordas K, Siegel EH, Olney DK, Katz J, Tielsch JM, Kariger $\mathrm{PK}$, et al.The effects of iron and/or zinc supplementation on maternal reports of sleep in infants from Nepal and Zanzibar. Journal of Developmental and Behavioral Pediatrics 2009;30(2):131-9.

Olney DK. Modeling the Effects of Anemia, Malaria, Growth and Micronutrient Supplementation on Development of Young Zanzibari Children. Davis, CA: University of California, Davis, 2006.

Olney DK, Kariger PK, Stoltzfus RJ, Khalfan SS, Ali NS, Tielsch JM, et al.Development of nutritionally at-risk young 
children is predicted by malaria, anemia, and stunting in Pemba, Zanzibar. Journal of Nutrition 2009;139(4): 763-72.

Olney DK, Pollitt E, Kariger PK, Khalfan SS, Ali NS, Tielsch JM, et al.Combined iron and folic acid supplementation with or without zinc reduces time to walking unassisted among Zanzibari infants 5- to 11-mo old. Journal of Nutrition 2006;136(9):2427-34.

Olney DK, Pollitt E, Kariger PK, Khalfan SS, Ali NS, Tielsch JM, et al.Young Zanzibari children with iron deficiency, iron deficiency anemia, stunting, or malaria have lower motor activity scores and spend less time in locomotion. Journal of Nutrition 2007;137(12):2756-62. Sazawal S, Black RE, Ramsan M, Chwaya HM, Dutta A, Dhingra U, et al.Effect of zinc supplementation on mortality in children aged 1-48 months: a communitybased randomised placebo-controlled trial. Lancet 2007; 369(9565):927-34.

* Sazawal S, Black RE, Ramsan M, Chwaya HM, Stoltzfus RJ, Dutta A, et al.Effects of routine prophylactic supplementation with iron and folic acid on admission to hospital and mortality in preschool children in a high malaria transmission setting: community-based, randomised, placebo-controlled trial. Lancet 2006;367 (9505):133-43.

Schultink 1997 \{published data only (unpublished sought but not used)\}

Schultink W, Merzenich M, Gross R, Shrimpton R, Dillon D. Effects of iron-zinc supplementation on the iron, zinc, and vitamin A status of anaemic pre-school children in Indonesia. Food and Nutrition Bulletin 1997;18:311-7.

Sempertegui 1996 \{published data only (unpublished sought but not used)\}

Correa León E, Torres M, Navarrete F, Aguirre L, Saa B. Deficiencia de Zinc e Inmunidad Celular. Quito, Ecuador: FCM, 1992.

* Sempertegui F, Estrella B, Correa E, Aguirre L, Saa B, Torres $\mathrm{M}$, et al.Effects of short-term zinc supplementation on cellular immunity, respiratory symptoms, and growth of malnourished Equadorian children. European Journal of Clinical Nutrition 1996;50(1):42-6.

Shah 2011 \{published data only\}

Shah U, Malik MA, Alam S, Shaheen A, Mohammad R, Al Tannir M. The efficacy of zinc supplementation in young children with recurrent acute lower respiratory infections: a randomized double-blind placebo controlled trial. Journal of Paediatrics and Child Health 2011;47(Suppl 2):13 (Abstract O43).

Shankar 2000 \{published data only (unpublished sought but not used)\}

* Shankar AH, Genton B, Baisor M, Paino J, Tamja S, Adiguma T, et al.The influence of zinc supplementation on morbidity due to Plasmodium falciparum: a randomized trial in preschool children in Papua New Guinea. American Journal of Tropical Medicine and Hygiene 2000;62(6):663-9. Shankar AH, Genton B, Tamja S, Arnold S, Wu L, Baisor $\mathrm{M}$, et al.Zinc supplementation can reduce malaria-related morbidity in preschool children. American Journal of
Tropical Medicine and Hygiene 1997;57(3 Suppl):249

(Abstract 434).

Silva 2006 \{published data only (unpublished sought but not used)\} Silva APR, Vitolo MR, Zara LF, Castro CFS. Effect of zinc supplementation for children 1-5 years old [Efeito da suplementação de zinco a crianças de 1 a 5 anos de idade]. Jornal de Pediatria 2006;82(3):227-31.

Smith 1999 \{published data only\}

Smith JC, Makdani D, Hegar A, Rao D, Douglass LW. Vitamin A and zinc supplementation of preschool children. Journal of the American College of Nutrition 1999;18(3): 213-22.

\section{Soofi 2013 \{published and unpublished data\}}

Soofi S, Cousens S, Iqbal SP, Akhund T, Khan J, Ahmed I, et al.Effect of provision of daily zinc and iron with several micronutrients on growth and morbidity among young children in Pakistan: a cluster-randomised trial. Lancet 2013;382(9886):29-40.

Tielsch 2006 \{published and unpublished data\} Christian P, Morgan ME, Murray-Kolb L, LeClerq SC, Khatry SK, Schaefer B, et al.Preschool iron-folic acid and zinc supplementation in children exposed to iron-folic acid in utero confers no added cognitive benefit in early schoolage. Journal of Nutrition 2011;141(11):2042-8.

Coles CL, Sherchand JB, Khatry SK, Katz J, LeClerq SC, Mullany LC, et al.Zinc modifies the association between nasopharyngeal Streptococcus pneumoniae carriage and risk of acute lower respiratory infection among young children in rural Nepal. Journal of Nutrition 2008;138(12):2462-7. De Benoist B, Darnton-Hill I, Lynch S, Allen L, Savioli L. Zinc and iron supplementation trials in Nepal and Tanzania. Lancet 2006;367(9513):816.

Katz J, Khatry SK, LeClerq SC, Mullany LC, Yanik EL, Stoltzfus RJ, et al.Daily supplementation with iron plus folic acid, zinc, and their combination is not associated with younger age at first walking unassisted in malnourished preschool children from a deficient population in rural Nepal. Journal of Nutrition 2010;140(7):1317-21. Kordas K, Siegel EH, Olney DK, Katz J, Tielsch JM, Chwaya HM, et al.Maternal reports of sleep in 6-18 monthold infants from Nepal and Zanzibar: association with iron deficiency anemia and stunting. Early Human Development 2008;84(6):389-98.

Kordas K, Siegel EH, Olney DK, Katz J, Tielsch JM, Kariger $\mathrm{PK}$, et al.The effects of iron and/or zinc supplementation on maternal reports of sleep in infants from Nepal and Zanzibar. Journal of Developmental and Behavioral Pediatrics 2009;30(2):131-9.

Murray-Kolb LE, Khatry SK, Katz J, Schaefer BA, Cole PM, Le Clerq SC, et al.Preschool micronutrient supplementation effects on intellectual and motor function in school-aged Nepalese children. Archives of Pediatrics and Adolescent Medicine 2012;166(5):404-10.

Siegel EH. Anemia, Motor Development, and Cognition: A Randomized Trial of Iron-Folic Acid andlor Zinc 
Supplementation in Young Nepali Children. Baltimore, MD: The Johns Hopkins University, 2005.

Siegel EH, Kordas K, Stoltzfus RJ, Katz J, Khatry SK, LeClerq SC, et al.Inconsistent effects of iron-folic acid and/ or zinc supplementation on the cognitive development of infants. Journal of Health, Population and Nutrition 2011; 29(6):593-604.

Siegel EH, Stoltzfus RJ, Kariger PK, Katz J, Khatry SK, LeClerq SC, et al.Growth indices, anemia, and diet independently predict motor milestone acquisition of infants in south central Nepal. Journal of Nutrition 2005; 135(12):2840-4.

Siegel EH, Stoltzfus RJ, Khatry SK, LeClerq SC, Katz J, Tielsch JM. Epidemiology of anemia among 4- to 17month-old children living in south central Nepal. European Journal of Clinical Nutrition 2005;60(2):228-35.

Surkan PJ, Shankar M, Katz J, Siegel EH, Leclerq SC, Khatry SK, et al.Beneficial effects of zinc supplementation on head circumference of Nepalese infants and toddlers: a randomized controlled trial. European Journal of Clinical Nutrition 2012;66(7):836-42.

Tielsch JM, Khatry SK, Stoltzfus RJ, Katz J, LeClerq SC, Adhikari R, et al.Effect of daily zinc supplementation on child mortality in southern Nepal: a community-based, cluster randomised, placebo-controlled trial. Lancet 2007; 370(9594):1230-9.

* Tielsch JM, Khatry SK, Stoltzfus RJ, Katz J, LeClerq SC, Adhikari R, et al.Effect of routine prophylactic supplementation with iron and folic acid on preschool child mortality in southern Nepal: community-based, clusterrandomised, placebo-controlled trial. Lancet 2006;367 (9505):144-52.

Tielsch 2006 (2) \{published and unpublished data\} Christian P, Morgan ME, Murray-Kolb L, LeClerq SC, Khatry SK, Schaefer B, et al.Preschool iron-folic acid and zinc supplementation in children exposed to iron-folic acid in utero confers no added cognitive benefit in early schoolage. Journal of Nutrition 2011;141(11):2042-8.

Coles CL, Sherchand JB, Khatry SK, Katz J, LeClerq SC, Mullany LC, et al.Zinc modifies the association between nasopharyngeal Streptococcus pneumoniae carriage and risk of acute lower respiratory infection among young children in rural Nepal. Journal of Nutrition 2008;138(12):2462-7. De Benoist B, Darnton-Hill I, Lynch S, Allen L, Savioli L. Zinc and iron supplementation trials in Nepal and Tanzania. Lancet 2006;367(9513):816.

Katz J, Khatry SK, LeClerq SC, Mullany LC, Yanik EL, Stoltzfus RJ, et al.Daily supplementation with iron plus folic acid, zinc, and their combination is not associated with younger age at first walking unassisted in malnourished preschool children from a deficient population in rural Nepal. Journal of Nutrition 2010;140(7):1317-21. Kordas K, Siegel EH, Olney DK, Katz J, Tielsch JM, Chwaya HM, et al.Maternal reports of sleep in 6-18 monthold infants from Nepal and Zanzibar: association with iron deficiency anemia and stunting. Early Human Development
2008;84(6):389-98.

Kordas K, Siegel EH, Olney DK, Katz J, Tielsch JM, Kariger $\mathrm{PK}$, et al.The effects of iron and/or zinc supplementation on maternal reports of sleep in infants from Nepal and Zanzibar. Journal of Developmental and Behavioral Pediatrics 2009;30(2):131-9.

Murray-Kolb LE, Khatry SK, Katz J, Schaefer BA, Cole PM, Le Clerq SC, et al.Preschool micronutrient supplementation effects on intellectual and motor function in school-aged Nepalese children. Archives of Pediatrics and Adolescent Medicine 2012;166(5):404-10.

Siegel EH. Anemia, Motor Development, and Cognition: A Randomized Trial of Iron-Folic Acid andlor Zinc Supplementation in Young Nepali Children. Baltimore, MD: The Johns Hopkins University, 2005.

Siegel EH, Kordas K, Stoltzfus RJ, Katz J, Khatry SK, LeClerq SC, et al.Inconsistent effects of iron-folic acid and/ or zinc supplementation on the cognitive development of infants. Journal of Health, Population and Nutrition 2011; 29(6):593-604.

Siegel EH, Stoltzfus RJ, Kariger PK, Katz J, Khatry SK, LeClerq SC, et al.Growth indices, anemia, and diet independently predict motor milestone acquisition of infants in south central Nepal. Journal of Nutrition 2005; 135(12):2840-4.

Siegel EH, Stoltzfus RJ, Khatry SK, LeClerq SC, Katz J, Tielsch JM. Epidemiology of anemia among 4- to 17month-old children living in south central Nepal. European Journal of Clinical Nutrition 2005;60(2):228-35.

Surkan PJ, Shankar M, Katz J, Siegel EH, LeClerq SC, Khatry SK, et al.Beneficial effects of zinc supplementation on head circumference of Nepalese infants and toddlers: a randomized controlled trial. European Journal of Clinical Nutrition 2012;66(7):836-42.

Tielsch JM, Khatry SK, Stoltzfus RJ, Katz J, LeClerq SC, Adhikari R, et al.Effect of daily zinc supplementation on child mortality in southern Nepal: a community-based, cluster randomised, placebo-controlled trial. Lancet 2007; 370(9594):1230-9.

* Tielsch JM, Khatry SK, Stoltzfus RJ, Katz J, LeClerq SC, Adhikari R, et al.Effect of routine prophylactic supplementation with iron and folic acid on preschool child mortality in southern Nepal: community-based, clusterrandomised, placebo-controlled trial. Lancet 2006;367 (9505):144-52.

Tupe 2009 \{published and unpublished data\} Chiplonkar SA, Kawade R. Effect of zinc- and micronutrient-rich food supplements on zinc and vitamin A status of adolescent girls. Nutrition 2012;28(5):551-8.

* Tupe RP, Chiplonkar SA. Zinc supplementation improved cognitive performance and taste acuity in Indian adolescent girls. Journal of the American College of Nutrition 2009;28 (4):388-96.

Uckardes 2009 \{published and unpublished data\}

* Uckardes Y, Ozmert EN, Unal F, Yurdakok K. Effects of zinc supplementation on parent and teacher behaviour 
rating scores in low socioeconomic level Turkish primary school children. Acta Pediatrica 2009;98(4):731-6. Uckardes Y, Ozmert EN, Unal F, Yurdakok K. The effect of zinc supplementation on Hacettepe Psychological Adaptation Scale scores in low socioeconomic level primary school children [Düs, ük sosyoekonomik düzey ilkög retim $c_{3}$ ocukları nda $c_{3}$ inko desteg ${ }^{\circ}$ inin Hacettepe Ruhsal Uyum Ölcs ę e` i skorları na etkisi].

Cs ocuk Sağ a ğ $g^{\prime}$ I ve Hastah klan Dergisi 2009;52 (2):53-9.

Uckardes Y, Tekcicek M, Ozmert EN, Yurdakok K. The effect of systemic zinc supplementation on oral health in low socioeconomic level children. Turkish Journal of Pediatrics 2009;51(5):424-8.

Udomkesmalee 1992 \{published data only (unpublished sought but not used)\}

Kramer TR, Udomkesmalee E, Dhanamitta S, Sirisinha S, Charoenkiatkul S, Tuntipopipat $S$, et al.Lymphocyte responsiveness of children supplemented with vitamin A and zinc. American Journal of Clinical Nutrition 1993;58 (4):566-70.

* Udomkesmalee E, Dhanamitta $S$, Sirisinha $S$, Charoenkiatkul S, Tuntipopipat S, Banjong O, et al.Effect of vitamin $\mathrm{A}$ and zinc supplementation on the nutriture of children in Northeast Thailand. American Journal of Clinical Nutrition 1992;56(1):50-7.

Udomkesmalee 1992 (2) \{published data only (unpublished sought but not used)\}

Kramer TR, Udomkesmalee E, Dhanamitta S, Sirisinha $S$, Charoenkiatkul S, Tuntipopipat $S$, et al.Lymphocyte responsiveness of children supplemented with vitamin A and zinc. American Journal of Clinical Nutrition 1993;58 (4):566-70.

* Udomkesmalee E, Dhanamitta S, Sirisinha S, Charoenkiatkul S, Tuntipopipat S, Banjong O, et al.Effect of vitamin A and zinc supplementation on the nutriture of children in Northeast Thailand. American Journal of Clinical Nutrition 1992;56(1):50-7.

Umeta 2000 \{published data only (unpublished sought but not used)\} Gibson RS. Zinc supplementation for infants. Lancet 2000; 355(9220):2008-9.

Umeta M, West CE, Haidar J. Zinc supplements increased growth more in stunted infants than in non-stunted infants. Evidence-Based Medicine 2001;6(2):50.

* Umeta M, West CE, Haidar J, Deurenberg P, Hautvast JG. Zinc supplementation and stunted infants in Ethiopia: a randomised controlled trial. Lancet 2000;355(9220): 2021-6.

Vakili 2009 \{published data only (unpublished sought but not used)\} Vakili R, Vahedian M, Khodaei GH, Mahmoudi M. Effects of zinc supplementation in occurrence and duration of common cold in school aged children during cold season: a double-blind placebo-controlled trial. Iranian Journal of Pediatrics 2009;19(4):376-80.
Veenemans 2011 \{published data only (unpublished sought but not used)\}

Veenemans J. Effect of Preventive Supplementation with Zinc and Other Micronutrients on Malaria and Diarrhoeal Morbidity in African Children. Wageningen, Netherlands: Wageningen University, 2011.

Veenemans J, Mank T, Ottenhof M, Baidjoe A, Mbugi EV, Demir AY, et al.Protection against diarrhea associated with Giardia intestinalis is lost with multi-nutrient supplementation: a study in Tanzanian children. PLoS Neglected Tropical Diseases 2011;5(6):e1158.

* Veenemans J, Milligan P, Prentice AM, Schouten LRA, Inja N, Van Der Heijden AC, et al.Effect of supplementation with zinc and other micronutrients on malaria in Tanzanian children: a randomised trial. PLoS Medicine 2011;8(11): e1001125.

Veenemans J, Schouten LRA, Ottenhof MJ, Mank TG, Uges DRA, Mbugi EV, et al.Effect of preventive supplementation with zinc and other micronutrients on non-malarial morbidity in Tanzanian pre-school children: a randomized trial. PLoS ONE 2012;7(8):e41630.

Veenemans 2011 (2) \{published data only (unpublished sought but not used)\}

Veenemans J. Effect of Preventive Supplementation with Zinc and Other Micronutrients on Malaria and Diarrhoeal Morbidity in African Children. Wageningen, Netherlands: Wageningen University, 2011.

Veenemans J, Mank T, Ottenhof M, Baidjoe A, Mbugi EV, Demir AY, et al.Protection against diarrhea associated with Giardia intestinalis is lost with multi-nutrient supplementation: a study in Tanzanian children. PLoS Neglected Tropical Diseases 2011;5(6):e1158.

* Veenemans J, Milligan P, Prentice AM, Schouten LRA, Inja N, Van Der Heijden AC, et al.Effect of supplementation with zinc and other micronutrients on malaria in Tanzanian children: a randomised trial. PLoS Medicine 2011;8(11): e1001125.

Veenemans J, Schouten LRA, Ottenhof MJ, Mank TG, Uges DRA, Mbugi EV, et al.Effect of preventive supplementation with zinc and other micronutrients on non-malarial morbidity in Tanzanian pre-school children: a randomized trial. PLoS ONE 2012;7(8):e41630.

Walravens 1983 \{published data only (unpublished sought but not used)\}

Hambidge KM, Krebs NF, Walravens PA. Growth velocity of young children receiving a dietary zinc supplement. Nutrition Research 1985;5(Suppl 1):S306-16.

Krebs NF, Hambidge KM, Walravens PA. Increased food intake of young children receiving a zinc supplement. American Journal of Diseases of Children 1984;138(3):270-3. * Walravens PA, Krebs NF, Hambidge KM. Linear growth of low income preschool children receiving a zinc supplement. American Journal of Clinical Nutrition 1983;38(2):195-201.

Walravens 1989 \{published data only (unpublished sought but not used)\}

Walravens PA, Hambidge KM, Koepfer DM. Zinc supplementation in infants with a nutritional pattern of 
failure to thrive: a double-blind, controlled study. Pediatrics 1989;83(4):532-8.

Wessells 2012b \{published data only\}

Wessells KR, Ouedraogo ZP, Rouamba N, Hess SY, Ouedraogo JB, Brown KH. Short-term zinc supplementation with dispersible tablets or zinc sulfate solution yields similar positive effects on plasma zinc concentration of young children in Burkina Faso: a randomized controlled trial. Journal of Pediatrics 2012;160 (1):129-35.

Wessells R, Ouedraogo ZP, Rouamba N, Hess SY, Ouedraogo JB, Brown KH. The effect of zinc supplementation, provided as either a liquid $\mathrm{ZnSO} 4$ solution or a dispersible tablet, on plasma zinc concentration among young Burkinabe children. FASEB Journal 2011;25: 236.1.

Wuehler 2008 \{published and unpublished data\} Wuehler S. Estimation of the Global Risk of Zinc Deficiency and Assessment of the Impact of Three Doses of Zinc Supplementation, With or Without Copper, on Markers of Zinc and Copper Status, Morbidity and Growth Among Young Ecuadorian Children. Davis, CA: University of California, Davis, 2007

* Wuehler SE, Sempertegui F, Brown KH. Dose-response trial of prophylactic zinc supplements, with or without copper, in young Ecuadorian children at risk of zinc deficiency. American Journal of Clinical Nutrition 2008;87 (3):723-33.

\section{References to studies excluded from this review}

Ahmed 2009b \{published data only (unpublished sought but not used)\}

Ahmed T, Svennerholm AM, Al Tarique A, Sultana GNN, Qadri F. Enhanced immunogenicity of an oral inactivated cholera vaccine in infants in Bangladesh obtained by zinc supplementation and by temporary withholding breastfeeding. Vaccine 2009;27(9):1433-9.

Bates 1993 \{published data only\}

Bates CJ, Evans PH, Dardenne M, Prentice A, Lunn PG, Northrop-Clewes CA, et al.A trial of zinc supplementation in young rural Gambian children. British Journal of Nutrition 1993;69(1):243-55.

Behrens 1990 \{published data only\} Behrens RH, Tomkins AM, Roy SK. Zinc supplementation during diarrhoea, a fortification against malnutrition?. Lancet 1990;336(18):442-3.

Berger 2006 \{published data only (unpublished sought but not used)\} Berger J, Ninh NX, Khan NC, Nhien NV, Lien DK, Trung NQ, et al.Efficacy of combined iron and zinc supplementation on micronutrient status and growth in Vietnamese infants. European Journal of Clinical Nutrition 2006;60(4):443-54.

Dijkhuizen MA, Winichagoon P, Wieringa FT, Wasantwisut E, Utomo B, Ninh NX, et al.Zinc supplementation improved length growth only in anemic infants in a multi- country trial of iron and zinc supplementation in SouthEast Asia. Journal of Nutrition 2008;138(10):1969-75. Wieringa FT, Berger J, Dijkhuizen MA, Hidayat A, Ninh NX, Utomo B, et al.Combined iron and zinc supplementation in infants improved iron and zinc status, but interactions reduced efficacy in a multicountry trial in Southeast Asia. Journal of Nutrition 2007;137(2):466-71.

Bobat 2005 \{published data only\}

Bobat R, Coovadia H, Stephen C, Naidoo KL, McKerrow N, Black RE, et al.Safety and efficacy of zinc supplementation for children with HIV-1 infection in South Africa: a randomised double-blind placebo-controlled trial. Lancet 2005;366(9500):1862-7.

Brooks 2005 \{published data only (unpublished sought but not used)\} Brooks WA, Santosham M, Naheed A, Goswami D, Wahed MA, Diener-West M, et al.Effect of weekly zinc supplements on incidence of pneumonia and diarrhoea in children younger than 2 years in an urban, low-income population in Bangladesh: randomised controlled trial. Lancet 2005;366(9490):999-1004.

Campos 2004 \{published data only\} Campos D Jr, Veras Neto MC, Silva Filho VL, Leite MF, Holanda MBS, Cunha NF. Zinc supplementation may recover taste for salt meals [Suplementacao com zinco pode recuperar apetite para refeicoes de sal]. Jornal de Pediatria 2004;80(1):55-9.

\section{Cuevas 2002 \{published data only\}}

Cuevas LE, Almeida LMD, Mazunder P, Paixao AC, Silva AM, Maciel L, et al.Effect of zinc on the tuberculin response of children exposed to adults with smear-positive tuberculosis. Annals of Tropical Paediatrics: International Child Health 2002;22(4):313-9.

Duggan 2003 \{published data only\}

Duggan C, Penny ME, Hibberd P, Gil A, Huapaya A, Cooper A, et al.Oligofructose-supplemented infant cereal: 2 randomized, blinded, community-based trials in Peruvian infants. American Journal of Clinical Nutrition 2003;77(4): $937-42$.

Fahmida 2007 \{published data only (unpublished sought but not used)\} Fahmida U, Rumawas JSP, Utomo B, Patmonodewo S, Schultink W. Zinc-iron, but not zinc-alone supplementation, increased linear growth of stunted infants with low haemoglobin. Asia Pacific Journal of Clinical Nutrition 2007;16(2):301-9.

\section{Hashemipour 2009 \{published data only\}} Hashemipour M, Kelishadi R, Shapouri J. Effect of zinc supplementation on insulin resistance and components of the metabolic syndrome in prepubescent obese children. Pediatric Diabetes 2009;10(Suppl 11):94 (Abstract P/199/ FRI).

Hashemipour M, Kelishadi R, Shapouri J, Sarrafzadegan N, Amini M, Tavakoli N, et al.Effect of zinc supplementation on insulin resistance and components of the metabolic 
syndrome in prepubertal obese children. Hormones 2009;8 (4):279-85.

Kelishadi R, Hashemipour M, Adeli K, Tavakoli N, Movahedian-Attar A, Shapouri J, et al.Effect of zinc supplementation on markers of insulin resistance, oxidative stress, and inflammation among prepubescent children with metabolic syndrome. Metabolic Syndrome and Related Disorders 2010;8(6):505-10.

Heinig 2006 \{published data only\}

Heinig MJ, Brown KH, Lonnerdal B, Dewey KG. Zinc supplementation does not affect growth, morbidity, or motor development of U.S. breastfed infants at 4-10 mo. FASEB Journal 1998;12:A970 (Abstract 5617).

Heinig MJ, Brown KH, Lonnerdal B, Dewey KG. Zinc supplementation does not affect growth, morbidity, or motor development of US term breastfed infants at 4-10 mo of age. American Journal of Clinical Nutrition 2006;84 (3):594-601.

Hess 2011 \{published data only\}

Hess SY, Bado L, Aaron GJ, Ouedraogo JB, Zeilani M, Brown KH. Acceptability of zinc-fortified, lipid-based nutrient supplements (LNS) prepared for young children in Burkina Faso. Maternal and Child Nutrition 2011;7(4): 357-67.

Imamoglu 2005 \{published data only\} Imamoglu S, Bereket A, Turan S, Taga Y, Haklar G. Effect of zinc supplementation on growth hormone secretion, IGF-I, IGFBP-3, somatomedin generation, alkaline phosphatase, osteocalcin and growth in prepubertal children with idiopathic short stature. Journal of Pediatric Endocrinology and Metabolism 2005;18(1):69-74.

Kordas 2005 \{published data only\}

Kordas K, Stoltzfus RJ, Lopez P, Rico JA, Rosado JL. Iron and zinc supplementation does not improve parent or teacher ratings of behavior in first grade Mexican children exposed to lead. Journal of Pediatrics 2005;147(5):632-9. Rico JA, Kordas K, Lopez P, Rosado JL, Garcia Vargas G, Ronquillo D, et al.Efficacy of iron and/or zinc supplementation on cognitive performance of lead-exposed Mexican schoolchildren: a randomized, placebo-controlled trial. Pediatrics 2006;117(3):e518-27.

Rosado JL, Lopez P, Kordas K, Garcia-Vargas G, Ronquillo $\mathrm{D}$, Alatorre J, et al.Iron and/or zinc supplementation did not reduce blood lead concentrations in children in a randomized, placebo-controlled trial. Journal of Nutrition 2006;136(9):2378-83.

Osendarp 2002 \{published data only\} Osendarp SJM, Santosham M, Black RE, Wahed MA, Van Raaij JMA, Fuchs GJ. Effect of zinc supplementation between 1 and 6 mo of life on growth and morbidity of Bangladeshi infants in urban slums. American Journal of Clinical Nutrition 2002;76(6):1401-8.

Payne-Robinson 1991 \{published data only\} Payne-Robinson HM, Golden MH, Golden BE, Simeon DT. The zinc sandwich and growth. Lancet 1991;337 (8746):925-6.
Perrone 1999 \{published data only\}

Perrone L, Salerno M, Gialanella G, Feng SL, Moro R, Di Lascio R, et al.Long-term zinc and iron supplementation in children of short stature: effect of growth and on trace element content in tissues. Journal of Trace Elements in Medicine and Biology 1999;13(1-2):51-6.

Ronaghy 1969 \{published data only\} Ronaghy H, Fox MR, Garn SM, Israel H, Harp A, Moe PG, et al.Controlled zinc supplementation for malnourished school boys: a pilot experiment. American Journal of Clinical Nutrition 1969;22(10):1279-89.

Ronaghy 1974 \{published data only\} Ronaghy HA, Reinhold JG, Mahloudji M, Ghavami P, Fox MR, Halsted JA. Zinc supplementation of malnourished schoolboys in Iran: increased growth and other effects. American Journal of Clinical Nutrition 1974;27(2):112-21.

Roxas 1980 \{published data only\}

Roxas BV, Intengan CL, Juliano BO. Effect of zinc supplementation and high-protein rice on the growth of preschool children on a rice-based diet. Qualitas Plantarum 1980;30(3-4):213-22.

Shingwekar 1979 \{published data only\} Shingwekar AG, Mohanram M, Reddy V. Effect of zinc supplementation on plasma levels of vitamin A and retinolbinding protein in malnourished children. Clinica Chimica Acta 1979;93(1):97-100.

\section{Shrivastava 1993 \{published data only\}}

Shrivastava SP, Roy AK, Jana UK. Zinc supplementation in protein energy malnutrition. Indian Pediatrics 1993;30(6): $779-82$.

Walravens 1992 \{published data only\} Walravens PA, Chakar A, Mokni R, Denise J, Lemonnier D. Zinc supplements in breastfed infants. Lancet 1992;340 (8821):683-5.

Wasantwisut 2006 \{published data only (unpublished sought but not used)\}

Dijkhuizen MA, Winichagoon P, Wieringa FT, Wasantwisut E, Utomo B, Ninh NX, et al.Zinc supplementation improved length growth only in anemic infants in a multicountry trial of iron and zinc supplementation in SouthEast Asia. Journal of Nutrition 2008;138(10):1969-75. Pongcharoen T. Long-Term Effects of Iron and Zinc Supplementation During Infancy on Cognitive Performance and Growth 8 Years Later: A Follow-Up Study. Atlanta, GA: Emory University, 2010.

Pongcharoen T, DiGirolamo AM, Ramakrishnan U, Winichagoon P, Flores R, Martorell R. Association of micronutrient status and early childhood stunting with cognitive performance among school children in northeast Thailand. FASEB Journal 2009;23(Meeting abstract supplement):917.12.

Pongcharoen T, DiGirolamo AM, Ramakrishnan U, Winichagoon P, Flores R, Martorell R. Long-term effects of iron and zinc supplementation during infancy on cognitive function at $9 \mathrm{y}$ of age in northeast Thai children: a follow- 
up study. American Journal of Clinical Nutrition 2011;93 (3):636-43.

Wasantwisut E, Winichagoon P, Chitchumroonchokchai C, Yamborisut U, Boonpraderm A, Pongcharoen T, et al.Iron and zinc supplementation improved iron and zinc status, but not physical growth, of apparently healthy, breast-fed infants in rural communities of northeast Thailand. Journal of Nutrition 2006;136(9):2405-11.

Wieringa FT, Berger J, Dijkhuizen MA, Hidayat A, Ninh NX, Utomo B, et al.Combined iron and zinc supplementation in infants improved iron and zinc status, but interactions reduced efficacy in a multicountry trial in Southeast Asia. Journal of Nutrition 2007;137(2):466-71.

Yanfeng 1997 \{published data only\}

Yanfeng X, Ling W, Jing Y, Rong Z. The effect of status of zinc, calcium on growth of children aged 3-6 years in Xi' an and analysis of effectiveness of zinc supplement. Journal of Xi'an Medical University 1997;9(1):48-51.

Zeba 2008 \{published data only\}

Zeba AN, Sorgho H, Rouamba N, Zongo I, Rouamba J, Guiguemde RT, et al.Major reduction of malaria morbidity with combined vitamin $\mathrm{A}$ and zinc supplementation in young children in Burkina Faso: a randomized double blind trial. Nutrition Journal 2008;7:7.

Zimmermann 2013 \{published data only\}

Zimmermann MB. Water-based zinc intervention trial in zinc deficient children. http://clinicaltrials.gov/show/ NCT01472211 (accessed 30 January 2013).

\section{References to studies awaiting assessment}

Arabaci 2010 \{published data only (unpublished sought but not used)\} Arabaci FI, Kaya A, Gultekin A, Icagasoglu FD, Mutlu EC. Comparison of efficacies of divalent, trivalent irons and divalent iron plus zinc preparations in paediatric patients with iron deficiency anemia. Turkiye Klinikleri Pediatri 2010;19(3):210-5.

Chicourel 2001 \{published data only (unpublished sought but not used)\}

Chicourel EL. Zinco: Efeito da Suplementaçāo no

Desenvolvimento Físico e Cognitivo de Pré-Escolares. São

Paulo, Brazil: Universidade de São Paulo, 2001.

Jimenez 2000 \{published data only\}

Jimenez R, Sagaro E, Lafita Y. How growth infants supplemented with zinc sulfate after an episode of persistent diarrhea. Journal of Pediatric Gastroenterology and Nutrition 2000;31(Suppl 2):S26 (Abstract 92).

Mitter 2009 \{published data only (unpublished sought but not used)\} Mitter SS, Havt A, Moore SR, Mota RM, Oria RB, Guerrant $\mathrm{RL}$, et al.Zinc supplementation exposes associations between the interleukin $8(-251 \mathrm{~A} / \mathrm{T})$ polymorphism and markers for higher intestinal inflammation in children from Northeast Brazil. American Journal of Tropical Medicine and Hygiene 2009;81(5 Suppl 1):23-4 (Abstract 83).

Smith 1985 \{published data only\}

Smith RM, King RA, Spargo RM, Cheek DB, Field JB, Veitch LG. Growth-retarded Aboriginal children with low plasma zinc levels do not show a growth response to supplementary zinc. Lancet 1985;1(8434):923-4.

\section{References to ongoing studies}

\author{
CTRI/2010/091/001417 \{published data only (unpublished sought \\ but not used)\} \\ CTRI/2010/091/001417. A clinical trial to study the \\ effect of zinc sulfate in reducing the incidence of diarrhea, \\ acute respiratory tract infections and in promoting growth \\ in infants of 6-11 months of age. http://apps.who.int/ \\ trialsearch/Trial.aspx?TrialID=CTRI/2010/091/001417 \\ (accessed 30 January 2013).
}

\section{NCT00133406 \{published data only (unpublished sought but not} used)\}

NCT00133406. Long-term impact and intervention for diarrhea in Brazil. http://apps.who.int/trialsearch/ Trial.aspx?TrialID=NCT00133406 (accessed 30 January 2013).

\section{NCT00228254 \{published data only (unpublished sought but not} used)\}

NCT00228254. Vitamin A and zinc: prevention of pneumonia (VAZPOP) study. http://clinicaltrials.gov/ct2/ show/NCT00228254 (accessed 30 January 2013).

\section{NCT00374023 \{published data only\}}

NCT00374023. A study on immunological effect of vitamin $\mathrm{A}$ and zinc in a placebo controlled 4 cell trial. http://clinicaltrials.gov/show/NCT00374023 (accessed 30 January 2013).

\section{NCT00421668 \{published data only\}}

NCT00421668. A trial of zinc and micronutrients in Tanzanian children. http://clinicaltrials.gov/ct2/show/ NCT00421668 (accessed 30 January 2013).

NCT00589264 \{published data only (unpublished sought but not used)\}

Colombo J, Caulfield LE, Kannass KN, Albornoz C, Lazarte F, Zavaleta N. Six months of zinc supplementation affects measures of attention in Peruvian infants at 12 months of age. FASEB Journal 2011;25(Meeting abstract supplement): 236.2.

* NCT00589264. Zinc and biobehavioral development in early childhood. http://clinicaltrials.gov/ct2/show/ NCT00589264 (accessed 30 January 2013).

Zavaleta N, Respicio G, Colombo J, Kannass KN, Caulfield LE. Changes in iron and zinc status in Peruvian infants consuming an iron syrup with or without zinc from 6 to 18 months of age. FASEB Journal 2011;25(Meeting abstract supplement):236.4

NCT00944359 \{published data only (unpublished sought but not used)\}

NCT00944359. Impact of preventive and therapeutic zinc supplementation programs among young children. http:/ /clinicaltrials.gov/ct2/show/NCT00944359 (accessed 30 January 2013). 


\section{NCT00967551 \{published data only\}}

NCT00967551. Micronutrient sprinkles in a daycare center. http://clinicaltrials.gov/show/NCT00967551

(accessed 30 January 2013).

NCT00980421 \{published data only (unpublished sought but not used)\}

NCT00980421. Safety of various mode of delivery of iron supplement on iron toxicity markers in preschool children. http://clinicaltrials.gov/ct2/show/NCT00980421 (accessed 30 January 2013).

NCT01306097 \{published data only\}

NCT01306097. Zinc supplementation and severe and recurrent diarrhea [http://clinicaltrials.gov/show/ NCT01306097]. (accessed 30 January 2013).

\section{NCT01616693 \{published data only\}}

NCT01616693. Zinc and/or probiotic supplementation of rotavirus and oral polio virus vaccines. http:// clinicaltrials.gov/ct2/show/NCT01616693 (accessed 30 January 2013).

\section{Additional references}

\section{Abba 2010}

Abba K, Gulani A, Sachdev HS. Zinc supplements for preventing otitis media. Cochrane Database of Systematic Reviews 2010, Issue 2. [DOI: 10.1002/ 14651858.CD006639.pub2]

\section{Aggarwal 2007}

Aggarwal R, Sentz J, Miller MA. Role of zinc administration in prevention of childhood diarrhea and respiratory illnesses: a meta-analysis. Pediatrics 2007;119(6):1120-30.

\section{Allen 1998}

Allen LH. Zinc and micronutrient supplements for children. American Journal of Clinical Nutrition 1998;68(2):495-8S.

\section{Altman 2001}

Altman DG, Schulz KF, Moher D, Egger M, Davidoff F, Elbourne D, et al.The revised CONSORT statement for reporting randomized trials: explanation and elaboration. Annals of Internal Medicine 2001;134(8):663-94.

Awasthi 2013

Awasthi S, Peto R, Read S, Clark S, Pande V, Bundy D. Vitamin A supplementation every 6 months with retinol in 1 million pre-school children in north India: DEVTA, a cluster-randomised trial. Lancet 2013;381(9876):1469-77.

\section{Balshem 2011}

Balshem H, Helfand M, Schünemann HJ, Oxman AD, Kunz R, Brozek J, et al.GRADE guidelines: 3. Rating the quality of evidence. Journal of Clinical Epidemiology 2011; 64(4):401-6.

Behrman 2004

Behrman JR, Alderman H, Hoddinott J. Malnutrition and hunger. In: Lomborg B editor(s). Global Crises, Global Solutions. Cambridge, UK: Cambridge University Press, 2004:363-420.

\section{Bhutta 1999}

Bhutta ZA, Black RE, Brown KH, Gardner JM, Gore S, Hidayat A, et al.Prevention of diarrhea and pneumonia by zinc supplementation in children in developing countries: pooled analysis of randomized controlled trials. Journal of Pediatrics 1999;135(6):689-97.

\section{Black 2008}

Black RE, Allen LH, Bhutta ZA, Caulfield LE, De Onis M, Ezzati M, et al.Maternal and child undernutrition: global and regional exposures and health consequences. Lancet 2008;371(9608):243-60.

Black 2010

Black RE, Cousens S, Johnson HL, Lawn JE, Rudan I, Bassani DG, et al.Global, regional, and national causes of child mortality in 2008: a systematic analysis. Lancet 2010; 375(9730):1969-87.

Black 2013

Black RE, Victora CG, Walker SP, Bhutta ZA, Christian P, De Onis $\mathrm{M}$, et al.Maternal and child undernutrition and overweight in low-income and middle-income countries. Lancet 2013;6736(13):427-51.

\section{Borenstein 2005}

Borenstein M, Hedges L, Higgins J, Rothstein H. Comprehensive Meta-analysis Version 2. Englewood, NJ: Biostat, 2005.

Boy 2009

Boy E, Mannar V, Pandav C, De Benoist B, Viteri F, Fontaine $\mathrm{O}$, et al.Achievements, challenges, and promising new approaches in vitamin and mineral deficiency control. Nutrition Reviews 2009;67(Suppl 1):S24-30.

Brown 2002

Brown KH, Peerson JM, Rivera J, Allen LH. Effect of supplemental zinc on the growth and serum zinc concentrations of prepubertal children: a meta-analysis of randomized controlled trials. American Journal of Clinical Nutrition 2002;75(6):1062-71.

\section{Brown 2009}

Brown KH, Peerson JM, Baker SK, Hess SY. Preventive zinc supplementation among infants, preschoolers, and older prepubertal children. Food and Nutrition Bulletin 2009;30 (1):S12-40.

Bryce 2005

Bryce J, Boschi-Pinto C, Shibuya K, Black RE, WHO Child Health Epidemiology Reference Group. WHO estimates of the causes of death in children. Lancet 2005;365(9465): $1147-52$.

Caulfield 2004

Caulfield LE, Black RE. Zinc deficiency. In: Ezzati M, Lopez AD, Rodgers A, Murray CJL editor(s). Comparative Quantification of Health Risks: Global and Regional Burden of Disease Attributable to Selected Major Risk Factors. Vol. 1, Geneva: World Health Organization, 2004:257-80.

\section{Cousins 1994}

Cousins RJ. Metal elements and gene expression. Annual Review of Nutrition 1994;14(1):449-69. 
De-Regil 2011

De-Regil LM, Suchdev PS, Vist GE, Walleser S, Peña-Rosas JP. Home fortification of foods with multiple micronutrient powders for health and nutrition in children under two years of age. Cochrane Database of Systematic Reviews 2011, Issue 9. [DOI: 10.1002/14651858.CD008959.pub2]

\section{Dekker 2010}

Dekker LH, Villamor E. Zinc supplementation in children is not associated with decreases in hemoglobin concentrations. Journal of Nutrition 2010;140(5):1035-40.

\section{Devereaux 2004}

Devereaux PJ, Choi Peter TL, El-Dika S, Bhandari M, Montori VM, Schünemann HJ, et al.An observational study found that authors of randomized controlled trials frequently use concealment of randomization and blinding, despite the failure to report these methods. Journal of Clinical Epidemiology 2004;57(12):1232-6.

Engle-Stone 2007

Engle-Stone R, Hess SY. IZiNCG Technical Brief

No. 1: Quantifying the risk of zinc deficiency: recommended indicators. www.izincg.org/publications/ files/English 'brief1.pdf (accessed 27 January 2011).

Fagundes-Neto 1984

Fagundes-Neto U, Viaro T, Wehba J, Reis da Silva Patricio F, Machado NL. Tropical enteropathy (environmental enteropathy) in early childhood: a syndrome caused by contaminated environment. Journal of Tropical Pediatrics 1984;30(4):204-9.

Fischer Walker 2004

Fischer Walker CL, Black RE. Zinc and the risk for infectious disease. Annual Review of Nutrition 2004;24: $255-75$.

Fischer Walker 2008

Fischer Walker CL, Ezzati M, Black RE. Global and regional child mortality and burden of disease attributable to zinc deficiency. European Journal of Clinical Nutrition 2008;63 (5):591-7.

\section{Fisher 1975}

Fisher GL. Function and homeostasis of copper and zinc in mammals. Science of the Total Environment 1975;4(4): 373-412.

Fosmire 1990

Fosmire GJ. Zinc toxicity. American Journal of Clinical Nutrition 1990;51(2):225-7.

Gibson 2006

Gibson RS. Zinc: the missing link in combating micronutrient malnutrition in developing countries. Proceedings of the Nutrition Society 2006;65(1):51-60.

\section{Gogia 2012}

Gogia S, Sachdev HS. Zinc supplementation for mental and motor development in children. Cochrane Database of Systematic Reviews 2012, Issue 12. [DOI: 10.1002/ 14651858.CD007991]

\section{Guyatt 2008}

Guyatt GH, Wyer P, Ioannidis J. When to believe a subgroup analysis. In: Guyatt GH, Rennie D, Meade
MO, Cook DJ editor(s). The Users' Guides to the Medical Literature: A Manual for Evidence-Based Clinical Practice. 2nd Edition. New York, NY: McGraw-Hill, 2008:571-96.

\section{Guyatt 2011a}

Guyatt GH, Oxman AD, Kunz R, Woodcock J, Brozek J, Helfand M, et al.GRADE guidelines: 7. Rating the quality of evidence-inconsistency. Journal of Clinical Epidemiology 2011;64(12):1294-302.

Guyatt 2011b

Guyatt GH, Oxman AD, Vist G, Kunz R, Brozek J, AlonsoCoello P, et al.GRADE guidelines: 4. Rating the quality of evidence - study limitations (risk of bias). Journal of Clinical Epidemiology 2011;64(4):407-15.

\section{Haider 2009}

Haider BA, Bhutta ZA. The effect of therapeutic zinc supplementation among young children with selected infections: a review of the evidence. Food and Nutrition Bulletin 2009;30(1):S41-59.

\section{Haider 2011}

Haider BA, Lassi ZS, Ahmed A, Bhutta ZA. Zinc supplementation as an adjunct to antibiotics in the treatment of pneumonia in children 2 to 59 months of age. Cochrane Database of Systematic Reviews 2011, Issue 10. [DOI: 10.1002/14651858.CD007368.pub2]

\section{Hambidge 2007} Hambidge KM, Krebs NF. Zinc deficiency: a special challenge. Journal of Nutrition 2007;137(4):1101-5.

\section{Hess 2009a}

Hess SY, Brown KH. Impact of zinc fortification on zinc nutrition. Food and Nutrition Bulletin 2009;30(1):S79-107.

Hess 2009b

Hess SY, Lönnerdal B, Hotz C, Rivera JA, Brown KH. Recent advances in knowledge of zinc nutrition and human health. Food and Nutrition Bulletin 2009;30(1):S5-11.

\section{Higgins 2011}

Higgins JPT, Green S (editors). Cochrane Handbook for Systematic Reviews of Interventions Version 5.1.0 [updated March 2011]. The Cochrane Collaboration, 2011. Available from www.cochrane-handbook.org.

\section{Horton 2009}

Horton S, Begin F, Greig A, Lakshman A. Micronutrient supplements for child survival (vitamin A and zinc). http: //copenhagenconsensus.com/publication/micronutrientsupplements-child-survival 2009.

\section{Hotz 2004}

Hotz C, Brown KH, International Zinc Nutrition Consultative Group (IZiNCG). Assessment of the risk of zinc deficiency in populations and options for its control. Food and Nutrition Bulletin 2004;25(1 Suppl 2):S94-203.

\section{Humphreys 2010}

Humphreys EH, Smith NM, Azman H, McLeod D, Rutherford GW. Prevention of diarrhoea in children with HIV infection or exposure to maternal HIV infection. Cochrane Database of Systematic Reviews 2010, Issue 6. [DOI: 10.1002/14651858.CD008563] 


\section{Imdad 2010}

Imdad A, Herzer K, Mayo-Wilson E, Yakoob MY, Bhutta ZA. Vitamin A supplementation for preventing morbidity and mortality in children from 6 months to 5 years of age. Cochrane Database of Systematic Reviews 2010, Issue 12. [DOI: 10.1002/14651858.CD008524.pub2]

\section{Imdad 2011}

Imdad A, Bhutta ZA. Effect of preventive zinc supplementation on linear growth in children under 5 years of age in developing countries: a meta-analysis of studies for input to the lives saved tool. BMC Public Health 2011;11 (Suppl 3):S22.

\section{Institute of Medicine 2001}

Institute of Medicine. Dietary Reference Intakes for Vitamin A, Vitamin K, Arsenic, Boron, Chromium, Copper, Iodine, Iron, Manganese, Molybdenum, Nickel, Silicon, Vanadium, and Zinc. Washington, DC: National Academy Press, 2001.

Irlam 2010

Irlam JH, Visser MME, Rollins NN, Siegfried N. Micronutrient supplementation in children and adults with HIV infection. Cochrane Database of Systematic Reviews 2010, Issue 12. [DOI: 10.1002/ 14651858.CD003650.pub3]

\section{Larson 2008}

Larson CP, Roy SK, Khan AI, Rahman AS, Qadri F. Zinc treatment to under-five children: applications to improve child survival and reduce burden of disease. Journal of Health, Population and Nutrition 2008;26(3):356-65.

\section{Lassi 2010}

Lassi ZS, Haider BA, Bhutta ZA. Zinc supplementation for the prevention of pneumonia in children aged 2 months to 59 months. Cochrane Database of Systematic Reviews 2010, Issue 12. [DOI: 10.1002/14651858.CD005978.pub2]

\section{Lazzerini 2008}

Lazzerini M, Ronfani L. Oral zinc for treating diarrhoea in children. Cochrane Database of Systematic Reviews 2008, Issue 3. [DOI: 10.1002/14651858.CD005436.pub2]

\section{MacDonald 2000}

MacDonald RS. The role of zinc in growth and cell proliferation. Journal of Nutrition 2000;130(5):S1500-8.

Maggini 2010

Maggini S, Wenzlaff S, Hornig D. Essential role of vitamin $\mathrm{C}$ and zinc in child immunity and health. Journal of International Medical Research 2010;38(2):386-414.

\section{Mahomed 2007}

Mahomed K, Bhutta ZA, Middleton P. Zinc supplementation for improving pregnancy and infant outcome. Cochrane Database of Systematic Reviews 2007 Issue 2. [DOI: 10.1002/14651858.CD000230.pub3]

\section{Maret 2006}

Maret W, Sandstead HH. Zinc requirements and the risks and benefits of zinc supplementation. Journal of Trace Elements in Medicine and Biology 2006;20:3-18.

\section{Mayo-Wilson 2011}

Mayo-Wilson E, Imdad A, Herzer K, Yakoob MY, Bhutta ZA. Vitamin A supplements for preventing mortality, illness and blindness in children under 5: a systematic review and meta-analysis. BMJ 2011;343:d5094.

\section{McKay 2010}

McKay S, Gaudier E, Campbell DI, Prentice AM, Albers R. Environmental enteropathy: new targets for nutritional interventions. International Health 2010;2(3):172-80.

Patel 2011

Patel A, Mamtani M, Badhoniya N, Kulkarni H. What zinc supplementation does and does not achieve in diarrhea prevention: a systematic review and meta-analysis. $B M C$ Infectious Diseases 2011;11:122.

Prasad 1963

Prasad AS, Miale A, Farid Z, Sandstead HH, Schulert AR, Darby WJ. Biochemical studies on dwarfism, hypogonadism, and anemia. Archives of Internal Medicine 1963;111(4):407-28.

Prasad 2009

Prasad AS. Impact of the discovery of human zinc deficiency on health. Journal of the American College of Nutrition 2009; 28(3):257-65.

\section{Ramakrishnan 2009}

Ramakrishnan U, Nguyen P, Martorell R. Effects of micronutrients on growth of children under $5 \mathrm{y}$ of age: meta-analyses of single and multiple nutrient interventions. American Journal of Clinical Nutrition 2009;89(1):191-203.

\section{Review Manager 2013}

The Nordic Cochrane Centre, The Cochrane Collaboration. Review Manager (RevMan). 5.2. Copenhagen: The Nordic Cochrane Centre, The Cochrane Collaboration, 2013.

\section{Roth 2010}

Roth DE, Richard SA, Black RE. Zinc supplementation for the prevention of acute lower respiratory infection in children in developing countries: meta-analysis and metaregression of randomized trials. International Journal of Epidemiology 2010;39(3):795-808.

Salazar-Lindo 2004

Salazar-Lindo E, Allen S, Brewster DR, Elliott EJ, Fasano A, Phillips $\mathrm{AD}$, et al.Intestinal infections and environmental enteropathy: working group report of the Second World Congress of Pediatric Gastroenterology, Hepatology, and Nutrition. Journal of Pediatric Gastroenterology and Nutrition 2004;39(2):S662-9.

\section{Salgueiro 2002}

Salgueiro MJ, Zubillaga MB, Lysionek AE, Caro RA, Weill R, Boccio JR. The role of zinc in the growth and development of children. Nutrition 2002;18(6):510-9.

\section{Sandstead 1991}

Sandstead HH. Zinc deficiency: a public health problem?. Archives of Pediatrics \& Adolescent Medicine 1991;145(8): 853-9. 


\section{Sandstrom 1985}

Sandstrom B, Davidsson L, Cederblad A, Lonnerdal B. Oral iron, dietary ligands and zinc absorption. Journal of Nutrition 1985;115(3):411-4

Sandstrom 2001

Sandstrom B. Micronutrient interactions: effects on absorption and bioavailability. British Journal of Nutrition 2001;85(Suppl 2):S181-5.

Shankar 1998

Shankar AH, Prasad AS. Zinc and immune function: the biological basis of altered resistance to infection. American Journal of Clinical Nutrition 1998;68(2):S447-63.

Shrimpton 2005

Shrimpton R, Gross R, Darnton-Hill I, Young M. Zinc deficiency: what are the most appropriate interventions?. BMJ 2005;330(7487):347-9.

Singh 2011

Singh M, Das RR. Zinc for the common cold. Cochrane Database of Systematic Reviews 2011, Issue 2. [DOI: 10.1002/14651858.CD001364.pub3]

Stefanidou 2006

Stefanidou M, Maravelias C, Dona A, Spiliopoulou C. Zinc: a multipurpose trace element. Archives of Toxicology 2006;80(1):1-9.

Tuerk 2009

Tuerk MJ, Fazel N. Zinc deficiency. Current Opinion in Gastroenterology 2009;25(2):136-43.

Wazny 2013

Wazny K, Zipursky A, Black R, Curtis V, Duggan C, Guerrant $\mathrm{R}$, et al.Setting research priorities to reduce mortality and morbidity of childhood diarrhoeal disease in the next 15 years. PLOS Medicine 2013;10(5):e1001446.

Wessells 2012a

Wessells KR, Brown KH. Estimating the global prevalence of zinc deficiency: results based on zinc availability in national food supplies and the prevalence of stunting. PloS One 2012;7:e50568.

\section{WHO 2000}

World Health Organization. Management of the Child with a Serious Infection or Severe Malnutrition: Guidelines for Care at the First-Referral Level in Developing Countries. Geneva: WHO, 2000.

\section{WHO 2009}

World Health Organization. Global Health Risks: Mortality and Burden of Disease Attributable to Selected Major Risks.

Geneva: WHO, 2009.

\section{WHO/FAO 2004}

World Health Organization, Food, Agricultural

Organization of the United Nations. Vitamin and Mineral

Requirements in Human Nutrition. Geneva: WHO, 2004.

\section{WHO/UNICEF 2004}

World Health Organization/UNICEF. Clinical Management of Acute Diarrhoea. Geneva and New York: WHO/ UNICEF, 2004.

\section{WHO/UNICEF 2005}

World Health Organization/UNICEF. Handbook: Integrated Management of Childhood Illness. Geneva and New York: WHO/UNICEF, 2005.

Williams 1970

Williams BB, Mills CF. The experimental production of zinc deficiency in the rat. British Journal of Nutrition 1970; 24(4):989-1003.

\section{World Bank 2011}

World Bank. Country and Lending Groups. http:// data.worldbank.org/about/country-classifications/countryand-lending-groups (accessed 29 May 2011).

\section{Yakoob 2011}

Yakoob MY, Theodoratou E, Jabeen A, Imdad A, Eisele TP, Ferguson J, et al.Preventive zinc supplementation in developing countries: impact on mortality and morbidity due to diarrhea, pneumonia and malaria. BMC Public Health 2011;11(Suppl 3):S23.

* Indicates the major publication for the study 


\section{CHARACTERISTICS OF STUDIES}

\section{Characteristics of included studies [ordered by study ID]}

\begin{tabular}{ll} 
Ahmed 2009a & \\
\hline Methods & CRCT?: IRCT; Cross-over?: non-cross-over \\
\hline Participants & $\begin{array}{l}\text { Country: Bangladesh; Setting: Mirpur, a slum area in Dhaka; Urbanicity: urban } \\
\text { Inclusion criteria: healthy } \\
\text { Exclusion criteria: history of gastrointestinal disorder; suffered from any diarrhoeal dis- } \\
\text { ease in the past } 2 \text { weeks; febrile illness in the preceding week; received antibiotic treat- } \\
\text { ment at least } 7 \text { days prior to enrolment; } \leq 2 \text { SD (weight/length as NCHS); stool that } \\
\text { was positive for common enteric pathogens } \\
\text { Baseline characteristics } \\
\text { Avg age (mo): } 14 ; \text { Min age (mo): } 10 ; \text { Max age (mo): } 18 ; \% \text { Female: } 53 \\
\text { Avg HAZ: N/A; Stunting: unclear; Avg height (cm): } 74.3 ; \text { Avg zinc concentration }(\mu \mathrm{g} / \\
\text { dL): } 73 \\
\text { Total N: 40; Group } 1 \mathrm{~N}: 20 ; \text { Group } 2 \mathrm{~N}: 20\end{array}$ \\
\hline
\end{tabular}

Interventions

Group 1: zinc

Formulation: solution; Compound: acetate; Frequency: daily; Duration (mo): 1.5; Dose (mg): 20; Co-intervention(s): oral inactivated cholera vaccine

Group 2: no zinc

Placebo not given; Co-intervention(s): oral inactivated cholera vaccine

Outcomes No outcomes of interest reported in a way that can be meta-analysed

Notes

- In addition to the study groups mentioned in this table, there was a group of participants who received zinc only; but there was no placebo group to which this zinc group could be compared in this review. So, baseline characteristics reported in this table are weighted averages of all groups except this zinc group, since this group is not included in any metaanalyses in this review

- The trial authors might have meant to report " $\leq-2$ SD (weight/length as NCHS)" rather than " $\leq 2 \mathrm{SD}$ (weight/length as NCHS)" as part of this study's exclusion criteria

\section{Risk of bias}

\begin{tabular}{|c|c|c|}
\hline Bias & Authors' judgement & Support for judgement \\
\hline $\begin{array}{l}\text { Random sequence generation (selection } \\
\text { bias) }\end{array}$ & Unclear risk & $\begin{array}{l}\text { Quote: "The children were randomly as- } \\
\text { signed..." } \\
\text { Comment: insufficient details available to } \\
\text { make a judgement as to whether or not an } \\
\text { allocation sequence was generated using a } \\
\text { truly random method }\end{array}$ \\
\hline Allocation concealment (selection bias) & Unclear risk & $\begin{array}{l}\text { Quote: N/A } \\
\text { Comment: insufficient details available to } \\
\text { make a judgement }\end{array}$ \\
\hline
\end{tabular}

Zinc supplementation for preventing mortality, morbidity, and growth failure in children aged 6 months to 12 years of age (Review) 
Ahmed 2009a (Continued)

\begin{tabular}{|c|c|c|}
\hline $\begin{array}{l}\text { Blinding of participants (performance } \\
\text { bias) } \\
\text { All outcomes }\end{array}$ & Unclear risk & $\begin{array}{l}\text { Quote: “...no zinc placebo was adminis- } \\
\text { tered...” } \\
\text { Comment: given that no placebo was pro- } \\
\text { vided, it seems likely that people involved } \\
\text { with the study were aware of which study } \\
\text { group participants were in. It is unclear how } \\
\text { measured outcomes might be influenced by } \\
\text { this lack of blinding }\end{array}$ \\
\hline $\begin{array}{l}\text { Blinding of personnel (performance bias) } \\
\text { All outcomes }\end{array}$ & Unclear risk & $\begin{array}{l}\text { Quote: "...no zinc placebo was adminis- } \\
\text { tered..." } \\
\text { Comment: given that no placebo was pro- } \\
\text { vided, it seems likely that people involved } \\
\text { with the study were aware of which study } \\
\text { group participants were in. It is unclear how } \\
\text { measured outcomes might be influenced by } \\
\text { this lack of blinding }\end{array}$ \\
\hline $\begin{array}{l}\text { Blinding of outcome assessment (detection } \\
\text { bias) } \\
\text { All outcomes }\end{array}$ & Unclear risk & $\begin{array}{l}\text { Quote: “...no zinc placebo was adminis- } \\
\text { tered...” } \\
\text { Comment: given that no placebo was pro- } \\
\text { vided, it seems likely that people involved } \\
\text { with the study were aware of which study } \\
\text { group participants were in. It is unclear how } \\
\text { measured outcomes might be influenced by } \\
\text { this lack of blinding }\end{array}$ \\
\hline $\begin{array}{l}\text { Incomplete outcome data (attrition bias) } \\
\text { All outcomes }\end{array}$ & Low risk & $\begin{array}{l}\text { \% Missing: } 5 \\
\text { Reasons/details: N/A } \\
\text { Comment: } 5 \% \text { of the randomised partici- } \\
\text { pants eligible for our review had data miss- } \\
\text { ing; this } 5 \% \text { missing figure includes all } \\
\text { groups except the zinc group, since this } \\
\text { group is not included in any meta-analy- } \\
\text { ses in this review. } 2 \text { children, both in the } \\
\text { vaccine + zinc group, did not complete } \\
\text { the study. Reasons for missing data were } \\
\text { not given. However, the amount of missing } \\
\text { data seems too minimal to impact results }\end{array}$ \\
\hline Selective reporting (reporting bias) & Unclear risk & $\begin{array}{l}\text { Comment: no trial protocol referenced by } \\
\text { the study }\end{array}$ \\
\hline Other bias & Low risk & Comment: appears to be free of other bias \\
\hline
\end{tabular}

Zinc supplementation for preventing mortality, morbidity, and growth failure in children aged 6 months to 12 years of age (Review) 


\begin{tabular}{|c|c|}
\hline Methods & CRCT?: IRCT; Cross-over?: non-cross-over \\
\hline Participants & $\begin{array}{l}\text { Country: Bangladesh; Setting: N/A; Urbanicity: peri-urban } \\
\text { Inclusion criteria: undernourished } \\
\text { Exclusion criteria: N/A } \\
\text { Baseline characteristics } \\
\text { Avg age (mo): 34.8; Min age (mo): N/A; Max age (mo): N/A; \% Female: N/A } \\
\text { Avg HAZ: N/A; Stunting: both - separate data not given; Avg height }(\mathrm{cm}): \text { N/A; Avg } \\
\text { zinc concentration ( } \mu \mathrm{g} / \mathrm{dL}) \text { : N/A } \\
\text { Total N: } 256 \text {; Group } 1 \mathrm{~N} \text { : N/A; Group } 2 \mathrm{~N} \text { : N/A }\end{array}$ \\
\hline Interventions & $\begin{array}{l}\text { Group 1: zinc } \\
\text { Formulation: solution; Compound: acetate; Frequency: daily; Duration (mo): 15; Dose } \\
\text { (mg): 20; Co-intervention(s): Vitamins A, D, and C } \\
\text { Group 2: no zinc } \\
\text { Placebo given; Co-intervention(s): Vitamins A, D, and C }\end{array}$ \\
\hline Outcomes & $\begin{array}{l}\text { Height, weight } \\
\text { Time point (wk): } 60\end{array}$ \\
\hline Notes & $\begin{array}{l}\text { Though "both baseline and final measurements of weight and height were available in } \\
197 \text { ( } 93 \text { and } 104 \text { in zinc and placebo groups respectively) children", the numbers of } \\
\text { children initially randomised to each group is not reported }\end{array}$ \\
\hline
\end{tabular}

\section{Risk of bias}

\begin{tabular}{lll} 
Bias & Authors' judgement & Support for judgement \\
\hline $\begin{array}{l}\text { Random sequence generation (selection } \\
\text { bias) }\end{array}$ & Unclear risk & $\begin{array}{l}\text { Quote: “...randomized clinical trial...” } \\
\text { Comment: insufficient details available to } \\
\text { make a judgement as to whether or not an } \\
\text { allocation sequence was generated using a } \\
\text { truly random method }\end{array}$ \\
\hline $\begin{array}{l}\text { Allocation concealment (selection bias) } \\
\begin{array}{l}\text { Blinding of participants (performance } \\
\text { bias) } \\
\text { All outcomes }\end{array}\end{array}$ & Unclear risk & $\begin{array}{l}\text { Quote: N/A } \\
\text { Comment: insufficient details available to } \\
\text { make a judgement }\end{array}$ \\
\hline $\begin{array}{l}\text { Blinding of personnel (performance bias) } \\
\text { All outcomes }\end{array}$ & Unclear risk & $\begin{array}{l}\text { Quote: “...double blind...clinical trial...” } \\
\text { Comment: insufficient details available to } \\
\text { make a judgement }\end{array}$ \\
\hline $\begin{array}{l}\text { Blinding of outcome assessment (detection } \\
\text { bias) } \\
\text { All outcomes }\end{array}$ & Unclear risk & $\begin{array}{l}\text { Quote: “...double blind...clinical trial...” } \\
\text { Comment: insufficient details available to } \\
\text { make a judgement }\end{array}$ \\
\hline
\end{tabular}

Zinc supplementation for preventing mortality, morbidity, and growth failure in children aged 6 months to 12 years of age (Review)

Copyright @ 2014 The Cochrane Collaboration. Published by John Wiley \& Sons, Ltd. 


\section{Akramuzzaman 1994 (Continued)}

\begin{tabular}{|c|c|c|}
\hline $\begin{array}{l}\text { Incomplete outcome data (attrition bias) } \\
\text { All outcomes }\end{array}$ & Unclear risk & $\begin{array}{l}\text { \% Missing: N/A } \\
\text { Reasons/details: N/A } \\
\text { Comment: "Of } 256 \text { children, both base- } \\
\text { line and final measurements of weight and } \\
\text { height were available in } 197 \text { ( } 93 \text { and } 104 \text { in } \\
\text { zinc and placebo groups respectively) chil- } \\
\text { dren." So, no more than } 59 \text { participants } \\
\text { ( } 23 \% \text { of the original } 256 \text { randomised) were } \\
\text { missing. However, the number randomised } \\
\text { to each study group was not reported; nor } \\
\text { was the exact number of participants miss- } \\
\text { ing in the zinc group, the exact number of } \\
\text { participants missing in the placebo group, } \\
\text { or reasons for missing data }\end{array}$ \\
\hline Selective reporting (reporting bias) & Unclear risk & $\begin{array}{l}\text { Comment: no trial protocol referenced by } \\
\text { the study }\end{array}$ \\
\hline Other bias & Low risk & Comment: appears to be free of other bias \\
\hline
\end{tabular}

\section{Alarcon 2004}

Methods CRCT?: IRCT; Cross-over?: non-cross-over

Participants

Country: Peru; Setting: Collique, a shanty town of Lima, Peru; Urbanicity: peri-urban Inclusion criteria: moderately anaemic (haemoglobin concentration between 70 and 99. $9 \mathrm{~g} / \mathrm{L}$ )

Exclusion criteria: severe anaemia (haemoglobin $<70.0 \mathrm{~g} / \mathrm{L}$ ); mild anaemia (haemoglobin 100.0 to $109.9 \mathrm{~g} / \mathrm{L}$ ); chronic disease; any dietary restrictions; received treatment with one of the micronutrients in the study in the previous 6 mo; measles; received a measles vaccine in the preceding $2 \mathrm{mo}$; severe malnutrition (defined as weight-for-height $<-3$ SDs, height-for-age < -3 SDs, or both)

Baseline characteristics

Avg age (mo): 17.4; Min age (mo): 6; Max age (mo): 35; \% Female: N/A

Avg HAZ: -1.04; Stunting: unclear; Avg height (cm): 76.8; Avg zinc concentration $(\mu \mathrm{g} /$ dL): N/A

Total N: 223; Group 1 N: 112; Group 2 N: 111

Interventions

Outcomes
Group 1: zinc

Formulation: solution; Compound: sulfate; Frequency: 6 days/wk; Duration (mo): 4.5; Dose (mg): $3 \mathrm{mg} / \mathrm{kg}$; Co-intervention(s): $3 \mathrm{mg} / \mathrm{kg}$ iron

Group 2: no zinc

Placebo given; Co-intervention(s): $3 \mathrm{mg} / \mathrm{kg}$ iron

Incidence of all-cause diarrhoea, prevalence of all-cause diarrhoea, height, weight, weightto-height ratio, study withdrawal, participants with $\geq 1$ side effect, blood haemoglobin concentration, prevalence of anaemia, serum or plasma ferritin concentration, prevalence of iron deficiency 
In addition to the study groups mentioned in this table, there was a group of 112 participants who received zinc, iron, and vitamin A. Baseline characteristics reported in this table are weighted averages of all groups except the group that received zinc, iron, and vitamin A, since this group is not included in any meta-analyses in this review

Risk of bias

\begin{tabular}{|c|c|c|}
\hline Bias & Authors' judgement & Support for judgement \\
\hline $\begin{array}{l}\text { Random sequence generation (selection } \\
\text { bias) }\end{array}$ & Unclear risk & $\begin{array}{l}\text { Quote: "The children were... allocated by } \\
\text { block randomization..." } \\
\text { Comment: insufficient details available to } \\
\text { make a judgement as to whether or not an } \\
\text { allocation sequence was generated using a } \\
\text { truly random method }\end{array}$ \\
\hline Allocation concealment (selection bias) & Unclear risk & $\begin{array}{l}\text { Quote: N/A } \\
\text { Comment: insufficient details available to } \\
\text { make a judgement }\end{array}$ \\
\hline $\begin{array}{l}\text { Blinding of participants (performance } \\
\text { bias) } \\
\text { All outcomes }\end{array}$ & Low risk & $\begin{array}{l}\text { Quote: "This was a...dou- } \\
\text { ble-blind trial...Supplements, prepared as } \\
\text { syrup, were individually bottled and coded } \\
\text { according to treatment group. The code } \\
\text { was known only to the pharmacist and was } \\
\text { not broken until the data analyses were } \\
\text { completed. The placebos were tested be- } \\
\text { fore the study started, and no visual or } \\
\text { organoleptic differences in the preparations } \\
\text { could be detected." } \\
\text { Comment: sufficient blinding seems likely }\end{array}$ \\
\hline $\begin{array}{l}\text { Blinding of personnel (performance bias) } \\
\text { All outcomes }\end{array}$ & Low risk & $\begin{array}{l}\text { Quote: "This was a...dou- } \\
\text { ble-blind trial...Supplements, prepared as } \\
\text { syrup, were individually bottled and coded } \\
\text { according to treatment group. The code } \\
\text { was known only to the pharmacist and was } \\
\text { not broken until the data analyses were } \\
\text { completed. The placebos were tested be- } \\
\text { fore the study started, and no visual or } \\
\text { organoleptic differences in the preparations } \\
\text { could be detected." } \\
\text { Comment: sufficient blinding seems likely }\end{array}$ \\
\hline $\begin{array}{l}\text { Blinding of outcome assessment (detection } \\
\text { bias) } \\
\text { All outcomes }\end{array}$ & Low risk & $\begin{array}{l}\text { Quote: "This was a...dou- } \\
\text { ble-blind trial...Supplements, prepared as } \\
\text { syrup, were individually bottled and coded }\end{array}$ \\
\hline
\end{tabular}




\begin{tabular}{|c|c|c|}
\hline & & $\begin{array}{l}\text { according to treatment group. The code } \\
\text { was known only to the pharmacist and was } \\
\text { not broken until the data analyses were } \\
\text { completed. The placebos were tested be- } \\
\text { fore the study started, and no visual or } \\
\text { organoleptic differences in the preparations } \\
\text { could be detected." } \\
\text { Comment: sufficient blinding seems likely }\end{array}$ \\
\hline $\begin{array}{l}\text { Incomplete outcome data (attrition bias) } \\
\text { All outcomes }\end{array}$ & Low risk & $\begin{array}{l}\text { \% Missing: } 4 \\
\text { Reasons/details: in the zinc + iron group: } \\
2 \text { "moved", and } 1 \text { withdrew because their } \\
\text { mothers "believed after } 5-7 \text { wk of treatment } \\
\text { that their children were 'healthy' and re- } \\
\text { fused further treatment." In the iron group: } \\
2 \text { "moved", } 2 \text { withdrew because their moth- } \\
\text { ers "believed after } 5-7 \text { wk of treatment that } \\
\text { their children were 'healthy' and refused } \\
\text { further treatment", } 1 \text { was "absent at last } \\
\text { sampling", and } 2 \text { "stopped treatment for } \\
\text { perceived side effects (constipation, stom- } \\
\text { achaches, and staining of the teeth)." } \\
\text { Comment: } 4 \% \text { of the randomised partici- } \\
\text { pants eligible for our review had data miss- } \\
\text { ing; this } 4 \% \text { missing figure includes all } \\
\text { groups except the group that received zinc, } \\
\text { iron, and vitamin A, since this group is not } \\
\text { included in any meta-analyses in this re- } \\
\text { view. Missing data seem too minimal to im- } \\
\text { pact results }\end{array}$ \\
\hline Selective reporting (reporting bias) & Unclear risk & $\begin{array}{l}\text { Comment: no trial protocol referenced by } \\
\text { the study }\end{array}$ \\
\hline Other bias & Low risk & Comment: appears to be free of other bias \\
\hline
\end{tabular}

Albert 2003

Methods CRCT?: IRCT; Cross-over?: non-cross-over

Participants

Country: Bangladesh; Setting: Dhaka; Urbanicity: urban

Inclusion criteria: vitamin A deficiency (serum retinol level $<20 \mu \mathrm{g} / \mathrm{dL}$; determined by testing of a blood sample obtained for pre-enrolment screening); nutritional status corresponding to a weight-for-age score that was $\geq 61 \%$ of the median National Center for Health Standards standard

Exclusion criteria: received vitamin A supplementation during the preceding 6 months; history of night blindness or sickness due to underlying illnesses such as diarrhoea, respiratory tract infections, or other infections 
Albert 2003 (Continued)

\begin{tabular}{|c|c|}
\hline & $\begin{array}{l}\text { Baseline characteristics } \\
\text { Avg age (mo): N/A; Min age (mo): 24; Max age (mo): 60; \% Female: N/A } \\
\text { Avg HAZ: N/A; Stunting: unclear; Avg height }(\mathrm{cm}): \text { N/A; Avg zinc concentration }(\mu \mathrm{g} / \\
\text { dL): } 62 \\
\text { Total N: } 256 \text {; Group } 1 \text { N: N/A; Group } 2 \text { N: N/A; Group } 3 \text { N: N/A; Group } 4 \text { N: N/A }\end{array}$ \\
\hline Interventions & $\begin{array}{l}\text { Group 1: zinc } \\
\text { Formulation: solution; Compound: acetate; Frequency: daily; Duration (mo): 1.5; Dose } \\
\text { (mg): 20; Co-intervention(s): killed oral cholera vaccine } \\
\text { Group 2: no zinc } \\
\text { Placebo given; Co-intervention(s): killed oral cholera vaccine } \\
\text { Group 3: zinc } \\
\text { Co-intervention(s): killed oral cholera vaccine; 200,000 IU vitamin A syrup } 2 \text { weeks } \\
\text { after the start of zinc supplementation } \\
\text { Group 4: no zinc } \\
\text { Placebo given; Co-intervention(s): killed oral cholera vaccine; } 200,000 \text { IU vitamin A } \\
\text { syrup } 2 \text { weeks after the start of zinc supplementation }\end{array}$ \\
\hline Outcomes & $\begin{array}{l}\text { Prevalence of zinc deficiency } \\
\text { Time point (wk): } 6\end{array}$ \\
\hline Notes & $\begin{array}{l}\text { - At the end of the study, } 61,63,62 \text {, and } 63 \text { children remained in the vitamin } \mathrm{A} \text {, zinc, } \\
\text { vitamin } \mathrm{A}+\text { zinc, and placebo groups, respectively; however, the number of children } \\
\text { randomised to each study group is not reported } \\
\text { - Though the percentage of trial participants who were female is approximately } 44 \% \text {, } \\
\text { the reported ratio of boys to girls did not add up in the zinc group } \\
\text { - Though the unit of baseline zinc concentration was reported to be } \mathrm{mg} / \mathrm{dL} \text {, it seems } \\
\text { that the unit should be } \mathrm{mg} / \mathrm{L} \text {. Assuming that the intended unit of zinc concentration } \\
\text { was actually } \mathrm{mg} / \mathrm{L} \text {, then the average baseline zinc concentration was } 62 \mu \mathrm{g} / \mathrm{dL}\end{array}$ \\
\hline
\end{tabular}

\section{Risk of bias}

\begin{tabular}{|c|c|c|}
\hline Bias & Authors' judgement & Support for judgement \\
\hline $\begin{array}{l}\text { Random sequence generation (selection } \\
\text { bias) }\end{array}$ & Unclear risk & $\begin{array}{l}\text { Quote: "...children were randomly as- } \\
\text { signed...The randomization code..." } \\
\text { Comment: Though a "randomization } \\
\text { code" was used, there are insufficient de- } \\
\text { tails available to make a judgement as to } \\
\text { whether or not an allocation sequence was } \\
\text { generated using a truly random method }\end{array}$ \\
\hline Allocation concealment (selection bias) & Low risk & $\begin{array}{l}\text { Quote: "The randomization code was bro- } \\
\text { ken after completion of the study. Bottles of } \\
\text { syrup were serially numbered according to } \\
\text { the randomization list, and this numbering } \\
\text { corresponded to the study serial numbers. } \\
\text { Enrolled children were assigned numbered } \\
\text { bottles in the order in which they were re- }\end{array}$ \\
\hline
\end{tabular}




\begin{tabular}{|c|c|c|}
\hline & & $\begin{array}{l}\text { cruited." } \\
\text { Comment: indicates sequentially num- } \\
\text { bered drug containers of identical appear- } \\
\text { ance to conceal allocation }\end{array}$ \\
\hline $\begin{array}{l}\text { Blinding of participants (performance } \\
\text { bias) } \\
\text { All outcomes }\end{array}$ & Low risk & $\begin{array}{l}\text { Quote: “...double-blind trial...” "The zinc } \\
\text { syrup and its placebo syrup looked very } \\
\text { similar...The randomization code was bro- } \\
\text { ken after completion of the study." } \\
\text { Comment: sufficient blinding seems likely }\end{array}$ \\
\hline $\begin{array}{l}\text { Blinding of personnel (performance bias) } \\
\text { All outcomes }\end{array}$ & Low risk & $\begin{array}{l}\text { Quote: “...double-blind trial..." "The zinc } \\
\text { syrup and its placebo syrup looked very } \\
\text { similar...The randomization code was bro- } \\
\text { ken after completion of the study." } \\
\text { Comment: sufficient blinding seems likely }\end{array}$ \\
\hline $\begin{array}{l}\text { Blinding of outcome assessment (detection } \\
\text { bias) } \\
\text { All outcomes }\end{array}$ & Low risk & $\begin{array}{l}\text { Quote: “...double-blind trial..." "The zinc } \\
\text { syrup and its placebo syrup looked very } \\
\text { similar...The randomization code was bro- } \\
\text { ken after completion of the study." } \\
\text { Comment: sufficient blinding seems likely }\end{array}$ \\
\hline $\begin{array}{l}\text { Incomplete outcome data (attrition bias) } \\
\text { All outcomes }\end{array}$ & Low risk & $\begin{array}{l}\text { \% Missing: } 3 \\
\text { Reasons/details: N/A } \\
\text { Comment: missing data seem too minimal } \\
\text { to impact results }\end{array}$ \\
\hline Selective reporting (reporting bias) & High risk & $\begin{array}{l}\text { Comment: serum zinc concentration was } \\
\text { measured, but is not reported in a way that } \\
\text { can be meta-analysed }\end{array}$ \\
\hline Other bias & Low risk & Comment: appears to be free of other bias \\
\hline
\end{tabular}

\section{Albert 2003 (2)}

Methods

Participants

Interventions

\begin{tabular}{ll}
\hline Outcomes & Prevalence of zinc deficiency \\
\hline Notes & As Albert 2003 above \\
\hline
\end{tabular}


Methods

Participants
CRCT?: IRCT; Cross-over?: non-cross-over

Country: Senegal; Setting: neighbourhood of Dakar; Urbanicity: urban Inclusion criteria: length-for-age z score (LAZ) and weight-for-length z score (WLZ) > 2.0 with respect to the World Health Organization growth standard; haemoglobin concentration $>80 \mathrm{~g} / \mathrm{L}$; no consumption of zinc-fortified foods or zinc-containing vitaminmineral supplements; no symptomatic infections within the preceding $2 \mathrm{wk}$

Exclusion criteria: N/A

Baseline characteristics

Avg age (mo): 13.2; Min age (mo): 9; Max age (mo): 17; \% Female: 52.6

Avg HAZ: -0.44; Stunting: non-stunted; Avg height (cm): 75; Avg zinc concentration $(\mu \mathrm{g} / \mathrm{dL}): 63.3$

Total N: 97; Group 1 N: 50; Group 2 N: 47

Interventions
Group 1: zinc
Formulation: solution; Compound: sulfate; Frequency: daily; Duration (mo): $0.5 ;$ Dose
(mg): 6; Co-intervention(s): $200 \mathrm{mg}$ albendazole as a single oral dose at enrolment; 30
g dry weight iron-fortified cereal porridge; a liquid multivitamin supplement
Group 2: no zinc
Placebo given; Co-intervention(s): $200 \mathrm{mg}$ albendazole as a single oral dose at enrolment;
$30 \mathrm{~g}$ dry weight iron-fortified cereal porridge; a liquid multivitamin supplement

Outcomes Serum or plasma zinc concentration

Time point (wk): 2

Notes

In addition to the study groups mentioned in this table, there was a group of 40 participants who received $30 \mathrm{~g}$ dry weight iron-fortified cereal porridge with added zinc to provide $6 \mathrm{mg}$ zinc per $25 \mathrm{~g}$ dry weight of porridge, but who did not receive any zinc supplement. Baseline characteristics reported in this table are weighted averages of all groups except this "ZnFort group", since this group is not included in any meta-analyses in this review

\section{Risk of bias}

Bias

Random sequence generation (selection Low risk bias)
Authors' judgement

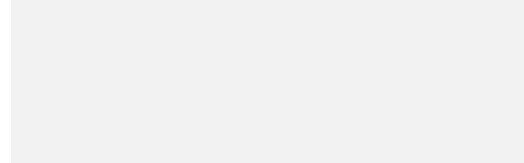

Allocation concealment (selection bias) Unclear risk

\section{Support for judgement}

Quote: "Eligible children were randomly assigned to 1 of 3 treatment groups for a $15-d$ period by using a computer-generated block randomization scheme, with a varied block length of 3, 6, or 9 (www.randomization.com)."

Comment: N/A

Quote: N/A

Comment: insufficient details available to make a judgement 
Ba Lo 2011 (Continued)

\begin{tabular}{|c|c|c|}
\hline $\begin{array}{l}\text { Blinding of participants (performance } \\
\text { bias) } \\
\text { All outcomes }\end{array}$ & Low risk & $\begin{array}{l}\text { Quote: "A double-blind } \\
\text { intervention trial...Group assignments re- } \\
\text { mained masked until all biochemical and } \\
\text { statistical analyses were completed." } \\
\text { Comment: sufficient blinding seems likely }\end{array}$ \\
\hline $\begin{array}{l}\text { Blinding of personnel (performance bias) } \\
\text { All outcomes }\end{array}$ & Low risk & $\begin{array}{l}\text { Quote: "A double-blind } \\
\text { intervention trial...Group assignments re- } \\
\text { mained masked until all biochemical and } \\
\text { statistical analyses were completed." } \\
\text { Comment: sufficient blinding seems likely }\end{array}$ \\
\hline $\begin{array}{l}\text { Blinding of outcome assessment (detection } \\
\text { bias) } \\
\text { All outcomes }\end{array}$ & Low risk & $\begin{array}{l}\text { Quote: "A double-blind } \\
\text { intervention trial...Group assignments re- } \\
\text { mained masked until all biochemical and } \\
\text { statistical analyses were completed." } \\
\text { Comment: sufficient blinding seems likely }\end{array}$ \\
\hline
\end{tabular}

Incomplete outcome data (attrition bias) High risk All outcomes
\% Missing: 32

Reasons/details: in the zinc group: 2 participants were missing due to illness, 6 due to travel, 7 due to "insufficient consumption of porridge", and 1 due to withdrawn consent. In the control group: 1 participant was missing due to illness, 6 due to travel, 5 due to "insufficient consumption of porridge", and 3 due to withdrawn consent Comment: $32 \%$ of the randomised participants eligible for our review had data missing; this $32 \%$ missing figure includes all groups except the "ZnFort group", since the ZnFort group is not included in any metaanalyses in this review. A large proportion of data is missing. Different proportions of each study group were missing due to "insufficient consumption of porridge" and withdrawn consent. Those who were randomised, but not analysed also had slightly different anthropometric data at baseline

Selective reporting (reporting bias) Low risk
Comment: length, weight, and haemoglobin concentration were measured at baseline and at the end of the supplementation period, but are not reported as post-intervention outcomes. Diarrhoea prevalence was measured, but is not reported in a way that can be meta-analysed. All of these outcomes were pre-specified in the protocol 
Ba Lo 2011 (Continued)

for this study. However, the authors of this study explained that there was probably not sufficient time to allow for detectable differences in morbidity or growth, and that these outcomes were included in the measurements simply to control for any baseline differences or possible confounding Protocol identifier: NCT0094398

$\begin{array}{lll}\text { Other bias } & \text { Low risk } \quad \text { Comment: appears to be free of other bias }\end{array}$

Baqui 2003

Methods

Participants
CRCT?: IRCT; Cross-over?: non-cross-over

Country: Bangladesh; Setting: Matlab subdistrict; Urbanicity: rural Inclusion criteria: N/A

Exclusion criteria: fed infant formula; severe malnutrition (mid-upper arm circumference (MUAC) < $110 \mathrm{~mm}$ ); severe anaemia (haemoglobin concentration < $90 \mathrm{~g} / \mathrm{L}$ ); signs of neurological disorders, physical disability, or chronic illness that might affect feeding, activity, and cognitive development; family not planning to stay in the trial area for 6 mo

Baseline characteristics

Avg age (mo): 6; Min age (mo): 6; Max age (mo): 6; \% Female: 47.2

Avg HAZ: -1.2; Stunting: both - separate data not given; Avg height (cm): 64.1; Avg zinc concentration $(\mu \mathrm{g} / \mathrm{dL}): 67.6$

Total N: 645; Group 1 N: 161; Group 2 N: 157; Group 3 N: 162; Group 4 N: 165

Interventions

Group 1: zinc

Formulation: solution; Compound: acetate; Frequency: weekly; Duration (mo): 6; Dose (mg): 20; Co-intervention(s): $1 \mathrm{mg}$ riboflavin

Group 2: no zinc

Placebo given; Co-intervention(s): $1 \mathrm{mg}$ riboflavin

Group 3: zinc

Co-intervention(s): $20 \mathrm{mg}$ iron, $1 \mathrm{mg}$ riboflavin

Group 4: no zinc

Placebo given; Co-intervention(s): $20 \mathrm{mg}$ iron, $1 \mathrm{mg}$ riboflavin

Outcomes

All-cause mortality, incidence of all-cause diarrhoea, incidence of severe diarrhoea, incidence of LRTI, height, weight, weight-to-height ratio, serum or plasma zinc concentration, blood haemoglobin concentration, serum or plasma ferritin concentration, serum or plasma copper concentration

Time point (wk): 24

Notes

- In addition to the 645 participants mentioned in this table, there was a group of 154 participants who received a micronutrient mix (MM). Baseline characteristics reported in this table were obtained from the Baqui 2003 trial report and are weighted averages of all groups except the MM group, because the MM group is not included in any meta- 
Baqui 2003 (Continued)

analyses in this review

- Though vitamin A was not directly provided in this study, "Because vitamin A supplementation is a national program in Bangladesh, infants in all groups received 100,000

IU of vitamin A...at the beginning of the study."

Risk of bias

\begin{tabular}{|c|c|c|}
\hline Bias & Authors' judgement & Support for judgement \\
\hline $\begin{array}{l}\text { Random sequence generation (selection } \\
\text { bias) }\end{array}$ & Unclear risk & $\begin{array}{l}\text { Quote: "Block randomization was done } \\
\text { within strata to ensure equivalent enroll- } \\
\text { ment..." } \\
\text { Comment: insufficient details available to } \\
\text { make a judgement as to whether or not an } \\
\text { allocation sequence was generated using a } \\
\text { truly random method }\end{array}$ \\
\hline Allocation concealment (selection bias) & Unclear risk & $\begin{array}{l}\text { Quote: N/A } \\
\text { Comment: insufficient details available to } \\
\text { make a judgement }\end{array}$ \\
\hline
\end{tabular}

Blinding of participants (performance Low risk bias)

All outcomes
Quote: “...double-blind, randomized, controlled community trial...Each study infant received a weekly dose of the assigned supplement, which was presented in the same type of capsules and labeled in such a way that the various types of supplements could not be differentiated." "The supplements were prepared as capsules, which were mixed with flavored syrup and fed to the infants. The mixtures were similar in taste and appearance."

Comment: sufficient blinding seems likely

Blinding of personnel (performance bias) Low risk All outcomes
Quote: “...double-blind, randomized, controlled community trial...Each study infant received a weekly dose of the assigned supplement, which was presented in the same type of capsules and labeled in such a way that the various types of supplements could not be differentiated." "The supplements were prepared as capsules, which were mixed with flavored syrup and fed to the infants. The mixtures were similar in taste and appearance."

Comment: sufficient blinding seems likely 
Baqui 2003 (Continued)

Blinding of outcome assessment (detection Low risk bias)

All outcomes
Quote: “...double-blind, randomized, controlled community trial...Each study infant received a weekly dose of the assigned supplement, which was presented in the same type of capsules and labeled in such a way that the various types of supplements could not be differentiated." "The supplements were prepared as capsules, which were mixed with flavored syrup and fed to the infants. The mixtures were similar in taste and appearance."

Comment: sufficient blinding seems likely

\% Missing: 12

Reasons/details: 14, 19, 30, and 12 participants "refused continued participation" in the iron, zinc, iron-zinc, and control group, respectively; in the zinc group, 2 migrated out and 1 died; in the control group, 1 migrated out. " $6 \%$ in the iron + zinc group dropped out due to vomiting. In contrast, $0-2 \%$ of the infants in other groups dropped out due to vomiting", though it is unclear whether or not these participants who dropped out due to vomiting are included in the number of participants who "refused continued participation." For the sub-set of participants contributing zinc, haemoglobin, ferritin, and copper concentration data, "It was not possible to obtain 2 blood samples from all children and some samples were found to be hemolyzed or insufficient in quantity." For the sub-set of participants contributing height, weight, and height-to-rate ratio data, "Staff availability, transportation, and inclement weather were the primary reasons for missing data."

Comment: $12 \%$ of the 645 randomised participants eligible for our review had data missing for diarrhoea and LRTI outcomes; this $12 \%$ missing figure includes all groups except the micronutrient mix (MM) group, since the MM group is not included in any meta-analyses in this review. "The baseline characteristics of the children who were excluded or lost to follow up were comparable to those of the children who continued in 
Baqui 2003 (Continued)

the study", and missing data seem unlikely to bias results

\begin{tabular}{|c|c|c|}
\hline Selective reporting (reporting bias) & High risk & $\begin{array}{l}\text { Comment: number of participants who } \\
\text { dropped out due to vomiting was mea- } \\
\text { sured, but is not reported in a way that can } \\
\text { be meta-analysed }\end{array}$ \\
\hline Other bias & Low risk & Comment: appears to be free of other bias \\
\hline
\end{tabular}

\section{Baqui 2003 (2)}

\begin{tabular}{l|l} 
Methods & \\
\hline Participants & \\
\hline Interventions & $\begin{array}{l}\text { All-cause mortality, incidence of all-cause diarrhoea, incidence of severe diarrhoea, incidence of LRTI, height, weight, } \\
\text { weight-to-height ratio, serum or plasma zinc concentration, blood haemoglobin concentration, serum or plasma } \\
\text { ferritin concentration, serum or plasma copper concentration }\end{array}$ \\
\hline Outcomes & As Baqui 2003 above \\
\hline Notes & \begin{tabular}{l} 
Als \\
\hline
\end{tabular}
\end{tabular}

Bhandari 2002

Methods

Participants

\section{CRCT?: IRCT; Cross-over?: non-cross-over}

Country: India; Setting: the urban slum of Dakshinpuri, New Deli; Urbanicity: urban Inclusion criteria: in family that did not intend to emigrate

Exclusion criteria: likely to move out of the study area within the next 4 months; required urgent hospitalisation on the scheduled enrolment day; received massive dose of vitamin A (100,000 IU (30 mg) for infants and 200,000 IU (60 mg) for older children) within the last 2 months

Baseline characteristics

Avg age (mo): 15.3; Min age (mo): 6; Max age (mo): 30; \% Female: 47.7

Avg HAZ: -1.82; Stunting: both - separate data not given; Avg height (cm): 72.7; Avg zinc concentration $(\mu \mathrm{g} / \mathrm{dL}): 62$

Total N: 2482; Group 1 N: 1241; Group 2 N: 1241
Group 1: zinc

Formulation: solution; Compound: gluconate; Frequency: daily; Duration (mo): 4; Dose (mg): $10 \mathrm{mg}$ to children 6 to 12 months of age, $20 \mathrm{mg}$ to children 12 to 30 months of age; Co-intervention(s): 100,000 IU vitamin A at enrolment for infants, 200,000 IU vitamin A at enrolment for older children

Group 2: no zinc

Placebo given; Co-intervention(s): 100,000 IU vitamin A at enrolment for infants, 200, $000 \mathrm{IU}$ vitamin $\mathrm{A}$ at enrolment for older children 
Bhandari 2002 (Continued)

Outcomes

Notes
All-cause mortality, all-cause hospitalisation, incidence of all-cause diarrhoea, prevalence of all-cause diarrhoea, incidence of severe diarrhoea, incidence of persistent diarrhoea, incidence of LRTI, height, weight, weight-to-height ratio, serum or plasma zinc concentration, prevalence of zinc deficiency, study withdrawal, vomiting episodes, serum or plasma ferritin concentration, serum or plasma copper concentration, prevalence of copper deficiency

Time point (wk): 16 to 17

"...all included subjects were given a massive dose of vitamin A...at enrollment in addition to zinc or placebo as required by the national program policy."

\section{Risk of bias}

\section{Bias}

Random sequence generation (selection Low risk bias)
Authors' judgement

\section{Support for judgement}

Quote: “A simple randomization scheme in blocks of 8 was generated...using the SAS software..."

Comment: N/A
Quote: "A simple randomization scheme... was generated by a person at Statens Serum Institut, who was not involved in the field work or the data analysis... The zinc and placebo syrups were prepared and packaged in unbreakable bottles by GK Pharma ApS (Køge, Denmark), which also labeled the bottles with unique identification numbers according to the randomization code. The zinc and placebo syrups were similar in... packaging."

Comment: indicates central randomisation (i.e. randomisation by someone not involved with enrolling patients) and sequentially numbered drug containers of identical appearance to conceal allocation
Blinding of participants (performance Low risk bias)

All outcomes
Quote: “A double-blind, randomized, placebo-controlled trial was conducted... The zinc and placebo syrups were similar in appearance, taste, and packaging."

Comment: sufficient blinding seems likely
Blinding of personnel (performance bias) Low risk All outcomes
Quote: "A double-blind, randomized, placebo-controlled trial was conducted... The zinc and placebo syrups were similar in appearance, taste, and packaging." Comment: sufficient blinding seems likely 
Bhandari 2002 (Continued)

Blinding of outcome assessment (detection Low risk

bias)

All outcomes
Quote: “A double-blind, randomized, placebo-controlled trial was conducted... The zinc and placebo syrups were similar in appearance, taste, and packaging."

Comment: sufficient blinding seems likely

\% Missing: 10

Reasons/details: in the zinc group, 13 participants "refused further participation on the first weekly visit", 35 "refused further participation" after the first weekly visit, and 100 moved. In the placebo group, 5 participants "refused further participation on the first weekly visit", 16 "refused further participation" after the first weekly visit, and 84 moved. "Eight children in the zinc group and none in the placebo group discontinued the intervention because of vomiting." It seems that these 8 children are probably included among those who refused further participation. "Three children, all in the placebo group, died."

Comment: reasons for missing data were similar between study groups. Migration was the most common reason for missing data, and this reason is unlikely to bias results

Selective reporting (reporting bias) High risk

Comment: plasma ferritin was measured, but is not reported. Plasma ferritin was not pre-specified in the protocol for this study. All-cause hospitalisation was reported, but was not pre-specified in the protocol for this study

Protocol identifier: NCT00272116

Other bias

Low risk

Comment: appears to be free of other bias

Bhandari 2007

Methods

Participants
CRCT?: CRCT; Cross-over?: non-cross-over

Country: India; Setting: north and northwest New Delhi; Urbanicity: urban Inclusion criteria: local residents; unlikely to move away over the next 6 months; unlikely to be absent from the study area for 3 months or more over the subsequent year Exclusion criteria: major congenital anomalies, severe malnutrition, or any serious condition that affected the ability of the child to consume the supplement. Children with visible severe wasting were enrolled after rehabilitation. Children with illnesses requiring 
hospitalisation were excluded temporarily and screened again after recovery

Baseline characteristics

Avg age (mo): 14.88; Min age (mo): 6; Max age (mo): 23; \% Female: 47.1

Avg HAZ: -1.95; Stunting: both - separate data not given; Avg height (cm): 72.35; Avg zinc concentration $(\mu \mathrm{g} / \mathrm{dL}): 64.27$

Total N: 72,438; Group 1 N: 36,293; Group 2 N: 36,145

Total clusters: 68,146; Group 1 clusters: 34,201; Group 2 clusters: 33,945

Interventions
Group 1: zinc

Formulation: pill/tablet; Compound: sulfate; Frequency: daily; Duration (mo): 12; Dose (mg): 10; Co-intervention(s): $12.5 \mathrm{mg}$ iron, $50 \mu \mathrm{g}$ folic acid

Group 2: no zinc

Placebo given; Co-intervention(s): $12.5 \mathrm{mg}$ iron, $50 \mu \mathrm{g}$ folic acid
Outcomes

All-cause mortality, mortality due to all-cause diarrhoea, mortality due to LRTI, all-cause hospitalisation, hospitalisation due to all-cause diarrhoea, hospitalisation due to LRTI, height, weight, prevalence of stunting, serum or plasma zinc concentration, prevalence of zinc deficiency, participants with $\geq 1$ vomiting episode, serum or plasma ferritin concentration, prevalence of iron deficiency, serum or plasma copper concentration Time point (wk): 52

Notes

All baseline and outcome data from this study included in this review apply only to the subset of this study's participants who were at least 6 months of age at baseline

\section{Risk of bias}

\section{Bias}

Random sequence generation (selection Low risk bias)
Authors' judgement
Allocation concealment (selection bias) Low risk

\section{Support for judgement}

Quote: “Two randomization lists were computer generated (one for each stratum) ...Each list had permuted blocks of 16 participants randomly allocated to 16 letter codes. Half of the 16 letter codes were randomly assigned to the zinc and IFA group and the other half to the IFA group."

Comment: N/A
Quote: “...randomization lists were computer generated...by a staff member of the World Health Organization (WHO).” Participants were "randomly allocated to 16 letter codes. Half of the 16 letter codes were randomly assigned to the zinc and IFA group and the other half to the IFA group. This code was only available with the WHO and the company that prepared and packaged the supplement...Randomization lists containing only serial numbers (that represented household numbers) and 
respective letter codes were made available to the investigators, but they did not know which of the 16 letter codes represented the 2 study groups."

Comment: indicates central randomisation (i.e. randomisation by someone not involved with enrolling patients) to conceal allocation

Blinding of participants (performance Low risk bias)

All outcomes

Blinding of personnel (performance bias) Low risk

All outcomes

Blinding of outcome assessment (detection Low risk bias)

All outcomes

Incomplete outcome data (attrition bias) Low risk All outcomes
Quote: “...double blind cluster-randomized controlled trial...The control group tablets were similar in appearance and taste except they contained a placebo for zinc." Comment: sufficient blinding seems likely

Quote: “...double blind cluster-randomized controlled trial... The control group tablets were similar in appearance and taste except they contained a placebo for zinc." Comment: sufficient blinding seems likely

Quote: “...double blind cluster-randomized controlled trial... The control group tablets were similar in appearance and taste except they contained a placebo for zinc." Comment: sufficient blinding seems likely

\% Missing: 4

Reasons/details: in the zinc + iron + folic acid group: 173 participants died, 31 participants "refused further participation", and 1394 "moved away before completing 12 mo follow-up." In the iron + folic acid group: 165 participants died, 17 participants "refused further participation", and 1369 "moved away before completing 12 mo follow-up."

Comment: reasons for missing data were similar between study groups. Migration was the most common reason for missing data, and this reason is unlikely to bias results. Missing data seem too minimal to impact results

Selective reporting (reporting bias) High risk
Comment: prevalence of stunting and mean plasma copper concentration were pre-specified as secondary outcomes in the protocol for this study, but are not reported. Height and weight were measured, 
Bhandari 2007 (Continued)

but were not pre-specified in the protocol for this study and are not reported. Plasma zinc concentration, prevalence of iron deficiency, hospitalisation due to any cause, mortality due to diarrhoea, and mortality due to LRTI were reported, but were not pre-specified in the protocol for this study; though related outcomes, such as prevalence of zinc deficiency, plasma ferritin concentration, hospitalisations due to diarrhoea and pneumonia, and all-cause mortality, were pre-specified in the protocol for this study

Protocol identifier: NCT00269542

Brown 2007

Methods

Participants
CRCT?: IRCT; Cross-over?: non-cross-over

Country: Peru; Setting: Trujillo, a city on the northern coast of Peru; Urbanicity: periurban

Inclusion criteria: length-for-age $\mathrm{z}$ score $(\mathrm{LAZ})<-0.5$; weight-for-length $\mathrm{z}$ score $>-3$ (to exclude those with acute malnutrition, who were referred for treatment); haemoglobin $>8.0 \mathrm{~g} / \mathrm{dL}$

Exclusion criteria: congenital abnormalities or chronic diseases affecting growth; use of infant formula providing $>1 \mathrm{mg} \mathrm{Zn/d} \geq 5$ times/wk; a twin enrolled in the study; families that were not planning to remain in the study community for the next 7 mo Baseline characteristics

Avg age (mo): 7.5; Min age (mo): 6; Max age (mo): 8; \% Female: 51.5

Avg HAZ: -1.19; Stunting: both - separate data not given; Avg height (cm): 65.4; Avg zinc concentration $(\mu \mathrm{g} / \mathrm{dL}): 77.6$

Total N: 200; Group 1 N: 101; Group 2 N: 99
Group 1: zinc

Formulation: solution; Compound: sulfate; Frequency: daily; Duration (mo): 6; Dose (mg): 3; Co-intervention(s): $30 \mathrm{~g}$ dry weight of an iron-fortified cereal porridge; an aqueous multivitamin (MV) supplement

Group 2: no zinc

Placebo given; Co-intervention(s): $30 \mathrm{~g}$ dry weight of an iron-fortified cereal porridge; an aqueous multivitamin (MV) supplement
Outcomes
Prevalence of all-cause diarrhoea, incidence of severe diarrhoea, incidence of LRTI, height, weight, weight-to-height ratio, serum or plasma zinc concentration, blood haemoglobin concentration, prevalence of anaemia, serum or plasma ferritin concentration, prevalence of iron deficiency, serum or plasma copper concentration Time point (wk): 24 
Brown 2007 (Continued)

Notes

In addition to the study groups mentioned in this table, there was a group of 102 participants who received $30 \mathrm{~g}$ dry weight of an iron- and zinc-fortified cereal porridge along with the aqueous multivitamin (MV) supplement. Baseline characteristics reported in this table are weighted averages of all groups except this zinc-fortified group, since this group is not included in any meta-analyses in this review

\section{Risk of bias}

\section{Bias}

Random sequence generation (selection Low risk bias)
Authors' judgement

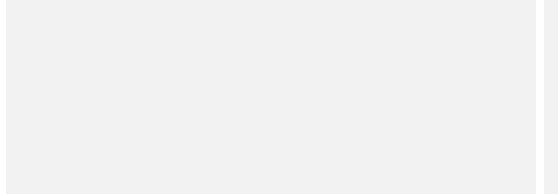

\section{Support for judgement}

Quote: participants "were randomly assigned to...treatment groups by using a block randomization scheme, with a varied block length of 3 or 6 ." "We used the random number generator within SAS to randomly shuffle the treatments within each block."

Comment: N/A
Quote: in response to the question, "Could you describe how you ensured that participants, and investigators enrolling participants, could not tell which group a new participant would be assigned to?" an author of this study replied as follows: "One of the study investigators (Mary Penny) was responsible for coding and treatment assignment. She was not involved with the implementation of the study at the field site and the rest of the investigators, study personnel, and of course participants, were not aware of the coding and treatment assignment. The trial was conducted in a city 600 km north of Lima. Dr. Penny kept the code in Lima and every month sent coded porridge and supplements to the field site." Comment: sufficient allocation concealment seems likely

Blinding of participants (performance Low risk bias)

All outcomes
Quote: "Zinc supplements were delivered in coded bottles undistinguishable from placebo. A lab technician in Lima prepared zinc supplements and placebos and placed this in the coded bottles. Zinc supplements and placebo had the same appearance, taste, etc."

Comment: sufficient blinding seems likely 
Brown 2007 (Continued)

Blinding of personnel (performance bias) Low risk

All outcomes
Quote: "Zinc supplements were delivered in coded bottles undistinguishable from placebo. A lab technician in Lima prepared zinc supplements and placebos and placed this in the coded bottles. Zinc supplements and placebo had the same appearance, taste, etc.”

Comment: sufficient blinding seems likely

Blinding of outcome assessment (detection Low risk bias)

All outcomes

Incomplete outcome data (attrition bias)

Unclear risk

All outcomes
Quote: "Zinc supplements were delivered in coded bottles undistinguishable from placebo. A lab technician in Lima prepared zinc supplements and placebos and placed this in the coded bottles. Zinc supplements and placebo had the same appearance, taste, etc."

Comment: sufficient blinding seems likely

\% Missing: 11

Reasons/details: N/A

Comment: $11 \%$ of the randomised participants eligible for our review had data missing; this $11 \%$ missing figure includes all groups except the zinc-fortified group, since this group is not included in any meta-analyses in this review. No information was reported on reasons for dropout. Furthermore, the authors reported that, "One possible limitation of our study was the disproportionate number of dropouts from the 2 groups that received additional zinc and the fact that those who left the study early differed slightly with regard to their initial rates of breastfeeding, anthropometric indicators of nutritional status, and prevalence of diarrhea...Nevertheless... the overall attrition rate was relatively small, as were the differences between the children who left the study early and those who completed the study, so these should not have exerted any major effect on the results.

Comment: in response to an inquiry concerning the protocol for this study, an author replied as follows: "This trial was conducted, if I am not mistaken, before trial registry was implemented. Unfortunately, I cannot share the protocol with you given 
Brown 2007 (Continued)

we do not share these with external investigators. Nevertheless, I can tell you that all reported outcomes in the article were prespecified before the start of the trial." Furthermore, based on the trial reports for this study, there were no outcomes of interest to this review that were: (a) measured, but (b) not reported in a way that can be metaanalysed

\section{Castillo-Durán 1994}

Methods

Participants
CRCT?: IRCT; Cross-over?: non-cross-over

Country: Chile; Setting: slums of Santiago; Urbanicity: peri-urban

Inclusion criteria: in the low-income group, defined by the Graffar scale; short stature, defined as length measurements less than the 5th percentile for age according to WHO/ NCHS standards

Exclusion criteria: chronic diseases (e.g. celiac disease, fetal alcohol syndrome, cardiac or chronic renal disease, genetic disorders)

Baseline characteristics

Avg age (mo): 127.4; Min age (mo): 72; Max age (mo): 168; \% Female: 48

Avg HAZ: N/A; Stunting: stunted; Avg height (cm): N/A; Avg zinc concentration ( $\mu \mathrm{g} /$ dL): N/A

Total N: 114 or 113; Group 1 N: N/A; Group 2 N: N/A

\section{Group 1: zinc}

Formulation: capsule; Compound: sulfate; Frequency: daily; Duration (mo): 12; Dose (mg): 10; Co-intervention(s): N/A

Group 2: no zinc

Placebo given; Co-intervention(s): N/A
Outcomes

Notes

Height, weight

Time point (wk): 52

- It is unclear whether 114 or 113 participants were randomised. The number of participants randomised to the zinc group was not reported; nor was the number of participants randomised to the placebo group

- The HAZ outcome in this study was calculated, in part, based on the assumption that some height data reported in "F for difference between changes" format had a pre post correlation of 0.5 ; however assuming a pre post correlation of 0.2 or 0.8 did not change the calculated result for this outcome

\section{Risk of bias}


Castillo-Durán 1994 (Continued)

Random sequence generation (selection Unclear risk bias)
Quote: "Patients were assigned randomly..."

Comment: insufficient details available to make a judgement as to whether or not an allocation sequence was generated using a truly random method

Quote: N/A

Comment: insufficient details available to make a judgement

Blinding of participants (performance Low risk bias)

All outcomes

Unclear risk

Quote: "For each age and gender group, children were assigned randomly to a supplement $(\mathrm{S})$ or placebo $(\mathrm{P})$ group in a double-blind fashion." Participants were "followed up for 12 months using a doubleblind design."

Comment: sufficient blinding seems likely

Blinding of personnel (performance bias) Low risk All outcomes

Blinding of outcome assessment (detection Low risk bias)

All outcomes

Incomplete outcome data (attrition bias) Unclear risk All outcomes
Quote: "For each age and gender group, children were assigned randomly to a supplement $(\mathrm{S})$ or placebo $(\mathrm{P})$ group in a double-blind fashion." Participants were "followed up for 12 months using a doubleblind design."

Comment: sufficient blinding seems likely

Quote: "For each age and gender group, children were assigned randomly to a supplement $(\mathrm{S})$ or placebo $(\mathrm{P})$ group in a double-blind fashion." Participants were "followed up for 12 months using a doubleblind design."

Comment: sufficient blinding seems likely

\% Missing: 30

Reasons/details: "Thirty-four other subjects were left out during the initial 3 months of the study because of poor compliance with ingestion of the supplemental capsule..."

Comment: a large proportion of data is missing. The number of participants randomised to the zinc group was not reported; nor was the number of participants randomised to the placebo group. Thus, it is difficult to tell whether amounts of missing data were similar between study groups 
Castillo-Durán 1994 (Continued)

\begin{tabular}{l|l|l}
\hline Selective reporting (reporting bias) & High risk & $\begin{array}{l}\text { Comment: height (for pre-adolescent fe- } \\
\text { males), weight (for all participants ex- } \\
\text { cept pre-adolescent males), and weight-for- } \\
\text { height were measured, but are not reported } \\
\text { in a way that can be meta-analysed. It is } \\
\text { unclear whether the plasma zinc concentra- } \\
\text { tion reported was measured at baseline or } \\
\text { after supplementation as a post-interven- } \\
\text { tion outcome }\end{array}$ \\
\hline Other bias & Low risk & Comment: appears to be free of other bias \\
\hline
\end{tabular}

Castillo-Durán 2002

Methods

Participants

Outcomes
CRCT?: IRCT; Cross-over?: non-cross-over

Country: Chile; Setting: Santiago; Urbanicity: urban

Inclusion criteria: normal weight and length; free from chronic diseases; literate mothers able to understand and sign written consent

Exclusion criteria: N/A

Baseline characteristics

Avg age (mo): N/A; Min age (mo): 17; Max age (mo): 19; \% Female: 0

Avg HAZ: N/A; Stunting: non-stunted; Avg height $(\mathrm{cm})$ : N/A; Avg zinc concentration $(\mu \mathrm{g} / \mathrm{dL}): \mathrm{N} / \mathrm{A}$

Total N: 42; Group 1 N: 21; Group 2 N: 21

\section{Group 1: zinc}

Formulation: solution; Compound: sulfate; Frequency: daily; Duration (mo): 12; Dose (mg): 5; Co-intervention(s): N/A

Group 2: no zinc

Placebo given; Co-intervention(s): N/A

No outcomes of interest reported in a way that can be meta-analysed

Notes

\section{Risk of bias}

\begin{tabular}{|c|c|c|}
\hline Bias & Authors' judgement & Support for judgement \\
\hline $\begin{array}{l}\text { Random sequence generation (selection } \\
\text { bias) }\end{array}$ & Unclear risk & $\begin{array}{l}\text { Quote: "Children were randomized..." } \\
\text { Comment: insufficient details available to } \\
\text { make a judgement as to whether or not an } \\
\text { allocation sequence was generated using a } \\
\text { truly random method }\end{array}$ \\
\hline
\end{tabular}

Zinc supplementation for preventing mortality, morbidity, and growth failure in children aged 6 months to 12 years of age (Review) 
Castillo-Durán 2002 (Continued)

\begin{tabular}{|c|c|c|}
\hline Allocation concealment (selection bias) & Unclear risk & $\begin{array}{l}\text { Quote: N/A } \\
\text { Comment: insufficient details available to } \\
\text { make a judgement }\end{array}$ \\
\hline $\begin{array}{l}\text { Blinding of participants (performance } \\
\text { bias) } \\
\text { All outcomes }\end{array}$ & Unclear risk & $\begin{array}{l}\text { Quote: “...double blind trial..." } \\
\text { Comment: insufficient details available to } \\
\text { make a judgement }\end{array}$ \\
\hline $\begin{array}{l}\text { Blinding of personnel (performance bias) } \\
\text { All outcomes }\end{array}$ & Unclear risk & $\begin{array}{l}\text { Quote: “...double blind trial...” } \\
\text { Comment: insufficient details available to } \\
\text { make a judgement }\end{array}$ \\
\hline $\begin{array}{l}\text { Blinding of outcome assessment (detection } \\
\text { bias) } \\
\text { All outcomes }\end{array}$ & Unclear risk & $\begin{array}{l}\text { Quote: “...double blind trial..." } \\
\text { Comment: insufficient details available to } \\
\text { make a judgement }\end{array}$ \\
\hline $\begin{array}{l}\text { Incomplete outcome data (attrition bias) } \\
\text { All outcomes }\end{array}$ & Unclear risk & $\begin{array}{l}\text { \% Missing: } 19 \\
\text { Reasons/details: "Eight children were ex- } \\
\text { cluded due to non compliance with daily } \\
\text { administration of syrup or to change of ad- } \\
\text { dress limiting home visits." } \\
\text { Comment: a fairly large proportion of data } \\
\text { is missing, and neither reasons for, nor } \\
\text { amounts of, missing data were reported } \\
\text { separately for the zinc group versus the } \\
\text { placebo group }\end{array}$ \\
\hline Selective reporting (reporting bias) & High risk & $\begin{array}{l}\text { Comment: plasma zinc concentration, } \\
\text { weight, and length were measured, but are } \\
\text { not reported in a way that can be meta- } \\
\text { analysed. "Morbidity outcomes" were mea- } \\
\text { sured, but the exact types of morbidity } \\
\text { outcomes measured were not defined; so, } \\
\text { other outcomes, such as diarrhoea or LRTI, } \\
\text { might have been measured but not reported }\end{array}$ \\
\hline Other bias & Low risk & Comment: appears to be free of other bias \\
\hline
\end{tabular}

Cavan 1993

Methods

Participants
CRCT?: IRCT; Cross-over?: non-cross-over

Country: Guatemala; Setting: Guatemala City; Urbanicity: peri-urban Inclusion criteria: N/A

Exclusion criteria: receiving vitamin and/or mineral supplementation at home in the last 2 mo Baseline characteristics

Avg age (mo): 81.5; Min age (mo): 68; Max age (mo): 96; \% Female: 45 
Cavan 1993 (Continued)

Avg HAZ: -1.51; Stunting: both - separate data not given; Avg height (cm): 112.2; Avg zinc concentration $(\mu \mathrm{g} / \mathrm{dL}): 93.5$

Total N: 162; Group 1 N: 80; Group 2 N: 82

Interventions Group 1: zinc

Formulation: pill/tablet; Compound: amino acid chelate; Frequency: “...each school day..."; Duration (mo): 6.25; Dose (mg): 10; Co-intervention(s): vitamin-mineral supplement that contained multiple micronutrients (including iron)

Group 2: no zinc

Placebo given; Co-intervention(s): vitamin-mineral supplement that contained multiple micronutrients (including iron)

Outcomes

Height, weight, weight-to-height ratio, serum or plasma zinc concentration

Time point (wk): 25

Notes

Risk of bias

\begin{tabular}{|c|c|c|}
\hline Bias & Authors' judgement & Support for judgement \\
\hline $\begin{array}{l}\text { Random sequence generation (selection } \\
\text { bias) }\end{array}$ & Low risk & $\begin{array}{l}\text { Quote: "Children were pair matched by sex } \\
\text { and age to constitute two groups: thereafter, } \\
\text { a coin toss was used to assign the groups to } \\
\text { one or the other coded treatment." } \\
\text { Comment: N/A }\end{array}$ \\
\hline
\end{tabular}

Allocation concealment (selection bias) Low risk

Quote: “...a coin toss was used to assign the groups to one or the other coded treatment. ..only the color varied between the two supplements...Only the company (Jamieson Co, Windsor, Ontario), which manufactured the supplements, was familiar with the color code; the code was broken only on completion of the project."

Comment: sufficient allocation concealment seems likely

Blinding of participants (performance Low risk bias)

All outcomes
Quote: “...a double-blind zinc-supplementation study...The zinc and placebo supplements were indistinguishable in taste and size; only the color varied between the two supplements...Only the company (Jamieson Co, Windsor, Ontario), which manufactured the supplements, was familiar with the color code; the code was broken only on completion of the project." Comment: sufficient blinding seems likely 


\section{Cavan 1993 (Continued)}

\begin{tabular}{l|l|l}
$\begin{array}{l}\text { Blinding of personnel (performance bias) } \\
\text { All outcomes }\end{array}$ & Low risk & $\begin{array}{l}\text { Quote: “...a double-blind zinc-supple- } \\
\text { mentation study...The zinc and placebo } \\
\text { supplements were indistinguishable in taste } \\
\text { and size; only the color varied between } \\
\text { the two supplements...Only the company } \\
\text { (Jamieson Co, Windsor, Ontario), which } \\
\text { manufactured the supplements, was famil- } \\
\text { iar with the color code; the code was bro- } \\
\text { ken only on completion of the project.” } \\
\text { Comment: sufficient blinding seems likely }\end{array}$ \\
\hline
\end{tabular}

Blinding of outcome assessment (detection Low risk bias)

All outcomes

Quote: “...a double-blind zinc-supplementation study...The zinc and placebo supplements were indistinguishable in taste and size; only the color varied between the two supplements... Only the company (Jamieson Co, Windsor, Ontario), which manufactured the supplements, was familiar with the color code; the code was broken only on completion of the project."

Comment: sufficient blinding seems likely

Incomplete outcome data (attrition bias) Low risk

\% Missing: 3.7

All outcomes

Reasons/details: N/A

Comment: though no reasons for missing data were given, missing data seem too minimal to impact results

Selective reporting (reporting bias) High risk

Comment: plasma copper concentration was measured as an outcome, but is not reported as an outcome

Other bias

Low risk

Comment: appears to be free of other bias

\section{Chang 2010}

Methods

Participants
CRCT?: IRCT; Cross-over?: non-cross-over

Country: Bangladesh; Setting: Mirzapur, a sub-district (thana) north of Dhaka; Urbanicity: rural

Inclusion criteria: permanent resident of the selected villages

Exclusion criteria: severe malnutrition (weight-for-height $\mathrm{z}$-score $<-3 \mathrm{SD}$ ); severe anaemia (haemoglobin $<70 \mathrm{~g} / \mathrm{l}$ ); chronic illnesses that would impair feeding ability; planned move during the study period; active fever $>38.5^{\circ} \mathrm{C}$; a sibling enrolled in the study Baseline characteristics

Avg age (mo): 11; Min age (mo): 6; Max age (mo): 18; \% Female: 48.4

Avg HAZ: -1.3; Stunting: both - separate data not given; Avg height (cm): N/A; Avg 
zinc concentration $(\mu \mathrm{g} / \mathrm{dL}): 65.3$

Total N: 1000; Group 1 N: 198; Group 2 N: 201; Group 3 N: 400; Group 4 N: 201

Group 1: zinc
Formulation: pill/tablet; Compound: sulfate; Frequency: every other day; Duration (mo)
: 6; Dose $(\mathrm{mg}): 5 \mathrm{mg}$ to children aged younger than 12 months; 10 to children aged 12
months or older; Co-intervention(s): N/A
Group 2: no zinc
Placebo given; Co-intervention(s): N/A
Group 3: zinc
Co-intervention(s): for children aged younger than 12 months: 6.25 mg iron every other
day; 25 IU folic acid every other day. For children aged 12 months or older: $12.5 \mathrm{mg}$
iron every other day; 50 IU folic acid every other day
Group 4: no zinc
Placebo given; Co-intervention(s): for children aged younger than $12 \mathrm{months:} 6.25 \mathrm{mg}$
iron every other day; 25 IU folic acid every other day. For children aged $12 \mathrm{months}$ or
older: $12.5 \mathrm{mg}$ iron every other day; 50 IU folic acid every other day

Outcomes

All-cause mortality, all-cause hospitalisation, incidence of all-cause diarrhoea, prevalence of all-cause diarrhoea, hospitalisation due to all-cause diarrhoea, hospitalisation due to LRTI, serum or plasma zinc concentration, vomiting episodes, blood haemoglobin concentration, prevalence of anaemia

Time point (wk): 26

Notes

Risk of bias

Bias

Random sequence generation (selection Low risk bias)

Allocation concealment (selection bias) Low risk

\section{Support for judgement}

Quote: "Block randomization in groups of 10 were computer generated."

Comment: N/A

Quote: "Sealed envelopes concealing supplement group allocation were opened sequentially only after complete determination of enrollment eligibility."

Comment: sufficient allocation concealment seems likely

Blinding of participants (performance Low risk bias)

All outcomes
Quote: “...double blind, placebo-controlled factorial community trial...Placebo was identical in color, shape, taste...The manufacturer provided supplements with blinded designation. The principal investigator alone stored the code in a remote location from the study site. The code was not revealed until the time of manuscript 
Chang 2010 (Continued)

preparation."

Comment: sufficient blinding seems likely

Blinding of personnel (performance bias) Low risk

All outcomes

Quote: “...double blind, placebo-controlled factorial community trial...Placebo was identical in color, shape, taste...The manufacturer provided supplements with blinded designation. The principal investigator alone stored the code in a remote location from the study site. Analyses were performed in a blinded manner. The code was not revealed until the time of manuscript preparation."

Comment: sufficient blinding seems likely

Blinding of outcome assessment (detection Low risk bias)

All outcomes
Quote: “...double blind, placebo-controlled factorial community trial...Placebo was identical in color, shape, taste...The manufacturer provided supplements with blinded designation. The principal investigator alone stored the code in a remote location from the study site. Analyses were performed in a blinded manner. The code was not revealed until the time of manuscript preparation."

Comment: sufficient blinding seems likely

Incomplete outcome data (attrition bias) Low risk All outcomes
\% Missing: 0.3

Reasons/details: For diarrhoea and hospitalisation outcomes: in the placebo group, 2 participants died; in the zinc + iron group, 1 withdrew. For zinc, haemoglobin, and anaemia outcomes: In the zinc group, 2 participants were lost to follow-up (LTFU) and 10 refused to have their blood drawn; in the placebo group 2 were LTFU and 10 refused to have their blood drawn; in the zinc + iron group, 7 were LTFU and 16 refused to have their blood drawn; and in the iron group, 2 were LTFU and 7 refused to have their blood drawn

Comment: reasons for, and amount of, missing data were similar between study groups. Missing data seem too minimal to impact results

Comment: all-cause hospitalisations, hospitalisations due to diarrhoea, hospitalisation due to pneumonia, and incidence of 
Chang 2010 (Continued)

vomiting as a side effect were reported, but were not pre-specified in the protocol for this study. However, these were not reported as primary outcomes Protocol identifier: NCT00470158

Other bias

Low risk

Comment: appears to be free of other bias

Chang 2010 (2)

Methods

Participants

Interventions

Outcomes All-cause mortality, all-cause hospitalisation, incidence of all-cause diarrhoea, prevalence of all-cause diarrhoea, hospitalisation due to all-cause diarrhoea, hospitalisation due to LRTI, serum or plasma zinc concentration, vomiting episodes, blood haemoglobin concentration, prevalence of anaemia

Notes As Chang 2010 above

Chen 2012

Methods CRCT?: CRCT; Cross-over?: non-cross-over

Participants

Country: China; Setting: Banan District, a suburb of Chongqing; Urbanicity: peri-urban Inclusion criteria: 1) not having any chronic infectious diseases; 2) haemoglobin concentration $360 \mathrm{~g} / \mathrm{L}$; 3) C-reaction protein $(\mathrm{CRP})<5 \mathrm{mg} / \mathrm{L}$; 4) parental/guardian agreement to avoid additional supplementing vitamin and mineral during the investigation

Exclusion criteria: evidence of recent acute or chronic illnesses and/or haemoglobin concentration $<60 \mathrm{~g} / \mathrm{L}$

Baseline characteristics

Avg age (mo): 51.60; Min age (mo): 36; Max age (mo): 72; \% Female: 44

Avg HAZ: -0.26; Stunting: unclear; Avg height $(\mathrm{cm}): 102$; Avg zinc concentration $(\mu \mathrm{g} /$ dL): $25.6 \%$ of participants had zinc serum level $<10.7$

Total N: 361; Group 1 N: 122; Group 2 N: 119

Interventions

Group 1: zinc

Formulation: pill/tablet; Compound: gluconate; Frequency: 5 days/wk; Duration (mo) : 6; Dose (mg): 10; Co-intervention(s): vitamin A

Group 2: no zinc

Placebo not given; Co-intervention(s): vitamin A

Outcomes

Height, weight, weight-to-height ratio, serum zinc, blood haemoglobin

Time point (wk): 26

Notes

Zinc supplementation for preventing mortality, morbidity, and growth failure in children aged 6 months to 12 years of age (Review)

Copyright @ 2014 The Cochrane Collaboration. Published by John Wiley \& Sons, Ltd. 
Chen 2012 (Continued)

Risk of bias

\begin{tabular}{|c|c|c|}
\hline Bias & Authors' judgement & Support for judgement \\
\hline $\begin{array}{l}\text { Random sequence generation (selection } \\
\text { bias) }\end{array}$ & Unclear risk & $\begin{array}{l}\text { Quote: "Three kindergartens were ran- } \\
\text { domly selected out of } 7 \text { in this region; } \\
\text { and } 3 \text { classes were chosen from each of } \\
\text { them... The selected classes in each kinder- } \\
\text { garten were randomly assigned to receive } \\
\text { vitamin A (A group), vitamin A plus zinc } \\
\text { (AZ group), or vitamin A combined with } \\
\text { multiple micronutrients (contain vitamins } \\
\text { B-1, B-2, B-6, B-12, C, D, folate, niaci- } \\
\text { namide, and calcium)." }\end{array}$ \\
\hline Allocation concealment (selection bias) & Unclear risk & Quote: N/A \\
\hline $\begin{array}{l}\text { Blinding of participants (performance } \\
\text { bias) } \\
\text { All outcomes }\end{array}$ & High risk & No placebo \\
\hline
\end{tabular}

Blinding of personnel (performance bias) High risk

All outcomes
Intervention was continued at the weekends by sending parents a supply of sachets with instructions (doesn't state whether these sachets also had the contents on the packet, if so risk of to the blinding status of the participants)

\section{No placebo}

Blinding of outcome assessment (detection Unclear risk bias)

All outcomes

Incomplete outcome data (attrition bias) Unclear risk All outcomes

Selective reporting (reporting bias) Unclear risk

Comment: $22 \%$ intervention and $28 \%$ control missing

Trial not registered. Authors say "We cannot share our protocol with you. It's not a public file."

Comment: appears to be free of other bias 
Methods

Participants
CRCT?: IRCT; Cross-over?: non-cross-over

Country: South Africa; Setting: Northern KwaZulu-Natal Province; Urbanicity: rural Inclusion criteria: N/A

Exclusion criteria: less than $60 \%$ of median weight-for-age using United States National Center for Health Statistics standards; nutritional oedema; received vitamin or micronutrient supplements in the previous month; diarrhoea for more than 7 days at the time of study enrolment; enrolled in another study of a clinical intervention

Baseline characteristics

Avg age (mo): 6; Min age (mo): 6; Max age (mo): 6; \% Female: 48

Avg HAZ: -0.45; Stunting: both - separate data given; Avg height (cm): N/A; Avg zinc concentration $(\mu \mathrm{g} / \mathrm{dL}): \mathrm{N} / \mathrm{A}$

Total N: 227; Group 1 N: 112; Group 2 N: 115
Interventions Group 1: zinc

Formulation: pill/tablet; Compound: gluconate; Frequency: daily; Duration (mo): 18; Dose (mg): 10; Co-intervention(s): 1250 IU vitamin A

Group 2: no zinc

Placebo given; Co-intervention(s): 1250 IU vitamin A

Outcomes

All-cause mortality, all-cause hospitalisation, incidence of all-cause diarrhoea, prevalence of all-cause diarrhoea, hospitalisation due to all-cause diarrhoea, incidence of severe diarrhoea, incidence of persistent diarrhoea, vomiting episodes, blood haemoglobin concentration, prevalence of anaemia

Time point (wk): 52 (biochemical outcomes), 72 (morbidity and mortality outcomes)

Notes

- In addition to the study groups mentioned in this table, there was a group of participants who received zinc along with multiple micronutrients. Baseline characteristics reported in this table are weighted averages of all groups except this zinc and multiple micronutrient group, since this group is not included in any meta-analyses in this review

- HIV-positive children are not eligible for this review, so the baseline characteristics and most outcome data that are reported in this review only apply to this trial's HIVuninfected child participants. (For a few outcomes, separate data were not reported for HIV-uninfected participants; however, HIV-uninfected participants comprise the majority of participants in analyses of these outcomes.)

- 28 participants in the vitamin A group and 26 participants in the vitamin A + zinc groups "were found to have hemoglobin below $10 \mathrm{~g} / \mathrm{dL}$ during the routine testing performed on all study participants" and "were given therapeutic iron as per South Africa Department of Health guidelines...." However, "Use of any other micronutrient supplements during the study was rare."

- "All supplements were given daily at home from entry into the study until 24 months of age... The median duration of enrollment in the study was 447 days and did not differ significantly between groups." 
Chhagan 2009 (Continued)

\begin{tabular}{|c|c|c|}
\hline $\begin{array}{l}\text { Random sequence generation (selection } \\
\text { bias) }\end{array}$ & Low risk & $\begin{array}{l}\text { Quote: "An allocation list was prepared us- } \\
\text { ing computer-generated random numbers } \\
\text { and a block size of six." } \\
\text { Comment: N/A }\end{array}$ \\
\hline Allocation concealment (selection bias) & Low risk & $\begin{array}{l}\text { Quote: "The manufacturer prepared num- } \\
\text { bered packs of tablets corresponding to } \\
\text { the allocation list. Children enrolled in the } \\
\text { study were assigned by a study physician } \\
\text { to one of the three study cohorts after re- } \\
\text { sults of the HIV tests became available. The } \\
\text { physician then allocated the next pack of } \\
\text { tablets from the blocks assigned to that co- } \\
\text { hort to the participant." } \\
\text { Comment: sufficient allocation conceal- } \\
\text { ment seems likely }\end{array}$ \\
\hline
\end{tabular}

Blinding of participants (performance Low risk

bias)

Quote: “...double-blind, controlled trial...

All outcomes

All three formulations were similar in color, taste, appearance and size...participants were blind to the treatment assignments."

Comment: sufficient blinding seems likely

Blinding of personnel (performance bias) Low risk

All outcomes

Quote: “...double-blind, controlled trial... All three formulations were similar in color, taste, appearance and size...study staff... were blind to the treatment assignments." Comment: sufficient blinding seems likely

Blinding of outcome assessment (detection Low risk bias)

All outcomes

Quote: “...double-blind, controlled trial... All three formulations were similar in color, taste, appearance and size... Investigators... were blind to the treatment assignments." Comment: sufficient blinding seems likely

Incomplete outcome data (attrition bias) Unclear risk

\% Missing: 37

All outcomes

Reasons/details: among all 373 enrolled trial participants, including HIV-positive participants and participants in the multiple micronutrient group: "Thirty-seven children withdrew and one died before any home visits took place... Twelve (3.6\%) of the 335 children with at least one home visit died during the study...An additional $88(26.2 \%)$ of the 335 children who had at least one home visit did not complete the study...Fifty-seven children moved out of the area during the study. Reasons given 
Chhagan 2009 (Continued)

\begin{tabular}{|c|c|c|}
\hline & & $\begin{array}{l}\text { for withdrawal in the other } 31 \text { children in- } \\
\text { cluded lack of time by parent to participate } \\
\text { ( } 2 \text { children), the child not liking the taste } \\
\text { of the tablets ( } 3 \text { children), objections from } \\
\text { grandparent or father ( } 2 \text { children) and un- } \\
\text { specified reasons in } 24 \text { children." } \\
\text { Comment: a large proportion of the data } \\
\text { is missing, and reasons for missing data } \\
\text { were not reported separately for each study } \\
\text { group }\end{array}$ \\
\hline Selective reporting (reporting bias) & High risk & $\begin{array}{l}\text { Comment: weight and growth were pre- } \\
\text { specified as outcomes in the protocol for } \\
\text { this study; however, weight-for-age z-score } \\
\text { was measured but not reported, and height- } \\
\text { for-age z-score was measured but not re- } \\
\text { ported in a way that can be meta-anal- } \\
\text { ysed. All-cause hospitalisations, incidence } \\
\text { of LRTI, haemoglobin concentration, and } \\
\text { prevalence of anaemia were reported, but } \\
\text { were not pre-specified in the protocol for } \\
\text { this study } \\
\text { Protocol identifier: NCT00133419; IS- } \\
\text { RCTN39226623 }\end{array}$ \\
\hline Other bias & Unclear risk & $\begin{array}{l}\text { Comment: "Because of a delay in ship- } \\
\text { ment, } 243 \text { children enrolled in the study } \\
\text { did not receive supplements for } 11 \text { weeks. } \\
\text {." This lack of supplement receipt could } \\
\text { have influenced the outcomes, if the zinc } \\
\text { + vitamin A group had a significantly dif- } \\
\text { ferent proportion of children who did not } \\
\text { receive supplements than the vitamin A } \\
\text { group }\end{array}$ \\
\hline
\end{tabular}

Clark 1999

Methods

Participants
CRCT?: IRCT; Cross-over?: non-cross-over

Country: United Kingdom; Setting: Sheffield; Urbanicity: urban

Inclusion criteria: healthy

Exclusion criteria: history of metabolic disease; taking any medication known to influence bone metabolism or zinc status

Baseline characteristics

Avg age (mo): 146.4; Min age (mo): N/A; Max age (mo): N/A; \% Female: 100

Avg HAZ: N/A; Stunting: non-stunted; Avg height (cm): 154; Avg zinc concentration $(\mu \mathrm{g} / \mathrm{dL}): 80.3$

Total N: 47; Group 1 N: N/A; Group 2 N: N/A 
Clark 1999 (Continued)

\begin{tabular}{ll}
\hline Interventions & $\begin{array}{l}\text { Group 1: zinc } \\
\text { Formulation: unclear; Compound: citrate; Frequency: daily; Duration (mo): } 1.5 ; \text { Dose } \\
(\mathrm{mg}): 15 ; \text { Co-intervention(s): N/A }\end{array}$ \\
$\begin{array}{l}\text { Group 2: no zinc } \\
\text { Placebo given; Co-intervention(s): N/A }\end{array}$ \\
\hline Outcomes & $\begin{array}{l}\text { Height, weight, serum or plasma zinc concentration } \\
\text { Time point (wk): } 10\end{array}$ \\
\hline Notes & - The number of participants randomised to each study group is not explicitly reported. \\
& $\begin{array}{l}\text { However, given the numbers of participants analysed in the zinc and placebo groups for } \\
\text { baseline and final outcome measures, there were at least 25 participants in the zinc group } \\
\text { and at least } 21 \text { participants in the placebo group } \\
\text { - For all outcomes, "Baseline to final measure was } 10 \text { weeks; supplementation took place } \\
\text { over the last } 6 \text { weeks." }\end{array}$ \\
\hline
\end{tabular}

Risk of bias

\begin{tabular}{|c|c|c|}
\hline Bias & Authors' judgement & Support for judgement \\
\hline $\begin{array}{l}\text { Random sequence generation (selection } \\
\text { bias) }\end{array}$ & Unclear risk & $\begin{array}{l}\text { Quote: "These girls...were randomised..." } \\
\text { Comment: insufficient details available to } \\
\text { make a judgement as to whether or not an } \\
\text { allocation sequence was generated using a } \\
\text { truly random method }\end{array}$ \\
\hline Allocation concealment (selection bias) & Unclear risk & $\begin{array}{l}\text { Quote: N/A } \\
\text { Comment: insufficient details available to } \\
\text { make a judgement }\end{array}$ \\
\hline $\begin{array}{l}\text { Blinding of participants (performance } \\
\text { bias) } \\
\text { All outcomes }\end{array}$ & Low risk & $\begin{array}{l}\text { Quote: “...double-blind controlled } \\
\text { trial...identical placebo...” } \\
\text { Comment: sufficient blinding seems likely }\end{array}$ \\
\hline $\begin{array}{l}\text { Blinding of personnel (performance bias) } \\
\text { All outcomes }\end{array}$ & Low risk & $\begin{array}{l}\text { Quote: “...double-blind controlled } \\
\text { trial...identical placebo...” } \\
\text { Comment: sufficient blinding seems likely }\end{array}$ \\
\hline $\begin{array}{l}\text { Blinding of outcome assessment (detection } \\
\text { bias) } \\
\text { All outcomes }\end{array}$ & Low risk & $\begin{array}{l}\text { Quote: “...double-blind controlled } \\
\text { trial...identical placebo...” } \\
\text { Comment: sufficient blinding seems likely }\end{array}$ \\
\hline $\begin{array}{l}\text { Incomplete outcome data (attrition bias) } \\
\text { All outcomes }\end{array}$ & Low risk & $\begin{array}{l}\text { \% Missing: N/A } \\
\text { Reasons/details: N/A } \\
\text { Comment: the exact number of partici- } \\
\text { pants missing for each study group was } \\
\text { not explicitly reported, nor were reasons for } \\
\text { missing data. However, for outcomes of in- }\end{array}$ \\
\hline
\end{tabular}

Zinc supplementation for preventing mortality, morbidity, and growth failure in children aged 6 months to 12 years of age (Review) 
Clark 1999 (Continued)

\begin{tabular}{l|l|l} 
& & $\begin{array}{l}\text { terest to this review, between } 42 \text { and } 46 \\
\text { participants were analysed. So, between } 2 \% \\
\text { and } 11 \% \text { of data are missing for outcomes } \\
\text { of interest to this review. Missing data seem } \\
\text { too minimal to impact results }\end{array}$ \\
\hline Selective reporting (reporting bias) & Unclear risk & $\begin{array}{l}\text { Comment: no trial protocol referenced by } \\
\text { the study }\end{array}$ \\
\hline Other bias & Low risk & Comment: appears to be free of other bias \\
\hline
\end{tabular}

Cole 2012

\begin{tabular}{|c|c|}
\hline Methods & CRCT?: IRCT; Cross-over?: non-cross-over \\
\hline Participants & $\begin{array}{l}\text { Country: Brazil; Setting: Salvador-Bahia; Urbanicity: Not reported } \\
\text { Inclusion criteria: healthy children attending day care. (“Institutionalized"?) } \\
\text { Exclusion criteria: chronic medical problems including sickle cell disease, congenital } \\
\text { heart disease } \\
\text { Baseline characteristics } \\
\text { Avg age (mo): } 25.63 \text {; Min age (mo): } 6 \text {; Max age (mo): 48; \% Female: } 0.42 \\
\text { Avg HAZ: N/A; Stunting: N/A; Avg height (cm): N/A; Avg zinc concentration ( } \mu \mathrm{g} / \mathrm{dL}) \\
\text { : N/A } \\
\text { Total N: } 143 \text {; Group } 1 \mathrm{~N}: 75 \text {; Group } 2 \mathrm{~N}: 68\end{array}$ \\
\hline Interventions & $\begin{array}{l}\text { Group 1: zinc } \\
\text { Formulation: powder/paste; Compound: gluconate; Frequency: daily; Duration (mo): } \\
\text { 3; Dose (mg): 5; Co-intervention(s): sprinkles (including vitamin A and iron) } \\
\text { Group 2: no zinc } \\
\text { Placebo given; Co-intervention(s): sprinkles (including vitamin A and iron) }\end{array}$ \\
\hline Outcomes & $\begin{array}{l}\text { Incidence of all-cause diarrhoea } \\
\text { Time point (wk): } 13\end{array}$ \\
\hline
\end{tabular}

Notes

Monitoring was undertaken to make sure plates were not swapped, that children ate the food, and it was recorded if they did not eat the meal, or only ate half

\section{Risk of bias}

Bias

Authors' judgement

Random sequence generation (selection Low risk bias)

\section{Support for judgement}

Quote: “A randomização foi feita por berçários e salas, de acordo com sequência gerada por computador." - randomisation was done by nursery and classroom, according to a computer generated sequence. "The kids were randomized based on the classes that they were put in the daycare 
Cole 2012 (Continued)

\begin{tabular}{|c|c|c|}
\hline & & $\begin{array}{l}\text { since that would make delivery of the mi- } \\
\text { cronutrient sprinkle package easy." (Per- } \\
\text { sonal communication) } \\
\text { Comment: not clear how participants were } \\
\text { clustered and how this was included in the } \\
\text { analysis }\end{array}$ \\
\hline Allocation concealment (selection bias) & Unclear risk & Quote: N/A \\
\hline $\begin{array}{l}\text { Blinding of participants (performance } \\
\text { bias) } \\
\text { All outcomes }\end{array}$ & Low risk & Quote: "duplo cego" - double blind \\
\hline $\begin{array}{l}\text { Blinding of personnel (performance bias) } \\
\text { All outcomes }\end{array}$ & High risk & $\begin{array}{l}\text { Quote: "Os suplementos apenas eram aber- } \\
\text { tos e adicionados às refeiçôes no momento } \\
\text { de servir, por nutricionistas não cegas para } \\
\text { o estudo, já que os sachês estavam identi- } \\
\text { ficados quanto à presença de zinco" - the } \\
\text { supplements were only opened and added } \\
\text { to the meals at the moment of serving, by } \\
\text { nutritionists who were not blinded to the } \\
\text { study, since the sachets were marked as to } \\
\text { whether they included zinc or not } \\
\text { Comment: intervention was continued at } \\
\text { the weekends by sending parents a supply } \\
\text { of sachets with instructions (does not state } \\
\text { whether these sachets also had the contents } \\
\text { on the packet; if so a risk to the blinding } \\
\text { status of the participants) }\end{array}$ \\
\hline $\begin{array}{l}\text { Blinding of outcome assessment (detection } \\
\text { bias) } \\
\text { All outcomes }\end{array}$ & Low risk & $\begin{array}{l}\text { Quote: "Todos os médicos envolvidos es- } \\
\text { tavam cegos para o estudo" - all medics in- } \\
\text { volved were blinded to the study } \\
\text { Comment: this relates to those people un- } \\
\text { dertaking outcome assessment }\end{array}$ \\
\hline $\begin{array}{l}\text { Incomplete outcome data (attrition bias) } \\
\text { All outcomes }\end{array}$ & Low risk & $\begin{array}{l}\text { Quote: "Todas completaram o estudo." - } \\
\text { all participants completed the study }\end{array}$ \\
\hline Selective reporting (reporting bias) & Unclear risk & $\begin{array}{l}\text { Comment: } \\
\text { protocol registration NCT00967551. Pri- } \\
\text { mary outcome reported, but unclear what } \\
\text { other outcomes were measured }\end{array}$ \\
\hline Other bias & Low risk & Comment: appears to be free of other bias \\
\hline
\end{tabular}

Zinc supplementation for preventing mortality, morbidity, and growth failure in children aged 6 months to 12 years of age (Review) 
Methods

Participants
CRCT?: IRCT; Cross-over?: non-cross-over

Country: Brazil; Setting: Vila Mariana, São Paulo; Urbanicity: urban Inclusion criteria: N/A

Exclusion criteria: any organic or genetic condition that was correlated with growth retardation

Baseline characteristics

Avg age (mo): 91.72; Min age (mo): 72; Max age (mo): 120; \% Female: 47.5

Avg HAZ: N/A; Stunting: both - separate data given; Avg height $(\mathrm{cm}):$ N/A; Avg zinc concentration $(\mu \mathrm{g} / \mathrm{dL}): \mathrm{N} / \mathrm{A}$

Total N: 199; Group 1 N: 99; Group 2 N: 100

\section{Group 1: zinc}

Formulation: solution; Compound: amino acid chelate; Frequency: weekly; Duration (mo): 3; Dose (mg): 30; Co-intervention(s): N/A

Group 2: no zinc

Placebo given; Co-intervention(s): N/A

Outcomes

Height, weight, weight-to-height ratio

Time point (wk): 24

Notes

Quotes for this study are translated from Portuguese

Risk of bias

$\begin{array}{lll}\text { Bias Authors' judgement } & \text { Support for judgement }\end{array}$

Random sequence generation (selection Low risk bias)

Blinding of participants (performance Low risk bias)

All outcomes
Quote: “...Randomized...Trial...With the help of the computer program Epi Info $6.02 \ldots$ children were randomized through the Statcalc sub-routine."

Comment: N/A

Quote: N/A

Comment: insufficient details available to make a judgement

Quote: “...Double-Blind Trial...Each container contained the name and number of the child...properly labeled by a person not part of the research, who was the only one to know who was receiving medication or placebo."

Comment: sufficient blinding seems likely

Blinding of personnel (performance bias) Low risk All outcomes
Quote: “...Double-Blind Trial...Each container contained the name and number of the child...properly labeled by a person not part of the research, who was the only 
De Fonseca 2002 (Continued)

one to know who was receiving medication or placebo."

Comment: sufficient blinding seems likely

Blinding of outcome assessment (detection Low risk

bias)

All outcomes
Quote: “...Double-Blind Trial...Each container contained the name and number of the child...properly labeled by a person not part of the research, who was the only one to know who was receiving medication or placebo."

Comment: sufficient blinding seems likely
Incomplete outcome data (attrition bias) Unclear risk All outcomes
$\%$ Missing: 50

Reasons/details: during the period of supplementation, 29 children were excluded due to school transfer or unexplained absence, 2 children due to refusal to continue taking the drug, and 3 due to self reported side effects. At the end of the supplementation period, 6 children were excluded due to not having reached the minimum total of 12 doses of supplement or placebo, due to absences on the day of the week that supplementation took place. 60 children, who had one or more gaps in anthropometric measurements in December 2000 and/or March 2001, were also excluded. One hypothesis for this large loss is that some children changed neighbourhoods during the semester, but had not changed schools so as not to disrupt school performance. But at the end of the school year, these children went to new schools, because of their proximity to their new dwellings

Comment: a large proportion of data is missing, and neither reasons for, nor amounts of, missing data were reported separately for the zinc versus the placebo group

Comment: side effects, such as nausea and epigastric pain, were measured, but are not reported in a way that can be meta-analysed

Other bias Low risk 
Methods

Participants
CRCT?: IRCT; Cross-over?: non-cross-over

Country: Iran; Setting: 2 villages east of Shiraz; Urbanicity: rural Inclusion criteria: N/A

Exclusion criteria: heart failure; Down syndrome

Baseline characteristics

Avg age (mo): N/A; Min age (mo): 72; Max age (mo): 144; \% Female: 0

Avg HAZ: N/A; Stunting: unclear; Avg height $(\mathrm{cm})$ : N/A; Avg zinc concentration $(\mu \mathrm{g} /$ dL): N/A

Total N: 60; Group 1 N: 30; Group 2 N: 30

\begin{tabular}{ll}
\hline Interventions & Group 1: zinc \\
& Formulation: solution; Compound: sulfate; Frequency: daily; Duration (mo): 6; Dose \\
& $(\mathrm{mg}): 8$; Co-intervention(s): N/A \\
Group 2: no zinc & Placebo given; Co-intervention(s): N/A
\end{tabular}

Height, weight

Time point (wk): 24

\section{Notes}

\section{Risk of bias}

\begin{tabular}{|c|c|c|}
\hline Bias & Authors' judgement & Support for judgement \\
\hline $\begin{array}{l}\text { Random sequence generation (selection } \\
\text { bias) }\end{array}$ & Unclear risk & $\begin{array}{l}\text { Quote: “...randomized clinical } \\
\text { trial...children were selected randomly and } \\
\text { divided into two groups... One child was } \\
\text { assigned to the experimental group and an- } \\
\text { other one was placed in the control group } \\
\text { until the total size was reached." } \\
\text { Comment: insufficient details available to } \\
\text { make a judgement as to whether or not an } \\
\text { allocation sequence was generated using a } \\
\text { truly random method }\end{array}$ \\
\hline Allocation concealment (selection bias) & Unclear risk & $\begin{array}{l}\text { Quote: N/A } \\
\text { Comment: insufficient details available to } \\
\text { make a judgement }\end{array}$ \\
\hline $\begin{array}{l}\text { Blinding of participants (performance } \\
\text { bias) } \\
\text { All outcomes }\end{array}$ & Low risk & $\begin{array}{l}\text { Quote: } \\
\text { ble-blind......dinical trial...The syrups con- } \\
\text { taining zinc sulfate and placebo were iden- } \\
\text { tical and the taste and smell of the solutions } \\
\text { were the same...The placebo was provided } \\
\text { in completely similar bottles..." } \\
\text { Comment: sufficient blinding seems likely }\end{array}$ \\
\hline
\end{tabular}


Dehbozorgi 2007 (Continued)

\begin{tabular}{|c|c|c|}
\hline $\begin{array}{l}\text { Blinding of personnel (performance bias) } \\
\text { All outcomes }\end{array}$ & Low risk & $\begin{array}{l}\text { Quote: “...dou- } \\
\text { ble-blind...clinical trial...The syrups con- } \\
\text { taining zinc sulfate and placebo were iden- } \\
\text { tical and the taste and smell of the solutions } \\
\text { were the same...The placebo was provided } \\
\text { in completely similar bottles..." } \\
\text { Comment: sufficient blinding seems likely }\end{array}$ \\
\hline $\begin{array}{l}\text { Blinding of outcome assessment (detection } \\
\text { bias) } \\
\text { All outcomes }\end{array}$ & Low risk & $\begin{array}{l}\text { Quote: “...dou- } \\
\text { ble-blind...clinical trial...The syrups con- } \\
\text { taining zinc sulfate and placebo were iden- } \\
\text { tical and the taste and smell of the solutions } \\
\text { were the same...The placebo was provided } \\
\text { in completely similar bottles..." } \\
\text { Comment: sufficient blinding seems likely }\end{array}$ \\
\hline $\begin{array}{l}\text { Incomplete outcome data (attrition bias) } \\
\text { All outcomes }\end{array}$ & Unclear risk & $\begin{array}{l}\text { \% Missing: N/A } \\
\text { Reasons/details: N/A } \\
\text { Comment: amount of, and reasons for, } \\
\text { missing data were not reported }\end{array}$ \\
\hline Selective reporting (reporting bias) & High risk & $\begin{array}{l}\text { Comment: side effects were measured, but } \\
\text { are not reported }\end{array}$ \\
\hline Other bias & Low risk & Comment: appears to be free of other bias \\
\hline
\end{tabular}

DiGirolamo 2010

Methods

Participants
CRCT?: IRCT; Cross-over?: non-cross-over

Country: Guatemala; Setting: low-income community in Guatemala City; Urbanicity: urban

Inclusion criteria: in grades 1 to 4

Exclusion criteria: any known severe illness shown to affect zinc status such as sickle cell disease, cystic fibrosis, renal or liver disease, severe burns, or acrodermatitis enteropathica; any other severe or chronic illness not necessarily linked to zinc status (e.g. cancer, diabetes, or seizures)

Baseline characteristics

Avg age (mo): 108; Min age (mo): 72; Max age (mo): 132; \% Female: 50

Avg HAZ: -1.2; Stunting: both - separate data not given; Avg height (cm): N/A; Avg zinc concentration $(\mu \mathrm{g} / \mathrm{dL}): 75.3$

Total N: 750; Group 1 N: 378; Group 2 N: 372

Interventions

Group 1: zinc

Formulation: pill/tablet; Compound: oxide; Frequency: 5 days/wk; Duration (mo): 5.8; Dose (mg): 10; Co-intervention(s): N/A

Group 2: no zinc

Placebo given; Co-intervention(s): N/A 
DiGirolamo 2010 (Continued)

Outcomes

Height, weight, serum or plasma zinc concentration, prevalence of zinc deficiency Time point (wk): 24

Notes

"At approximately the time our study began, the local government in the study community implemented a school-based fortified milk program. Children in 4 out of the 5 schools received $200 \mathrm{~mL}$ whole milk/d fortified with" approximately $1.6 \mathrm{mg}$ zinc per 200 $\mathrm{mL}$ along with multiple micronutrients. "Children in the fifth school... received" a daily "food supplement", which contained " $2.1 \mathrm{mg}$ zinc" along with multiple micronutrients. However, these government-provided nutrients would have been received by both zinc the zinc group and the placebo group, "and the randomized controlled trial design of the study makes it very unlikely that this biased" its "results, as there is no reason to believe that one group received more of these nutrients than the other group."

\section{Risk of bias}

\begin{tabular}{l|l|l} 
Bias & Authors' judgement & Support for judgement \\
\hline $\begin{array}{l}\text { Random sequence generation (selection } \\
\text { bias) }\end{array}$ & Low risk & $\begin{array}{l}\text { Quote: "Individual children within each } \\
\text { classroom were randomly assigned by using } \\
\text { a computer-generated list on the basis of }\end{array}$ \\
& & $\begin{array}{l}\text { a 1:1:1:1 allocation ratio without blocking } \\
\text { constraints." }\end{array}$ \\
& Comment: N/A \\
\hline
\end{tabular}

Allocation concealment (selection bias) Low risk
Quote: "The zinc and placebo tablets were divided into color-coded vials ( 2 colors assigned to zinc; 2 colors assigned to placebo) by a staff member at INCAP who was not involved in the study...All study participants and members of the study team were blinded to the treatment code, which was maintained in sealed envelopes at INCAP and Rollins School of Public Health. The envelopes were opened at the end of the study after preliminary data analyses had been completed."

Comment: sufficient allocation concealment seems likely

Quote:

"...double-blind,

Blinding of participants (performance Low risk bias)

All outcomes controlled trial...The placebo was similar in taste and appearance to the zinc tablet. ..All study participants...were blinded to the treatment code, which was maintained in sealed envelopes at INCAP and Rollins School of Public Health. The envelopes were opened at the end of the study after preliminary data analyses had been com- 
DiGirolamo 2010 (Continued)

pleted.“

Comment: sufficient blinding seems likely

Blinding of personnel (performance bias) Low risk

All outcomes

Quote:

..double-blind, controlled trial...The zinc and placebo tablets were divided into colorcoded vials ( 2 colors assigned to zinc; 2 colors assigned to placebo) by a staff member at INCAP who was not involved in the study...Individuals who administered the supplements $(n=7)$ received a list of all children in their classroom enrolled in the study and their assigned color group...The placebo was similar in taste and appearance to the zinc tablet."

Comment: sufficient blinding seems likely

Blinding of outcome assessment (detection Low risk bias)

All outcomes
Quote:

"...double-

blind, controlled trial...The placebo was similar in taste and appearance to the zinc tablet...All...members of the study team were blinded to the treatment code, which was maintained in sealed envelopes at INCAP and Rollins School of Public Health. The envelopes were opened at the end of the study after preliminary data analyses had been completed."

Comment: sufficient blinding seems likely

\% Missing: 4.7

Reasons/details: "Of the 750 children, 30 (4.0\%) children never received treatment or completed the baseline assessment. Of the children who received at least one tablet in the zinc group, 3 were lost: 1 participant was lost due to "parent refusal", 1 "did not go to final evaluation", and 1 had a change of address. Of the children who received at least one tablet in the zinc group, 2 were lost: 1 participant was lost due to a change of address, and 1 due to "parent refusal."

Comment: missing data seem too minimal to impact results

Selective reporting (reporting bias) Unclear risk
Comment: weight and height were reported, but were not pre-specified in the protocol for this study. However, these were not reported as primary outcomes

Protocol identifier: NCT00283660 
DiGirolamo 2010 (Continued)

$\begin{array}{lll}\text { Other bias } & \text { Low risk } \quad \text { Comment: appears to be free of other bias }\end{array}$

Ebrahimi 2006

\begin{tabular}{ll} 
Methods & CRCT?: IRCT; Cross-over?: non-cross-over \\
\hline Participants & $\begin{array}{l}\text { Country: Iran; Setting: Yasuj city, in the southwest of Iran; Urbanicity: urban } \\
\text { Inclusion criteria: N/A } \\
\text { Exclusion criteria: N/A } \\
\text { Baseline characteristics } \\
\text { Avg age (mo): N/A; Min age (mo): 96; Max age (mo): 132; \% Female: } 53 \\
\text { Avg HAZ: N/A; Stunting: unclear; Avg height (cm): N/A; Avg zinc concentration ( } \mu \text { g/ } \\
\text { dL): N/A } \\
\text { Total N: 804; Group 1 N: 386; Group 2 N: } 418\end{array}$ \\
\hline Group 1: zinc \\
\hline Formulation: solution; Compound: unclear; Frequency: 6 days/wk; Duration (mo): 7; \\
Dose (mg): $10 ;$ Co-intervention(s): N/A \\
Group 2: no zinc \\
Placebo given; Co-intervention(s): N/A
\end{tabular}

Risk of bias

\begin{tabular}{|c|c|c|}
\hline Bias & Authors' judgement & Support for judgement \\
\hline $\begin{array}{l}\text { Random sequence generation (selection } \\
\text { bias) }\end{array}$ & Unclear risk & $\begin{array}{l}\text { Quote: "Children were randomly assigned } \\
\text { to zinc or placebo group..." } \\
\text { Comment: insufficient details available to } \\
\text { make a judgement as to whether or not an } \\
\text { allocation sequence was generated using a } \\
\text { truly random method }\end{array}$ \\
\hline Allocation concealment (selection bias) & Unclear risk & $\begin{array}{l}\text { Quote: N/A } \\
\text { Comment: insufficient details available to } \\
\text { make a judgement }\end{array}$ \\
\hline $\begin{array}{l}\text { Blinding of participants (performance } \\
\text { bias) } \\
\text { All outcomes }\end{array}$ & Low risk & $\begin{array}{l}\text { Quote: “...double blind placebo controlled } \\
\text { trial...Zinc and also placebo were admin- } \\
\text { istrated to the children, between meals, in } \\
\text { an identical form (syrup) and identical pre- } \\
\text { coded containers." } \\
\text { Comment: sufficient blinding seems likely }\end{array}$ \\
\hline
\end{tabular}


Ebrahimi 2006 (Continued)

\begin{tabular}{|c|c|c|}
\hline $\begin{array}{l}\text { Blinding of personnel (performance bias) } \\
\text { All outcomes }\end{array}$ & Low risk & $\begin{array}{l}\text { Quote: “... double blind placebo controlled } \\
\text { trial...Zinc and also placebo were admin- } \\
\text { istrated to the children, between meals, in } \\
\text { an identical form (syrup) and identical pre- } \\
\text { coded containers." } \\
\text { Comment: sufficient blinding seems likely }\end{array}$ \\
\hline $\begin{array}{l}\text { Blinding of outcome assessment (detection } \\
\text { bias) } \\
\text { All outcomes }\end{array}$ & Low risk & $\begin{array}{l}\text { Quote: “...double blind placebo controlled } \\
\text { trial...Zinc and also placebo were admin- } \\
\text { istrated to the children, between meals, in } \\
\text { an identical form (syrup) and identical pre- } \\
\text { coded containers." } \\
\text { Comment: sufficient blinding seems likely }\end{array}$ \\
\hline $\begin{array}{l}\text { Incomplete outcome data (attrition bias) } \\
\text { All outcomes }\end{array}$ & Unclear risk & $\begin{array}{l}\text { \% Missing: N/A } \\
\text { Reasons/details: N/A } \\
\text { Comment: amount of, and reasons for, } \\
\text { missing data were not reported }\end{array}$ \\
\hline Selective reporting (reporting bias) & Unclear risk & $\begin{array}{l}\text { Comment: no trial protocol referenced by } \\
\text { the study }\end{array}$ \\
\hline Other bias & Low risk & Comment: appears to be free of other bias \\
\hline
\end{tabular}

Fallahi 2007

\begin{tabular}{|c|c|}
\hline Methods & CRCT?: IRCT; Cross-over?: non-cross-over \\
\hline Participants & $\begin{array}{l}\text { Country: Iran; Setting: Khorramabad city, capital of Lorestan province in western Iran; } \\
\text { Urbanicity: urban } \\
\text { Inclusion criteria: in } 5 \text { th grade } \\
\text { Exclusion criteria: renal failure, thalassaemia, tuberculosis, parasitic diseases, or infec- } \\
\text { tions; taking supplementary vitamins and minerals } \\
\text { Baseline characteristics } \\
\text { Avg age (mo): 133.2; Min age (mo): } 132 \text {; Max age (mo): 143; \% Female: } 62 \\
\text { Avg HAZ: N/A; Stunting: unclear; Avg height (cm): 139.6; Avg zinc concentration ( } \mu \mathrm{g} / \\
\text { dL): } 71.7 \\
\text { Total N: } 53 \text {; Group } 1 \mathrm{~N}: 26 \text {; Group } 2 \mathrm{~N}: 27\end{array}$ \\
\hline Interventions & $\begin{array}{l}\text { Group 1: zinc } \\
\text { Formulation: capsule; Compound: sulfate; Frequency: } 6 \text { days/wk; Duration (mo): 4; } \\
\text { Dose (mg): 20; Co-intervention(s): } 20 \mathrm{mg} \text { iron } \\
\text { Group 2: no zinc } \\
\text { Placebo given; Co-intervention(s): } 20 \mathrm{mg} \text { iron }\end{array}$ \\
\hline Outcomes & $\begin{array}{l}\text { Serum or plasma zinc concentration, blood haemoglobin concentration, serum or plasma } \\
\text { ferritin concentration } \\
\text { Time point (wk): } 16\end{array}$ \\
\hline
\end{tabular}

Zinc supplementation for preventing mortality, morbidity, and growth failure in children aged 6 months to 12 years of age (Review)

Copyright @ 2014 The Cochrane Collaboration. Published by John Wiley \& Sons, Ltd. 
Fallahi 2007 (Continued)

Notes
- In addition to the study groups mentioned in this table, there was a group of participants
who received zinc only; but there was no placebo group to which this zinc group could
be compared in this review. So, baseline characteristics reported in this table are weighted
averages of all groups except this zinc group, since this group is not included in any meta-
analyses in this review
- The number of participants randomised might be off by 1 person, given discrepant
numbers stated in the trial report
- Though the unit of baseline height is not explicitly stated, it seems likely that the unit
is $\mathrm{cm}$. Assuming that the unit is $\mathrm{cm}$, then the baseline height is $139.6 \mathrm{~cm}$

\section{Risk of bias}

\begin{tabular}{|c|c|c|}
\hline Bias & Authors' judgement & Support for judgement \\
\hline $\begin{array}{l}\text { Random sequence generation (selection } \\
\text { bias) }\end{array}$ & Unclear risk & $\begin{array}{l}\text { Quote: “...children...were randomly sup- } \\
\text { plemented..." } \\
\text { Comment: insufficient details available to } \\
\text { make a judgement as to whether or not an } \\
\text { allocation sequence was generated using a } \\
\text { truly random method }\end{array}$ \\
\hline Allocation concealment (selection bias) & Unclear risk & $\begin{array}{l}\text { Quote: N/A } \\
\text { Comment: insufficient details available to } \\
\text { make a judgement }\end{array}$ \\
\hline $\begin{array}{l}\text { Blinding of participants (performance } \\
\text { bias) } \\
\text { All outcomes }\end{array}$ & Unclear risk & $\begin{array}{l}\text { Quote: “...double-blind clinical trial...” } \\
\text { Comment: insufficient details available to } \\
\text { make a judgement }\end{array}$ \\
\hline $\begin{array}{l}\text { Blinding of personnel (performance bias) } \\
\text { All outcomes }\end{array}$ & Unclear risk & $\begin{array}{l}\text { Quote: “...double-blind clinical trial...” } \\
\text { Comment: insufficient details available to } \\
\text { make a judgement }\end{array}$ \\
\hline $\begin{array}{l}\text { Blinding of outcome assessment (detection } \\
\text { bias) } \\
\text { All outcomes }\end{array}$ & Unclear risk & $\begin{array}{l}\text { Quote: “...double-blind clinical trial...” } \\
\text { Comment: insufficient details available to } \\
\text { make a judgement }\end{array}$ \\
\hline
\end{tabular}

Incomplete outcome data (attrition bias) Low risk

All outcomes

\begin{abstract}
\% Missing: N/A
Reasons/details: "Only one child dropped out of the study before the end of the 4 months."

Comment: it is unclear which study group this one participant belonged to. However, even if this participant was in the iron group or the iron + zinc group, only approximately $2 \%$ of data would be missing for participants eligible for this review. The
\end{abstract}


Fallahi 2007 (Continued)

amount of missing data seems too minimal to impact results

\begin{tabular}{l|ll} 
Selective reporting (reporting bias) & Unclear risk & $\begin{array}{l}\text { Comment: no trial protocol referenced by } \\
\text { the study }\end{array}$ \\
\hline Other bias & Low risk & Comment: appears to be free of other bias \\
\hline
\end{tabular}

Friis 1997

Methods

CRCT?: IRCT; Cross-over?: non-cross-over

Participants

Country: Zimbabwe; Setting: Chiredzi District in southeastern Zimbabwe; Urbanicity: rural

Inclusion criteria: attending grades 3 to 6

Exclusion criteria: N/A

Baseline characteristics

Avg age (mo): 132; Min age (mo): 132; Max age (mo): 204; \% Female: 54

Avg HAZ: -1.18; Stunting: unclear; Avg height (cm): N/A; Avg zinc concentration $(\mu \mathrm{g} /$ dL): 77.8

Total N: 313; Group 1 N: 156; Group 2 N: 157

Group 1: zinc
Formulation: pill/tablet; Compound: sulfate; Frequency: "On school days"; Duration
(mo): 12; Dose $(\mathrm{mg}): 30 \mathrm{mg}$ to children weighing below $29.5 \mathrm{~kg} ; 50 \mathrm{mg}$ to children
weighing $29.5 \mathrm{~kg}$ or above; Co-intervention(s): N/A
Group 2: no zinc
Placebo given; Co-intervention(s): N/A

Outcomes

Height, weight, weight-to-height ratio, serum or plasma zinc concentration Time point (wk): 52

Notes

- "Of the $370 \mathrm{~d}$ long study period, school leaves, weekends and public holidays comprised $185 \mathrm{~d}$. The maximum number of tablets that could be taken by a child was thus 185 , equivalent to a tablet every other day."

- Due to "severe drought" a "school-based food supplementation programme" was introduced "in the middle of June 1992, after completion of the three-month followup examination, and was still in operation at the time of cessation of the zinc/placebo supplementation. The food supplementation programme provided the children with imported maize, dried fish, sugar beans and oil."

\section{Risk of bias}

\begin{tabular}{|c|c|c|}
\hline Bias & Authors' judgement & Support for judgement \\
\hline $\begin{array}{l}\text { Random sequence generation (selection } \\
\text { bias) }\end{array}$ & Unclear risk & $\begin{array}{l}\text { Quote: "Children were allocated to either } \\
\text { zinc or placebo according to the result of } \\
\text { simple randomization." }\end{array}$ \\
\hline
\end{tabular}

Zinc supplementation for preventing mortality, morbidity, and growth failure in children aged 6 months to 12 years of age (Review) 
Friis 1997 (Continued)

Comment: insufficient details available to make a judgement as to whether or not an allocation sequence was generated using a truly random method

Allocation concealment (selection bias) Unclear risk
Quote: "The code was not broken before the data entry, cleaning and analysis were completed."

Comment: despite this statement, the method of allocation concealment is not described in sufficient detail to allow a definite judgement

Quote:

“...double-

Blinding of participants (performance Low risk bias)

All outcomes

blind, placebo-controlled trial...zinc sulphate tablets or identical-looking placebo tablets... The code was not broken before the data entry, cleaning and analysis were completed."

Comment: sufficient blinding seems likely

Blinding of personnel (performance bias) Low risk All outcomes

Quote:

“...double-

blind, placebo-controlled trial...zinc sulphate tablets or identical-looking placebo tablets...The code was not broken before the data entry, cleaning and analysis were completed."

Comment: sufficient blinding seems likely

Blinding of outcome assessment (detection Low risk bias)

All outcomes

Quote:

“...double-

blind, placebo-controlled trial...zinc sulphate tablets or identical-looking placebo tablets...The code was not broken before the data entry, cleaning and analysis were completed."

Comment: sufficient blinding seems likely

Incomplete outcome data (attrition bias) Unclear risk

\% Missing: 11.8

All outcomes

Selective reporting (reporting bias)

High risk
Reasons/details: “. ...among the 37 (11.8\%) children lost to 12-months follow-up, 22 were in the placebo and 15 in the zinc group..."

Comment: no information was reported on reasons for missing data

Comment: change in serum ferritin concentration was measured, but is not reported in a way that can be meta-analysed. Prevalence of zinc deficiency and iron de- 
Friis 1997 (Continued)

ficiency may have been measured as outcomes, but are not reported

Other bias

Low risk

Comment: appears to be free of other bias

Garcia 1998

Methods

Participants

Interventions

Notes
CRCT?: IRCT; Cross-over?: cross-over

Country: Chile; Setting: N/A; Urbanicity: unclear

Inclusion criteria: idiopathic short stature; diminished growth velocity; no other pathological condition nor GH deficiency; zinc intake $<10 \mathrm{mg} /$ day

Exclusion criteria: N/A

Baseline characteristics

Avg age (mo): 93.6; Min age (mo): 66; Max age (mo): 159.6; \% Female: 0

Avg HAZ: -2.6; Stunting: both - separate data not given; Avg height (cm): 111.8; Avg zinc concentration $(\mu \mathrm{g} / \mathrm{dL}): 110$

Total N: 33; Group 1 N: 16; Group 2 N: 17

Group 1: zinc

Formulation: unclear; Compound: acetate; Frequency: daily; Duration (mo): 6; Dose (mg): 20; Co-intervention(s): N/A

Group 2: no zinc

Placebo given; Co-intervention(s): N/A

Height, weight, serum or plasma zinc concentration

Time point (wk): 24

- The country in which this study took place was not explicitly stated. However, based on the trial authors' affiliations, the language in which the trial report for this study was written, and the hospital from which ethical approval for this study was obtained, it seems that the study took place in Chile

- The trial report for this study is written in Spanish, so quotes from it are English translations

\section{Risk of bias}

\begin{tabular}{|c|c|c|}
\hline Bias & Authors' judgement & Support for judgement \\
\hline $\begin{array}{l}\text { Random sequence generation (selection } \\
\text { bias) }\end{array}$ & Unclear risk & $\begin{array}{l}\text { Quote: “...a study was carried out in } 33 \text { eu- } \\
\text { trophic prepubertal boys... They were ran- } \\
\text { domly assigned..." } \\
\text { Comment: insufficient details available to } \\
\text { make a judgement as to whether or not an al- } \\
\text { location sequence was generated using a truly } \\
\text { random method }\end{array}$ \\
\hline
\end{tabular}

Zinc supplementation for preventing mortality, morbidity, and growth failure in children aged 6 months to 12 years of age (Review) 
Garcia 1998 (Continued)

\begin{tabular}{|c|c|c|}
\hline Allocation concealment (selection bias) & Unclear risk & $\begin{array}{l}\text { Quote: "They were randomly assigned in a } \\
\text { double blind fashion...Pharmaceutical prepa- } \\
\text { rations were not identifiable..." } \\
\text { Comment: despite this statement, the method } \\
\text { of allocation concealment is not described in } \\
\text { sufficient detail to allow a definite judgement }\end{array}$ \\
\hline $\begin{array}{l}\text { Blinding of participants (performance } \\
\text { bias) } \\
\text { All outcomes }\end{array}$ & Low risk & $\begin{array}{l}\text { Quote: “...in a double blind fashion...The } \\
\text { pharmaceutical preparations were not identi- } \\
\text { fiable..." } \\
\text { Comment: sufficient blinding seems likely }\end{array}$ \\
\hline $\begin{array}{l}\text { Blinding of personnel (performance bias) } \\
\text { All outcomes }\end{array}$ & Low risk & $\begin{array}{l}\text { Quote: “...in a double blind fashion...The } \\
\text { pharmaceutical preparations were not identi- } \\
\text { fiable..." } \\
\text { Comment: sufficient blinding seems likely }\end{array}$ \\
\hline $\begin{array}{l}\text { Blinding of outcome assessment (detection } \\
\text { bias) } \\
\text { All outcomes }\end{array}$ & Low risk & $\begin{array}{l}\text { Quote: “...in a double blind fashion...The } \\
\text { pharmaceutical preparations were not identi- } \\
\text { fiable..." } \\
\text { Comment: sufficient blinding seems likely }\end{array}$ \\
\hline $\begin{array}{l}\text { Incomplete outcome data (attrition bias) } \\
\text { All outcomes }\end{array}$ & Low risk & $\begin{array}{l}\text { \% Missing: } 3 \\
\text { Reasons/details: } 1 \text { patient, who started pu- } \\
\text { berty during the study, was excluded } \\
\text { Comment: though it is unclear whether exclu- } \\
\text { sion based on initiation of puberty is likely to } \\
\text { bias results, the amount of missing data seems } \\
\text { too minimal to impact results }\end{array}$ \\
\hline Selective reporting (reporting bias) & Unclear risk & $\begin{array}{l}\text { Comment: no trial protocol referenced by the } \\
\text { study }\end{array}$ \\
\hline Other bias & Low risk & Comment: appears to be free of other bias \\
\hline
\end{tabular}

Gibson 1989

Methods

Participants
CRCT?: IRCT; Cross-over?: non-cross-over

Country: Canada; Setting: southern Ontario; Urbanicity: unclear

Inclusion criteria: male; height-for-age $\leq 15$ th percentile according to reference data of the National Center for Health Statistics (NCHS); midparent height > 25th percentile; Caucasian; full term with weight-for-height appropriate for gestational age; apparently healthy with no detectable medical reasons for poor growth

Exclusion criteria: N/A

Baseline characteristics

Avg age (mo): 75.8; Min age (mo): 59; Max age (mo): 95; \% Female: 0

Avg HAZ: -1.39; Stunting: both - separate data not given; Avg height (cm): 110.9; Avg 
Gibson 1989 (Continued)

zinc concentration $(\mu \mathrm{g} / \mathrm{dL}): 105$

Total N: 60; Group 1 N: 30; Group 2 N: 30

$\begin{array}{ll}\text { Interventions } & \text { Group 1: zinc } \\ & \text { Formulation: solution; Compound: sulfate; Frequency: daily; Duration (mo): 12; Dose } \\ & \text { (mg): 10; Co-intervention(s): N/A } \\ & \text { Group 2: no zinc } \\ & \text { Placebo given; Co-intervention(s): N/A }\end{array}$

Outcomes

Height, weight, weight-to-height ratio, serum or plasma zinc concentration

Time point (wk): 52

Notes

Risk of bias

\begin{tabular}{|c|c|c|}
\hline Bias & Authors' judgement & Support for judgement \\
\hline $\begin{array}{l}\text { Random sequence generation (selection } \\
\text { bias) }\end{array}$ & Unclear risk & $\begin{array}{l}\text { Quote: "The subjects were...pair-matched } \\
\text { as closely as possible for initial height } \\
\text { percentile...initial hair Zn concentra- } \\
\text { tions....age...midpoint height percentile, } \\
\text { and reported presence or absence of a picky } \\
\text { appetite. The first member of each pair was } \\
\text { randomly assigned..." } \\
\text { Comment: insufficient details available to } \\
\text { make a judgement as to whether or not an } \\
\text { allocation sequence was generated using a } \\
\text { truly random method }\end{array}$ \\
\hline Allocation concealment (selection bias) & Low risk & $\begin{array}{l}\text { Quote: "The first member of each pair was } \\
\text { randomly assigned by an investigator not } \\
\text { involved in the project..." } \\
\text { Comment: indicates central randomisation } \\
\text { (i.e. randomisation by someone not in- } \\
\text { volved with enrolling patients) to conceal } \\
\text { allocation }\end{array}$ \\
\hline
\end{tabular}

Blinding of participants (performance Low risk bias)

All outcomes
Quote: “A double-blind, pair-matched 12mo study...The control children received 1 $\mathrm{mL}$ of a placebo solution indistinguishable from the $\mathrm{Zn}$ solution in color and flavor, which was administered in a similar manner."

Comment: sufficient blinding seems likely

Quote: “A double-blind, pair-matched 12mo study...The control children received 1 $\mathrm{mL}$ of a placebo solution indistinguishable 
Gibson 1989 (Continued)

from the $\mathrm{Zn}$ solution in color and flavor, which was administered in a similar manner."

Comment: sufficient blinding seems likely

Blinding of outcome assessment (detection Low risk bias)

All outcomes
Quote: “A double-blind, pair-matched 12mo study...The control children received 1 $\mathrm{mL}$ of a placebo solution indistinguishable from the $\mathrm{Zn}$ solution in color and flavor, which was administered in a similar manner."

Comment: sufficient blinding seems likely

\% Missing: 0

Reasons/details: N/A

Comment: N/A

Comment: no trial protocol referenced by the study

Comment: appears to be free of other bias

Gracia 2005

Methods

Participants
CRCT?: IRCT; Cross-over?: non-cross-over

Country: Colombia; Setting: Cali; Urbanicity: urban

Inclusion criteria: healthy at the moment of the examination for selecting study participants; without chronic illness or clinical manifestations of malnutrition; adequate food consumption that satisfied their energy and protein requirements

Exclusion criteria: N/A

Baseline characteristics

Avg age (mo): N/A; Min age (mo): 24; Max age (mo): 59; \% Female: N/A

Avg HAZ: 0; Stunting: both - separate data not given; Avg height (cm): 95.84; Avg zinc concentration $(\mu \mathrm{g} / \mathrm{dL}): 72.6$

Total N: 350; Group 1 N: 175; Group 2 N: 175
Interventions

Outcomes

\section{Group 1: zinc}

Formulation: unclear; Compound: unclear; Frequency: daily; Duration (mo): 8; Dose (mg): 12; Co-intervention(s): mineral and vitamin supplement

Group 2: no zinc

Placebo given; Co-intervention(s): mineral and vitamin supplement
Height, weight-to-height ratio

Time point (wk): 32
- Though the exact numbers of participants randomised to each study group was not explicitly stated, the trial report does state that they planned to have 2 study groups of 
Gracia 2005 (Continued)

equal numbers

- In this study, all children with parasites at baseline were treated

- Though the English abstract for this trial report states that zinc and placebo were provided for 9 months, the Spanish abstract and the full text of this trial report state that zinc and placebo were provided for 8 months

- The trial report for this study is written in Spanish, so quotes from it are English translations

\section{Risk of bias}

\begin{tabular}{|c|c|c|}
\hline Bias & Authors' judgement & Support for judgement \\
\hline $\begin{array}{l}\text { Random sequence generation (selection } \\
\text { bias) }\end{array}$ & Unclear risk & $\begin{array}{l}\text { Quote: “...they were randomly divided in } \\
\text { two groups..." } \\
\text { Comment: insufficient details available to } \\
\text { make a judgement as to whether or not an } \\
\text { allocation sequence was generated using a } \\
\text { truly random method }\end{array}$ \\
\hline Allocation concealment (selection bias) & Unclear risk & $\begin{array}{l}\text { Quote: N/A } \\
\text { Comment: insufficient details available to } \\
\text { make a judgement }\end{array}$ \\
\hline $\begin{array}{l}\text { Blinding of participants (performance } \\
\text { bias) } \\
\text { All outcomes }\end{array}$ & Low risk & $\begin{array}{l}\text { Quote: "...a double blind study...The } \\
\text { packaging of the two preparations were } \\
\text { identical...and its composition was kept } \\
\text { secret until the end of the analy- } \\
\text { sis... Neither...nor the parents knew the } \\
\text { composition of the supplement that corre- } \\
\text { sponded to each child." } \\
\text { Comment: sufficient blinding seems likely }\end{array}$ \\
\hline $\begin{array}{l}\text { Blinding of personnel (performance bias) } \\
\text { All outcomes }\end{array}$ & Low risk & $\begin{array}{l}\text { Quote: "...a double blind study...The } \\
\text { packaging of the two preparations were } \\
\text { identical... and its composition was kept se- } \\
\text { cret until the end of the analysis." } \\
\text { Comment: sufficient blinding seems likely }\end{array}$ \\
\hline $\begin{array}{l}\text { Blinding of outcome assessment (detection } \\
\text { bias) } \\
\text { All outcomes }\end{array}$ & Low risk & $\begin{array}{l}\text { Quote: "...a double blind study...The } \\
\text { packaging of the two preparations were } \\
\text { identical....and its composition was kept se- } \\
\text { cret until the end of the analysis... Neither } \\
\text { the group of investigators nor...knew the } \\
\text { composition of the supplement that corre- } \\
\text { sponded to each child...The codes of the } \\
\text { two supplements were only opened once } \\
\text { the analysis was concluded." } \\
\text { Comment: sufficient blinding seems likely }\end{array}$ \\
\hline
\end{tabular}

Zinc supplementation for preventing mortality, morbidity, and growth failure in children aged 6 months to 12 years of age (Review) 
Gracia 2005 (Continued)

\begin{tabular}{|c|c|c|}
\hline $\begin{array}{l}\text { Incomplete outcome data (attrition bias) } \\
\text { All outcomes }\end{array}$ & Unclear risk & $\begin{array}{l}\text { \% Missing: } 34 \\
\text { Reasons/details: of the } 350 \text { children with } \\
\text { which the study began, } 22 \% \text { were missing } \\
\text { due to migration from the study area, and } \\
\text { a few withdrew because the physician sug- } \\
\text { gested it or due to the family's decision } \\
\text { Comment: migration was the most com- } \\
\text { mon reason for missing data, and this } \\
\text { reason is unlikely to bias results. How- } \\
\text { ever, } 12 \% \text { of data were missing for reasons } \\
\text { other than migration, and reasons for, and } \\
\text { amount of, missing data is not reported sep- } \\
\text { arately for either study group }\end{array}$ \\
\hline Selective reporting (reporting bias) & High risk & $\begin{array}{l}\text { Comment: serum zinc concentration was } \\
\text { measured, but is not reported in a way that } \\
\text { can be meta-analysed. Prevalence of stunt- } \\
\text { ing was measured as an outcome, but is not } \\
\text { reported as an outcome }\end{array}$ \\
\hline Other bias & Low risk & Comment: appears to be free of other bias \\
\hline
\end{tabular}

Gupta 2003

Methods

Participants
CRCT?: IRCT; Cross-over?: non-cross-over

Country: India; Setting: 3 adjoining villages about $10 \mathrm{~km}$ away from Kolkata, West Bengal; Urbanicity: rural

Inclusion criteria: residing permanently in these villages with their parents

Exclusion criteria: N/A

Baseline characteristics

Avg age (mo): N/A; Min age (mo): 6; Max age (mo): 41; \% Female: 53.93

Avg HAZ: N/A; Stunting: unclear; Avg height (cm): N/A; Avg zinc concentration $(\mu \mathrm{g} /$ dL): N/A

Total N: 280; Group 1 N: 186; Group 2 N: 94

\section{Group 1: zinc}

Formulation: solution; Compound: sulfate; Frequency: 5 days/wk or weekly; Duration (mo): 4; Dose (mg): $10 \mathrm{mg}$ or $50 \mathrm{mg}$; Co-intervention(s): N/A

Group 2: no zinc

Placebo given; Co-intervention(s): N/A
Outcomes

Notes
Incidence of all-cause diarrhoea

Time point (wk): 16

95 children received " $10 \mathrm{mg}$ zinc for $5 \mathrm{~d}$ wk-1", 91 children received " $50 \mathrm{mg}$ zinc once weekly", and 94 children received placebo 


\section{Gupta 2003 (Continued)}

\section{Risk of bias}

\begin{tabular}{|c|c|c|}
\hline Bias & Authors' judgement & Support for judgement \\
\hline $\begin{array}{l}\text { Random sequence generation (selection } \\
\text { bias) }\end{array}$ & Low risk & $\begin{array}{l}\text { Quote: "The randomization was done by a } \\
\text { statistician using random number tables." } \\
\text { Comment: N/A }\end{array}$ \\
\hline Allocation concealment (selection bias) & Low risk & $\begin{array}{l}\text { Quote: "The two zinc syrups and placebo } \\
\text { were...prepared in identical bottles...bottles } \\
\text { were numbered according to the random } \\
\text { number by the pharmaceutical company, } \\
\text { which kept the code number to maintain } \\
\text { confidentiality." } \\
\text { Comment: indicates central randomisation } \\
\text { (i.e. randomisation by someone not in- } \\
\text { volved with enrolling patients) and sequen- } \\
\text { tially numbered drug containers of identi- } \\
\text { cal appearance to conceal allocation }\end{array}$ \\
\hline
\end{tabular}

Blinding of participants (performance Low risk bias)

Quote: “...double-blind...The two zinc

All outcomes syrups and placebo were similar in colour and taste and were prepared in identical bottles."

Comment: sufficient blinding seems likely

Blinding of personnel (performance bias) Low risk All outcomes

Quote: “...double-blind...The two zinc syrups and placebo were similar in colour and taste and were prepared in identical bottles."

Comment: sufficient blinding seems likely

Blinding of outcome assessment (detection Low risk bias)

Quote: “...double-blind...The two zinc syrups and placebo were similar in colour and taste and were prepared in identical bottles."

Comment: sufficient blinding seems likely

Incomplete outcome data (attrition bias) Low risk \% Missing: 0

All outcomes

Reasons/details: N/A

Comment: though the authors did not explicitly report that there was no missing data, it seems from the text and tables that there were no missing data

Comment: side effects (e.g. vomiting) were measured, but are not reported in a way that can be meta-analysed 


\section{Gupta 2003 (Continued)}

\begin{tabular}{l|l} 
Other bias $\quad$ Low risk Comment: appears to be free of other bias
\end{tabular}

\section{Gupta 2007}

Methods

Participants

\section{CRCT?: CRCT; Cross-over?: non-cross-over}

Country: India; Setting: 11 villages located $35 \mathrm{~km}$ from Kolkata; Urbanicity: rural Inclusion criteria: N/A

Exclusion criteria: N/A

Baseline characteristics

Avg age (mo): N/A; Min age (mo): 6; Max age (mo): 48; \% Female: 51

Avg HAZ: N/A; Stunting: unclear; Avg height $(\mathrm{cm})$ : N/A; Avg zinc concentration $(\mu \mathrm{g} /$ dL): N/A

Total N: 1878; Group 1 N: 943; Group 2 N: 935

Total clusters: 30; Group 1 clusters: N/A; Group 2 clusters: N/A

\begin{tabular}{ll} 
Interventions & $\begin{array}{l}\text { Group 1: zinc } \\
\text { Formulation: solution; Compound: unclear; Frequency: weekly; Duration (mo): 6; Dose } \\
(\mathrm{mg}): 50 \text {; Co-intervention(s): vitamin B complex }\end{array}$ \\
& $\begin{array}{l}\text { Group 2: no zinc } \\
\text { Placebo given; Co-intervention(s): vitamin B complex }\end{array}$ \\
\hline Outcomes & $\begin{array}{l}\text { Incidence of all-cause diarrhoea, participants with } \geq 1 \text { vomiting episode } \\
\text { Time point (wk): } 52 \text { (incidence of all-cause diarrhoea), } 24 \text { (participants with } \geq 1 \text { vom- } \\
\text { iting episode) }\end{array}$ \\
\hline Notes & \\
\hline
\end{tabular}

Risk of bias

\begin{tabular}{|c|c|c|}
\hline Bias & Authors' judgement & Support for judgement \\
\hline $\begin{array}{l}\text { Random sequence generation (selection } \\
\text { bias) }\end{array}$ & Unclear risk & $\begin{array}{l}\text { Quote: "For distribution of the children } \\
\text { into } 2 \text { groups, areas of } 30 \text { surveillance work- } \\
\text { ers were randomly divided into } 2 \text { groups." } \\
\text { Comment: insufficient details available to } \\
\text { make a judgement as to whether or not an } \\
\text { allocation sequence was generated using a } \\
\text { truly random method }\end{array}$ \\
\hline Allocation concealment (selection bias) & Unclear risk & $\begin{array}{l}\text { Quote: N/A } \\
\text { Comment: insufficient details available to } \\
\text { make a judgement }\end{array}$ \\
\hline
\end{tabular}

Blinding of participants (performance Low risk

bias)

All outcomes

Quote: “...double blind study...The zinc and placebo syrups in vitamin B-complex base were prepared with identical color, 
Gupta 2007 (Continued)

taste, and odor. The syrups were supplied in similar sized amber colored bottles...Each bottle was labeled with a code number...For maintenance of confidentiality, the code numbers of each group were kept with a third person who was not directly associated with the study."

Comment: sufficient blinding seems likely

Blinding of personnel (performance bias) Low risk All outcomes
Quote: “...double blind study...The zinc and placebo syrups in vitamin B-complex base were prepared with identical color, taste, and odor. The syrups were supplied in similar sized amber colored bottles...Each bottle was labeled with a code number...For maintenance of confidentiality, the code numbers of each group were kept with a third person who was not directly associated with the study."

Comment: sufficient blinding seems likely

Quote: “...double blind study...The zinc and placebo syrups in vitamin B-complex base were prepared with identical color, taste, and odor. The syrups were supplied in similar sized amber colored bottles...Each bottle was labeled with a code number...For maintenance of confidentiality, the code numbers of each group were kept with a third person who was not directly associated with the study."

Comment: sufficient blinding seems likely

Incomplete outcome data (attrition bias) High risk All outcomes

\section{\% Missing: 9}

Reasons/details: "One hundred and sixtysix children were excluded from the study because the guardians of 45 children refused to accept the syrup, 67 children left the area, 50 discontinued syrup, 2 children died, 1 due to drowning and another due to snake bite and 2 children had cardiac disorders." (However, $45+67+50+2$ $+1+2=167$, not 166). Among the 50 children for whom syrup was discontinued, "In 17...it was because of vomiting and in 33...because of advice from the local doctor/guardians of the family." In addition, "Ninety-five...guardians of the study children could not be motivated", and it is un- 
Gupta 2007 (Continued)

Selective reporting (reporting bias)
High risk

Low risk clear whether or not some, or all, of the children of these guardians were excluded and/or were among the 45 children who "refused to accept the syrup."

Comment: a somewhat sizeable proportion of data is missing, and neither reasons for, nor amounts of, missing data were reported separately for the zinc versus the placebo group. It is also unclear what implications for missing data might result from the fact that "Ninety-five...guardians of the study children could not be motivated."

Comment: all-cause mortality was measured, but is not reported in a way that can be meta-analysed

Comment: appears to be free of other bias

Hambidge 1978

Methods

Participants

Interventions

Notes

\section{Risk of bias}

CRCT?: IRCT; Cross-over?: non-cross-over

Country: United States of America; Setting: Denver, Colorado; Urbanicity: urban Inclusion criteria: height-for-age percentiles below the 10th for McCammon's standards; hair zinc concentration less than $105 \mu \mathrm{g} / \mathrm{g}$

Exclusion criteria: N/A

Baseline characteristics

Avg age (mo): 52.6; Min age (mo): 38; Max age (mo): 61; \% Female: 44

Avg HAZ: N/A; Stunting: unclear; Avg height (cm): N/A; Avg zinc concentration $(\mu \mathrm{g} /$ dL): N/A

Total N: 75; Group 1 N: 38; Group 2 N: 37

Group 1: zinc

Formulation: solution; Compound: sulfate; Frequency: 5 days/wk; Duration (mo): 6; Dose (mg): 14; Co-intervention(s): N/A

Group 2: no zinc

Placebo given; Co-intervention(s): N/A

Height, weight

Time point (wk): 24

"At the completion of this study, parents were requested to administer the zinc sulfate (or placebo) for a further 6 month period at home. Twenty-two test children and 25 controls (including 10 of the male pairs) remained in this study, but many of them did not take the syrup regularly." 
Hambidge 1978 (Continued)

\begin{tabular}{|c|c|c|}
\hline Bias & Authors' judgement & Support for judgement \\
\hline $\begin{array}{l}\text { Random sequence generation (selection } \\
\text { bias) }\end{array}$ & Unclear risk & $\begin{array}{l}\text { Quote: "The zinc-supplemented and con- } \\
\text { trol children were pair-matched as closely } \\
\text { as possible according to sex, ethnic origin, } \\
\text { age, initial height percentile and initial hair } \\
\text { zinc level." "The first member of each pair } \\
\text { was assigned randomly to receive either the } \\
\text { zinc supplement or the placebo." } \\
\text { Comment: insufficient details available to } \\
\text { make a judgement as to whether or not an } \\
\text { allocation sequence was generated using a } \\
\text { truly random method }\end{array}$ \\
\hline Allocation concealment (selection bias) & Unclear risk & $\begin{array}{l}\text { Quote: N/A } \\
\text { Comment: insufficient details available to } \\
\text { make a judgement }\end{array}$ \\
\hline $\begin{array}{l}\text { Blinding of participants (performance } \\
\text { bias) } \\
\text { All outcomes }\end{array}$ & Unclear risk & $\begin{array}{l}\text { Quote: "The study was designed as a dou- } \\
\text { ble-blind controlled investigation." } \\
\text { Comment: insufficient details available to } \\
\text { make a judgement }\end{array}$ \\
\hline $\begin{array}{l}\text { Blinding of personnel (performance bias) } \\
\text { All outcomes }\end{array}$ & Unclear risk & $\begin{array}{l}\text { Quote: "The study was designed as a dou- } \\
\text { ble-blind controlled investigation." } \\
\text { Comment: insufficient details available to } \\
\text { make a judgement }\end{array}$ \\
\hline $\begin{array}{l}\text { Blinding of outcome assessment (detection } \\
\text { bias) } \\
\text { All outcomes }\end{array}$ & Unclear risk & $\begin{array}{l}\text { Quote: "The study was designed as a dou- } \\
\text { ble-blind controlled investigation." } \\
\text { Comment: insufficient details available to } \\
\text { make a judgement }\end{array}$ \\
\hline $\begin{array}{l}\text { Incomplete outcome data (attrition bias) } \\
\text { All outcomes }\end{array}$ & Unclear risk & $\begin{array}{l}\text { \% Missing: } 11 \\
\text { Reasons/details: in the zinc group, } 2 \text { partic- } \\
\text { ipants were missing. In the control group, } \\
6 \text { participants were missing } \\
\text { Comment: the control group had a larger } \\
\text { amount of missing data than the zinc } \\
\text { group, and reasons for missing data were } \\
\text { not reported }\end{array}$ \\
\hline Selective reporting (reporting bias) & Unclear risk & $\begin{array}{l}\text { Comment: no trial protocol referenced by } \\
\text { the study }\end{array}$ \\
\hline Other bias & Low risk & Comment: appears to be free of other bias \\
\hline
\end{tabular}

Zinc supplementation for preventing mortality, morbidity, and growth failure in children aged 6 months to 12 years of age (Review) 
Methods

Participants
CRCT?: IRCT; Cross-over?: non-cross-over

Country: China; Setting: Luoyang City, Henan Province; Urbanicity: urban Inclusion criteria: height below -1 SD height-for-age of the standard; living in their local communities for at least 2 years; without any chronic or acute diseases

Exclusion criteria: absent from the kindergarten for a continuous period of more than 30 days

Baseline characteristics

Avg age (mo): 48.17; Min age (mo): 36; Max age (mo): 60; \% Female: 50

Avg HAZ: N/A; Stunting: unclear; Avg height (cm): 95.9; Avg zinc concentration $(\mu \mathrm{g} /$ dL): N/A

Total N: 119; Group 1 N: 34; Group 2 N: 28; Group 3 N: 28; Group 4 N: 29

Formulation: tablets or added to milk powder; Compound: unclear; Frequency: 5 days/ wk; Duration (mo): 12; Dose (mg): 3.5; Co-intervention(s): N/A

Group 2: no zinc

Placebo given; Co-intervention(s): N/A

Group 3: zinc

Co-intervention(s): $250 \mathrm{mg}$ calcium; $200 \mu \mathrm{g}$ vitamin A

Group 4: no zinc

Placebo given; Co-intervention(s): $250 \mathrm{mg}$ calcium; $200 \mu \mathrm{g}$ vitamin A One was a group of 37 participants who, received zinc and calcium. The other was a group of 34 participants of normal height, who received placebo. Baseline characteristics reported in this table are weighted averages of all groups except these 2 groups, since these 2 groups are not included in any meta-analyses in this review

- The trial reports for this study state that, "Micronutrients were added to milk powder or in the form of tablets and provided alternately."

\section{Risk of bias}

Bias

Random sequence generation (selection Unclear risk bias)
Authors' judgement

Copyright $\odot 2014$ The Cochrane Collaboration. Published by John Wiley \& Sons, Ltd.

\section{Support for judgement}

Quote: “...children...were randomly assigned to five groups...children were divided into five groups and randomly assigned to different supplementations..." Comment: insufficient details available to make a judgement as to whether or not an allocation sequence was generated using a truly random method 
Han 2002 (Continued)

\begin{tabular}{|c|c|c|}
\hline Allocation concealment (selection bias) & Unclear risk & $\begin{array}{l}\text { Quote: N/A } \\
\text { Comment: insufficient details available to } \\
\text { make a judgement }\end{array}$ \\
\hline $\begin{array}{l}\text { Blinding of participants (performance } \\
\text { bias) } \\
\text { All outcomes }\end{array}$ & Low risk & $\begin{array}{l}\text { Quote: "A double-blind placebo-con- } \\
\text { trolled trial was conducted... The place- } \\
\text { bos were indistinguishable from the sup- } \\
\text { plements in both appearance and taste." } \\
\text { Comment: sufficient blinding seems likely }\end{array}$ \\
\hline $\begin{array}{l}\text { Blinding of personnel (performance bias) } \\
\text { All outcomes }\end{array}$ & Low risk & $\begin{array}{l}\text { Quote: "A double-blind placebo-con- } \\
\text { trolled trial was conducted... The place- } \\
\text { bos were indistinguishable from the sup- } \\
\text { plements in both appearance and taste." } \\
\text { Comment: sufficient blinding seems likely }\end{array}$ \\
\hline $\begin{array}{l}\text { Blinding of outcome assessment (detection } \\
\text { bias) } \\
\text { All outcomes }\end{array}$ & Low risk & $\begin{array}{l}\text { Quote: "A double-blind placebo-con- } \\
\text { trolled trial was conducted... The place- } \\
\text { bos were indistinguishable from the sup- } \\
\text { plements in both appearance and taste." } \\
\text { Comment: sufficient blinding seems likely }\end{array}$ \\
\hline $\begin{array}{l}\text { Incomplete outcome data (attrition bias) } \\
\text { All outcomes }\end{array}$ & Unclear risk & $\begin{array}{l}\text { \% Missing: } 12 \\
\text { Reasons/details: N/A } \\
\text { Comment: } 12 \% \text { of the randomised par- } \\
\text { ticipants eligible for our review had data } \\
\text { missing for diarrhoea outcomes; this } 12 \% \\
\text { missing figure includes all groups except } \\
\text { the zinc + calcium group and the normal } \\
\text { height placebo group, since these } 2 \text { groups } \\
\text { are not included in any meta-analyses in } \\
\text { this review. For diarrhoea outcomes: } 1,6 \text {, } \\
4 \text {, and } 3 \text { participants were missing in the } \\
\text { zinc, placebo, zinc + calcium + vitamin A, } \\
\text { and calcium + vitamin A groups, respec- } \\
\text { tively. No information was reported on rea- } \\
\text { sons for missing data }\end{array}$ \\
\hline Selective reporting (reporting bias) & Unclear risk & $\begin{array}{l}\text { Comment: incidence and prevalence of res- } \\
\text { piratory illness, which meets the criteria of } \\
\text { this review, may have been measured and } \\
\text { reported; but it is unclear how respiratory } \\
\text { illness was defined in this study. No trial } \\
\text { protocol referenced by the study }\end{array}$ \\
\hline Other bias & Low risk & Comment: appears to be free of other bias \\
\hline
\end{tabular}

Zinc supplementation for preventing mortality, morbidity, and growth failure in children aged 6 months to 12 years of age (Review) 
Han 2002 (2)

Methods

Participants

Interventions

Outcomes Incidence of all-cause diarrhoea, height, weight

Notes As Han 2002 above

Hettiarachchi 2008

\begin{tabular}{|c|c|}
\hline Methods & CRCT?: CRCT; Cross-over?: non-cross-over \\
\hline Participants & $\begin{array}{l}\text { Country: Sri Lanka; Setting: Galle District; Urbanicity: multiple } \\
\text { Inclusion criteria: haemoglobin level } \geq 80 \mathrm{~g} / \mathrm{L} \\
\text { Exclusion criteria: suffering from acute or chronic diseases; inflammatory conditions; a } \\
\text { history of any drug consumption other than paracetamol or antihistamines for minor } \\
\text { ailments; currently consuming nutrient supplements; donated blood or received a blood } \\
\text { transfusion within the last } 4 \text { months } \\
\text { Baseline characteristics } \\
\text { Avg age (mo): } 145.35 \text {; Min age (mo): } 144 \text {; Max age (mo): } 155 \text {; \% Female: } 65 \\
\text { Avg HAZ: }-1.16 \text {; Stunting: both - separate data not given; Avg height }(\mathrm{cm}): 143.25 \text {; Avg } \\
\text { zinc concentration }(\mu \mathrm{g} / \mathrm{dL}): 56.17 \\
\text { Total N: } 341 \text {; Group } 1 \mathrm{~N}: 107 \text {; Group } 2 \mathrm{~N} \text { : } 59 \text {; Group } 3 \mathrm{~N} \text { : } 127 \text {; Group } 4 \mathrm{~N}: 48 \\
\text { Total clusters: } 14 \text {; Group } 1 \text { clusters: N/A; Group } 2 \text { clusters: N/A; Group } 3 \text { clusters: N/ } \\
\text { A; Group } 4 \text { clusters: N/A }\end{array}$ \\
\hline Interventions & $\begin{array}{l}\text { Group 1: zinc } \\
\text { Formulation: capsule; Compound: sulfate; Frequency: } 5 \text { days/wk; Duration (mo): 6; } \\
\text { Dose (mg): 14; Co-intervention(s): N/A } \\
\text { Group 2: no zinc } \\
\text { Placebo given; Co-intervention(s): N/A } \\
\text { Group 3: zinc } \\
\text { Co-intervention(s): } 50 \mathrm{mg} \text { iron } \\
\text { Group 4: no zinc } \\
\text { Placebo given; Co-intervention(s): } 50 \mathrm{mg} \text { iron }\end{array}$ \\
\hline
\end{tabular}

Outcomes

Height, weight, prevalence of stunting, serum or plasma zinc concentration, prevalence of zinc deficiency, blood haemoglobin concentration, prevalence of anaemia, serum or plasma ferritin concentration, prevalence of iron deficiency

Time point (wk): 25

Notes

- All baseline and outcome data from this study included in this review apply only to the subset of this study's participants who were less than 13 years of age at baseline - "All the study subjects were treated for parasites by giving mebendazole $(500 \mathrm{mg})$ as a single oral dose (mass-treatment) approximately 2 weeks before the start of the study."

\section{Risk of bias}

Zinc supplementation for preventing mortality, morbidity, and growth failure in children aged 6 months to 12 years of age (Review) 
Hettiarachchi 2008 (Continued)

\begin{tabular}{|c|c|c|}
\hline Bias & Authors' judgement & Support for judgement \\
\hline $\begin{array}{l}\text { Random sequence generation (selection } \\
\text { bias) }\end{array}$ & Unclear risk & $\begin{array}{l}\text { Quote: “...randomized into one of four } \\
\text { groups..." } \\
\text { Comment: insufficient details available to } \\
\text { make a judgement as to whether or not an } \\
\text { allocation sequence was generated using a } \\
\text { truly random method }\end{array}$ \\
\hline Allocation concealment (selection bias) & Unclear risk & $\begin{array}{l}\text { Quote: “...randomized into one of four } \\
\text { groups...using a double-blind approach." } \\
\text { Comment: insufficient details available to } \\
\text { make a judgement }\end{array}$ \\
\hline $\begin{array}{l}\text { Blinding of participants (performance } \\
\text { bias) } \\
\text { All outcomes }\end{array}$ & Low risk & $\begin{array}{l}\text { Quote: “...double-blind approach.” "...All } \\
\text { capsules (iron, zinc, combined \& Placebo) } \\
\text { were of same colour capsule in same mean } \\
\text { weight" } \\
\text { Comment: sufficient blinding seems likely }\end{array}$ \\
\hline
\end{tabular}

Blinding of personnel (performance bias) Low risk All outcomes

Quote: “...double-blind approach.” “...the class teacher who gave the supplement during breakfast break were not aware about the content of the supplement...All capsules (iron, zinc, combined \& Placebo) were of same colour capsule in same mean weight"

Comment: sufficient blinding seems likely

Blinding of outcome assessment (detection Low risk bias)

All outcomes

Quote: “...double-blind approach.” "Research assistant who distribute supplements to the class...were not aware about the content of the supplement...All capsules (iron, zinc, combined \& Placebo) were of same colour capsule in same mean weight"

Comment: sufficient blinding seems likely

Incomplete outcome data (attrition bias) Unclear risk \% Missing: 16

All outcomes

Reasons/details: 7, 18, 13, and 18 participants from the zinc, placebo, iron + zinc, and iron groups, respectively, were "dropped for various reasons: withdrawal from the study... refusal to give blood after supplementation.... and absence on the day of the post-supplementation blood collection..."

Comment: a fairly large proportion of data is missing, and reasons for missing data 
Hettiarachchi 2008 (Continued)

were not reported separately for each study group

\begin{tabular}{|c|c|c|}
\hline Selective reporting (reporting bias) & Unclear risk & $\begin{array}{l}\text { Comment: no trial protocol referenced by } \\
\text { the study }\end{array}$ \\
\hline Other bias & Low risk & Comment: appears to be free of other bias \\
\hline
\end{tabular}

Hettiarachchi 2008 (2)

Methods

Participants

Interventions

Outcomes Height, weight, prevalence of stunting, serum or plasma zinc concentration, prevalence of zinc deficiency, blood haemoglobin concentration, prevalence of anaemia, serum or plasma ferritin concentration, prevalence of iron deficiency

Notes As Hettiarachchi 2008 above

\section{Hong 1982}

\begin{tabular}{|c|c|}
\hline Methods & CRCT?: IRCT; Cross-over?: cross-over \\
\hline Participants & $\begin{array}{l}\text { Country: China; Setting: villages, Anhui Province, and Shanghai City; Urbanicity: mul- } \\
\text { tiple } \\
\text { Inclusion criteria: weight lower than the 10th percentile for children at equivalent height } \\
\text { and age } \\
\text { Exclusion criteria: hereditary, endocrine, and metabolic disorders } \\
\text { Baseline characteristics } \\
\text { Avg age (mo): N/A; Min age (mo): 4; Max age (mo): 72; \% Female: } 49.4 \\
\text { Avg HAZ: N/A; Stunting: both - separate data not given; Avg height }(\mathrm{cm}) \text { : N/A; Avg } \\
\text { zinc concentration }(\mu \mathrm{g} / \mathrm{dL}): 70.3 \\
\text { Total N: } 158 \text {; Group } 1 \mathrm{~N} \text { : N/A; Group } 2 \mathrm{~N} \text { : N/A }\end{array}$ \\
\hline Interventions & $\begin{array}{l}\text { Group 1: zinc } \\
\text { Formulation: solution; Compound: sulfate; Frequency: daily; Duration (mo): 2.4; Dose } \\
(\mathrm{mg}) \text { : unclear; Co-intervention(s): vitamin B complex } \\
\text { Group 2: no zinc } \\
\text { Placebo given; Co-intervention(s): vitamin B complex }\end{array}$ \\
\hline Outcomes & $\begin{array}{l}\text { Height, weight, serum or plasma zinc concentration } \\
\text { Time point (wk): } 10\end{array}$ \\
\hline
\end{tabular}




\begin{tabular}{|c|c|c|}
\hline Notes & \multicolumn{2}{|c|}{$\begin{array}{l}\text { - Of the } 158 \text { participants randomised, } 119 \text { were } 12 \text { months of age or older } \\
\text { - } 64 \text { participants in the zinc group and } 67 \text { participants in the control group completed } \\
\text { the study; but the number of participants randomised to each group was not reported } \\
\text { - } 92 \text { children in the trial, who were found to be anaemic, were provided iron; the trial } \\
\text { report did not state the dose or the duration of iron provided, nor did it state how many } \\
\text { of these children were in the zinc group or the placebo group } \\
\text { - The trial report for this study is written in Chinese, so quotes from it are English } \\
\text { translations }\end{array}$} \\
\hline \multicolumn{3}{|l|}{ Risk of bias } \\
\hline Bias & Authors' judgement & Support for judgement \\
\hline $\begin{array}{l}\text { Random sequence generation (selection } \\
\text { bias) }\end{array}$ & Unclear risk & $\begin{array}{l}\text { Quote: “...randomly assigned..." } \\
\text { Comment: insufficient details available to } \\
\text { make a judgement as to whether or not an al- } \\
\text { location sequence was generated using a truly } \\
\text { random method }\end{array}$ \\
\hline Allocation concealment (selection bias) & Unclear risk & $\begin{array}{l}\text { Quote: N/A } \\
\text { Comment: insufficient details available to } \\
\text { make a judgement }\end{array}$ \\
\hline $\begin{array}{l}\text { Blinding of participants (performance } \\
\text { bias) } \\
\text { All outcomes }\end{array}$ & Unclear risk & $\begin{array}{l}\text { Quote: “... double blind...” } \\
\text { Comment: insufficient details available }\end{array}$ \\
\hline $\begin{array}{l}\text { Blinding of personnel (performance bias) } \\
\text { All outcomes }\end{array}$ & Unclear risk & $\begin{array}{l}\text { Quote: “...double blind...” } \\
\text { Comment: insufficient details available }\end{array}$ \\
\hline $\begin{array}{l}\text { Blinding of outcome assessment (detection } \\
\text { bias) } \\
\text { All outcomes }\end{array}$ & Unclear risk & $\begin{array}{l}\text { Quote: “...double blind...” } \\
\text { Comment: insufficient details available }\end{array}$ \\
\hline $\begin{array}{l}\text { Incomplete outcome data (attrition bias) } \\
\text { All outcomes }\end{array}$ & Unclear risk & $\begin{array}{l}\text { \% Missing: } 19 \\
\text { Reasons/details: N/A } \\
\text { Comment: the following were not reported: } \\
\text { number of participants randomised to each } \\
\text { group, amount of missing data for each group, } \\
\text { reasons for missing data in each group }\end{array}$ \\
\hline Selective reporting (reporting bias) & Unclear risk & $\begin{array}{l}\text { Comment: no trial protocol referenced by the } \\
\text { study }\end{array}$ \\
\hline Other bias & Low risk & Comment: appears to be free of other bias \\
\hline
\end{tabular}


Methods

Participants

Outcomes

Height, weight

Time point (wk): 52

Baseline characteristics $(\mu \mathrm{g} / \mathrm{dL}): \mathrm{N} / \mathrm{A}$

\section{Group 1: zinc}

Group 2: no zinc
Country: Turkey; Setting: Ankara; Urbanicity: urban

Inclusion criteria: height between the $3 \mathrm{rd}$ and 10 th percentiles for age; product of a term pregnancy; birth measurements appropriate for gestational age; no detectable medical reasons for poor growth

Exclusion criteria: N/A

Avg age (mo): 50; Min age (mo): 25; Max age (mo): 76; \% Female: 12

Avg HAZ: -1.55; Stunting: non-stunted; Avg height (cm): 94.2; Avg zinc concentration

Total N: 25; Group 1 N: 16; Group 2 N: 9

Formulation: solution; Compound: sulfate; Frequency: daily; Duration (mo): 12; Dose (mg): 10; Co-intervention(s): N/A

Placebo given; Co-intervention(s): N/A

Notes

Risk of bias

Bias

Random sequence generation (selection Low risk bias)
Authors' judgement
Quote: "The participants for the study were randomized to study or control groups " by "a lottery"."

Comment: it seems likely that the allocation sequence was generated using a truly random method

Allocation concealment (selection bias) Unclear risk

Quote: N/A

Comment: insufficient details available to make a judgement

Quote: “...double-blind study design.”

Comment: sufficient blinding seems likely

bias)

All outcomes

Blinding of personnel (performance bias) Low risk

All outcomes
Quote: “...double-blind study design...Zinc and placebo were given to children by their kindergarten teachers... Test and control groups were not known by the kindergarten teachers..."

Comment: sufficient blinding seems likely 


\section{Ince 1995 (Continued)}

\begin{tabular}{|c|c|c|}
\hline $\begin{array}{l}\text { Blinding of outcome assessment (detection } \\
\text { bias) } \\
\text { All outcomes }\end{array}$ & Low risk & $\begin{array}{l}\text { Quote: } \\
\text { ble-blind study design.... Test and control } \\
\text { groups were not known by...the investiga- } \\
\text { tor who performed anthropometry..." } \\
\text { Comment: sufficient blinding seems likely }\end{array}$ \\
\hline $\begin{array}{l}\text { Incomplete outcome data (attrition bias) } \\
\text { All outcomes }\end{array}$ & Low risk & $\begin{array}{l}\text { \% Missing: } 0 \\
\text { Reasons/details: N/A } \\
\text { Comment: N/A }\end{array}$ \\
\hline Selective reporting (reporting bias) & Unclear risk & $\begin{array}{l}\text { Comment: no trial protocol referenced by } \\
\text { the study }\end{array}$ \\
\hline Other bias & Low risk & Comment: appears to be free of other bias \\
\hline
\end{tabular}

Kartasurya 2012

\begin{tabular}{|c|c|c|}
\hline Methods & \multicolumn{2}{|c|}{ CRCT?: IRCT; Cross-over?: non-cross-over } \\
\hline Participants & \multicolumn{2}{|c|}{$\begin{array}{l}\text { Country: Indonesia; Setting: Semarang; Urbanicity: unclear } \\
\text { Inclusion criteria: apparently healthy children } \\
\text { Exclusion criteria: moderately and severely malnourished children } \\
\text { Baseline characteristics } \\
\text { Avg age (mo): 42.24; Min age (mo): 24; Max age (mo): 60; \% Female: } 48 \% \\
\text { Avg HAZ: }-1.73 \text {; Stunting: non-stunted; Avg height }(\mathrm{cm}) \text { : Not reported; Avg zinc con- } \\
\text { centration }(\mu \mathrm{g} / \mathrm{dL}) \text { : Not reported } \\
\text { Total N: } 826 \text {; Group } 1 \mathrm{~N}: 415 \text {; Group } 2 \mathrm{~N}: 411\end{array}$} \\
\hline Interventions & \multicolumn{2}{|c|}{$\begin{array}{l}\text { Group 1: zinc } \\
\text { Formulation: solution; Compound: sulfate; Frequency: daily; Duration (mo): 4; Dose } \\
\text { (mg): 10; Co-intervention(s): vitamin A } \\
\text { Group 2: no zinc } \\
\text { Placebo given; Co-intervention(s): vitamin A }\end{array}$} \\
\hline Outcomes & \multicolumn{2}{|l|}{ All-cause mortality } \\
\hline \multicolumn{3}{|l|}{ Notes } \\
\hline \multicolumn{3}{|l|}{ Risk of bias } \\
\hline Bias & Authors' judgement & Support for judgement \\
\hline $\begin{array}{l}\text { Random sequence generation (selection } \\
\text { bias) }\end{array}$ & Low risk & $\begin{array}{l}\text { Quote: "one of the physicians (not inves- } \\
\text { tigators) used random numbers to allocate } \\
\text { each child" }\end{array}$ \\
\hline
\end{tabular}


Kartasurya 2012 (Continued)

\begin{tabular}{|c|c|c|}
\hline Allocation concealment (selection bias) & Low risk & $\begin{array}{l}\text { Quote: "one of the physicians (not inves- } \\
\text { tigators) used random numbers to allocate } \\
\text { each child" }\end{array}$ \\
\hline $\begin{array}{l}\text { Blinding of participants (performance } \\
\text { bias) } \\
\text { All outcomes }\end{array}$ & Low risk & $\begin{array}{l}\text { Quote: "Supplements were prepared and } \\
\text { labelled with alphabetic codes by the Phar- } \\
\text { macy Department of Diponegoro Univer- } \\
\text { sity. There was no difference between the } \\
\text { syrups in taste or appearance." }\end{array}$ \\
\hline $\begin{array}{l}\text { Blinding of personnel (performance bias) } \\
\text { All outcomes }\end{array}$ & Low risk & $\begin{array}{l}\text { Quote: "Supplements were prepared and } \\
\text { labelled with alphabetic codes by the Phar- } \\
\text { macy Department of Diponegoro Univer- } \\
\text { sity. There was no difference between the } \\
\text { syrups in taste or appearance." }\end{array}$ \\
\hline $\begin{array}{l}\text { Blinding of outcome assessment (detection } \\
\text { bias) } \\
\text { All outcomes }\end{array}$ & Low risk & $\begin{array}{l}\text { Quote: "Supplements were prepared and } \\
\text { labelled with alphabetic codes by the Phar- } \\
\text { macy Department of Diponegoro Univer- } \\
\text { sity. There was no difference between the } \\
\text { syrups in taste or appearance." }\end{array}$ \\
\hline $\begin{array}{l}\text { Incomplete outcome data (attrition bias) } \\
\text { All outcomes }\end{array}$ & Low risk & $\begin{array}{l}\text { Quote: "Stopped taking zinc or placebo" } \\
\text { Comment: } 3 \% \text { missing }\end{array}$ \\
\hline Selective reporting (reporting bias) & High risk & $\begin{array}{l}\text { Registered retrospectively: ACTRN } \\
12611000659909 \\
\text { Comment: only mortality reported - mor- } \\
\text { bidity not reported }\end{array}$ \\
\hline Other bias & Low risk & Comment: appears to be free of other bias \\
\hline
\end{tabular}

Kikafunda 1998

Methods

Participants
CRCT?: IRCT; Cross-over?: non-cross-over

Country: Uganda; Setting: a suburb of Kampala; Urbanicity: peri-urban Inclusion criteria: N/A

Exclusion criteria: major medical or physical problems

Baseline characteristics

Avg age (mo): 55.8; Min age (mo): 33; Max age (mo): 89; \% Female: 46

Avg HAZ: -0.7; Stunting: unclear; Avg height (cm): 103.4; Avg zinc concentration $(\mu \mathrm{g} /$ dL): N/A

Total N: 155; Group 1 N: 79; Group 2 N: 76

Group 1: zinc

Formulation: pill/tablet; Compound: sulfate; Frequency: 5 days/wk; Duration (mo): 6; Dose (mg): 10; Co-intervention(s): N/A 


\begin{tabular}{ll} 
& $\begin{array}{l}\text { Group 2: no zinc } \\
\text { Placebo given; Co-intervention(s): N/A }\end{array}$ \\
\hline Outcomes & $\begin{array}{l}\text { Height, weight } \\
\text { Time point (wk): } 32\end{array}$ \\
\hline Notes & $\begin{array}{l}\text { "Because of the nature of school terms in Uganda, the treatment period was 2-phased, } \\
\text { each phase lasting } 3 \text { mo with a 2-mo period in between with no supplements when the } \\
\text { children were on vacation." }\end{array}$ \\
\hline
\end{tabular}

\section{Risk of bias}

\begin{tabular}{|c|c|c|}
\hline Bias & Authors' judgement & Support for judgement \\
\hline $\begin{array}{l}\text { Random sequence generation (selection } \\
\text { bias) }\end{array}$ & Unclear risk & $\begin{array}{l}\text { Quote: "The randomization procedure was } \\
\text { stratified according to sex..." } \\
\text { Comment: insufficient details available to } \\
\text { make a judgement as to whether or not an } \\
\text { allocation sequence was generated using a } \\
\text { truly random method }\end{array}$ \\
\hline Allocation concealment (selection bias) & Unclear risk & $\begin{array}{l}\text { Quote: N/A } \\
\text { Comment: insufficient details available to } \\
\text { make a judgement }\end{array}$ \\
\hline $\begin{array}{l}\text { Blinding of participants (performance } \\
\text { bias) } \\
\text { All outcomes }\end{array}$ & Low risk & $\begin{array}{l}\text { Quote: "The study was randomized, dou- } \\
\text { ble-blind...The zinc and placebo tablets, } \\
\text { which were indistinguishable in both color } \\
\text { and taste..." } \\
\text { Comment: sufficient blinding seems likely }\end{array}$ \\
\hline $\begin{array}{l}\text { Blinding of personnel (performance bias) } \\
\text { All outcomes }\end{array}$ & Low risk & $\begin{array}{l}\text { Quote: "The study was randomized, dou- } \\
\text { ble-blind...The zinc and placebo tablets, } \\
\text { which were indistinguishable in both color } \\
\text { and taste..." } \\
\text { Comment: sufficient blinding seems likely }\end{array}$ \\
\hline $\begin{array}{l}\text { Blinding of outcome assessment (detection } \\
\text { bias) } \\
\text { All outcomes }\end{array}$ & Low risk & $\begin{array}{l}\text { Quote: "The study was randomized, dou- } \\
\text { ble-blind...The zinc and placebo tablets, } \\
\text { which were indistinguishable in both color } \\
\text { and taste..." } \\
\text { Comment: sufficient blinding seems likely }\end{array}$ \\
\hline $\begin{array}{l}\text { Incomplete outcome data (attrition bias) } \\
\text { All outcomes }\end{array}$ & Unclear risk & $\begin{array}{l}\text { \% Missing: } 27 \\
\text { Reasons/details: "Two children from school } \\
3 \text {, one from the zinc and the other from } \\
\text { the control group, dropped out of the } \\
\text { trial before the end of phase } 1 \text { because of } \\
\text { insufficient funds for tuition...Forty chil- }\end{array}$ \\
\hline
\end{tabular}




\begin{tabular}{|c|c|c|}
\hline & & $\begin{array}{l}\text { dren...did not return for phase } 2 \text { of the } \\
\text { trial, mainly because of a change of schools } \\
\text { or insufficient funds." "Phase } 1 \text { " refers to } \\
\text { months } 0 \text { to } 3 \text { and "phase } 2 \text { " refers to } \\
\text { months } 6 \text { to } 8 \\
\text { Comment: a large proportion of data is } \\
\text { missing, and no information was reported } \\
\text { for "phase } 2 \text { " on differences between study } \\
\text { groups in numbers of participants who } \\
\text { dropped out }\end{array}$ \\
\hline Selective reporting (reporting bias) & High risk & $\begin{array}{l}\text { Comment: diarrhoea incidence } \\
\text { and malaria incidence were measured, but } \\
\text { are not reported }\end{array}$ \\
\hline Other bias & Low risk & Comment: appears to be free of other bias \\
\hline
\end{tabular}

\section{Kurugöl 2006}

Methods

Participants
CRCT?: IRCT; Cross-over?: non-cross-over

Country: Turkey; Setting: the city of Izmir; Urbanicity: urban

Inclusion criteria: overall good health

Exclusion criteria: known chronic disease; immunodeficiency disorder; asthma; history of sensitivity to or an idiosyncratic experience with zinc; parents who were unwilling or unable to comply with clinical study procedures

Baseline characteristics

Avg age (mo): 67.2; Min age (mo): 24; Max age (mo): 120; \% Female: 50.5

Avg HAZ: N/A; Stunting: unclear; Avg height (cm): N/A; Avg zinc concentration ( $\mu \mathrm{g} /$ dL): N/A

Total N: 200; Group 1 N: 100; Group 2 N: 100

Interventions Group 1: zinc

Formulation: solution; Compound: sulfate; Frequency: daily; Duration (mo): 7; Dose (mg): 15; Co-intervention(s): N/A

Group 2: no zinc

Placebo given; Co-intervention(s): N/A

Outcomes

Study withdrawal, participants with $\geq 1$ side effect, participants with $\geq 1$ vomiting episode

Time point (wk): 28

The dose was increased to 2 times per day (30 mg of zinc) at the onset of cold, until symptoms resolved

\section{Risk of bias}

Bias 


\section{Kurugöl 2006 (Continued)}

\begin{tabular}{|c|c|c|}
\hline $\begin{array}{l}\text { Random sequence generation (selection } \\
\text { bias) }\end{array}$ & Low risk & $\begin{array}{l}\text { Quote: "A statistical consultant pro- } \\
\text { grammed a computer-generated random- } \\
\text { ization code..." } \\
\text { Comment: N/A }\end{array}$ \\
\hline Allocation concealment (selection bias) & Low risk & $\begin{array}{l}\text { Quote: "A statistical consultant pro- } \\
\text { grammed a computer-generated random- } \\
\text { ization code and prepared the packages of } \\
\text { medication. The packages were randomly } \\
\text { distributed to the study personnel, all of } \\
\text { whom were blind to the group assignments. } \\
\text { " } \\
\text { Comment: indicates central randomisation } \\
\text { to conceal allocation }\end{array}$ \\
\hline
\end{tabular}

Blinding of participants (performance Low risk bias)

All outcomes

Quote: "This randomized, double-blind, placebo-controlled, prospective study... Placebo and active syrups were identical in appearance, texture and flavouring content, except that the placebo lacked the zinc component...All parents were also blind to the group assignments."

Comment: sufficient blinding seems likely

Blinding of personnel (performance bias) Low risk All outcomes
Quote: "This randomized, double-blind, placebo-controlled, prospective study... Placebo and active syrups were identical in appearance, texture and flavouring content, except that the placebo lacked the zinc component...The packages were randomly distributed to the study personnel, all of whom were blind to the group assignments.

Comment: sufficient blinding seems likely

Blinding of outcome assessment (detection Low risk bias)

All outcomes
Quote: "This randomized, double-blind, placebo-controlled, prospective study... Placebo and active syrups were identical in appearance, texture and flavouring content, except that the placebo lacked the zinc component...The packages were randomly distributed to the study personnel, all of whom were blind to the group assignments.

Comment: sufficient blinding seems likely

\% Missing: 3

Reasons/details: overall, $97 \%(\mathrm{n}=194)$ of the children $(97$ in the zinc group and 97 
Kurugöl 2006 (Continued)

\begin{tabular}{|c|c|c|}
\hline & & $\begin{array}{l}\text { in the placebo group) completed the } 7 \text {-mo } \\
\text { study period; } 6 \text { ( } 3 \%) \text { discontinued, } 4 \text { for } \\
\text { non-compliance and } 2 \text { for adverse effects } \\
\text { due to medication } \\
\text { Comment: amount of missing data was } \\
\text { similar between study groups. Missing data } \\
\text { seem too minimal to impact results }\end{array}$ \\
\hline Selective reporting (reporting bias) & Unclear risk & $\begin{array}{l}\text { Comment: no trial protocol referenced by } \\
\text { the study }\end{array}$ \\
\hline Other bias & Low risk & Comment: appears to be free of other bias \\
\hline
\end{tabular}

Larson 2010

Methods

Participants
CRCT?: IRCT; Cross-over?: non-cross-over

Country: Bangladesh; Setting: Mirpur district, Dhaka; Urbanicity: urban

Inclusion criteria: an acute episode of diarrhoea of 24 to $72 \mathrm{~h}$ duration

Exclusion criteria: severe dehydration; suspected cholera or pneumonia; bipedal oedema; currently receiving zinc; a weight-for-height z-score below -3; already participating in another study involving nutritional or therapeutic interventions

Baseline characteristics

Avg age (mo): 15.4; Min age (mo): 6; Max age (mo): 24; \% Female: 50

Avg HAZ: -1.72; Stunting: unclear; Avg height (cm): 73.6; Avg zinc concentration ( $\mu \mathrm{g} /$ dL): N/A

Total N: 353; Group 1 N: 176; Group 2 N: 177
Interventions

Outcomes
Group 1: zinc

Formulation: solution; Compound: sulfate; Frequency: daily; Duration (mo): 3; Dose (mg): 10; Co-intervention(s): N/A

Group 2: no zinc

Placebo given; Co-intervention(s): N/A

All-cause mortality, incidence of all-cause diarrhoea, blood haemoglobin concentration Time point (wk): 6 (blood haemoglobin concentration), 36 (all-cause mortality, incidence of all-cause diarrhoea)

- All children received 10 days of zinc treatment $(20 \mathrm{mg} /$ day $)$ for an episode of acute childhood diarrhoea before they were divided into zinc versus placebo groups for the preventive supplementation randomised controlled trial phase of this study

- It is unclear whether the maximum age of eligible trial participants at baseline was 23 or 24 months

\section{Risk of bias}


Larson 2010 (Continued)

Random sequence generation (selection Low risk bias)

Allocation concealment (selection bias) Low risk
Quote: “...lots were numbered and randomly assigned in permuted blocks of six (three placebo, three zinc).”

Comment: N/A

Quote: "All placebo and zinc-containing bottles of syrup...were serially numbered in lots of 100. These lots were listed and then sequentially selected based upon random assignment...each child received a 3month supply of syrup (five bottles) and the lot number was recorded. The randomization code was not broken until after all children had completed the trial and the data had been entered and verified."

Comment: seems to indicate sequentially numbered drug containers of identical appearance to conceal allocation

Blinding of participants (performance Low risk bias)

All outcomes

All outcomes

Quote: “...double-blind field trial...The randomization code was not broken until after all children had completed the trial and the data had been entered and verified." "...children received $10 \mathrm{mg} / \mathrm{d}$ zinc (zinc sulfate, syrup formulation) or placebo (placebo syrup, similar in appearance and taste)..."

Comment: sufficient blinding seems likely

Blinding of outcome assessment (detection Low risk bias)

All outcomes
Quote: “...double-blind field trial...The randomization code was not broken until after all children had completed the trial and the data had been entered and verified." “...children received $10 \mathrm{mg} / \mathrm{d}$ zinc (zinc sulfate, syrup formulation) or placebo (placebo syrup, similar in appearance and taste)...”

Comment: sufficient blinding seems likely 
Larson 2010 (Continued)

\begin{tabular}{|c|c|c|}
\hline $\begin{array}{l}\text { Incomplete outcome data (attrition bias) } \\
\text { All outcomes }\end{array}$ & Low risk & $\begin{array}{l}\text { \% Missing: } 6 \\
\text { Reasons/details: In the zinc group: } 12 \text { chil- } \\
\text { dren were lost and } 1 \text { died. In the placebo } \\
\text { group: } 7 \text { children were lost } \\
\text { Comment: reasons for, and amount of, } \\
\text { missing data were similar between study } \\
\text { groups. Missing data seem too minimal to } \\
\text { impact results }\end{array}$ \\
\hline Selective reporting (reporting bias) & High risk & $\begin{array}{l}\text { Comment: height-for age z-score, weight- } \\
\text { for age z-score, weight-for-height z-score, } \\
\text { serum zinc concentration, and serum cop- } \\
\text { per concentration were measured, but are } \\
\text { not reported in a way that can be meta- } \\
\text { analysed. Of these outcomes, only serum } \\
\text { zinc concentration was pre-specified in the } \\
\text { protocol for this study. Haemoglobin con- } \\
\text { centration was reported, but was not pre- } \\
\text { specified in the protocol for this study } \\
\text { Protocol identifier: NCT00408356 }\end{array}$ \\
\hline Other bias & Low risk & Comment: appears to be free of other bias \\
\hline
\end{tabular}

\section{Lind 2003}

Methods

Participants
CRCT?: IRCT; Cross-over?: non-cross-over

Country: Indonesia; Setting: Purworejo district, central Java; Urbanicity: rural Inclusion criteria: healthy; singleton; mother who had been monitored during pregnancy and birth

Exclusion criteria: metabolic or neurologic disorders; physical handicaps affecting development, feeding, or activity; severe or protracted illness; haemoglobin concentrations < $90 \mathrm{~g} / \mathrm{L}$ on assessment of eligibility

Baseline characteristics

Avg age (mo): 6; Min age (mo): 6; Max age (mo): 6; \% Female: 48

Avg HAZ: -0.34; Stunting: both - separate data not given; Avg height (cm): 65.4; Avg zinc concentration $(\mu \mathrm{g} / \mathrm{dL}): 60.8$

Total N: 680; Group 1 N: 170; Group 2 N: 170; Group 3 N: 170; Group 4 N: 170

Interventions

Group 1: zinc

Formulation: solution; Compound: sulfate; Frequency: daily; Duration (mo): 6; Dose (mg): 10; Co-intervention(s): $30 \mathrm{mg}$ ascorbic acid

Group 2: no zinc

Placebo given; Co-intervention(s): $30 \mathrm{mg}$ ascorbic acid

Group 3: zinc

Co-intervention(s): $10 \mathrm{mg}$ iron; $30 \mathrm{mg}$ ascorbic acid

Group 4: no zinc

Placebo given; Co-intervention(s): $10 \mathrm{mg}$ iron; $30 \mathrm{mg}$ ascorbic acid 
Lind 2003 (Continued)

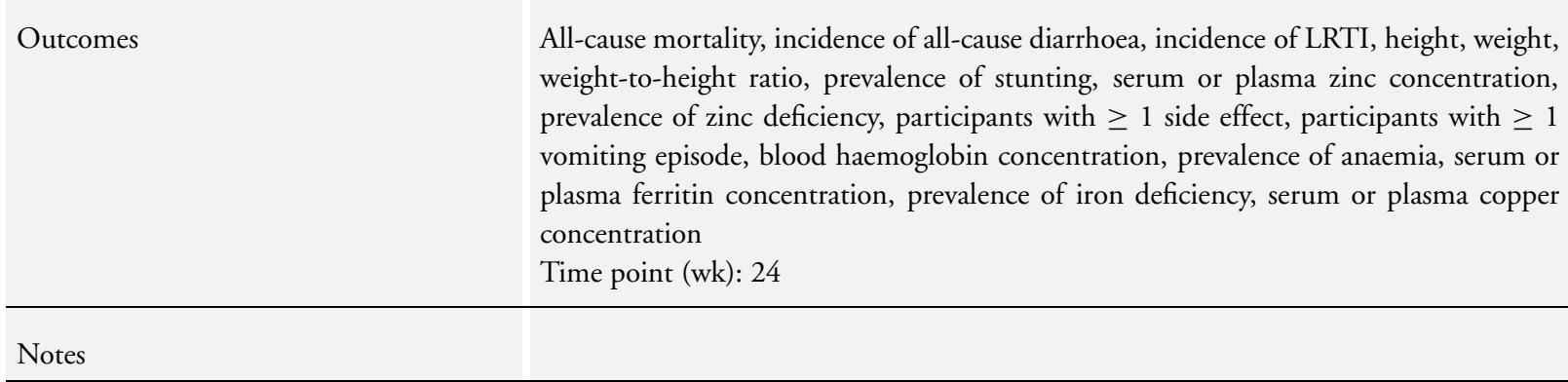

Risk of bias

\begin{tabular}{lll} 
Bias & Authors' judgement & Support for judgement \\
\hline $\begin{array}{l}\text { Random sequence generation (selection } \\
\text { bias) }\end{array}$ & Unclear risk & $\begin{array}{l}\text { Quote: "Randomization was planned and } \\
\text { generated by an independent statistician, } \\
\text { and was performed in blocks of } 20 . "\end{array}$ \\
& & $\begin{array}{l}\text { Comment: insufficient details available to } \\
\text { make a judgement as to whether or not an } \\
\text { allocation sequence was generated using a } \\
\text { truly random method }\end{array}$
\end{tabular}

Allocation concealment (selection bias) Low risk

Quote: "Randomization was planned and generated by an independent statistician..."

Comment: indicates central randomisation (i.e. randomisation by someone not involved with enrolling patients) to conceal allocation

Blinding of participants (performance Low risk bias)

All outcomes
Quote: “...double blind, placebo-controlled trial...The pharmaceutical company marked the 4 different supplements with letter codes, blinded to...participants. Information on group assignment was kept in a safe at the administrative offices of Gadjah Mada and Umeå Universities until after the intent-to-treat analysis."

Comment: sufficient blinding seems likely

Blinding of personnel (performance bias) Low risk All outcomes
Quote: “...double blind, placebo-controlled trial...The pharmaceutical company marked the 4 different supplements with letter codes, blinded to researchers... Information on group assignment was kept in a safe at the administrative offices of Gadjah Mada and Umeå Universities until after the intent-to-treat analysis." 
Lind 2003

Comment: sufficient blinding seems likely

Blinding of outcome assessment (detection Low risk bias)

All outcomes
Quote: “...double blind, placebo-controlled trial...The pharmaceutical company marked the 4 different supplements with letter codes, blinded to researchers... Information on group assignment was kept in a safe at the administrative offices of Gadjah Mada and Umeå Universities until after the intent-to-treat analysis. The laboratory assessing the biochemical outcomes was not aware of the randomization groups.

Comment: sufficient blinding seems likely

\% Missing: 2

Reasons/details: for all outcomes: 1, 1, 3, and 4 participants in the zinc, placebo, zinc + iron, and iron groups, respectively, "refused supplement...discontinued intervention"; 2 from the zinc group died; and 3 from the zinc + iron group moved. For height, weight, and weight-to-height ratio outcomes: 5, 5, 3, and 3 participants in the zinc, placebo, zinc + iron, and iron groups, respectively, were "excluded from analysis" due to "incomplete anthropometric data." For serum zinc, haemoglobin, serum ferritin, and serum copper outcomes: 13,14 , 9 , and 10 participants in the zinc, placebo, zinc + iron, and iron groups, respectively, were "excluded from analysis" because they "refused 2nd blood sample"; and 20, 12, 19 , and 20 participants in the zinc, placebo, zinc + iron, and iron groups, respectively, were "excluded from analysis" because there was "insufficient serum volume" from them Comment: reasons for, and amount of, missing data were similar between study groups. Missing data seems too minimal to impact results

Selective reporting (reporting bias) Low risk

Comment: all pre-specified outcomes reported using pre-specified methods Protocol identifier: N/A - obtained through an email from a study author 
Lind 2003 (2)

Methods

Participants

Interventions

Outcomes All-cause mortality, incidence of all-cause diarrhoea, incidence of LRTI, height, weight, weight-to-height ratio, prevalence of stunting, serum or plasma zinc concentration, prevalence of zinc deficiency, participants with $\geq 1$ side effect, participants with $\geq 1$ vomiting episode, blood haemoglobin concentration, prevalence of anaemia, serum or plasma ferritin concentration, prevalence of iron deficiency, serum or plasma copper concentration

Notes $\quad$ As Lind 2003 above

\section{Long 2006}

\begin{tabular}{|c|c|}
\hline Methods & CRCT?: IRCT; Cross-over?: non-cross-over \\
\hline Participants & $\begin{array}{l}\text { Country: Mexico; Setting: La Magdalena Atlicpac, a peri-urban community located on } \\
\text { the eastern periphery of Mexico City; Urbanicity: peri-urban } \\
\text { Inclusion criteria: N/A } \\
\text { Exclusion criteria: diseases causing immunosuppression; any congenital or acquired al- } \\
\text { teration of the digestive tract that could alter the absorption of micronutrients; taking } \\
\text { vitamin supplements } \\
\text { Baseline characteristics } \\
\text { Avg age (mo): } 9.8 \text {; Min age (mo): 6; Max age (mo): } 15 \text {; \% Female: } 51 \\
\text { Avg HAZ: } 0.1 \text {; Stunting: both - separate data not given; Avg height }(\mathrm{cm}): 73.79 \text {; Avg } \\
\text { zinc concentration }(\mu \mathrm{g} / \mathrm{dL}): \mathrm{N} / \mathrm{A} \\
\text { Total N: } 786 \text {; Group } 1 \mathrm{~N}: 196 \text {; Group } 2 \mathrm{~N}: 198 \text {; Group } 3 \mathrm{~N}: \mathrm{N} / \mathrm{A} \text {; Group } 4 \mathrm{~N} \text { : N/A }\end{array}$ \\
\hline Interventions & $\begin{array}{l}\text { Group 1: zinc } \\
\text { Formulation: solution; Compound: methionine; Frequency: daily; Duration (mo): 12; } \\
\text { Dose (mg): 20; Co-intervention(s): N/A } \\
\text { Group 2: no zinc } \\
\text { Placebo given; Co-intervention(s): N/A } \\
\text { Group 3: zinc } \\
\text { Co-intervention(s): } 20,000 \mathrm{IU} \text { retinol every } 2 \text { months if age } \leq 12 \text { months, } 45,000 \mathrm{IU} \\
\text { retinol every } 2 \text { months if age }>12 \text { months } \\
\text { Group 4: no zinc } \\
\text { Placebo given; Co-intervention(s): } 20,000 \mathrm{IU} \text { retinol every } 2 \text { months if age } \leq 12 \text { months, } \\
\text { 45,000 IU retinol every } 2 \text { months if age }>12 \text { months }\end{array}$ \\
\hline
\end{tabular}

Outcomes

Incidence of all-cause diarrhoea, incidence of persistent diarrhoea, incidence of LRTI, height, weight, prevalence of stunting

Time point (wk): 52

Notes

- In the Long et al 2006 trial report, it is reported that 193 participants were randomised to the vitamin A + zinc group and 199 participants were randomised to the vitamin A group. In contrast, in the Long et al 2007 and Rosado et al 2009 trial reports, it is reported that 199 participants were randomised to the vitamin A + zinc group and 193

Zinc supplementation for preventing mortality, morbidity, and growth failure in children aged 6 months to 12 years of age (Review)

Copyright @ 2014 The Cochrane Collaboration. Published by John Wiley \& Sons, Ltd. 
participants were randomised to the vitamin A group

- There is some discrepancy between the average, minimum, and maximum ages reported in the different trial reports for this study. However, the mean age of participants in all trial reports falls within the age range of this review

Risk of bias

\begin{tabular}{|c|c|c|}
\hline Bias & Authors' judgement & Support for judgement \\
\hline $\begin{array}{l}\text { Random sequence generation (selection } \\
\text { bias) }\end{array}$ & Low risk & $\begin{array}{l}\text { Quote: "The randomization sequence was } \\
\text { generated by using a random-number ta- } \\
\text { ble..." } \\
\text { Comment: N/A }\end{array}$ \\
\hline Allocation concealment (selection bias) & Low risk & $\begin{array}{l}\text { Quote: "The randomization sequence } \\
\text { was generated...by project personnel from } \\
\text { CENSIA, a division of the Mexican Min- } \\
\text { istry of Health." "On acceptance, the child } \\
\text { was randomly assigned to } 1 \text { of the } 4 \text { groups } \\
\text { by the project field coordinator, who was } \\
\text { blinded to these groups." } \\
\text { Comment: sufficient allocation conceal- } \\
\text { ment seems likely }\end{array}$ \\
\hline $\begin{array}{l}\text { Blinding of participants (performance } \\
\text { bias) } \\
\text { All outcomes }\end{array}$ & Low risk & $\begin{array}{l}\text { Quote: “...double-blind randomized } \\
\text { trial...The vitamin A, zinc, and vitamin A } \\
\text { zinc supplements were prepared by person- } \\
\text { nel at the National Institute of Nutrition } \\
\text { in 5-mL solutions that were similar in taste } \\
\text { and appearance." } \\
\text { Comment: sufficient blinding seems likely }\end{array}$ \\
\hline $\begin{array}{l}\text { Blinding of personnel (performance bias) } \\
\text { All outcomes }\end{array}$ & Low risk & $\begin{array}{l}\text { Quote: “...double-blind random- } \\
\text { ized trial...The vitamin A, zinc, and vita- } \\
\text { min A zinc supplements were prepared by } \\
\text { personnel at the National Institute of Nu- } \\
\text { trition in 5-mL solutions that were similar } \\
\text { in taste and appearance...These solutions } \\
\text { were packaged in consecutively numbered, } \\
\text { color-coded, opaque plastic droplet bottles } \\
\text { to ensure that field personnel and the prin- } \\
\text { cipal investigator were blinded." } \\
\text { Comment: sufficient blinding seems likely }\end{array}$ \\
\hline $\begin{array}{l}\text { Blinding of outcome assessment (detection } \\
\text { bias) } \\
\text { All outcomes }\end{array}$ & Low risk & $\begin{array}{l}\text { Quote: “...double-blind random- } \\
\text { ized trial... The vitamin A, zinc, and vita- } \\
\text { min A zinc supplements were prepared by } \\
\text { personnel at the National Institute of Nu- } \\
\text { trition in } 5-\mathrm{mL} \text { solutions that were similar }\end{array}$ \\
\hline
\end{tabular}


Long 2006 (Continued)

\begin{tabular}{|c|c|c|}
\hline & & $\begin{array}{l}\text { in taste and appearance... These solutions } \\
\text { were packaged in consecutively numbered, } \\
\text { color-coded, opaque plastic droplet bottles } \\
\text { to ensure that field personnel and the prin- } \\
\text { cipal investigator were blinded." } \\
\text { Comment: sufficient blinding seems likely }\end{array}$ \\
\hline $\begin{array}{l}\text { Incomplete outcome data (attrition bias) } \\
\text { All outcomes }\end{array}$ & Low risk & $\begin{array}{l}\% \text { Missing: } 6 \\
\text { Reasons/details: "Seven children migrated } \\
\text { from the area with their families immedi- } \\
\text { ately after being randomly assigned..." In } \\
\text { addition to these seven, some participants } \\
\text { were "lost to follow-up", others "discon- } \\
\text { tinued interventions", and others were "ex- } \\
\text { cluded from analysis." The exact numbers } \\
\text { of participants who were lost, who discon- } \\
\text { tinued interventions, or who were excluded } \\
\text { varies slightly between trial reports. How- } \\
\text { ever, in the Long } 2006 \text { trial report, which } \\
\text { reports most of the outcomes of interest to } \\
\text { this review: in the zinc group, } 5 \text { were lost, } 3 \\
\text { discontinued, and } 5 \text { were excluded; in the } \\
\text { placebo group, } 3 \text { were lost, } 5 \text { discontinued, } \\
\text { and } 6 \text { were excluded; in the vitamin A + } \\
\text { zinc group, } 5 \text { were lost, } 1 \text { discontinued, and } \\
4 \text { were excluded; in the vitamin A group, } \\
2 \text { were lost, } 2 \text { discontinued, and } 2 \text { were ex- } \\
\text { cluded } \\
\text { Comment: reasons for, and amount of, } \\
\text { missing data were similar between study } \\
\text { groups. Missing data seems too minimal to } \\
\text { impact results }\end{array}$ \\
\hline Selective reporting (reporting bias) & Unclear risk & $\begin{array}{l}\text { Comment: side effects may have been mea- } \\
\text { sured, but are not reported for the placebo } \\
\text { group. No trial protocol referenced by the } \\
\text { study }\end{array}$ \\
\hline Other bias & Low risk & Comment: appears to be free of other bias \\
\hline
\end{tabular}

Long 2006 (2)

Methods

Participants

Interventions

Zinc supplementation for preventing mortality, morbidity, and growth failure in children aged 6 months to 12 years of age (Review)

Copyright @ 2014 The Cochrane Collaboration. Published by John Wiley \& Sons, Ltd. 
Long 2006 (2) (Continued)

\begin{tabular}{ll} 
Outcomes & $\begin{array}{l}\text { Incidence of all-cause diarrhoea, incidence of persistent diarrhoea, incidence of LRTI, height, weight, prevalence of } \\
\text { stunting }\end{array}$ \\
\hline Notes & As Long 2006 above.
\end{tabular}

\section{Mahloudji 1975}

\begin{tabular}{|c|c|}
\hline Methods & CRCT?: IRCT; Cross-over?: non-cross-over \\
\hline Participants & $\begin{array}{l}\text { Country: Iran; Setting: the village of Kherak, near Shiraz in southern Iran; Urbanicity: } \\
\text { rural } \\
\text { Inclusion criteria: N/A } \\
\text { Exclusion criteria: N/A } \\
\text { Baseline characteristics } \\
\text { Avg age (mo): N/A; Min age (mo): 72; Max age (mo): 144; \% Female: } 8 \\
\text { Avg HAZ: N/A; Stunting: unclear; Avg height (cm): N/A; Avg zinc concentration ( } \mu \mathrm{g} / \\
\text { dL): } 64.8 \\
\text { Total N: } 50 \text {; Group } 1 \mathrm{~N}: 25 \text {; Group } 2 \mathrm{~N}: 25\end{array}$ \\
\hline Interventions & $\begin{array}{l}\text { Group 1: zinc } \\
\text { Formulation: capsule; Compound: carbonate; Frequency: } 6 \text { days/wk; Duration (mo): } \\
\text { 16; Dose (mg): 20; Co-intervention(s): } 20 \mathrm{mg} \text { iron; vitamin and mineral supplements, } \\
\text { which contained multiple micronutrients; egg white and corn oil supplements } \\
\text { Group 2: no zinc } \\
\text { Placebo given; Co-intervention(s): } 20 \mathrm{mg} \text { iron; vitamin and mineral supplements, which } \\
\text { contained multiple micronutrients; egg white and corn oil supplements }\end{array}$ \\
\hline Outcomes & $\begin{array}{l}\text { Serum or plasma zinc concentration, blood haemoglobin concentration } \\
\text { Time point (wk): } 80\end{array}$ \\
\hline Notes & $\begin{array}{l}\text { - The supplement and placebo were given "during the school year... Treatment was dis- } \\
\text { continued in May } 1969 \text { and resumed in October of the same year." It seems that treat- } \\
\text { ment was started in October 1968, discontinued in May 1969, started again in October } \\
\text { 1969, and ended in May } 1970 \\
\text { - In addition to the study groups mentioned in this table, there was a group of } 25 \text { par- } \\
\text { ticipants who received "placebo capsules containing lactose and simulated supplement"; } \\
\text { but there was no zinc group to which this placebo group could be compared. So, this } \\
\text { group is not included in any meta-analyses in this review }\end{array}$ \\
\hline
\end{tabular}

\section{Risk of bias}

\begin{tabular}{|c|c|c|}
\hline Bias & Authors' judgement & Support for judgement \\
\hline $\begin{array}{l}\text { Random sequence generation (selection } \\
\text { bias) }\end{array}$ & Unclear risk & $\begin{array}{l}\text { Quote: "Care was taken to ensure that the } \\
\text { grouping was by chance." } \\
\text { Comment: insufficient details available to } \\
\text { make a judgement as to whether or not an }\end{array}$ \\
\hline
\end{tabular}

Zinc supplementation for preventing mortality, morbidity, and growth failure in children aged 6 months to 12 years of age (Review) 
Mahloudji 1975 (Continued)

allocation sequence was generated using a truly random method

\begin{tabular}{|c|c|c|}
\hline Allocation concealment (selection bias) & Unclear risk & $\begin{array}{l}\text { Quote: N/A } \\
\text { Comment: insufficient details available to } \\
\text { make a judgement }\end{array}$ \\
\hline $\begin{array}{l}\text { Blinding of participants (performance } \\
\text { bias) } \\
\text { All outcomes }\end{array}$ & Low risk & $\begin{array}{l}\text { Quote: "The supplement and simulated } \\
\text { supplement looked and tasted alike..." } \\
\text { Comment: sufficient blinding seems likely }\end{array}$ \\
\hline $\begin{array}{l}\text { Blinding of personnel (performance bias) } \\
\text { All outcomes }\end{array}$ & Low risk & $\begin{array}{l}\text { Quote: "The supplement and simulated } \\
\text { supplement looked and tasted alike..." } \\
\text { Comment: sufficient blinding seems likely }\end{array}$ \\
\hline $\begin{array}{l}\text { Blinding of outcome assessment (detection } \\
\text { bias) } \\
\text { All outcomes }\end{array}$ & Low risk & $\begin{array}{l}\text { Quote: "The supplement and simulated } \\
\text { supplement looked and tasted alike..." } \\
\text { Comment: sufficient blinding seems likely }\end{array}$ \\
\hline $\begin{array}{l}\text { Incomplete outcome data (attrition bias) } \\
\text { All outcomes }\end{array}$ & Unclear risk & $\begin{array}{l}\text { \% Missing: N/A } \\
\text { Reasons/details: N/A } \\
\text { Comment: the study reported that, "Sev- } \\
\text { enty-five children... were divided into three } \\
\text { groups." However, results were reported as } \\
\text { being out "of } 59 \text { children." Nothing (such } \\
\text { as reasons for missing data, and number } \\
\text { of participants with missing data, for each } \\
\text { study group) was reported to explain this } \\
75 \text { versus } 59 \text { children inconsistency }\end{array}$ \\
\hline
\end{tabular}

Selective reporting (reporting bias) High risk

Comment: height, weight, prevalence of zinc deficiency, and prevalence of anaemia were measured, but are not reported in a way that can be meta-analysed

Other bias

Low risk

Comment: appears to be free of other bias

Malik 2013

Methods

Participants
CRCT?: IRCT; Cross-over?: non-cross-over

Country: India; Setting: Delhi; Urbanicity: urban Inclusion criteria: all children 6 to 11 months of age residing in Gokulpuri, an urban re-settlement colony in North East District of Delhi, India and who were likely to stay until the completion of the study. To achieve the final sample size additional children were recruited from the similar adjacent area of Gangavihar

Exclusion criteria: any child receiving zinc supplement at the time of study or in the past 3 months, or severely malnourished, immune-deficient or on steroid therapy, severely 
ill children requiring hospitalisation, or children of families likely to migrate from the study area

Baseline characteristics

Avg age (mo): not mentioned; Min age (mo): 6 months; Max age (mo): 11; \% Female: not given

Avg HAZ: not given; Stunting: unclear; Avg height (cm): not given; Avg zinc concentration $(\mu \mathrm{g} / \mathrm{dL})$ : not given

Total N: 158; Group 1 N: 134; Group 2 N: 124

\begin{tabular}{ll} 
Interventions & $\begin{array}{l}\text { Group 1: zinc } \\
\text { Formulation: solution; Compound: unclear; Frequency: daily; Duration (mo): } 0.46 ; \\
\text { Dose (mg): 20; Co-intervention(s): none } \\
\text { Group 2: no zinc } \\
\text { Placebo given; Co-intervention(s): none }\end{array}$ \\
\hline Outcomes & $\begin{array}{l}\text { Mortality due to all-cause diarrhoea, incidence of all-cause diarrhoea, incidence of per- } \\
\text { sistent diarrhoea, prevalence of all-cause diarrhoea, vomiting } \\
\text { Time point (wk): } 22\end{array}$ \\
\hline
\end{tabular}

Notes

Risk of bias

\begin{tabular}{|c|c|c|}
\hline Bias & Authors' judgement & Support for judgement \\
\hline $\begin{array}{l}\text { Random sequence generation (selection } \\
\text { bias) }\end{array}$ & Low risk & $\begin{array}{l}\text { Quote: "We randomized the treatment al- } \\
\text { location; by simple randomization using } \\
\text { computer generated random numbers." }\end{array}$ \\
\hline Allocation concealment (selection bias) & Low risk & $\begin{array}{l}\text { Quote: "We randomized the treatment al- } \\
\text { location; by simple randomization using } \\
\text { computer generated random numbers." }\end{array}$ \\
\hline $\begin{array}{l}\text { Blinding of participants (performance } \\
\text { bias) } \\
\text { All outcomes }\end{array}$ & Low risk & $\begin{array}{l}\text { Quote: "The field investigator and parents } \\
\text { were blinded to the treatment allocation } \\
\text { and were unblinded at the end of the fol- } \\
\text { low-up period." }\end{array}$ \\
\hline $\begin{array}{l}\text { Blinding of personnel (performance bias) } \\
\text { All outcomes }\end{array}$ & Low risk & $\begin{array}{l}\text { Quote: "The field investigator and parents } \\
\text { were blinded to the treatment allocation } \\
\text { and were unblinded at the end of the fol- } \\
\text { low-up period." }\end{array}$ \\
\hline $\begin{array}{l}\text { Blinding of outcome assessment (detection } \\
\text { bias) } \\
\text { All outcomes }\end{array}$ & Low risk & $\begin{array}{l}\text { Quote: "The field investigator and parents } \\
\text { were blinded to the treatment allocation } \\
\text { and were unblinded at the end of the fol- } \\
\text { low-up period." }\end{array}$ \\
\hline
\end{tabular}


Incomplete outcome data (attrition bias) Low risk All outcomes
Quote: “Generalized Estimating Equations (GEE) were used to obtain an incident rate ratio (IRR) with $95 \%$ confidence intervals, in order to compare month-wise number of episodes and duration of diarrhea using Poisson log linear distribution, by intention to treat analysis... We included all children who had taken at least two doses of the intervention for the analyses. The follow-up visits for which the infant outcomes were not available were imputed using the worst case ( 2 episodes of diarrhea) and best case scenarios (no episodes). However this did not change the study results thus missing data was excluded from the final analysis." Comment: 7/141 and 7/131 not included in the analysis
Quote: "part of a larger study taking in to account four primary outcomes, viz. decrease in incidence of diarrhea and acute respiratory tract infections (ARI) and increase in length and weight" "We decided to adjust the IRRs for covariates which appeared to be different at baseline in the two groups."

Trial registration: CTRI/2010/091/ 001417

\section{Marinho 1991}

\begin{tabular}{|c|c|}
\hline Methods & CRCT?: IRCT; Cross-over?: non-cross-over \\
\hline Participants & $\begin{array}{l}\text { Country: Brazil; Setting: a poor district of Manaus (Amazonas); Urbanicity: urban } \\
\text { Inclusion criteria: parasitised with A. lumbricoides and/or G. lamblia } \\
\text { Exclusion criteria: N/A } \\
\text { Baseline characteristics } \\
\text { Avg age (mo): N/A; Min age (mo): 36; Max age (mo): 84; \% Female: } 50 \\
\text { Avg HAZ: N/A; Stunting: both - separate data not given; Avg height (cm): N/A; Avg } \\
\text { zinc concentration ( } \mu \mathrm{g} / \mathrm{dL} \text { ): N/A } \\
\text { Total N: } 240 \text {; Group } 1 \mathrm{~N} \text { : } 60 \text {; Group } 2 \mathrm{~N}: 60 \text {; Group } 3 \mathrm{~N} \text { : 60; Group } 4 \mathrm{~N}: 60\end{array}$ \\
\hline Interventions & $\begin{array}{l}\text { Group 1: zinc } \\
\text { Formulation: unclear; Compound: acetate; Frequency: daily; Duration (mo): 1; Dose } \\
\text { (mg): 5; Co-intervention(s): N/A } \\
\text { Group 2: no zinc }\end{array}$ \\
\hline
\end{tabular}




\begin{tabular}{ll} 
Placebo given; Co-intervention(s): N/A \\
Group 3: zinc \\
Co-intervention(s): $500 \mathrm{mg}$ vitamin A \\
$\begin{array}{l}\text { Group 4: no zinc } \\
\text { Placebo given; Co-intervention(s): } 500 \mathrm{mg} \text { vitamin A }\end{array}$ \\
\hline Outcomes & No outcomes of interest reported in a way that can be meta-analysed \\
\hline Notes & $\begin{array}{l}\text { "One-hundred-and-twenty of the parasitized children... were treated with mebenda- } \\
\text { zol...for } A \text {. lumbricoides and with metronidazol...for G. lamblia... The efficiency of the } \\
\text { parasitosis treatment was checked by carrying out another stool analysis." } 30 \text { of these } \\
\text { treated children were randomised to each study group; thus, each study group was com- } \\
\text { prised of } 30 \text { treated participants, and } 30 \text { untreated participants }\end{array}$ \\
\hline
\end{tabular}

\section{Risk of bias}

\begin{tabular}{|c|c|c|}
\hline Bias & Authors' judgement & Support for judgement \\
\hline $\begin{array}{l}\text { Random sequence generation (selection } \\
\text { bias) }\end{array}$ & Unclear risk & $\begin{array}{l}\text { Quote: "The parasitized and non-para- } \\
\text { sitized groups were randomly assigned to } \\
\text { four sub-groups..." } \\
\text { Comment: insufficient details available to } \\
\text { make a judgement as to whether or not an } \\
\text { allocation sequence was generated using a } \\
\text { truly random method }\end{array}$ \\
\hline Allocation concealment (selection bias) & Unclear risk & $\begin{array}{l}\text { Quote: N/A } \\
\text { Comment: insufficient details available to } \\
\text { make a judgement }\end{array}$ \\
\hline $\begin{array}{l}\text { Blinding of participants (performance } \\
\text { bias) } \\
\text { All outcomes }\end{array}$ & Unclear risk & $\begin{array}{l}\text { Quote: N/A } \\
\text { Comment: insufficient details available to } \\
\text { make a judgement }\end{array}$ \\
\hline $\begin{array}{l}\text { Blinding of personnel (performance bias) } \\
\text { All outcomes }\end{array}$ & Unclear risk & $\begin{array}{l}\text { Quote: N/A } \\
\text { Comment: insufficient details available to } \\
\text { make a judgement }\end{array}$ \\
\hline $\begin{array}{l}\text { Blinding of outcome assessment (detection } \\
\text { bias) } \\
\text { All outcomes }\end{array}$ & Unclear risk & $\begin{array}{l}\text { Quote: N/A } \\
\text { Comment: insufficient details available to } \\
\text { make a judgement. }\end{array}$ \\
\hline $\begin{array}{l}\text { Incomplete outcome data (attrition bias) } \\
\text { All outcomes }\end{array}$ & Unclear risk & $\begin{array}{l}\text { \% Missing: N/A } \\
\text { Reasons/details: N/A } \\
\text { Comment: reasons for, and amount of, } \\
\text { missing data were not reported for either } \\
\text { study group }\end{array}$ \\
\hline
\end{tabular}


Marinho 1991 (Continued)

\begin{tabular}{l|ll}
\hline Selective reporting (reporting bias) & Unclear risk & $\begin{array}{l}\text { Comment: no trial protocol referenced by } \\
\text { the study }\end{array}$ \\
\hline Other bias & Low risk & Comment: appears to be free of other bias \\
\hline
\end{tabular}

Mazariegos 2010

\begin{tabular}{|c|c|}
\hline Methods & CRCT?: IRCT; Cross-over?: non-cross-over \\
\hline Participants & $\begin{array}{l}\text { Country: Guatemala; Setting: the town of San Juan Comalapa, in the province of Chi- } \\
\text { maltenango, in the Western Highlands of Guatemala; Urbanicity: rural } \\
\text { Inclusion criteria: living within } 12 \mathrm{~km} \text { of the township of Comalapa; apparently healthy } \\
\text { (based on maternal history without any prenatal or natal concerns and no history of } \\
\text { serious illness postnatally); home-cooked maize as the major family food staple } \\
\text { Exclusion criteria: refused verbal screening; did not eat tortillas in the home; family who } \\
\text { did not plan to stay in the geographical area for the next year } \\
\text { Baseline characteristics } \\
\text { Avg age (mo): } 6 \text {; Min age (mo): } 6 \text {; Max age (mo): } 6 \text {; \% Female: } 49.5 \\
\text { Avg HAZ: }-2.09 \text {; Stunting: both - separate data not given; Avg height }(\mathrm{cm}): 62.1 \text {; Avg } \\
\text { zinc concentration }(\mu \mathrm{g} / \mathrm{dL}): 110.5 \\
\text { Total N: } 412 \text {; Group } 1 \mathrm{~N}: 104 \text {; Group } 2 \mathrm{~N}: 105 \text {; Group } 3 \mathrm{~N}: 100 \text {; Group } 4 \mathrm{~N}: 103\end{array}$ \\
\hline Interventions & $\begin{array}{l}\text { Group 1: zinc } \\
\text { Formulation: pill/tablet; Compound: unclear; Frequency: daily; Duration (mo): 6; Dose } \\
(\mathrm{mg}) \text { : 5; Co-intervention(s): isohybrid control maize } \\
\text { Group 2: no zinc } \\
\text { Placebo given; Co-intervention(s): isohybrid control maize } \\
\text { Group 3: zinc } \\
\text { Co-intervention(s): low-phytate maize } \\
\text { Group 4: no zinc } \\
\text { Placebo given; Co-intervention(s): low-phytate maize }\end{array}$ \\
\hline
\end{tabular}

Outcomes

Height, weight, weight-to-height ratio, serum or plasma zinc concentration, study withdrawal, participants with $\geq 1$ side effect, vomiting episodes, participants with $\geq 1$ vomiting episode

Time point (wk): 24

Notes

Risk of bias

Bias Authors' judgement $\quad$ Support for judgement

Random sequence generation (selection Low risk bias)

Quote: "At the time of enrolment, families were assigned to receive maize labeled with 1 of 6 randomization colors. Permuted blocks were used in the generation of the 


\begin{tabular}{|c|c|c|}
\hline & & $\begin{array}{l}\text { randomization list. At age } 6 \text { mo, infants } \\
\text { were further randomized to the zinc sup- } \\
\text { plementation trial. The infants were ran- } \\
\text { domized to the treatment or control group } \\
\text { within the family's maize group assign- } \\
\text { ment, also using permuted blocks." } \\
\text { Comment: N/A }\end{array}$ \\
\hline Allocation concealment (selection bias) & Low risk & $\begin{array}{l}\text { Quote: in response to the question, "Could } \\
\text { you describe how you ensured that partic- } \\
\text { ipants, and investigators enrolling partic- } \\
\text { ipants, could not tell which group a new } \\
\text { participant would be assigned to?" an au- } \\
\text { thor of this study replied as follows: "The } \\
\text { randomization was undertaken by RTI-to- } \\
\text { tally detached from all investigators." RTI } \\
\text { stands for "Research Triangle Institute", } \\
\text { which was involved with data management } \\
\text { for the study } \\
\text { Comment: sufficient allocation conceal- } \\
\text { ment seems likely }\end{array}$ \\
\hline $\begin{array}{l}\text { Blinding of participants (performance } \\
\text { bias) } \\
\text { All outcomes }\end{array}$ & Low risk & $\begin{array}{l}\text { Quote: “...doubly masked trial...” } \\
\text { Comment: sufficient blinding seems likely }\end{array}$ \\
\hline $\begin{array}{l}\text { Blinding of personnel (performance bias) } \\
\text { All outcomes }\end{array}$ & Low risk & $\begin{array}{l}\text { Quote: "...doubly masked trial...Quality } \\
\text { control checks of maize...undertaken by } \\
\text { one of the investigating team (V. R.) at } \\
\text { the USDA facility in Aberdeen, Idaho, } \\
\text { to verify correct delivery of the assigned } \\
\text { maize. Apart from the members of the Data } \\
\text { Management Center at RTI, V.R. was the } \\
\text { only unmasked member of the investigat- } \\
\text { ing team." } \\
\text { Comment: sufficient blinding seems likely }\end{array}$ \\
\hline $\begin{array}{l}\text { Blinding of outcome assessment (detection } \\
\text { bias) } \\
\text { All outcomes }\end{array}$ & Low risk & $\begin{array}{l}\text { Quote: "...doubly masked trial...Quality } \\
\text { control checks of maize...undertaken by } \\
\text { one of the investigating team (V. R.) at } \\
\text { the USDA facility in Aberdeen, Idaho, } \\
\text { to verify correct delivery of the assigned } \\
\text { maize. Apart from the members of the Data } \\
\text { Management Center at RTI, V.R. was the } \\
\text { only unmasked member of the investigat- } \\
\text { ing team." } \\
\text { Comment: sufficient blinding seems likely }\end{array}$ \\
\hline
\end{tabular}




\section{Mazariegos 2010 (Continued)}

\begin{tabular}{|c|c|c|}
\hline $\begin{array}{l}\text { Incomplete outcome data (attrition bias) } \\
\text { All outcomes }\end{array}$ & Low risk & $\begin{array}{l}\text { \% Missing: } 7 \\
\text { Reasons/details: in the zinc group: } 4 \text { were } \\
\text { "missing" for the " } 12 \text { mo visit", } 4 \text { "moved", } \\
\text { and } 8 \text { "withdrew consent." In the placebo } \\
\text { group, } 4 \text { were "missing" for the " } 12 \text { mo } \\
\text { visit", } 4 \text { "moved", and } 4 \text { "withdrew con- } \\
\text { sent." "The small attrition rate in partici- } \\
\text { pant retention was primarily due to reloca- } \\
\text { tion from the area or withdrawal of consent } \\
\text { because of perceived study burden." } \\
\text { Comment: reasons for, and amount of, } \\
\text { missing data were similar between study } \\
\text { groups. Missing data seem too minimal to } \\
\text { impact results }\end{array}$ \\
\hline Selective reporting (reporting bias) & High risk & $\begin{array}{l}\text { Comment: diarrhoea prevalence, LRTI in- } \\
\text { cidence, and stunting rates were measured, } \\
\text { but are not reported in a way that can be } \\
\text { meta-analysed }\end{array}$ \\
\hline Other bias & Low risk & Comment: appears to be free of other bias \\
\hline
\end{tabular}

Meeks Gardner 1998

Methods

Participants
CRCT?: IRCT; Cross-over?: non-cross-over

Country: Jamaica; Setting: Kingston; Urbanicity: urban

Inclusion criteria: singleton; stunted (below -2.0 SD length-for-age and less than the median weight-for-length, NCHS references)

Exclusion criteria: obvious physical or mental handicap; provided vitamin-mineral supplements which contained iron and/or zinc by their caretakers

Baseline characteristics

Avg age (mo): 14.1; Min age (mo): 6; Max age (mo): 24; \% Female: 57

Avg HAZ: -2.9; Stunting: stunted; Avg height (cm): 68.7; Avg zinc concentration $(\mu \mathrm{g} /$ dL): N/A

Total N: 61; Group 1 N: 31; Group 2 N: 30
Interventions

Outcomes

\section{Group 1: zinc}

Formulation: solution; Compound: sulfate; Frequency: daily; Duration (mo): 3; Dose (mg): 5; Co-intervention(s): multivitamin supplement (Tropivite vitamin drops)

Group 2: no zinc

Placebo given; Co-intervention(s): multivitamin supplement (Tropivite vitamin drops)

All-cause hospitalisation, incidence of all-cause diarrhoea, incidence of LRTI, height, weight

Time point (wk): 12 (morbidity outcomes), 52 (growth outcomes) 
Meeks Gardner 1998 (Continued)

$\begin{array}{ll}\text { Notes } & \text { "Food supplements were expected to be provided by the nutrition clinics as part of their } \\ \text { routine care, but delivery was extremely irregular and caretakers had food supplements } \\ \text { on average only } 1 \text { week during the } 12 \text { week supplementation period." }\end{array}$

\section{Risk of bias}

\begin{tabular}{|c|c|c|}
\hline Bias & Authors' judgement & Support for judgement \\
\hline $\begin{array}{l}\text { Random sequence generation (selection } \\
\text { bias) }\end{array}$ & Unclear risk & $\begin{array}{l}\text { Quote: “...children were...randomly as- } \\
\text { signed..." } \\
\text { Comment: insufficient details available to } \\
\text { make a judgement as to whether or not an } \\
\text { allocation sequence was generated using a } \\
\text { truly random method }\end{array}$ \\
\hline Allocation concealment (selection bias) & Unclear risk & $\begin{array}{l}\text { Quote: N/A } \\
\text { Comment: insufficient details available to } \\
\text { make a judgement }\end{array}$ \\
\hline $\begin{array}{l}\text { Blinding of participants (performance } \\
\text { bias) } \\
\text { All outcomes }\end{array}$ & Low risk & $\begin{array}{l}\text { Quote: “...double-blind, placebo- } \\
\text { controlled trial...Caretakers were blind to } \\
\text { the children's group assignment." } \\
\text { Comment: sufficient blinding seems likely }\end{array}$ \\
\hline $\begin{array}{l}\text { Blinding of personnel (performance bias) } \\
\text { All outcomes }\end{array}$ & Low risk & $\begin{array}{l}\text { Quote: “...double-blind, placebo- } \\
\text { controlled trial..." } \\
\text { Comment: sufficient blinding seems likely }\end{array}$ \\
\hline $\begin{array}{l}\text { Blinding of outcome assessment (detection } \\
\text { bias) } \\
\text { All outcomes }\end{array}$ & Low risk & $\begin{array}{l}\text { Quote: “...double-blind, placebo- } \\
\text { controlled trial...All interviews and mea- } \\
\text { surements were carried out by members of } \\
\text { the study team who were unaware of the } \\
\text { children's group assignments." } \\
\text { Comment: sufficient blinding seems likely }\end{array}$ \\
\hline $\begin{array}{l}\text { Incomplete outcome data (attrition bias) } \\
\text { All outcomes }\end{array}$ & Unclear risk & $\begin{array}{l}\text { \% Missing: } 7 \\
\text { Reasons/details: } 4 \text { children, "all from the } \\
\text { control group, were hospitalized during the } \\
\text { study", and "stayed in hospital for more } \\
\text { than one night...It was necessary to ex- } \\
\text { clude them since in some cases hospitaliza- } \\
\text { tion may have included zinc supplements } \\
\text { and the feeding regimes would have been } \\
\text { markedly different from the situation at } \\
\text { home." } \\
\text { Comment: children who were hospitalised } \\
\text { probably represented the most severe cases } \\
\text { of illness and excluding } 4 \text { of them may have }\end{array}$ \\
\hline
\end{tabular}


reduced the likelihood of finding significant differences between the groups in the other morbidity variables examined

\begin{tabular}{l|ll} 
Selective reporting (reporting bias) & Unclear risk & $\begin{array}{l}\text { Comment: no trial protocol referenced by } \\
\text { the study }\end{array}$ \\
\hline Other bias & Low risk & Comment: appears to be free of other bias \\
\hline
\end{tabular}

\section{Meeks Gardner 2005}

Methods

Participants

\section{CRCT?: IRCT; Cross-over?: non-cross-over}

Country: Jamaica; Setting: the parishes of Kingston, St. Andrew, and St. Catherine; Urbanicity: unclear

Inclusion criteria: current weight-for-age z scores below -1.5 SDs of the National Center for Health Statistics references; weight-for-age below -2 SDs in the previous 3 mo Exclusion criteria: twins; physical or mental impairments that could affect development Baseline characteristics

Avg age (mo): 18.8; Min age (mo): 9; Max age (mo): 30; \% Female: 61

Avg HAZ: -1.42; Stunting: unclear; Avg height (cm): 77.1; Avg zinc concentration $(\mu \mathrm{g} /$ $\mathrm{dL}): \mathrm{N} / \mathrm{A}$

Total N: 126; Group 1 N: 35; Group 2 N: 42; Group 3 N: 26; Group 4 N: 23

Interventions Group 1: zinc

Formulation: solution; Compound: sulfate; Frequency: daily; Duration (mo): 6; Dose (mg): 10; Co-intervention(s): $0.5 \mathrm{ml}$ vitamin-iron drop, which contained multiple micronutrients

Group 2: no zinc

Placebo given; Co-intervention(s): $0.5 \mathrm{ml}$ vitamin-iron drop, which contained multiple micronutrients

Group 3: zinc

Co-intervention(s): psychosocial stimulation; $0.5 \mathrm{ml}$ vitamin-iron drop, which contained multiple micronutrients

Group 4: no zinc

Placebo given; Co-intervention(s): psychosocial stimulation; $0.5 \mathrm{ml}$ vitamin-iron drop, which contained multiple micronutrients

Outcomes

Incidence of all-cause diarrhoea, incidence of LRTI, height, weight, weight-to-height ratio, study withdrawal

Time point (wk): 24

Notes

"For logistic reasons, we could not extend the stimulation program. To achieve sufficient power to detect an effect of zinc, we continued enrolling children for a further 2 mo to the zinc trial only."

\section{Risk of bias}


Meeks Gardner 2005 (Continued)

\begin{tabular}{|c|c|c|}
\hline Bias & Authors' judgement & Support for judgement \\
\hline $\begin{array}{l}\text { Random sequence generation (selection } \\
\text { bias) }\end{array}$ & Unclear risk & $\begin{array}{l}\text { Quote: “...children were...randomly as- } \\
\text { signed..." } \\
\text { Comment: insufficient details available to } \\
\text { make a judgement as to whether or not an } \\
\text { allocation sequence was generated using a } \\
\text { truly random method }\end{array}$ \\
\hline Allocation concealment (selection bias) & Unclear risk & $\begin{array}{l}\text { Quote: N/A } \\
\text { Comment: insufficient details available to } \\
\text { make a judgement }\end{array}$ \\
\hline $\begin{array}{l}\text { Blinding of participants (performance } \\
\text { bias) } \\
\text { All outcomes }\end{array}$ & Low risk & $\begin{array}{l}\text { Quote: “...double-blind trial...parents or } \\
\text { guardians, who were unaware of the chil- } \\
\text { dren's assignment to zinc or placebo..." } \\
\text { Comment: sufficient blinding seems likely }\end{array}$ \\
\hline $\begin{array}{l}\text { Blinding of personnel (performance bias) } \\
\text { All outcomes }\end{array}$ & Low risk & $\begin{array}{l}\text { Quote: “...double-blind trial..." } \\
\text { Comment: sufficient blinding seems likely }\end{array}$ \\
\hline
\end{tabular}

Blinding of outcome assessment (detection Low risk

bias)

All outcomes
Quote: “...double-blind trial...testers were unaware of the assignment to interventions"

Comment: sufficient blinding seems likely
Incomplete outcome data (attrition bias) Low risk All outcomes
$\%$ Missing: 10

Reasons/details: "Reasons for withdrawal given by the parents from the zinc-supplemented group were as follows: children became anorexic $(n=2)$, child would vomit after the supplement $(\mathrm{n}=1)$, the fathers refused to allow participation after the mother had given consent $(\mathrm{n}=2)$ , and family moved away $(\mathrm{n}=1)$. From the placebo group, parents reported illness (jaundice and liver problems; $\mathrm{n}=2$ ), families moved away $(n=2)$, the mother was unhappy with the doctors from the research unit $(\mathrm{n}=1)$, or the mother felt that giving the supplement daily was too onerous ( $\mathrm{n}=$ 1)."

Comment: amount of missing data was similar between study groups. Reasons for missing data were varied. However, there was no reason that a large proportion of children in one study group did have but that children in the other study group did 
Meeks Gardner 2005 (Continued)

not have

\begin{tabular}{|c|c|c|}
\hline Selective reporting (reporting bias) & Unclear risk & $\begin{array}{l}\text { Comment: no trial protocol referenced by } \\
\text { the study }\end{array}$ \\
\hline Other bias & Unclear risk & $\begin{array}{l}\text { Comment: } \\
\text { "Children who received placebo were sig- } \\
\text { nificantly taller than those who received } \\
\text { zinc." This baseline difference could have } \\
\text { influenced height outcomes, which were re- } \\
\text { ported only as post-treatment scores, rather } \\
\text { than as changes from baseline }\end{array}$ \\
\hline
\end{tabular}

Mozaffari-Khosravi 2009

Methods

Participants

Outcomes

Height, weight, weight-to-height ratio, prevalence of stunting

Time point (wk): 52 urban Center for Health Statistics (NCHS) data

Exclusion criteria: N/A

Baseline characteristics

Avg age (mo): 38.8; Min age (mo): 25; Max age (mo): 69; \% Female: 55.3 zinc concentration $(\mu \mathrm{g} / \mathrm{dL})$ : N/A

Total N: 90; Group 1 N: 45; Group 2 N: 45

Group 1: zinc (mg): 5; Co-intervention(s): N/A

Group 2: no zinc

Placebo given; Co-intervention(s): N/A

Notes

Risk of bias

Bias Authors' judgement

Random sequence generation (selection Low risk bias)

Country: Iran; Setting: Azad-shahr suburb of Yazd city in central Iran; Urbanicity: peri-

Inclusion criteria: below the 25th percentile of height-for-age according to National

Avg HAZ: -1.59; Stunting: both - separate data not given; Avg height (cm): 91.2; Avg

Formulation: solution; Compound: sulfate; Frequency: daily; Duration (mo): 6; Dose 
Mozaffari-Khosravi 2009 (Continued)

Allocation concealment (selection bias) Low risk
Quote: "Vahidi pharmacy assigned codes to the different syrups and sent them to corresponding researcher, where they were kept secured until the end of the study."

Comment: sufficient allocation concealment seems likely

Quote: “...double-

Blinding of participants (performance Low risk bias)

All outcomes

blind, placebo-controlled supplementation trial..." The placebo group "received the same syrup in color, odor, and taste without zinc" as the zinc group. "Vahidi pharmacy assigned codes to the different syrups and sent them to corresponding researcher, where they were kept secured until the end of the study."

Comment: sufficient blinding seems likely

Blinding of personnel (performance bias) Low risk

All outcomes

Quote:

“...double-

blind, placebo-controlled supplementation trial..." The placebo group "received the same syrup in color, odor, and taste without zinc" as the zinc group. "Vahidi pharmacy assigned codes to the different syrups and sent them to corresponding researcher, where they were kept secured until the end of the study."

Comment: sufficient blinding seems likely

Blinding of outcome assessment (detection Low risk bias)

All outcomes

Incomplete outcome data (attrition bias) Unclear risk All outcomes

“...double-
Quote:

blind, placebo-controlled supplementation trial..." The placebo group "received the same syrup in color, odor, and taste without zinc" as the zinc group. "Vahidi pharmacy assigned codes to the different syrups and sent them to corresponding researcher, where they were kept secured until the end of the study."

Comment: sufficient blinding seems likely

\% Missing: 6

Reasons/details: "Five children from ZG group stepped out on grounds of going on trips, illness or other reasons..."

Comment: all missing data are from the zinc group and data missing due to "illness or other reasons" might impact results 
Mozaffari-Khosravi 2009 (Continued)

\begin{tabular}{l|l|l}
\hline Selective reporting (reporting bias) & Unclear risk & $\begin{array}{l}\text { Comment: no English language trial proto- } \\
\text { col referenced by the study. Only a Persian } \\
\text { language trial protocol was available and } \\
\text { this Persian language protocol could not be } \\
\text { translated }\end{array}$ \\
\hline Other bias & Low risk & Comment: appears to be free of other bias \\
\hline
\end{tabular}

Muller 2001

\begin{tabular}{|c|c|}
\hline Methods & CRCT?: IRCT; Cross-over?: non-cross-over \\
\hline Participants & $\begin{array}{l}\text { Country: Burkina Faso; Setting: } 18 \text { villages in the Nouna district of northwestern Burkina } \\
\text { Faso; Urbanicity: rural } \\
\text { Inclusion criteria: permanent resident of the study area } \\
\text { Exclusion criteria: serious underlying illness } \\
\text { Baseline characteristics } \\
\text { Avg age (mo): } 18.1 \text {; Min age (mo): 6; Max age (mo): 30; \% Female: } 49 \\
\text { Avg HAZ: }-1.6 \text {; Stunting: both - separate data given; Avg height (cm): 75.8; Avg zinc } \\
\text { concentration ( } \mu \mathrm{g} / \mathrm{dL}): 76.5 \\
\text { Total N: } 709 \text {; Group } 1 \mathrm{~N}: 356 \text {; Group } 2 \mathrm{~N}: 353\end{array}$ \\
\hline Interventions & $\begin{array}{l}\text { Group 1: zinc } \\
\text { Formulation: pill/tablet; Compound: sulfate; Frequency: } 6 \text { days/wk; Duration (mo): 6; } \\
\text { Dose (mg): } 12.5 \text {; Co-intervention(s): N/A } \\
\text { Group 2: no zinc } \\
\text { Placebo given; Co-intervention(s): N/A }\end{array}$ \\
\hline
\end{tabular}

Outcomes

All-cause mortality, incidence of all-cause diarrhoea, prevalence of all-cause diarrhoea, incidence of LRTI, prevalence of LRTI, incidence of malaria, prevalence of malaria, height, weight, weight-to-height ratio, serum or plasma zinc concentration, prevalence of zinc deficiency

Time point (wk): 12 (biochemical outcomes), 24 (morbidity, mortality, and growth outcomes)

Notes

Risk of bias

\begin{tabular}{lll}
\hline Bias & Authors' judgement & Support for judgement \\
\hline $\begin{array}{l}\text { Random sequence generation (selection } \\
\text { bias) }\end{array}$ & Low risk & $\begin{array}{l}\text { Quote: "Children were allocated zinc or } \\
\text { placebo in blocks of } 30 \text { (15 zinc, } 15 \\
\text { placebo) by computer generated randomly } \\
\text { permutated codes (prepared by the World } \\
\text { Health Organization).” } \\
\text { Comment: N/A }\end{array}$ \\
\end{tabular}

Zinc supplementation for preventing mortality, morbidity, and growth failure in children aged 6 months to 12 years of age (Review) 
Muller 2001 (Continued)

\begin{tabular}{l|l} 
Allocation concealment (selection bias) $\quad$ Low risk & $\begin{array}{l}\text { Quote: "The randomisation code was bro- } \\
\text { ken after the database was closed." "Ran- } \\
\text { domization was done independently before } \\
\text { the trial started. Investigators were not in- } \\
\text { volved. Fieldworkers had to follow the ran- } \\
\text { domization scheme." } \\
\text { Comment: sufficient allocation conceal- } \\
\text { ment seems likely }\end{array}$ \\
\end{tabular}

Blinding of participants (performance Low risk bias)

Quote: "Our study was designed as a. All outcomes ..double blind efficacy trial...The tablets were identical in appearance and taste... The randomisation code was broken after the database was closed"

Comment: sufficient blinding seems likely

Blinding of personnel (performance bias) Low risk All outcomes

Quote: "Our study was designed as a. ..double blind efficacy trial...The tablets were identical in appearance and taste... The randomisation code was broken after the database was closed"

Comment: sufficient blinding seems likely

Blinding of outcome assessment (detection Low risk bias)

All outcomes

Quote: "Our study was designed as a. ..double blind efficacy trial...The tablets were identical in appearance and taste... The randomisation code was broken after the database was closed"

Comment: sufficient blinding seems likely

Incomplete outcome data (attrition bias) Low risk

All outcomes

\% Missing: 6

Reasons/details: “...we excluded from the final analysis those who were absent from the study area for more than 14 consecutive days." Also, 5 children in the intervention group and 12 children in the placebo group died during the study

Comment: missing data seem too minimal to impact results

Selective reporting (reporting bias) Unclear risk

Comment: no trial protocol referenced by the study 


\begin{tabular}{|c|c|}
\hline Methods & CRCT?: IRCT; Cross-over?: non-cross-over \\
\hline Participants & $\begin{array}{l}\text { Country: Japan; Setting: N/A; Urbanicity: unclear } \\
\text { Inclusion criteria: height-for-age < }-2.0 \mathrm{SD} \text {; apparent good health with no evidence } \\
\text { of endocrinologic disorder, peak serum } \mathrm{GH} \text { level }>10 \mathrm{ng} / \mathrm{ml} \text { in insulin and clonidine } \\
\text { stimulation tests, and }>20 \mathrm{ng} / \mathrm{ml} \text { in the growth hormone releasing factor loading test; } \\
\text { mild-to-moderate zinc deficiency identified by zinc kinetic studies (zinc body clearance } \\
\geq 20 \mathrm{ml} / \mathrm{kg} \text { per hour); prepubertal status (Tanner breast and genitalia growth stage) } \\
\text { throughout the study period } \\
\text { Exclusion criteria: N/A } \\
\text { Baseline characteristics } \\
\text { Avg age (mo): 70.3; Min age (mo): N/A; Max age (mo): N/A; \% Female: } 47.6 \\
\text { Avg HAZ: -2.44; Stunting: stunted; Avg height }(\mathrm{cm}): \mathrm{N} / \mathrm{A} \text {; Avg zinc concentration }(\mu \mathrm{g} / \\
\text { dL): } 82 \\
\text { Total N: } 21 \text {; Group } 1 \mathrm{~N}: 10 \text {; Group } 2 \mathrm{~N}: 11\end{array}$ \\
\hline Interventions & $\begin{array}{l}\text { Group 1: zinc } \\
\text { Formulation: unclear; Compound: sulfate; Frequency: daily; Duration (mo): 6; Dose } \\
\text { (mg): } 5 \mathrm{mg} / \mathrm{kg} \text {; Co-intervention(s): N/A } \\
\text { Group 2: no zinc } \\
\text { Placebo not given; Co-intervention(s): N/A }\end{array}$ \\
\hline Outcomes & $\begin{array}{l}\text { Height, serum or plasma zinc concentration } \\
\text { Time point (wk): } 24\end{array}$ \\
\hline Notes & $\begin{array}{l}\text { The authors report that, "A total of } 21 \text { Japanese children ( } 11 \text { boys) with short stature } \\
\text { were studied. They were selected by the following tests: a Tanner evaluation, growth } \\
\text { hormone provocation test, and body zinc clearance test. The tests were performed on } \\
220 \text { patients with short stature hospitalized in our clinic." However, it seems that the } \\
\text { trial participants were only in the clinic for tests, and were living in the community at } \\
\text { the start of the trial }\end{array}$ \\
\hline
\end{tabular}

\section{Risk of bias}

Bias

Random sequence generation (selection Unclear risk bias)

\section{Support for judgement}

Quote: “...children were divided randomly into two groups..."

Comment: insufficient details available to make a judgement as to whether or not an allocation sequence was generated using a truly random method

Quote: N/A

Comment: insufficient details available to make a judgement 
Nakamura 1993 (Continued)

\begin{tabular}{l|l}
\hline $\begin{array}{l}\text { Blinding of participants (performance } \\
\text { bias) } \\
\text { All outcomes }\end{array}$ & $\begin{array}{l}\text { Quote: "None of the control subjects was } \\
\text { given placebo." }\end{array}$ \\
& $\begin{array}{l}\text { Comment: given that no placebo was pro- } \\
\text { vided, it seems likely that people involved } \\
\text { with the study were aware of which study } \\
\text { group participants were in. It is unclear how } \\
\text { measured outcomes might be influenced by } \\
\text { this lack of blinding }\end{array}$ \\
\hline
\end{tabular}

Blinding of personnel (performance bias) Unclear risk All outcomes

Quote: "None of the control subjects was given placebo."

Comment: given that no placebo was provided, it seems likely that people involved with the study were aware of which study group participants were in. It is unclear how measured outcomes might be influenced by this lack of blinding

Blinding of outcome assessment (detection Unclear risk bias)

All outcomes

Quote: "None of the control subjects was given placebo."

Comment: given that no placebo was provided, it seems likely that people involved with the study were aware of which study group participants were in. It is unclear how measured outcomes might be influenced by this lack of blinding

\begin{tabular}{|c|c|c|}
\hline $\begin{array}{l}\text { Incomplete outcome data (attrition bias) } \\
\text { All outcomes }\end{array}$ & Unclear risk & $\begin{array}{l}\text { \% Missing: N/A } \\
\text { Reasons/details: N/A } \\
\text { Comment: insufficient details available to } \\
\text { make a judgement }\end{array}$ \\
\hline Selective reporting (reporting bias) & Unclear risk & $\begin{array}{l}\text { Comment: no trial protocol referenced by } \\
\text { the study }\end{array}$ \\
\hline Other bias & Low risk & Comment: appears to be free of other bias \\
\hline
\end{tabular}

Ninh 1996

\begin{tabular}{ll} 
Methods & CRCT?: IRCT; Cross-over?: non-cross-over \\
\hline Participants & Country: Vietnam; Setting: an area near Hano, Vietnam; Urbanicity: rural \\
& Inclusion criteria: growth retardation evidenced by a WAZ score below -2 and an HAZ \\
& score below -2 as calculated from US National Center for Health Statistics reference \\
& data; otherwise healthy \\
& Exclusion criteria: obvious medical reasons for poor growth \\
& Baseline characteristics \\
& Avg age (mo): $17.6 ;$ Min age (mo): 4; Max age (mo): $36 ; \%$ Female: 54
\end{tabular}

Zinc supplementation for preventing mortality, morbidity, and growth failure in children aged 6 months to 12 years of age (Review) 
Ninh 1996 (Continued)

Avg HAZ: -2.61; Stunting: stunted; Avg height (cm): 71.3; Avg zinc concentration ( $\mu \mathrm{g} /$ dL): N/A

Total N: 210; Group 1 N: 105; Group 2 N: 105

$\begin{array}{ll}\text { Interventions } & \text { Group 1: zinc } \\ & \text { Formulation: solution; Compound: sulfate; Frequency: daily; Duration (mo): 5; Dose } \\ & (\mathrm{mg}): 10 ; \text { Co-intervention(s): N/A } \\ & \text { Group 2: no zinc } \\ & \text { Placebo given; Co-intervention(s): N/A }\end{array}$

Outcomes

Height, weight, weight-to-height ratio

Time point (wk): 20

Notes

Risk of bias

\begin{tabular}{|c|c|c|}
\hline Bias & Authors' judgement & Support for judgement \\
\hline $\begin{array}{l}\text { Random sequence generation (selection } \\
\text { bias) }\end{array}$ & Unclear risk & $\begin{array}{l}\text { Quote: "The subjects were pair-matched.. } \\
\text {.Each member of a pair was randomly as- } \\
\text { signed to take either a zinc supplement or } \\
\text { a placebo." } \\
\text { Comment: insufficient details available to } \\
\text { make a judgement as to whether or not an } \\
\text { allocation sequence was generated using a } \\
\text { truly random method }\end{array}$ \\
\hline
\end{tabular}

Allocation concealment (selection bias) Unclear risk

Quote: "The group to which the patient was assigned was unknown to the child's family and to the members of the investigation team."

Comment: despite this statement, the method of allocation concealment is not described in sufficient detail to allow a definite judgement

Blinding of participants (performance Low risk bias)

Quote: “...double-blind study...The group All outcomes to which the patient was assigned was unknown to the child's family...The two syrups were indistinguishable in taste and color."

Comment: sufficient blinding seems likely

Blinding of personnel (performance bias) Low risk All outcomes

Quote: “...double-blind study...The group to which the patient was assigned was unknown to the...members of the investigation team...The two syrups were indistinguishable in taste and color."

Zinc supplementation for preventing mortality, morbidity, and growth failure in children aged 6 months to 12 years of age (Review) 
Ninh 1996 (Continued)

Comment: sufficient blinding seems likely

Blinding of outcome assessment (detection Low risk bias)

All outcomes
Quote: “...double-blind study... The group to which the patient was assigned was unknown to the...members of the investigation team...The two syrups were indistinguishable in taste and color."

Comment: sufficient blinding seems likely

\% Missing: 30

Reasons/details: "Thirty-two pairs were excluded from analysis for various reasons: relocation ( $\mathrm{n}=3)$, accident $(\mathrm{n}=2)$, voluntary withdrawal by parent $(n=12)$, poor compliance with syrup administration (n $=5$ ), poor compliance with anthropometric measurements $(n=4)$, concurrent use of multivitamin-trace element preparations including zinc $(\mathrm{n}=4)$, and hospitalization (n = 2)."

Comment: amount of missing data was not reported separately for each study group. Thus, for instance, the placebo group could have more missing data for reasons such as withdrawal, non-compliance, and hospitalisation, while the zinc group could have more missing data due to the fact that "pairs were excluded" and that zinc group members thus had to be excluded when their corresponding placebo group members were

Selective reporting (reporting bias)

High risk

Comment: all-cause hospitalisation was measured, but is not reported in a way that can be meta-analysed

\section{Penny 2004}

\begin{tabular}{ll} 
Methods & CRCT?: IRCT; Cross-over?: non-cross-over \\
\hline Participants & Country: Peru; Setting: Canto Grande, a shanty town on the outskirts of Lima; Urban- \\
icity: peri-urban & Inclusion criteria: diarrhoea for $\geq 14$ days; intention to remain in the study area \\
& Exclusion criteria: been taking vitamins or minerals within the last 6 weeks; major \\
& congenital malformation affecting growth (e.g. trisomy 21) \\
Baseline characteristics & Avg age (mo): $18.9 ;$ Min age (mo): 6; Max age (mo): $35 ; \%$ Female: 50
\end{tabular}


Avg HAZ: -1.56; Stunting: both - separate data not given; Avg height (cm): 76.4; Avg zinc concentration $(\mu \mathrm{g} / \mathrm{dL}): 70.3$

Total N: 164; Group 1 N: 81; Group 2 N: 83

Interventions Group 1: zinc

Formulation: solution; Compound: gluconate; Frequency: daily; Duration (mo): 6; Dose (mg): 10; Co-intervention(s): N/A

Group 2: no zinc

Placebo given; Co-intervention(s): N/A

Outcomes
All-cause mortality, incidence of all-cause diarrhoea, prevalence of all-cause diarrhoea, incidence of severe diarrhoea, incidence of LRTI, height, weight, serum or plasma zinc concentration, vomiting episodes, blood haemoglobin concentration, serum or plasma ferritin concentration

Time point (wk): 24

\section{Notes}

Risk of bias

- In addition to the study groups mentioned in this table, there was a group of 82 participants who received "zinc plus vitamins and other minerals at 1-2 times recommended daily intakes." Baseline characteristics reported in this table are weighted averages of all groups except this zinc + multiple micronutrient group, since this group is not included in any meta-analyses in this review

- "The study was carried out in 2 phases. During the first phase we evaluated the effect of zinc or multiple micronutrient supplementation on the recovery from persistent diarrhea. During the second phase we assessed the effect of continued supplementation on morbidity from new infections during the following 6 mo."

-29 children in the placebo group and 28 children in the Zn group "consumed additional iron, either as prescribed by the study team because of anemia at baseline (hemoglobin < $9.0 \mathrm{~g} / \mathrm{dL}$ ) or for family-determined reasons;" of these children, 22 in the placebo group and 18 in the zinc group received additional iron for $\geq 7 \mathrm{~d}$. Additionally, "Children were offered a wafer biscuit and sugar candy after administration of the supplement because this had been shown in pretesting to reduce the nauseating aftertaste that was sometimes experienced with the supplement."

Bias

Random sequence generation (selection Low risk bias)

\section{Authors' judgement}

\section{Support for judgement}

Quote: "Children were stratified by current breast-feeding status and assigned a consecutive study number within each stratum. With the use of a computer-generated, block randomization scheme, each study number had been linked previously to 1 of 9 letter codes, each of which indicated 1 of the 3 treatment groups."

Comment: N/A 
Penny 2004 (Continued)

Allocation concealment (selection bias) Unclear risk

Quote: "The identities of the codes were not available to the field staff or investigators until after the data had been cleaned and analyzed."

Comment: despite this statement, the method of allocation concealment is not described in sufficient detail to allow a definite judgement

Blinding of participants (performance Low risk bias)

All outcomes

Quote: “...double-masked, placebo-controlled, community-based trial...Further flavoring and coloring agents and ascorbic acid were added in Lima to ensure that the supplements were indistinguishable in appearance and taste and to improve their acceptability. These additions were made by staff of the Instituto de Investigación $\mathrm{Nu}$ tricional who had no other involvement in the study."

Comment: sufficient blinding seems likely

Blinding of personnel (performance bias) Low risk All outcomes
Quote: “...double-masked, placebo-controlled, community-based trial...Further flavoring and coloring agents and ascorbic acid were added in Lima to ensure that the supplements were indistinguishable in appearance and taste and to improve their acceptability. These additions were made by staff of the Instituto de Investigación $\mathrm{Nu}$ tricional who had no other involvement in the study." "The identities of the codes were not available to the field staff or investigators until after the data had been cleaned and analyzed."

Comment: sufficient blinding seems likely

Blinding of outcome assessment (detection Low risk bias)

All outcomes
Quote: “...double-masked, placebo-controlled, community-based trial...Further flavoring and coloring agents and ascorbic acid were added in Lima to ensure that the supplements were indistinguishable in appearance and taste and to improve their acceptability. These additions were made by staff of the Instituto de Investigación $\mathrm{Nu}$ tricional who had no other involvement in the study." "The identities of the codes were not available to the field staff or investigators until after the data had been cleaned 
Penny 2004 (Continued)

and analyzed."

Comment: sufficient blinding seems likely

Incomplete outcome data (attrition bias) Low risk

All outcomes
\% Missing: 16

Reasons/details: in the zinc group: 10 participants were lost due to "permanent departure from the area", and 4 were lost due to "parental decision to withdraw." In the placebo group: 2 participants "died", 5 were lost due to "permanent departure from the area", and 6 were lost due to "parental decision to withdraw"

Comment: $16 \%$ of the randomised participants eligible for our review had data missing; this $16 \%$ missing figure includes all groups except the zinc + multiple micronutrient group, since this group is not included in any meta-analyses in this review. Numbers of participants lost due to death or parental decision to withdraw were similar between study groups. Though more participants in the zinc group moved, missing data due to migration are unlikely to bias results

Comment: no trial protocol referenced by the study

Comment: appears to be free of other bias

Rahman 2001

Methods

Participants
CRCT?: IRCT; Cross-over?: non-cross-over

Country: Bangladesh; Setting: slums of Dhaka; Urbanicity: urban

Inclusion criteria: N/A

Exclusion criteria: received any vitamin A supplementation within the past 4 mo; severe malnutrition (weight-for-age $<60 \%$ of the National Center for Health Statistics median) ; signs or symptoms of vitamin A or zinc deficiency; any systemic illness such as diarrhoea, respiratory infection, fever, or any other illness that warranted medical intervention at the time of enrolment

Baseline characteristics

Avg age (mo): 23.7; Min age (mo): 12; Max age (mo): 35; \% Female: 47

Avg HAZ: -2.41; Stunting: both - separate data not given; Avg height (cm): N/A; Avg zinc concentration $(\mu \mathrm{g} / \mathrm{dL}): 72.3$

Total N: 800; Group 1 N: 200; Group 2 N: 200; Group 3 N: 200; Group 4 N: 200 
Rahman 2001 (Continued)

$\begin{array}{ll}\text { Interventions } & \text { Group 1: zinc } \\ & \text { Formulation: solution; Compound: sulfate; Frequency: daily; Duration (mo): } \\ & (\mathrm{mg}): 20 ; \text { Co-intervention(s): N/A } \\ & \text { Group 2: no zinc } \\ & \text { Placebo given; Co-intervention(s): N/A } \\ & \text { Group 3: zinc } \\ & \text { Co-intervention(s): 200,000 IU vitamin A capsule on day } 14 \\ & \text { Group 4: no zinc } \\ & \text { Placebo given; Co-intervention(s): 200,000 IU vitamin A capsule on day } 14\end{array}$

Outcomes

Incidence of all-cause diarrhoea, prevalence of all-cause diarrhoea, incidence of persistent diarrhoea, prevalence of persistent diarrhoea, incidence of LRTI, prevalence of LRTI, height, weight, weight-to-height ratio, serum or plasma zinc concentration

Time point (wk): 12 (serum or plasma zinc concentration), 24 (morbidity and growth outcomes)

Notes

Risk of bias

\begin{tabular}{|c|c|c|}
\hline Bias & Authors' judgement & Support for judgement \\
\hline $\begin{array}{l}\text { Random sequence generation (selection } \\
\text { bias) }\end{array}$ & Low risk & $\begin{array}{l}\text { Quote: "The children were randomly as- } \\
\text { signed by a person not involved in the } \\
\text { study who used permuted blocks of ran- } \\
\text { dom numbers." } \\
\text { Comment: N/A }\end{array}$ \\
\hline
\end{tabular}

Allocation concealment (selection bias) Low risk

Quote: "The children were randomly assigned by a person not involved in the study..." "Sets of two bottles of syrup and a capsule were serially numbered according to the randomisation list and corresponding to the study serial numbers. The enrolled children were assigned the numbered bottles in the order in which they were enrolled...The zinc and placebo syrups were supplied in bottles that looked identical.. .The randomisation code was kept sealed until the completion of the study."

Comment: indicates central randomisation (i.e. randomisation by someone not involved with enrolling patients) and sequentially numbered drug containers of identical appearance to conceal allocation

Blinding of participants (performance Low risk

bias)

Quote: "This was a randomized, doubleblind, placebo-controlled trial." "The zinc

All outcomes and placebo syrups were supplied in bottles

Zinc supplementation for preventing mortality, morbidity, and growth failure in children aged 6 months to 12 years of age (Review)

Copyright (c) 2014 The Cochrane Collaboration. Published by John Wiley \& Sons, Ltd. 
Rahman 2001 (Continued)

that looked identical, and the appearance and consistency of the syrups were similar. ..The randomisation code was kept sealed until the completion of the study."

Comment: sufficient blinding seems likely

Blinding of personnel (performance bias) Low risk All outcomes
Quote: "This was a randomized, doubleblind, placebo-controlled trial." "The zinc and placebo syrups were supplied in bottles that looked identical, and the appearance and consistency of the syrups were similar. ..The randomisation code was kept sealed until the completion of the study."

Comment: sufficient blinding seems likely

Quote: "This was a randomized, doubleblind, placebo-controlled trial." "The zinc and placebo syrups were supplied in bottles that looked identical, and the appearance and consistency of the syrups were similar. ..The randomisation code was kept sealed until the completion of the study."

Comment: sufficient blinding seems likely

Incomplete outcome data (attrition bias) Low risk All outcomes
\% Missing: 17

Reasons/details: $17 \%$ of the 800 randomised participants had data missing for diarrhoea, LRTI, weight, and length outcomes: "Eighty-five children (16 in the zinc group, 31 in the A group, 14 in the ZA group, and 24 in the placebo group) were excluded from the study because they received an extra dose of vitamin A (a 60000 $\mathrm{RE}$ capsule) through the Bangladesh 'National Vitamin A Week' campaign. Fortynine children were subsequently lost to follow-up." In addition, "weight and length measurements at 6 mo were missing for 13 children."

Comment: reasons for, and amount of, missing data were similar between study groups. Receiving an additional dose of vitamin A from campaigns unrelated to the study was the most common reason for missing data, and this reason is unlikely to bias results. Also, "the baseline characteristics of the excluded children were not significantly different from those of the children who continued the study." 
Rahman 2001 (Continued)

\begin{tabular}{|c|c|c|}
\hline Selective reporting (reporting bias) & High risk & $\begin{array}{l}\text { Comment: vomiting was measured, but is } \\
\text { not reported in a way that can be meta- } \\
\text { analysed }\end{array}$ \\
\hline Other bias & Low risk & Comment: appears to be free of other bias \\
\hline
\end{tabular}

Rahman 2001 (2)

Methods

Participants

Interventions

Outcomes Incidence of all-cause diarrhoea, prevalence of all-cause diarrhoea, incidence of persistent diarrhoea, prevalence of persistent diarrhoea, incidence of LRTI, prevalence of LRTI, height, weight, weight-to-height ratio, serum or plasma zinc concentration

Notes As Rahman 2001 above

Richard 2006

Methods

Participants

\section{CRCT?: IRCT; Cross-over?: non-cross-over}

Country: Peru; Setting: the village of Santa Clara; Urbanicity: rural Inclusion criteria: N/A

Exclusion criteria: chronic illness (absence of congenital diseases or major illness requiring medical care and/or medication determined by the physician at baseline evaluation); severe malnutrition (weight-for-height z-score less than 2 SDs below the National Center for Health Statistics (Hyattsville, MD) reference population or clinical signs of marasmus or kwashiorkor)

\section{Baseline characteristics}

Avg age (mo): N/A; Min age (mo): 6; Max age (mo): 180; \% Female: 51.7

Avg HAZ: -2.08; Stunting: both - separate data not given; Avg height (cm): N/A; Avg zinc concentration $(\mu \mathrm{g} / \mathrm{dL}): 69$

Total N: 855; Group 1 N: 214; Group 2 N: 215; Group 3 N: 214; Group 4 N: 212

Interventions
Group 1: zinc

Formulation: solution; Compound: sulfate; Frequency: daily; Duration (mo): 7; Dose (mg): 20; Co-intervention(s): N/A

Group 2: no zinc

Placebo given; Co-intervention(s): N/A

Group 3: zinc

Co-intervention(s): $15 \mathrm{mg}$ iron

Group 4: no zinc

Placebo given; Co-intervention(s): $15 \mathrm{mg}$ iron 
Richard 2006 (Continued)

Outcomes

All-cause mortality, incidence of all-cause diarrhoea, incidence of LRTI, incidence of malaria, height, weight-to-height ratio, serum or plasma zinc concentration, blood haemoglobin concentration

Time point (wk): 28

Notes

Based on the distribution of participants in the 0 to 4,5 to 9 , and 10 to 15 year age groups in this study, it seems extremely likely that the majority of participants in this study were between 6 months and 12 years of age

\section{Risk of bias}

\section{Bias}

Random sequence generation (selection Low risk bias)

\begin{tabular}{l} 
Allocation concealment (selection bias) Unclear r \\
\hline $\begin{array}{l}\text { Blinding of participants (performance Low risk } \\
\text { bias) } \\
\text { All outcomes }\end{array}$
\end{tabular}

ing of personnel (performance bias) Low risk

Blinding of p
All outcomes

bias)

All outcomes

\section{Support for judgement}

Quote: "Using an algorithm in SAS version 6 ...we randomized children meeting the entry criteria in blocks of four into four supplement groups..."

Comment: N/A

Quote: N/A

Comment: insufficient details available to make a judgement

Quote: “...double-blind, placebocontrolled trial...The supplements were similar in appearance and taste, bottled in similar containers, and labeled with a supplement code...The participants...were. ..masked throughout the study to the supplement contents."

Comment: sufficient blinding seems likely

Quote:

“...double-

blind, placebo-controlled trial... The supplements were similar in appearance and taste, bottled in similar containers, and labeled with a supplement code...study personnel were...masked throughout the study to the supplement contents."

Comment: sufficient blinding seems likely

Quote:

“...double-

blind, placebo-controlled trial...The supplements were similar in appearance and taste, bottled in similar containers, and labeled with a supplement code...study personnel were...masked throughout the study to the supplement contents. The data an- 
Richard 2006 (Continued)

\begin{tabular}{|c|c|c|}
\hline & & $\begin{array}{l}\text { alyst was masked for the seminal analyses } \\
\text { and was unmasked for additional analyses } \\
\text { and sub-analyses. No data were excluded or } \\
\text { altered after unmasking." } \\
\text { Comment: sufficient blinding seems likely }\end{array}$ \\
\hline $\begin{array}{l}\text { Incomplete outcome data (attrition bias) } \\
\text { All outcomes }\end{array}$ & Low risk & $\begin{array}{l}\text { \% Missing: } 12.5 \\
\text { Reasons/details: in the zinc group: } 6,1 \text {, and } \\
16 \text { participants "migrated", "refused", and } \\
\text { were lost for "other" reasons, respectively. } \\
\text { In the placebo group: } 12,1 \text {, and } 13 \text { partic- } \\
\text { ipants "migrated", "refused", and were lost } \\
\text { for "other" reasons, respectively. In the iron } \\
\text { group: } 9,2 \text {, and } 18 \text { participants "migrated", } \\
\text { "refused", and were lost for "other" reasons, } \\
\text { respectively. In the iron + zinc group: } 7,5 \text {, } \\
\text { and } 17 \text { participants "migrated", "refused", } \\
\text { and were lost for "other" reasons, respec- } \\
\text { tively } \\
\text { Comment: reasons for, and amount of, } \\
\text { missing data were similar between study } \\
\text { groups }\end{array}$ \\
\hline Selective reporting (reporting bias) & Unclear risk & $\begin{array}{l}\text { Comment: prevalence of stunting, zinc de- } \\
\text { ficiency, anaemia, and iron deficiency may } \\
\text { have been measured as outcomes, but are } \\
\text { not reported. No trial protocol referenced } \\
\text { by the study }\end{array}$ \\
\hline Other bias & Low risk & Comment: appears to be free of other bias \\
\hline
\end{tabular}

Richard 2006 (2)

Methods

Participants

Interventions

Outcomes All-cause mortality, incidence of all-cause diarrhoea, incidence of LRTI, incidence of malaria, height, weight-toheight ratio, serum or plasma zinc concentration, blood haemoglobin concentration

Notes As Richard 2006 above 
Methods

Participants
CRCT?: IRCT; Cross-over?: non-cross-over

Country: Mexico; Setting: 5 communities in the Valley of Solís region of central Mexico; Urbanicity: rural

Inclusion criteria: N/A

Exclusion criteria: N/A

Baseline characteristics

Avg age (mo): 28.4; Min age (mo): 18; Max age (mo): 36; \% Female: N/A

Avg HAZ: -1.6; Stunting: both - separate data given; Avg height (cm): 83.3; Avg zinc concentration $(\mu \mathrm{g} / \mathrm{dL}): 96.7$

Total N: 219; Group 1 N: N/A; Group 2 N: N/A; Group 3 N: N/A; Group 4 N: N/A

Group 1: zinc
Formulation: solution; Compound: methionine; Frequency: 6 days/wk; Duration (mo)
: 12; Dose (mg): 20; Co-intervention(s): N/A
Group 2: no zinc
Placebo given; Co-intervention(s): N/A
Group 3: zinc
Co-intervention(s): $20 \mathrm{mg}$ iron
Group 4: no zinc
Placebo given; Co-intervention(s): $20 \mathrm{mg}$ iron

Outcomes

Incidence of all-cause diarrhoea, height, weight, weight-to-height ratio, serum or plasma zinc concentration, prevalence of zinc deficiency, blood haemoglobin concentration, prevalence of anaemia, serum or plasma ferritin concentration, prevalence of iron deficiency

Time point (wk): 52

Notes

Table 1 in the Rosado et al 1997 trial report, which reports baseline characteristics, states that the numbers of children at the beginning of the study are 54, 55, 55, and 53, for the zinc, placebo, zinc + iron, and iron groups respectively. However, these numbers do not add up to the 219 children which were reported to have enrolled in the study

\section{Risk of bias}

\begin{tabular}{|c|c|c|}
\hline Bias & Authors' judgement & Support for judgement \\
\hline $\begin{array}{l}\text { Random sequence generation (selection } \\
\text { bias) }\end{array}$ & Unclear risk & $\begin{array}{l}\text { Quote: "Children were... randomly as- } \\
\text { signed..." } \\
\text { Comment: insufficient details available to } \\
\text { make a judgement as to whether or not an } \\
\text { allocation sequence was generated using a } \\
\text { truly random method }\end{array}$ \\
\hline Allocation concealment (selection bias) & Unclear risk & $\begin{array}{l}\text { Quote: N/A } \\
\text { Comment: insufficient details available to } \\
\text { make a judgement }\end{array}$ \\
\hline
\end{tabular}

Zinc supplementation for preventing mortality, morbidity, and growth failure in children aged 6 months to 12 years of age (Review) 
Rosado 1997 (Continued)

Blinding of participants (performance Low risk bias)

All outcomes
Quote: “...double-blind, randomized community trial...Both the zinc and the iron salts were dissolved in a solution to disguise their bad taste and to ensure similar appearance...The solutions were coded....and the code was not broken until the end of data analysis."

Comment: sufficient blinding seems likely

Blinding of personnel (performance bias) Low risk

All outcomes

Blinding of outcome assessment (detection Low risk bias)

All outcomes

mplete outcome data (attrition bias) Low risk All outcomes

Selective reporting (reporting bias)

Unclear risk

Quote: “...double-blind, randomized community trial... Both the zinc and the iron salts were dissolved in a solution to disguise their bad taste and to ensure similar appearance...The solutions were coded in such a way that their content was unknown to any of the project personnel, and the code was not broken until the end of data analysis." Comment: sufficient blinding seems likely

Quote: “...double-blind, randomized community trial...Both the zinc and the iron salts were dissolved in a solution to disguise their bad taste and to ensure similar appearance...The solutions were coded in such a way that their content was unknown to any of the project personnel, and the code was not broken until the end of data analysis." Comment: sufficient blinding seems likely

\% Missing: 11

Reasons/details: "Only 25 children were dropped from the study before the end of the 12 mo, primarily because of a changing family situation."

Comment: "Changing family situation" was the primary reason for missing data, and this reason is unlikely to bias results

Comment: LRTI (i.e. "lower respiratory disease") that meets the criteria of this review may have been measured, but is not reported in a way that can be meta-analysed. No trial protocol referenced by the study

Other bias

Low risk

Comment: appears to be free of other bias 
Rosado 1997 (2)

Methods

Participants

Interventions

Outcomes Incidence of all-cause diarrhoea, height, weight, weight-to-height ratio, serum or plasma zinc concentration, prevalence of zinc deficiency, blood haemoglobin concentration, prevalence of anaemia, serum or plasma ferritin concentration, prevalence of iron deficiency

Notes As Rosado 1997 above

Rosales 2004

\begin{tabular}{ll}
\hline Methods & CRCT?: IRCT; Cross-over?: non-cross-over \\
\hline Participants & Country: Guatemala; Setting: Guatemala City; Urbanicity: urban \\
& Inclusion criteria: good health; absence of chronic diseases \\
& Exclusion criteria: N/A \\
& Baseline characteristics \\
& Avg age (mo): N/A; Min age (mo): 96; Max age (mo): 132; \% Female: 52 \\
& Avg HAZ: N/A; Stunting: unclear; Avg height (cm): N/A; Avg zinc concentration ( $\mu$ g/ \\
& dL): 65.4 \\
& Total N: 76; Group 1 N: 18; Group 2 N: 20; Group 3 N: 20; Group 4 N: 18 \\
\hline Interventions & Group 1: zinc \\
Formulation: solution; Compound: sulfate; Frequency: 5 days/wk; Duration (mo): $2 ;$ \\
Dose (mg): 42.5; Co-intervention(s): N/A \\
Group 2: no zinc \\
Placebo given; Co-intervention(s): N/A \\
Group 3: zinc \\
Co-intervention(s): 20 mg iron \\
Group 4: no zinc \\
Placebo given; Co-intervention(s): 20 mg iron
\end{tabular}

Outcomes

Serum or plasma zinc concentration, prevalence of zinc deficiency, blood haemoglobin concentration, serum or plasma ferritin concentration, prevalence of iron deficiency

Time point (wk): 8

Notes

Risk of bias

\begin{tabular}{ll} 
Bias Authors' judgement \\
\hline
\end{tabular}

Random sequence generation (selection Low risk bias)

\section{Support for judgement}

Quote: “They were systematically blocked randomized..." In response to a question about sequence generation, an author of this study replied as follows: "I believe that 


\begin{tabular}{|c|c|c|}
\hline & & $\begin{array}{l}\text { at the CeSSIAM center they used a table of } \\
\text { random numbers to generate the random } \\
\text { allocation sequence." } \\
\text { Comment: N/A }\end{array}$ \\
\hline Allocation concealment (selection bias) & Unclear risk & $\begin{array}{l}\text { Quote: N/A } \\
\text { Comment: insufficient details available to } \\
\text { make a judgement }\end{array}$ \\
\hline $\begin{array}{l}\text { Blinding of participants (performance } \\
\text { bias) } \\
\text { All outcomes }\end{array}$ & Low risk & $\begin{array}{l}\text { Quote: "Children were masked to the con- } \\
\text { tent of the mixture, which was prepared ev- } \\
\text { ery day at the school kitchen by one of the } \\
\text { investigators... To maintain masking,...the } \\
\text { children had no contact with the prepara- } \\
\text { tion area, and the drafts were assigned by } \\
\text { code number." } \\
\text { Comment: sufficient blinding seems likely }\end{array}$ \\
\hline $\begin{array}{l}\text { Blinding of personnel (performance bias) } \\
\text { All outcomes }\end{array}$ & Low risk & $\begin{array}{l}\text { Quote: "To maintain masking...the drafts } \\
\text { were assigned by code number." } \\
\text { Comment: sufficient blinding seems likely }\end{array}$ \\
\hline $\begin{array}{l}\text { Blinding of outcome assessment (detection } \\
\text { bias) } \\
\text { All outcomes }\end{array}$ & Low risk & $\begin{array}{l}\text { Quote: "To maintain masking, the inves- } \\
\text { tigator never had direct contact with the } \\
\text { subjects,...and the drafts were assigned by } \\
\text { code number." } \\
\text { Comment: sufficient blinding seems likely }\end{array}$ \\
\hline $\begin{array}{l}\text { Incomplete outcome data (attrition bias) } \\
\text { All outcomes }\end{array}$ & Low risk & $\begin{array}{l}\text { \% Missing: } 14 \\
\text { Reasons/details: } 2,5,1 \text {, and } 3 \text { children were } \\
\text { excluded from the zinc, placebo, iron and } \\
\text { zinc, and iron alone groups, respectively. All } \\
11 \text { of these children were excluded because } \\
\text { they "missed } 5 \text { or more days of classes and } \\
\text { did not receive at least } 90 \% \text { of the supple- } \\
\text { mentation dosage." } \\
\text { Comment: reasons for, and amount of, } \\
\text { missing data were similar between study } \\
\text { groups }\end{array}$ \\
\hline Selective reporting (reporting bias) & Unclear risk & $\begin{array}{l}\text { Comment: no trial protocol referenced by } \\
\text { the study }\end{array}$ \\
\hline Other bias & Low risk & Comment: appears to be free of other bias \\
\hline
\end{tabular}


Rosales 2004 (2)

Methods

Participants

Interventions

Outcomes Serum or plasma zinc concentration, prevalence of zinc deficiency, blood haemoglobin concentration, serum or plasma ferritin concentration, prevalence of iron deficiency

Notes As Rosales 2004 above

Ruel 1997

\begin{tabular}{|c|c|c|}
\hline Methods & \multicolumn{2}{|c|}{ CRCT?: IRCT; Cross-over?: non-cross-over } \\
\hline Participants & \multicolumn{2}{|c|}{$\begin{array}{l}\text { Country: Guatemala; Setting: the village of Santa Maria de Jesus; Urbanicity: rural } \\
\text { Inclusion criteria: N/A } \\
\text { Exclusion criteria: N/A } \\
\text { Baseline characteristics } \\
\text { Avg age (mo): 7.62; Min age (mo): 6; Max age (mo): 9; \% Female: } 43 \\
\text { Avg HAZ: -2.16; Stunting: both - separate data not given; Avg height (cm): 144.6; Avg } \\
\text { zinc concentration ( } \mu \mathrm{g} / \mathrm{dL}) \text { : N/A } \\
\text { Total N: } 108 \text {; Group } 1 \mathrm{~N} \text { : 55; Group } 2 \mathrm{~N}: 53\end{array}$} \\
\hline Interventions & \multicolumn{2}{|c|}{$\begin{array}{l}\text { Group 1: zinc } \\
\text { Formulation: solution; Compound: sulfate; Frequency: daily; Duration (mo): 7; Dose } \\
\text { (mg): 10; Co-intervention(s): N/A } \\
\text { Group 2: no zinc } \\
\text { Placebo given; Co-intervention(s): N/A }\end{array}$} \\
\hline Outcomes & \multicolumn{2}{|c|}{$\begin{array}{l}\text { Incidence of all-cause diarrhoea, prevalence of all-cause diarrhoea, height, weight, weight- } \\
\text { to-height ratio } \\
\text { Time point (wk): } 28\end{array}$} \\
\hline \multicolumn{3}{|l|}{ Notes } \\
\hline \multicolumn{3}{|l|}{ Risk of bias } \\
\hline Bias & Authors' judgement & Support for judgement \\
\hline $\begin{array}{l}\text { Random sequence generation (selection } \\
\text { bias) }\end{array}$ & Unclear risk & $\begin{array}{l}\text { Quote: “...randomized community } \\
\text { trial...” } \\
\text { Comment: insufficient details available to } \\
\text { make a judgement as to whether or not an } \\
\text { allocation sequence was generated using a } \\
\text { truly random method }\end{array}$ \\
\hline
\end{tabular}

Zinc supplementation for preventing mortality, morbidity, and growth failure in children aged 6 months to 12 years of age (Review) 
Ruel 1997 (Continued)

\begin{tabular}{|c|c|c|}
\hline Allocation concealment (selection bias) & Unclear risk & $\begin{array}{l}\text { Quote: N/A } \\
\text { Comment: insufficient details available to } \\
\text { make a judgement }\end{array}$ \\
\hline $\begin{array}{l}\text { Blinding of participants (performance } \\
\text { bias) } \\
\text { All outcomes }\end{array}$ & Low risk & $\begin{array}{l}\text { Quote: } \\
\text { “...double-blind placebo-controlled study. } \\
\text {.. The supplements were indistinguishable, } \\
\text { and neither the families nor...were aware of } \\
\text { the treatment group to which the infants } \\
\text { belonged.” } \\
\text { Comment: sufficient blinding seems likely }\end{array}$ \\
\hline $\begin{array}{l}\text { Blinding of personnel (performance bias) } \\
\text { All outcomes }\end{array}$ & Low risk & $\begin{array}{l}\text { Quote: } \\
\text { “...double-blind placebo-controlled study. } \\
\text {..The supplements were indistinguishable, } \\
\text { and neither...nor the study staff were aware } \\
\text { of the treatment group to which the infants } \\
\text { belonged.” } \\
\text { Comment: sufficient blinding seems likely }\end{array}$ \\
\hline $\begin{array}{l}\text { Blinding of outcome assessment (detection } \\
\text { bias) } \\
\text { All outcomes }\end{array}$ & Low risk & $\begin{array}{l}\text { Quote: } \\
\text { “...double-blind placebo-controlled study. } \\
\text {..The supplements were indistinguishable, } \\
\text { and neither...nor the study staff were aware } \\
\text { of the treatment group to which the infants } \\
\text { belonged." } \\
\text { Comment: sufficient blinding seems likely }\end{array}$ \\
\hline $\begin{array}{l}\text { Incomplete outcome data (attrition bias) } \\
\text { All outcomes }\end{array}$ & Low risk & $\begin{array}{l}\text { \% Missing: } 18 \\
\text { Reasons/details: } 19 \text { children ( } 10 \text { from the } \\
\text { zinc group and } 9 \text { from the placebo group) } \\
\text { "dropped out of the study attributable to } \\
\text { migration, or inability to comply with the } \\
\text { project requirements because of maternal } \\
\text { work, or late parental refusal." } \\
\text { Comment: amount of missing data was } \\
\text { similar between study groups. Reasons for } \\
\text { missing data are unlikely to bias results }\end{array}$ \\
\hline Selective reporting (reporting bias) & Unclear risk & $\begin{array}{l}\text { Comment: no trial protocol referenced by } \\
\text { the study }\end{array}$ \\
\hline Other bias & Low risk & Comment: appears to be free of other bias \\
\hline
\end{tabular}

Zinc supplementation for preventing mortality, morbidity, and growth failure in children aged 6 months to 12 years of age (Review) 
Methods

Participants

Interventions

Outcomes

Height, serum or plasma zinc conc
or plasma copper concentration

Time point (wk): 24 (biochemical outcomes), 56 (height)

Notes

Risk of bias

\section{Bias}

Random sequence generation (selection Unclear risk bias)
Country: Chile; Setting: Santiago; Urbanicity: peri-urban

Inclusion criteria: apparently healthy, a preschool child, of middle-to-low or low socioeconomic status

Exclusion criteria: a clinical condition predisposing to growth failure

Baseline characteristics

Avg age (mo): 39.8; Min age (mo): 27; Max age (mo): 50; \% Female: 53

Avg HAZ: -0.52; Stunting: both - separate data not given; Avg height (cm): 95.6; Avg zinc concentration $(\mu \mathrm{g} / \mathrm{dL}): 114.1$

Total N: 98; Group 1 N: 49; Group 2 N: 49

\section{Group 1: zinc}

Formulation: solution; Compound: sulfate; Frequency: daily; Duration (mo): 14; Dose (mg): 10; Co-intervention(s): N/A

Group 2: no zinc

Placebo given; Co-intervention(s): N/A 
Ruz 1997 (Continued)

(i.e. randomisation by someone not involved with enrolling patients) to conceal allocation

Blinding of participants (performance Low risk bias)

All outcomes
Quote: “...double-blind zinc supplementation trial...The study was conducted in a doubly-blinded fashion, and the code was broken only after the project had been finished...The zinc and placebo solutions were indistinguishable in appearance and taste." Comment: sufficient blinding seems likely

Blinding of personnel (performance bias) Low risk

All outcomes

Quote: “...double-blind zinc supplementation trial... The study was conducted in a doubly-blinded fashion, and the code was broken only after the project had been finished...The zinc and placebo solutions were indistinguishable in appearance and taste." Comment: sufficient blinding seems likely

Blinding of outcome assessment (detection Low risk bias)

All outcomes
Quote: “...double-blind zinc supplementation trial... The study was conducted in a doubly-blinded fashion, and the code was broken only after the project had been finished...The zinc and placebo solutions were indistinguishable in appearance and taste." Comment: sufficient blinding seems likely

Incomplete outcome data (attrition bias) Unclear risk All outcomes
\% Missing: 43

Reasons/details: "After 6 mo of intervention, 19 individuals had dropped out of the study, leaving 79; after 14 mo, the total number of children still participating was 56." Thus, $19 \%$ of data was missing for zinc, haemoglobin, ferritin, and copper concentrations (which were only measured at baseline and 6 months), and $43 \%$ of data were missing for all other outcomes. No reasons for dropout were reported Comment: a large proportion of data is missing, and no information was reported on differential dropout between study groups or reasons for dropout

Comment: diarrhoea, weight, weight-toheight ratio, and serum ferritin were measured, but are not reported in a way that can be meta-analysed. LRTI, which meets the criteria for this review, may have been 
Ruz 1997 (Continued)

measured; but it is not reported in a way that can be meta-analysed, and it is unclear how LRTI was defined in this study

Other bias

Low risk

Comment: appears to be free of other bias

Sandstead 1998

Methods

Participants
CRCT?: CRCT; Cross-over?: non-cross-over

Country: China; Setting: the 3 cities of Chonqing, Qingdao, and Shanghai; Urbanicity: urban

Inclusion criteria: 1 st grader

Exclusion criteria: N/A

Baseline characteristics

Avg age (mo): N/A; Min age (mo): 72; Max age (mo): 108; \% Female: N/A

Avg HAZ: N/A; Stunting: unclear; Avg height (cm): N/A; Avg zinc concentration $(\mu \mathrm{g} /$ dL): N/A

Please see 'Notes' for details about number of participants.

\begin{tabular}{ll} 
Interventions & $\begin{array}{l}\text { Group 1: zinc } \\
\text { Formulation: pill/tablet; Compound: unclear; Frequency: } 6 \text { days/wk; Duration (mo): } 2 . \\
\text { 5; Dose (mg): 20; Co-intervention(s): micronutrient mixture } \\
\text { Group 2: no zinc } \\
\text { Placebo given; Co-intervention(s): micronutrient mixture }\end{array}$ \\
\hline Outcomes & No outcomes of interest reported in a way that can be meta-analysed \\
\hline Notes & $\begin{array}{l}\text { - It was reported that "Subjects were divided equally between treatments"; but due to } \\
\text { inconsistent numbers reported across the } 2 \text { trial reports (Penland et al } 1997 \text { reports } 372 \\
\text { participants and Sandstead et al } 1998 \text { reports } 740 \text { participants), it is unclear how many } \\
\text { participants were in the trial } \\
\text { - In addition to the study groups mentioned in this table, there was a group of participants } \\
\text { who received zinc only; but there was no placebo group to which this zinc group could } \\
\text { be compared. So, this zinc group is not included in any meta-analyses in this review } \\
\text { - Baseline plasma zinc was reported as } 87.25 \mu \mathrm{g} / \mathrm{dL} \text { in Penland } 1997 \text { and } 86.37 \mu \mathrm{g} / \mathrm{dL} \\
\text { in Sandstead } 1998\end{array}$ \\
\hline
\end{tabular}

\section{Risk of bias}

\begin{tabular}{lll} 
Bias & Authors' judgement & Support for judgement \\
\hline $\begin{array}{l}\text { Random sequence generation (selection } \\
\text { bias) }\end{array}$ & Unclear risk & $\begin{array}{l}\text { Quote: “...randomized, controlled trial...” } \\
\text { Comment: insufficient details available to } \\
\text { make a judgement as to whether or not an } \\
\text { allocation sequence was generated using a } \\
\text { truly random method }\end{array}$
\end{tabular}

Zinc supplementation for preventing mortality, morbidity, and growth failure in children aged 6 months to I2 years of age (Review) 
Sandstead 1998 (Continued)

\begin{tabular}{|c|c|c|}
\hline Allocation concealment (selection bias) & Unclear risk & $\begin{array}{l}\text { Quote: N/A } \\
\text { Comment: insufficient details available to } \\
\text { make a judgement }\end{array}$ \\
\hline $\begin{array}{l}\text { Blinding of participants (performance } \\
\text { bias) } \\
\text { All outcomes }\end{array}$ & Low risk & $\begin{array}{l}\text { Quote: "Double-blind randomized con- } \\
\text { trolled treatment trial... Treatments } \\
\text { were....administered double-blind for } 10 \\
\text { weeks...identical appearing white tablets." } \\
\text { Comment: sufficient blinding seems likely }\end{array}$ \\
\hline $\begin{array}{l}\text { Blinding of personnel (performance bias) } \\
\text { All outcomes }\end{array}$ & Low risk & $\begin{array}{l}\text { Quote: "Double-blind randomized con- } \\
\text { trolled treatment trial...Treatments } \\
\text { were...administered double-blind for } 10 \\
\text { weeks...identical appearing white tablets." } \\
\text { Comment: sufficient blinding seems likely }\end{array}$ \\
\hline $\begin{array}{l}\text { Blinding of outcome assessment (detection } \\
\text { bias) } \\
\text { All outcomes }\end{array}$ & Low risk & $\begin{array}{l}\text { Quote: "Double-blind randomized con- } \\
\text { trolled treatment trial...Treatments } \\
\text { were....administered double-blind for } 10 \\
\text { weeks...identical appearing white tablets." } \\
\text { Comment: sufficient blinding seems likely }\end{array}$ \\
\hline $\begin{array}{l}\text { Incomplete outcome data (attrition bias) } \\
\text { All outcomes }\end{array}$ & Unclear risk & $\begin{array}{l}\text { \% Missing: N/A } \\
\text { Reasons/details: N/A } \\
\text { Comment: numbers of participants ran- } \\
\text { domised into each intervention group are } \\
\text { not clearly reported, and different num- } \\
\text { bers of participants are reported in Penland } \\
1997 \text { versus Sandstead } 1998\end{array}$ \\
\hline Selective reporting (reporting bias) & High risk & $\begin{array}{l}\text { Comment: plasma zinc concentration, hae- } \\
\text { moglobin, anaemia, serum ferritin concen- } \\
\text { tration, and iron deficiency were measured, } \\
\text { but are not reported in a way that can } \\
\text { be meta-analysed. The reported means and } \\
\text { number of participants analysed for plasma } \\
\text { zinc concentration are different between } \\
\text { the Penland } 1997 \text { and Sandstead } 1998 \text { trial } \\
\text { reports }\end{array}$ \\
\hline Other bias & Low risk & Comment: appears to be free of other bias \\
\hline
\end{tabular}


Methods

Participants
CRCT?: IRCT; Cross-over?: non-cross-over

Country: United States of America; Setting: Brownsville, Texas; Urbanicity: urban Inclusion criteria: N/A

Exclusion criteria: N/A

Baseline characteristics

Avg age (mo): N/A; Min age (mo): 72; Max age (mo): 84; \% Female: 33

Avg HAZ: N/A; Stunting: unclear; Avg height $(\mathrm{cm})$ : N/A; Avg zinc concentration $(\mu \mathrm{g} /$ dL): 97.4

Total N: 54; Group 1 N: 27; Group 2 N: 27

Formulation: unclear; Compound: sulfate; Frequency: 5 days/wk; Duration (mo): 2.5;

Dose (mg): 20; Co-intervention(s): multiple micronutrients

Group 2: no zinc

Placebo given; Co-intervention(s): multiple micronutrients

Outcomes

Serum or plasma zinc concentration, serum or plasma ferritin concentration

Time point (wk): 10

Notes

Risk of bias

\begin{tabular}{|c|c|c|}
\hline Bias & Authors' judgement & Support for judgement \\
\hline $\begin{array}{l}\text { Random sequence generation (selection } \\
\text { bias) }\end{array}$ & Unclear risk & $\begin{array}{l}\text { Quote: "They were divided into } 2 \text { groups } \\
\text { of similar composition and assigned ran- } \\
\text { domly...to one of the treatments..." } \\
\text { Comment: insufficient details available to } \\
\text { make a judgement as to whether or not an } \\
\text { allocation sequence was generated using a } \\
\text { truly random method }\end{array}$ \\
\hline
\end{tabular}

Allocation concealment (selection bias) Low risk

Blinding of participants (performance Low risk bias)

All outcomes
Quote: "The statistician assigned the treatments without specific knowledge of the subjects and held the code until completion of the trial."

Comment: indicates central randomisation to conceal allocation

Quote: “...treated in double-blind fashion in equal numbers... They were divided into 2 groups of similar composition and assigned....in a double-blind fashion to one of the treatments... The statistician assigned the treatments without specific knowledge of the subjects and held the code until completion of the trial." 
Sandstead 2008 (Continued)

Comment: sufficient blinding seems likely

Blinding of personnel (performance bias) Low risk

All outcomes
Quote: “...treated in double-blind fashion in equal numbers... They were divided into 2 groups of similar composition and assigned... in a double-blind fashion to one of the treatments...The statistician assigned the treatments without specific knowledge of the subjects and held the code until completion of the trial."

Comment: sufficient blinding seems likely
Blinding of outcome assessment (detection Low risk bias)

All outcomes
Quote: “...treated in double-blind fashion in equal numbers... They were divided into 2 groups of similar composition and assigned...in a double-blind fashion to one of the treatments... The statistician assigned the treatments without specific knowledge of the subjects and held the code until completion of the trial."

Comment: sufficient blinding seems likely

\% Missing: 15

Reasons/details: N/A

Comment: the amount of missing data was similar between study groups. In the zinc + micronutrients group, 2 were missing for the plasma zinc outcome, and 3 were missing for the serum ferritin outcome. In the micronutrients group, 2 were missing for the plasma zinc outcome, and 4 were missing for the serum ferritin outcome. However, a somewhat sizeable proportion of data is missing, and reasons for missing data were not stated. Also, Table 2 lists an inconsistent number of subjects for the serum ferritin outcome (stating that 46 subjects were analysed for this outcome, 24 in the zinc + micronutrients group, and 23 in the micronutrients group)

Comment: no trial protocol referenced by the study 
- "The study sample consisted of 90 healthy children...Approximately 15 to 22 children were assigned" to each study group. In addition to the study groups mentioned in this table, there was a group of participants who received placebo only; but there was no zinc group to which this placebo group could be compared in this review. The 90 participants who were randomised in this study includes this group of participants who only received placebo

- In addition, the authors report that "The present examination of the diet and nutrient intake of children 1 to 2 years old is part of a larger investigation undertaken by the University of Colorado Health Sciences Center. The primary objective of the larger study was to evaluate the efficacy of vitamin and mineral supplements in very young children.

" However, no information was available about this larger investigation

\section{Risk of bias}

\begin{tabular}{|c|c|c|}
\hline Bias & Authors' judgement & Support for judgement \\
\hline $\begin{array}{l}\text { Random sequence generation (selection } \\
\text { bias) }\end{array}$ & Unclear risk & $\begin{array}{l}\text { Quote: "The toddlers were randomly as- } \\
\text { signed..." } \\
\text { Comment: insufficient details available to } \\
\text { make a judgement as to whether or not an } \\
\text { allocation sequence was generated using a } \\
\text { truly random method }\end{array}$ \\
\hline Allocation concealment (selection bias) & Unclear risk & $\begin{array}{l}\text { Quote: N/A } \\
\text { Comment: insufficient details available to } \\
\text { make a judgement }\end{array}$ \\
\hline
\end{tabular}




\section{Sanjur 1990 (Continued)}

\begin{tabular}{l|l|l}
$\begin{array}{l}\text { Blinding of participants (performance } \\
\text { bias) } \\
\text { All outcomes }\end{array}$ & Low risk & $\begin{array}{l}\text { Quote: “...double-blind study...Group as- } \\
\text { signment was unknown to the toddlers and } \\
\text { their families...” }\end{array}$ \\
Comment: sufficient blinding seems likely
\end{tabular}

Blinding of personnel (performance bias) Low risk All outcomes

Quote: “...double-blind study...Group assignment was unknown to...the members of the investigating team."

Comment: sufficient blinding seems likely

Blinding of outcome assessment (detection Low risk

bias)

All outcomes
Quote: “...double-blind study...Group assignment was unknown to...the members of the investigating team."

Comment: sufficient blinding seems likely

$\%$ Missing: N/A

Reasons/details: N/A

Comment: the following were not reported: number of participants randomised to each group, amount of missing data for each group, reasons for missing data in each group

Comment: no trial protocol referenced by the study

Selective reporting (reporting bias) Unclear risk

Low risk

\section{Sayeg Porto 2000}

Methods

Participants
CRCT?: IRCT; Cross-over?: non-cross-over

Country: Brazil; Setting: Rio de Janeiro; Urbanicity: urban

Inclusion criteria: height-for-age -2 SD according to NCHS data; attendance at the Pediatric Endocrinology Service for at least 1 year without previous treatment; normal hematological values and biochemical analysis - calcium, phosphorus, alkaline phosphatase, iron, urea, creatinine, albumin, and globulins; normal endocrine function with normal thyroid hormones (T3, T4, and TSH); insulin growth factor-1 (IGF-1) level and growth hormone $(\mathrm{GH})$ post-exercise above $10 \mathrm{ng} / \mathrm{dl}$; bone age equivalent to height age Exclusion criteria: pubertal signs; in a family with a history of psychological problems; malabsorption; chronic infections; other known causes of growth failure

Baseline characteristics

Avg age (mo): 118.44; Min age (mo): 84; Max age (mo): 120; \% Female: 24

Avg HAZ: -2.67; Stunting: stunted; Avg height (cm): 121.6; Avg zinc concentration $(\mu \mathrm{g} / \mathrm{dL}): 100.7$

Total N: 21; Group 1 N: N/A; Group 2 N: N/A 
Sayeg Porto 2000 (Continued)

\begin{tabular}{ll}
\hline Interventions & $\begin{array}{l}\text { Group 1: zinc } \\
\text { Formulation: solution; Compound: sulfate; Frequency: daily; Duration (mo): 6; Dose } \\
(\mathrm{mg}): 5 \mathrm{mg} / \mathrm{kg} \text {; Co-intervention(s): N/A }\end{array}$ \\
$\begin{array}{l}\text { Group 2: no zinc } \\
\text { Placebo given; Co-intervention(s): N/A }\end{array}$ \\
\hline Outcomes & $\begin{array}{l}\text { Height, weight, serum or plasma zinc concentration, prevalence of zinc deficiency } \\
\text { Time point (wk): } 24 \text { (biochemical outcomes), } 52 \text { (growth outcomes) }\end{array}$ \\
\hline Notes & $\begin{array}{l}\text { The number of participants randomised to each study group is not reported, nor is } \\
\text { the number of participants in either study group who completed the study, nor is any } \\
\text { number of participants analysed for any outcome reported. However, it is assumed that } \\
\text { participants were split approximately evenly between study groups }\end{array}$ \\
\hline
\end{tabular}

\section{Risk of bias}

\begin{tabular}{|c|c|c|}
\hline Bias & Authors' judgement & Support for judgement \\
\hline $\begin{array}{l}\text { Random sequence generation (selection } \\
\text { bias) }\end{array}$ & Unclear risk & $\begin{array}{l}\text { Quote: "The } \\
\text { study was designed as a... randomized, con- } \\
\text { trolled trial...Children were randomized to } \\
\text { two groups..." } \\
\text { Comment: insufficient details available to } \\
\text { make a judgement as to whether or not an } \\
\text { allocation sequence was generated using a } \\
\text { truly random method }\end{array}$ \\
\hline Allocation concealment (selection bias) & Low risk & $\begin{array}{l}\text { Quote: "Randomization was performed by } \\
\text { a person not involved in the clinical man- } \\
\text { agement of the children." } \\
\text { Comment: indicates central randomisation } \\
\text { (i.e. randomisation by someone not in- } \\
\text { volved with enrolling patients) to conceal } \\
\text { allocation }\end{array}$ \\
\hline
\end{tabular}

Blinding of participants (performance Low risk bias)

All outcomes
Quote: "The study was designed as a double-blind...controlled trial...In the Pharmacy Department, two syrups were made with the same color and flavor, one of which contained zinc sulfate...Assignment to the zinc or placebo group was not known by the families..."

Comment: sufficient blinding seems likely

Quote: "The study was designed as a double-blind...controlled trial...In the Pharmacy Department, two syrups were made with the same color and flavor, one of which 
Sayeg Porto 2000 (Continued)

contained zinc sulfate...Assignment to the zinc or placebo group was not known by the...investigators."

Comment: sufficient blinding seems likely

Blinding of outcome assessment (detection Low risk bias)

All outcomes
Quote: "The study was designed as a double-blind...controlled trial...In the Pharmacy Department, two syrups were made with the same color and flavor, one of which contained zinc sulfate...Assignment to the zinc or placebo group was not known by the...investigators."

Comment: sufficient blinding seems likely

\% Missing: 14

Reasons/details: "During the supplementation period, three boys presented initial signs of puberty and were excluded from the study."

Comment: amount of missing data is not reported separately for each study group
Comment: side effects were measured but are not reported in a way that can be metaanalysed

Other bias

Low risk

Comment: appears to be free of other bias

\section{Sazawal 1996}

\begin{tabular}{|c|c|}
\hline Methods & CRCT?: IRCT; Cross-over?: non-cross-over \\
\hline Participants & $\begin{array}{l}\text { Country: India; Setting: Kalkaji, New Delhi; Urbanicity: urban } \\
\text { Inclusion criteria: reported passage of at least } 4 \text { unformed stools in the previous } 24 \text { h; a } \\
\text { diarrhoeal duration of < } 7 \mathrm{~d} \text {; permanent residence in the Kalkaji area } \\
\text { Exclusion criteria: malnutrition judged clinically to be sufficiently severe to require hos- } \\
\text { pitalisation } \\
\text { Baseline characteristics } \\
\text { Avg age (mo): } 16 \text {; Min age (mo): 6; Max age (mo): } 35 \text {; \% Female: } 47.7 \\
\text { Avg HAZ: N/A; Stunting: both - separate data not given; Avg height }(\mathrm{cm}): \mathrm{N} / \mathrm{A} \text {; Avg } \\
\text { zinc concentration }(\mu \mathrm{g} / \mathrm{dL}): 64.8 \\
\text { Total N: } 609 \text {; Group } 1 \mathrm{~N}: 298 \text {; Group } 2 \mathrm{~N}: 311\end{array}$ \\
\hline Interventions & $\begin{array}{l}\text { Group 1: zinc } \\
\text { Formulation: solution; Compound: gluconate; Frequency: daily; Duration (mo): 6; Dose } \\
\text { (mg): 10; Co-intervention(s): multiple micronutrients } \\
\text { Group 2: no zinc } \\
\text { Placebo given; Co-intervention(s): multiple micronutrients }\end{array}$ \\
\hline
\end{tabular}

Zinc supplementation for preventing mortality, morbidity, and growth failure in children aged 6 months to 12 years of age (Review) 


\section{Sazawal 1996 (Continued)}

Outcomes
Incidence of all-cause diarrhoea, prevalence of all-cause diarrhoea, incidence of persistent diarrhoea, incidence of LRTI, prevalence of LRTI, serum or plasma zinc concentration, blood haemoglobin concentration, serum or plasma copper concentration, prevalence of copper deficiency

Time point (wk): 17 (biochemical outcomes), 24 (morbidity outcomes)

"...a subgroup of children enrolled in a trial of the therapeutic effect of zinc supplementation...were randomly selected at the time of initial enrollment to enter a 6-mo followup trial after recovery from the enrollment diarrheal episode." The data in this review apply to the 6-mo follow-up trial. In this follow-up trial, during episodes of diarrhoeal illness, the dose of zinc was doubled to provide for excess stool losses

\section{Risk of bias}

\begin{tabular}{|c|c|c|}
\hline Bias & Authors' judgement & Support for judgement \\
\hline $\begin{array}{l}\text { Random sequence generation (selection } \\
\text { bias) }\end{array}$ & Low risk & $\begin{array}{l}\text { Quote: "Randomization schedules with } \\
\text { permuted blocks of fixed length of 10, ap- } \\
\text { propriate for double-blind studies, were } \\
\text { used." "At WHO two separate randomiza- } \\
\text { tion schedules were first made for long and } \\
\text { short follow up children, then the two were } \\
\text { combined into a single schedule such that } \\
\text { allocation to long and short follow up was } \\
\text { also random." } \\
\text { Comment: N/A }\end{array}$ \\
\hline
\end{tabular}

Allocation concealment (selection bias) Low risk

Quote: "The company prepared bottles with labels of A, B, C, D, R, F, three of these with zinc (intervention group solution) and the other three without zinc (control group solution). The identity of codes A-F was communicated to WHO by the company and was not revealed to the investigators in Delhi until the end of the study. Both sets of bottles...were identical in all respects... The randomization schedule prepared by WHO gave serial numbers in each of the 4 strata, with letter $\mathrm{A}$ through $\mathrm{F}$ denoting which code bottle should be assigned to the child. This randomization schedule was mailed by WHO directly to clinical pharmacology at AIIMS where only the pharmacy assistant was aware of the allocation. He relabelled the bottles with stratum serial numbers and provided the bottles as required. At the clinic, on enrollment, each child was assigned a stratum serial number 
corresponding to a bottle of supplement, which was also labeled with the child's identification number and name. The investigators and the field staff were unaware of A-F allocation."

Comment: indicates central randomisation (i.e. randomisation by someone not involved with enrolling patients) and sequentially numbered drug containers of identical appearance to conceal allocation

Blinding of participants (performance Low risk bias)

All outcomes

Blinding of personnel (performance bias) Low risk All outcomes

Blinding of outcome assessment (detection Low risk bias)

All outcomes
Quote: ”...double-blind randomized trial. ..Both sets of bottles and solutions were identical in all respects including color and taste."

Comment: sufficient blinding seems likely

Quote: ”...double-blind randomized trial. ..The identity of codes A-F was...not revealed to the investigators in Delhi until the end of the study. Both sets of bottles and solutions were identical in all respects including color and taste."

Comment: sufficient blinding seems likely

Quote: ”...double-blind randomized trial. ..The identity of codes A-F was...not revealed to the investigators in Delhi until the end of the study. Both sets of bottles and solutions were identical in all respects including color and taste." "“...duplicate blind measurements were taken by the two study physicians throughout the course of the study..."

Comment: sufficient blinding seems likely

Incomplete outcome data (attrition bias) Low risk

\% Missing: 7

Reasons/details: for diarrhoea outcomes: "Of the 609 children, 40 (Z 12, C 28) with actual follow-up of less than $30 \mathrm{~d}$ were excluded from the analysis." For LRTI outcomes: "Out of 609 children...6 children (zinc, $\mathrm{n}=1$; control, $\mathrm{n}=5$ )" were excluded from the analysis, because "their total surveillance was less than 15 days" due to being "absent continuously."

Comment: missing data seem too minimal to impact results 


\section{Sazawal 1996 (Continued)}

Selective reporting (reporting bias) High risk

Other bias
Comment: height and weight were measured as outcomes, but are not reported. Prevalence of zinc deficiency was measured, but is not reported in a way that can be meta-analysed due to different numbers reported in different trial reports

Comment: appears to be free of other bias

Sazawal 2006

Methods

Participants
CRCT?: CRCT; Cross-over?: non-cross-over

Country: Zanzibar; Setting: Pemba, an island of Zanzibar; Urbanicity: multiple

Inclusion criteria: likely to remain resident in the study area

Exclusion criteria: severe malnutrition needing rehabilitation

Baseline characteristics

Avg age (mo): 18.2; Min age (mo): 1; Max age (mo): 35; \% Female: 50

Avg HAZ: -1.5; Stunting: both - separate data not given; Avg height (cm): N/A; Avg zinc concentration $(\mu \mathrm{g} / \mathrm{dL}): 78.5$

Total N: 60,225; Group 1 N: 21,274; Group 2 N: 21,272; Group 3 N: 8914; Group 4 N: 8765

Total clusters: 33,899; Group 1 clusters: N/A; Group 2 clusters: N/A; Group 3 clusters: N/A; Group 4 clusters: N/A

Interventions

\section{Group 1: zinc}

Formulation: pill/tablet; Compound: sulfate; Frequency: daily; Duration (mo): 16; Dose $(\mathrm{mg}): 5 \mathrm{mg}$ to children aged younger than 12 months; 10 to children aged 12 months or older; Co-intervention(s): 200,000 IU of vitamin A every 6 months to children aged 12 months or older, 100,000 IU of vitamin A every 6 months to children aged younger than 12 months

Group 2: no zinc

Placebo given; Co-intervention(s): 200,000 IU of vitamin A every 6 months to children aged 12 months or older, 100,000 IU of vitamin A every 6 months to children aged younger than 12 months

Group 3: zinc

Co-intervention(s): $6.25 \mathrm{mg}$ iron and $25 \mu \mathrm{g}$ folic acid to children aged younger than 12 months; $12.5 \mathrm{mg}$ iron and $50 \mu \mathrm{g}$ folic acid to children aged 12 months or older; 100 , $000 \mathrm{IU}$ of vitamin A every 6 months to children aged younger than 12 months; 200, $000 \mathrm{IU}$ of vitamin A every 6 months to children aged 12 months or older Group 4: no zinc

Placebo given; Co-intervention(s): $6.25 \mathrm{mg}$ iron and $25 \mu \mathrm{g}$ folic acid to children aged younger than 12 months; $12.5 \mathrm{mg}$ iron and $50 \mu \mathrm{g}$ folic acid to children aged 12 months or older; 100,000 IU of vitamin A every 6 months to children aged younger than 12 months; 200,000 IU of vitamin A every 6 months to children aged 12 months or older 


\section{Sazawal 2006 (Continued)}

Outcomes
All-cause mortality, mortality due to all-cause diarrhoea, mortality due to LRTI, mortality due to malaria, height, weight, blood haemoglobin concentration, prevalence of anaemia, prevalence of iron deficiency

Time point (wk): 24 to 52 (biochemical and growth outcomes), 55 to 69 (morbidity and mortality outcomes)

\section{Notes}

\section{Risk of bias}

Authors' judgement

Random sequence generation (selection Low risk bias)

\section{Bias}

- "On recommendation of the Data and Safety Monitoring Board (DSMB)" of the study, the iron + folic acid + zinc (IFAZ) and iron + folic acid (IFA) groups "were stopped on Aug 19, 2003 because of overwhelming evidence of increased hospital admissions and a trend for increased mortality associated with iron supplementation...Children from the IFAZ and non-zinc IFA groups were switched to the zinc and placebo groups, respectively. "The numbers of participants listed in this table as being randomised to the zinc and placebo groups do not include those from the IFA and IFAZ groups who were switched to zinc or placebo

- "Children received zinc or placebo supplements until they were 48 months of age", or, in the case of the IFAZ and IFA groups, "until the iron and folic acid-containing groups were stopped." "At the time of stopping the trial, mean duration of follow-up in the study was 383 days" in the IFAZ and IFA groups reported in the Sazawal et al 2006 trial report. "The mean duration of supplementation was 484.7 days" in the zinc and placebo groups reported in the Sazawal et al 2007 trial report

- Iron deficiency was defined as zinc protoporphyrin $\geq 90 \mu \mathrm{mol} / \mathrm{mol} \mathrm{heme}$

\section{Support for judgement}

Quote: "Randomisation was by household, by an allocation sequence (permuted block randomisation with block length of 16) computer-generated by WHO." Comment: N/A

Quote: "The supplement code, which was not known to the investigators, was maintained at WHO. To ensure masking, we labeled the strips of supplements with 16 letter codes - four for each of the groups. This letter code was hidden in the batch number on each strip of tablets. On enrolment, we assigned every child a code. Labels with the child's name on were then printed from a computer database and attached by the pharmacy to the appropriate strip of supplements."

Comment: indicates central randomisation (i.e. randomisation by someone not involved with enrolling patients) to conceal allocation 
Sazawal 2006 (Continued)

Blinding of participants (performance Low risk bias)

All outcomes
Quote: “...double-masked, placebo-controlled trial...To ensure masking, we labelled the strips of supplements with 16 letter codes - four for each of the groups. This letter code was hidden in the batch number on each strip of tablets." "The halting of the IFAZ and IFA arms and switching of children to the other groups were done with the help of WHO and the DSMB statistician. The trial initially used 16-letter codes (four-letter codes assigned to the individual supplementation groups) and two-stage blinding. The four-letter codes for every group were known only to $\mathrm{WHO}$ and the manufacturer; the pharmacy dispensing the supplements knew only which letter code was assigned to each child, and the...family knew neither. At the time of switch, WHO and the DSMB statistician provided an alternative letter code for all of the redundant eight-letter codes...Tablets...were similar in packaging, appearance, taste, and inactive ingredients."

Comment: sufficient blinding seems likely

Blinding of personnel (performance bias) Low risk All outcomes
Quote: “...double-masked, placebo-controlled trial...To ensure masking, we labelled the strips of supplements with 16 letter codes - four for each of the groups. This letter code was hidden in the batch number on each strip of tablets." "The halting of the IFAZ and IFA arms and switching of children to the other groups were done with the help of WHO and the DSMB statistician. The trial initially used 16-letter codes (four-letter codes assigned to the individual supplementation groups) and two-stage blinding. The four-letter codes for every group were known only to $\mathrm{WHO}$ and the manufacturer; the pharmacy dispensing the supplements knew only which letter code was assigned to each child, and the study worker...knew neither. At the time of switch, WHO and the DSMB statistician provided an alternative letter code for all of the redundant eight-letter codes... Tablets...were similar in packaging, appearance, taste, and inactive ingredients."

Comment: sufficient blinding seems likely 
Sazawal 2006 (Continued)

Blinding of outcome assessment (detection Low risk bias)

All outcomes
Quote: “...double-masked, placebo-controlled trial...To ensure masking, we labelled the strips of supplements with 16 letter codes - four for each of the groups. This letter code was hidden in the batch number on each strip of tablets." "The halting of the IFAZ and IFA arms and switching of children to the other groups were done with the help of WHO and the DSMB statistician. The trial initially used 16-letter codes (four-letter codes assigned to the individual supplementation groups) and two-stage blinding. The four-letter codes for every group were known only to $\mathrm{WHO}$ and the manufacturer; the pharmacy dispensing the supplements knew only which letter code was assigned to each child, and the study worker...knew neither. At the time of switch, WHO and the DSMB statistician provided an alternative letter code for all of the redundant eight-letter codes. ..Tablets...were similar in packaging, appearance, taste, and inactive ingredients." Teams that assessed causes of death "were masked to supplement allocation."

Comment: sufficient blinding seems likely

Incomplete outcome data (attrition bias) Low risk All outcomes
\% Missing: 17

Reasons/details: in the zinc + iron + folic acid group reported in Sazawal 2006: 1075 participants "withdrew", 480 "outmigrated", and 146 "died". In the iron + folic acid group reported in Sazawal 2006: 1059 participants "withdrew", 445 "outmigrated", and 149 "died”. In the placebo group reported in Sazawal 2007a: 865 participants "withdrew", 2018 "outmigrated", and 483 "died". In the zinc group reported in Sazawal 2007a: 1090 participants "withdrew", 2141 "outmigrated", and 401 "died"

Comment: reasons for, and amount of, missing data were similar between the placebo and zinc groups. Reasons for, and amount of, missing data were similar between the iron + folic acid and zinc + iron + folic acid groups 
Sazawal 2006 (Continued)

Selective reporting (reporting bias) High risk
Comment: all-cause hospital admissions was pre-specified as a secondary outcome in the protocol for this study and was measured, but is not reported for the study group that received zinc. Hospitalisation due to diarrhoea, hospitalisation due to pneumonia, and hospitalisation due to malaria seem to be measured, but were not pre-specified in the protocol for this study, and are not reported; however, the related outcome of all-cause hospitalisation was pre-specified as a secondary outcome in the protocol for this study. Weightfor-height z-score was measured, but was not pre-specified in the protocol for this study, and is not reported. Malaria prevalence was measured, but was not pre-specified in the protocol for this study, and is not reported in a way that can be meta-analysed. Blood haemoglobin concentration, anaemia prevalence, prevalence of iron deficiency, height, and weight were reported, but were not pre-specified in the protocol for this study. Mortality due to diarrhoea, mortality due to pneumonia, and mortality due to malaria were reported, but were not pre-specified in the protocol for this study; however, the related outcome of all-cause mortality was pre-specified as a secondary outcome in the protocol for this study Protocol identifier: ISRCTN59549825

Sazawal 2006 (2)

Methods

Participants

Interventions

Outcomes All-cause mortality, all-cause hospitalisation, height, weight, blood haemoglobin concentration, prevalence of anaemia, prevalence of iron deficiency

Notes As Sazawal 2006 above

Zinc supplementation for preventing mortality, morbidity, and growth failure in children aged 6 months to 12 years of age (Review) 


\begin{tabular}{|c|c|}
\hline Methods & CRCT?: IRCT; Cross-over?: non-cross-over \\
\hline Participants & $\begin{array}{l}\text { Country: Indonesia; Setting: Tambora district of Jakarta; Urbanicity: urban } \\
\text { Inclusion criteria: pre-school children; stunted, as indicated by a height-for-age Z score } \\
\text { below -1.5; anaemic, as indicated by a haemoglobin concentration below } 110 \mathrm{~g} / \mathrm{L} \\
\text { Exclusion criteria: N/A } \\
\text { Baseline characteristics } \\
\text { Avg age (mo): } 38 \text {; Min age (mo): } 24 \text {; Max age (mo): } 60 \text {; \% Female: } 52 \\
\text { Avg HAZ: }-2.5 \text {; Stunting: both - separate data not given; Avg height }(\mathrm{cm}): 85.9 \text {; Avg } \\
\text { zinc concentration ( } \mu \mathrm{g} / \mathrm{dL}): 87.3 \\
\text { Total N: } 85 \text {; Group } 1 \mathrm{~N}: 43 \text {; Group } 2 \mathrm{~N}: 42\end{array}$ \\
\hline Interventions & $\begin{array}{l}\text { Group 1: zinc } \\
\text { Formulation: solution; Compound: phosphate; Frequency: daily; Duration (mo): 2; } \\
\text { Dose (mg): } 15 \text {; Co-intervention(s): } 30 \mathrm{mg} \text { iron } \\
\text { Group 2: no zinc } \\
\text { Placebo given; Co-intervention(s): } 30 \mathrm{mg} \text { iron }\end{array}$ \\
\hline Outcomes & $\begin{array}{l}\text { Serum or plasma zinc concentration, blood haemoglobin concentration, serum or plasma } \\
\text { ferritin concentration } \\
\text { Time point (wk): } 8\end{array}$ \\
\hline
\end{tabular}

Notes

“...all children received a deworming treatment (100 mg of pyrantel pamoate and 150 mg of mebendazole) before the start of the supplementation.”

\section{Risk of bias}

\begin{tabular}{|c|c|c|}
\hline Bias & Authors' judgement & Support for judgement \\
\hline $\begin{array}{l}\text { Random sequence generation (selection } \\
\text { bias) }\end{array}$ & Unclear risk & $\begin{array}{l}\text { Quote: "The children were randomly as- } \\
\text { signed to two groups." } \\
\text { Comment: insufficient details available to } \\
\text { make a judgement as to whether or not an } \\
\text { allocation sequence was generated using a } \\
\text { truly random method }\end{array}$ \\
\hline Allocation concealment (selection bias) & Unclear risk & $\begin{array}{l}\text { Quote: N/A } \\
\text { Comment: insufficient details available to } \\
\text { make a judgement }\end{array}$ \\
\hline $\begin{array}{l}\text { Blinding of participants (performance } \\
\text { bias) } \\
\text { All outcomes }\end{array}$ & Low risk & $\begin{array}{l}\text { Quote: "Both syrups were similar in ap- } \\
\text { pearance and taste, and supplementation } \\
\text { was double-blinded." } \\
\text { Comment: sufficient blinding seems likely }\end{array}$ \\
\hline $\begin{array}{l}\text { Blinding of personnel (performance bias) } \\
\text { All outcomes }\end{array}$ & Low risk & $\begin{array}{l}\text { Quote: "Both syrups were similar in ap- } \\
\text { pearance and taste, and supplementation } \\
\text { was double-blinded." } \\
\text { Comment: sufficient blinding seems likely }\end{array}$ \\
\hline
\end{tabular}




\section{Schultink 1997 (Continued)}

\begin{tabular}{|c|c|c|}
\hline $\begin{array}{l}\text { Blinding of outcome assessment (detection } \\
\text { bias) } \\
\text { All outcomes }\end{array}$ & Low risk & $\begin{array}{l}\text { Quote: "Both syrups were similar in ap- } \\
\text { pearance and taste, and supplementation } \\
\text { was double-blinded." } \\
\text { Comment: sufficient blinding seems likely }\end{array}$ \\
\hline $\begin{array}{l}\text { Incomplete outcome data (attrition bias) } \\
\text { All outcomes }\end{array}$ & Unclear risk & $\begin{array}{l}\text { \% Missing: } 21 \\
\text { Reasons/details: N/A } \\
\text { Comment: } 10 \text { participants were missing } \\
\text { in the zinc group, and } 8 \text { participants were } \\
\text { missing in the control group. So, the } \\
\text { amount of missing data was similar be- } \\
\text { tween study groups. However, reasons for } \\
\text { missing data were not reported }\end{array}$ \\
\hline Selective reporting (reporting bias) & Unclear risk & $\begin{array}{l}\text { Comment: no trial protocol referenced by } \\
\text { the study }\end{array}$ \\
\hline Other bias & Low risk & Comment: appears to be free of other bias \\
\hline
\end{tabular}

Sempertegui 1996

Methods

Participants
CRCT?: IRCT; Cross-over?: non-cross-over

Country: Ecuador; Setting: slum in the northeast region of the city of Quito; Urbanicity: urban

Inclusion criteria: attended a day-care centre (centro infantil No. 1 CAI, National Institute for the Children and the Family) for at least 6 months; malnourished according to height and weight parameters from the National Center for Health Statistics from the USA (NCHS)

Exclusion criteria: N/A

Baseline characteristics

Avg age (mo): 42.3; Min age (mo): 12; Max age (mo): 59; \% Female: 43.8

Avg HAZ: -2; Stunting: both - separate data not given; Avg height $(\mathrm{cm})$ : N/A; Avg zinc concentration $(\mu \mathrm{g} / \mathrm{dL}): 86.5$

Total N: 50; Group 1 N: 25; Group 2 N: 25

Interventions

Group 1: zinc

Formulation: solution; Compound: sulfate; Frequency: daily; Duration (mo): 2; Dose (mg): 10; Co-intervention(s): N/A

Group 2: no zinc

Placebo given; Co-intervention(s): N/A
Incidence of LRTI, height, weight, serum or plasma zinc concentration Time point (wk): 9 (serum or plasma zinc concentration), 17 (morbidity and growth outcomes)

Notes
Full text could not be obtained for the Correa León et al 1992 trial report for this study 


\section{Risk of bias}

\begin{tabular}{|c|c|c|}
\hline Bias & Authors' judgement & Support for judgement \\
\hline $\begin{array}{l}\text { Random sequence generation (selection } \\
\text { bias) }\end{array}$ & Low risk & $\begin{array}{l}\text { Quote: “...children were randomly as- } \\
\text { signed, by the Moses-Oakford algorithm... } \\
\text { " } \\
\text { Comment: N/A }\end{array}$ \\
\hline Allocation concealment (selection bias) & Unclear risk & $\begin{array}{l}\text { Quote: "The code was kept by the Ethical } \\
\text { Committee until the end of the study." } \\
\text { Comment: insufficient details available to } \\
\text { make a judgement }\end{array}$ \\
\hline $\begin{array}{l}\text { Blinding of participants (performance } \\
\text { bias) } \\
\text { All outcomes }\end{array}$ & Low risk & $\begin{array}{l}\text { Quote: “...double- } \\
\text { blind placebo-controlled trial...Zinc and } \\
\text { placebo syrups had an identical appearance } \\
\text { and flavor...The NS group received syrup } \\
\text { 'A' that contained placebo. The S group was } \\
\text { given syrup 'B' that contained zinc...The } \\
\text { code was kept by the Ethical Committee } \\
\text { until the end of the study." } \\
\text { Comment: sufficient blinding seems likely }\end{array}$ \\
\hline $\begin{array}{l}\text { Blinding of personnel (performance bias) } \\
\text { All outcomes }\end{array}$ & Low risk & $\begin{array}{l}\text { Quote: “...double- } \\
\text { blind placebo-controlled trial...Zinc and } \\
\text { placebo syrups had an identical appearance } \\
\text { and flavor... The NS group received syrup } \\
\text { 'A' that contained placebo. The S group was } \\
\text { given syrup 'B' that contained zinc...the } \\
\text { syrups were administered...by two pedia- } \\
\text { tricians...who did not know which group } \\
\text { was the actively supplemented group un- } \\
\text { til after the study was completed, and who } \\
\text { were not involved in the daily clinical ex- } \\
\text { amination of the children. The code was } \\
\text { kept by the Ethical Committee until the } \\
\text { end of the study." } \\
\text { Comment: sufficient blinding seems likely }\end{array}$ \\
\hline $\begin{array}{l}\text { Blinding of outcome assessment (detection } \\
\text { bias) } \\
\text { All outcomes }\end{array}$ & Low risk & $\begin{array}{l}\text { Quote: “...double- } \\
\text { blind placebo-controlled trial...Zinc and } \\
\text { placebo syrups had an identical appearance } \\
\text { and flavor...The NS group received syrup } \\
\text { 'A' that contained placebo. The S group was } \\
\text { given syrup 'B' that contained zinc...The } \\
\text { code was kept by the Ethical Committee } \\
\text { until the end of the study." }\end{array}$ \\
\hline
\end{tabular}

Zinc supplementation for preventing mortality, morbidity, and growth failure in children aged 6 months to 12 years of age (Review) 
Comment: sufficient blinding seems likely

\begin{tabular}{|c|c|c|}
\hline $\begin{array}{l}\text { Incomplete outcome data (attrition bias) } \\
\text { All outcomes }\end{array}$ & Low risk & $\begin{array}{l}\text { \% Missing: } 4 \\
\text { Reasons/details: “...two malnour- } \\
\text { ished children from the } S \text { group were lost } \\
\text { to follow-up when their families moved to } \\
\text { another province." } \\
\text { Comment: missing data seem too minimal } \\
\text { to impact results }\end{array}$ \\
\hline Selective reporting (reporting bias) & Unclear risk & $\begin{array}{l}\text { Comment: prevalence of zinc deficiency } \\
\text { may have been measured, but was not re- } \\
\text { ported in a way that could be meta-anal- } \\
\text { ysed. No trial protocol referenced by the } \\
\text { study }\end{array}$ \\
\hline Other bias & Low risk & Comment: appears to be free of other bias \\
\hline
\end{tabular}

Shah 2011

\begin{tabular}{ll}
\hline Methods & CRCT?: IRCT; Cross-over?: non-cross-over \\
\hline Participants & Country: India; Setting: near the Jawaharlal Nehru Medical College Hospital in Aligarh, \\
Uttar Pradesh, India; Urbanicity: urban \\
Inclusion criteria: recurrent acute lower respiratory infections; referred to department of \\
Pediatrics \\
Exclusion criteria: N/A \\
Baseline characteristics \\
Avg age (mo): N/A; Min age (mo): 6; Max age (mo): 59; \% Female: N/A \\
Avg HAZ: N/A; Stunting: unclear; Avg height (cm): N/A; Avg zinc concentration ( $\mu$ g/ \\
dL): N/A \\
Total N: N/A; Group 1 N: N/A; Group 2 N: N/A \\
\hline Group 1: zinc \\
Formulation: unclear; Compound: gluconate; Frequency: unclear; Duration (mo): $2 ;$ \\
Dose (mg): 10; Co-intervention(s): N/A \\
Group 2: no zinc \\
Placebo given; Co-intervention(s): N/A \\
\hline
\end{tabular}

\begin{tabular}{l|l} 
Outcomes & No outcomes of interest reported in a way that can be meta-analysed \\
\hline Notes & $\begin{array}{l}\text { Though, "The final analysis included } 96 \text { children allocated equally to the two groups", } \\
\text { the number of participants randomised is not reported, nor is the number of participants } \\
\text { randomised to each study group }\end{array}$ \\
\hline
\end{tabular}

\section{Risk of bias}

Bias 
Shah 2011 (Continued)

\begin{tabular}{|c|c|c|}
\hline $\begin{array}{l}\text { Random sequence generation (selection } \\
\text { bias) }\end{array}$ & Unclear risk & $\begin{array}{l}\text { Quote: "Children were randomly as- } \\
\text { signed..." } \\
\text { Comment: insufficient details available to } \\
\text { make a judgement as to whether or not an } \\
\text { allocation sequence was generated using a } \\
\text { truly random method }\end{array}$ \\
\hline Allocation concealment (selection bias) & Unclear risk & $\begin{array}{l}\text { Quote: N/A } \\
\text { Comment: insufficient details available to } \\
\text { make a judgement }\end{array}$ \\
\hline $\begin{array}{l}\text { Blinding of participants (performance } \\
\text { bias) } \\
\text { All outcomes }\end{array}$ & Unclear risk & $\begin{array}{l}\text { Quote: “...double blind controlled trial...” } \\
\text { Comment: insufficient details available to } \\
\text { make a judgement }\end{array}$ \\
\hline $\begin{array}{l}\text { Blinding of personnel (performance bias) } \\
\text { All outcomes }\end{array}$ & Unclear risk & $\begin{array}{l}\text { Quote: “...double blind controlled trial...” } \\
\text { Comment: insufficient details available to } \\
\text { make a judgement }\end{array}$ \\
\hline $\begin{array}{l}\text { Blinding of outcome assessment (detection } \\
\text { bias) } \\
\text { All outcomes }\end{array}$ & Unclear risk & $\begin{array}{l}\text { Quote: “...double blind controlled trial...” } \\
\text { Comment: insufficient details available to } \\
\text { make a judgement }\end{array}$ \\
\hline $\begin{array}{l}\text { Incomplete outcome data (attrition bias) } \\
\text { All outcomes }\end{array}$ & Unclear risk & $\begin{array}{l}\text { \% Missing: N/A } \\
\text { Reasons/details: N/A } \\
\text { Comment: the following were not re- } \\
\text { ported: number of participants ran- } \\
\text { domised, number of participants ran- } \\
\text { domised to each group, amount of miss- } \\
\text { ing data for each group, reasons for missing } \\
\text { data in each group }\end{array}$ \\
\hline Selective reporting (reporting bias) & High risk & $\begin{array}{l}\text { Comment: LRTI, which meets the criteria } \\
\text { of this review, may have been measured and } \\
\text { reported; but it is unclear how respiratory } \\
\text { illness was defined in this study. Serum zinc } \\
\text { concentration was measured, but is not re- } \\
\text { ported in a way that can be meta-analysed }\end{array}$ \\
\hline Other bias & Low risk & Comment: appears to be free of other bias \\
\hline
\end{tabular}


Methods

Participants
CRCT?: IRCT; Cross-over?: non-cross-over

Country: Papua New Guinea; Setting: north Wosera District of East Sepik Province, in northwestern Papua New Guinea; Urbanicity: rural

Inclusion criteria: planning to reside in the Wosera for at least 1 year; no apparent chronic or debilitating condition

Exclusion criteria: signs of severe zinc deficiency or malnutrition

Baseline characteristics

Avg age (mo): N/A; Min age (mo): 6; Max age (mo): 60; \% Female: 53

Avg HAZ: -1.9; Stunting: both - separate data not given; Avg height (cm): N/A; Avg zinc concentration $(\mu \mathrm{g} / \mathrm{dL}): 71$

Total N: 274; Group 1 N: 136; Group 2 N: 138
Outcomes

\section{Group 1: zinc}

Formulation: pill/tablet; Compound: gluconate; Frequency: 6 days/wk; Duration (mo) : 11.5; Dose (mg): 10; Co-intervention(s): N/A

Group 2: no zinc

Placebo given; Co-intervention(s): N/A

All-cause mortality, mortality due to malaria, prevalence of all-cause diarrhoea, incidence of malaria, height, weight-to-height ratio, serum or plasma zinc concentration, prevalence of zinc deficiency, blood haemoglobin concentration, prevalence of anaemia Time point (wk): 46

Notes

Risk of bias

\begin{tabular}{|c|c|c|}
\hline Bias & Authors' judgement & Support for judgement \\
\hline $\begin{array}{l}\text { Random sequence generation (selection } \\
\text { bias) }\end{array}$ & Low risk & $\begin{array}{l}\text { Quote: "Children within these strata were } \\
\text { individually allocated to computer-gener- } \\
\text { ated randomly permuted 4-person blocks } \\
\text { of two codes, Zn or placebo (PL)." } \\
\text { Comment: N/A }\end{array}$ \\
\hline
\end{tabular}

Allocation concealment (selection bias) Low risk

Quote: "The tablets were encoded and the assignment held off-site by personnel not involved in the study...The study code was broken after closing the databases following double entry of all data."

Comment: sufficient allocation concealment seems likely

Blinding of participants (performance Low risk bias)

All outcomes
Quote: “...doubleblind placebo-controlled trial...The study code was broken after closing the databases following double entry of all data...Placebos were indistinguishable from the sup- 
Shankar 2000 (Continued)

plements in color, size, or taste..."

Comment: sufficient blinding seems likely

\begin{tabular}{|c|c|c|}
\hline $\begin{array}{l}\text { Blinding of personnel (performance bias) } \\
\text { All outcomes }\end{array}$ & Low risk & $\begin{array}{l}\text { Quote: “...double- } \\
\text { blind placebo-controlled trial...The study } \\
\text { code was broken after closing the databases } \\
\text { following double entry of all data...Place- } \\
\text { bos were indistinguishable from the sup- } \\
\text { plements in color, size, or taste...” } \\
\text { Comment: sufficient blinding seems likely }\end{array}$ \\
\hline
\end{tabular}

Blinding of outcome assessment (detection Low risk

Quote:

“...double-

bias)

All outcomes

blind placebo-controlled trial...The study code was broken after closing the databases following double entry of all data...Placebos were indistinguishable from the supplements in color, size, or taste..."

Comment: sufficient blinding seems likely

Incomplete outcome data (attrition bias) Low risk

\% Missing: 23

All outcomes

Reasons/details: in the zinc group: 19 "migrated", 11 "refused", and 3 "died". In the placebo group: 19 "migrated”, 9 "refused”, and 1 "died"

Comment: reasons for, and amount of, missing data were similar between study groups

\begin{tabular}{|c|c|c|}
\hline Selective reporting (reporting bias) & High risk & $\begin{array}{l}\text { Comment: side effects were measured, but } \\
\text { are not reported in a way that can be meta- } \\
\text { analysed }\end{array}$ \\
\hline Other bias & Low risk & Comment: appears to be free of other bias \\
\hline
\end{tabular}

Silva 2006

Methods

CRCT?: IRCT; Cross-over?: non-cross-over

Participants

Country: Brazil; Setting: São Sebastiāo, Distrito Federal (DF); Urbanicity: unclear Inclusion criteria: N/A

Exclusion criteria: diseased, anaemic with haemoglobin levels lower than $9.0 \mathrm{~g} / \mathrm{dl}$, on medication or receiving supplementation, parasitic disease

Baseline characteristics

Avg age (mo): 23.5; Min age (mo): 12; Max age (mo): 59; \% Female: 56.9

Avg HAZ: -1.9; Stunting: both - separate data not given; Avg height (cm): N/A; Avg zinc concentration $(\mu \mathrm{g} / \mathrm{dL}): 56.1$

Total N: 60; Group 1 N: 30; Group 2 N: 30

Zinc supplementation for preventing mortality, morbidity, and growth failure in children aged 6 months to 12 years of age (Review) 
Silva 2006 (Continued)

\begin{tabular}{|c|c|c|}
\hline Interventions & \multicolumn{2}{|c|}{$\begin{array}{l}\text { Group 1: zinc } \\
\text { Formulation: solution; Compound: sulfate; Frequency: daily; Duration (mo): 4; Dose } \\
(\mathrm{mg}) \text { : 10; Co-intervention(s): } 2 \mathrm{~kg} \text { iron-fortified milk } \\
\text { Group 2: no zinc } \\
\text { Placebo given; Co-intervention(s): } 2 \mathrm{~kg} \text { iron-fortified milk }\end{array}$} \\
\hline Outcomes & \multicolumn{2}{|c|}{$\begin{array}{l}\text { Height, serum or plasma zinc concentration, blood haemoglobin concentration } \\
\text { Time point (wk): } 16\end{array}$} \\
\hline \multicolumn{3}{|l|}{ Notes } \\
\hline \multicolumn{3}{|l|}{ Risk of bias } \\
\hline Bias & Authors' judgement & Support for judgement \\
\hline $\begin{array}{l}\text { Random sequence generation (selection } \\
\text { bias) }\end{array}$ & Unclear risk & $\begin{array}{l}\text { Quote: “...the sample consisted of } 60 \text { indi- } \\
\text { viduals, who were randomly placed in two } \\
\text { groups... The children were placed in either } \\
\text { of two groups according to the supplemen- } \\
\text { tation they received. Of every two moth- } \\
\text { ers or surrogates who allowed their chil- } \\
\text { dren to participate in the study, one child } \\
\text { was assigned to the supplementation group } \\
\text { and another one was placed in the control } \\
\text { group..." } \\
\text { Comment: insufficient details available to } \\
\text { make a judgement as to whether or not an } \\
\text { allocation sequence was generated using a } \\
\text { truly random method }\end{array}$ \\
\hline Allocation concealment (selection bias) & Unclear risk & $\begin{array}{l}\text { Quote: N/A } \\
\text { Comment: insufficient details available to } \\
\text { make a judgement }\end{array}$ \\
\hline $\begin{array}{l}\text { Blinding of participants (performance } \\
\text { bias) } \\
\text { All outcomes }\end{array}$ & Unclear risk & $\begin{array}{l}\text { Quote: "A blinded randomized clinical trial } \\
\text { was carried out...The flask containing zinc } \\
\text { sulfate was labeled S...The flask containing } \\
\text { the syrup was labeled C. The flasks con- } \\
\text { taining placebo and zinc sulfate were iden- } \\
\text { tical and the taste and smell of the solutions } \\
\text { were the same." } \\
\text { Comment: people involved with the study } \\
\text { might have been able to tell which solution } \\
\text { was zinc and which was placebo based on } \\
\text { the different letter labels on the flasks }\end{array}$ \\
\hline $\begin{array}{l}\text { Blinding of personnel (performance bias) } \\
\text { All outcomes }\end{array}$ & Unclear risk & $\begin{array}{l}\text { Quote: “A blinded randomized clinical trial } \\
\text { was carried out...The flask containing zinc }\end{array}$ \\
\hline
\end{tabular}

Zinc supplementation for preventing mortality, morbidity, and growth failure in children aged 6 months to 12 years of age (Review) 


\begin{tabular}{|c|c|c|}
\hline & & $\begin{array}{l}\text { sulfate was labeled S...The flask containing } \\
\text { the syrup was labeled C. The flasks con- } \\
\text { taining placebo and zinc sulfate were iden- } \\
\text { tical and the taste and smell of the solutions } \\
\text { were the same." } \\
\text { Comment: People involved with the study } \\
\text { might have been able to tell which solution } \\
\text { was zinc and which was placebo based on } \\
\text { the different letter labels on the flasks }\end{array}$ \\
\hline $\begin{array}{l}\text { Blinding of outcome assessment (detection } \\
\text { bias) } \\
\text { All outcomes }\end{array}$ & Unclear risk & $\begin{array}{l}\text { Quote: "A blinded randomized clinical trial } \\
\text { was carried out...The flask containing zinc } \\
\text { sulfate was labeled S...The flask containing } \\
\text { the syrup was labeled C. The flasks con- } \\
\text { taining placebo and zinc sulfate were iden- } \\
\text { tical and the taste and smell of the solutions } \\
\text { were the same." } \\
\text { Comment: People involved with the study } \\
\text { might have been able to tell which solution } \\
\text { was zinc and which was placebo based on } \\
\text { the different letter labels on the flasks }\end{array}$ \\
\hline $\begin{array}{l}\text { Incomplete outcome data (attrition bias) } \\
\text { All outcomes }\end{array}$ & Low risk & $\begin{array}{l}\text { \% Missing: } 3 \\
\text { Reasons/details: "In the course of the study, } \\
\text { two children from the supplementation } \\
\text { group withdrew." } \\
\text { Comment: missing data seem too minimal } \\
\text { to impact results }\end{array}$ \\
\hline Selective reporting (reporting bias) & High risk & $\begin{array}{l}\text { Comment: side effects (i.e. "possible gas- } \\
\text { trointestinal symptoms (nausea, vomiting, } \\
\text { diarrhea), and loss of appetite caused by } \\
\text { zinc supplementation") were measured, but } \\
\text { are not reported. The percentage decrease } \\
\text { in the prevalence of anaemia for the placebo } \\
\text { group amounts to less than a single person } \\
\text { decrease, which seems to be an implausi- } \\
\text { ble result. "W/H" is reported, but it is un- } \\
\text { clear whether or not this refers to weight- } \\
\text { for-height or weight-for-age }\end{array}$ \\
\hline Other bias & Low risk & Comment: appears to be free of other bias \\
\hline
\end{tabular}


Methods

Participants

CRCT?: IRCT; Cross-over?: non-cross-over

Country: Belize; Setting: refugee camps Los Flores and Salvapan in Cayo District; Urbanicity: unclear

Inclusion criteria: low/marginal concentrations of both serum vitamin A and zinc Exclusion criteria: fever; serious respiratory infection

Baseline characteristics

Avg age (mo): N/A; Min age (mo): N/A; Max age (mo): N/A; \% Female: N/A

Avg HAZ: N/A; Stunting: both - separate data not given; Avg height $(\mathrm{cm}):$ N/A; Avg zinc concentration $(\mu \mathrm{g} / \mathrm{dL}): 75.2$

Total N: 51; Group 1 N: N/A; Group 2 N: N/A; Group 3 N: N/A; Group 4 N: N/A

Interventions Group 1: zinc

Formulation: solution; Compound: gluconate; Frequency: Weekly; Duration (mo): 6; Dose (mg): 70; Co-intervention(s): N/A

Group 2: no zinc

Placebo given; Co-intervention(s): N/A

Group 3: zinc

Co-intervention(s): $3030 \mathrm{RE}$ vitamin A

Group 4: no zinc

Placebo given; Co-intervention(s): 3030 RE vitamin A

Outcomes

Height, weight, serum or plasma zinc concentration, blood haemoglobin concentration Time point (wk): 24

Notes

- The trial reports contradictory information about the maximum age of eligible study participants. So, the minimum age was between 22 and 28 months, and the maximum age was between 66 and 72 months

- The number of participants randomised to each study group is not reported

Risk of bias

\begin{tabular}{|c|c|c|}
\hline Bias & Authors' judgement & Support for judgement \\
\hline $\begin{array}{l}\text { Random sequence generation (selection } \\
\text { bias) }\end{array}$ & Unclear risk & $\begin{array}{l}\text { Quote: "The children selected were ran- } \\
\text { domly assigned..." } \\
\text { Comment: insufficient details available to } \\
\text { make a judgement as to whether or not an } \\
\text { allocation sequence was generated using a } \\
\text { truly random method }\end{array}$ \\
\hline Allocation concealment (selection bias) & Unclear risk & $\begin{array}{l}\text { Quote: N/A } \\
\text { Comment: insufficient details available to } \\
\text { make a judgement }\end{array}$ \\
\hline $\begin{array}{l}\text { Blinding of participants (performance } \\
\text { bias) } \\
\text { All outcomes }\end{array}$ & Unclear risk & $\begin{array}{l}\text { Quote: N/A } \\
\text { Comment: insufficient details available to } \\
\text { make a judgement }\end{array}$ \\
\hline
\end{tabular}

Zinc supplementation for preventing mortality, morbidity, and growth failure in children aged 6 months to 12 years of age (Review)

Copyright () 2014 The Cochrane Collaboration. Published by John Wiley \& Sons, Ltd. 
Smith 1999 (Continued)

\begin{tabular}{|c|c|c|}
\hline $\begin{array}{l}\text { Blinding of personnel (performance bias) } \\
\text { All outcomes }\end{array}$ & Unclear risk & $\begin{array}{l}\text { Quote: N/A } \\
\text { Comment: insufficient details available to } \\
\text { make a judgement }\end{array}$ \\
\hline $\begin{array}{l}\text { Blinding of outcome assessment (detection } \\
\text { bias) } \\
\text { All outcomes }\end{array}$ & Unclear risk & $\begin{array}{l}\text { Quote: N/A } \\
\text { Comment: insufficient details available to } \\
\text { make a judgement }\end{array}$ \\
\hline $\begin{array}{l}\text { Incomplete outcome data (attrition bias) } \\
\text { All outcomes }\end{array}$ & Low risk & $\begin{array}{l}\text { \% Missing: } 16 \\
\text { Reasons/details: "Because of relocation of } \\
\text { residence and other causes, eight failed to } \\
\text { complete the study..." } \\
\text { Comment: migration was the most com- } \\
\text { mon reason for missing data, and this rea- } \\
\text { son is unlikely to bias results }\end{array}$ \\
\hline Selective reporting (reporting bias) & Unclear risk & $\begin{array}{l}\text { Comment: blood haemoglobin concentra- } \\
\text { tion and height-for-age z score were mea- } \\
\text { sured for the zinc versus vitamin A + zinc } \\
\text { comparison, but are not reported in a way } \\
\text { that can be meta-analysed. No trial proto- } \\
\text { col referenced by the study }\end{array}$ \\
\hline Other bias & Unclear risk & $\begin{array}{l}\text { Comment: "Analysis of pretreatment data } \\
\text { indicated that children who subsequently } \\
\text { received } \mathrm{Zn} \text { supplementation were heav- } \\
\text { ier ( } 1.1 \mathrm{~kg} \text { ) than were non- } \mathrm{Zn} \text {-treated sub- } \\
\text { jects. The effects of these weight differences } \\
\text { were significant variations in...weight-for- } \\
\text { age } \mathrm{Z} \text { score (WAZ)." This baseline dif- } \\
\text { ference could have influenced weight out- } \\
\text { comes, which were reported only as post- } \\
\text { treatment scores, rather than as changes } \\
\text { from baseline }\end{array}$ \\
\hline
\end{tabular}

Soofi 2013

Methods

Participants
CRCT?: CRCT; Cross-over?: non-cross-over

Country: Pakistan; Setting: Bilal Colony and Matiari, Sindh; Urbanicity: mixed Inclusion criteria: randomised at 6 months of age of age

Exclusion criteria: not mentioned

Baseline characteristics

Avg age (mo): 6; Min age (mo): 6; Max age (mo): 6; \% Female: 50\%

Avg HAZ: not given; Stunting: both - separate data not given; Avg height (cm): 64.4;

Avg zinc concentration $(\mu \mathrm{g} / \mathrm{dL}): 84.3$

Total N: 1305; Group 1 N: 659; Group 2 N: 646 
Soofi 2013 (Continued)

\begin{tabular}{|c|c|c|}
\hline Interventions & \multicolumn{2}{|c|}{$\begin{array}{l}\text { Group 1: zinc } \\
\text { Formulation: powder/paste; Compound: gluconate; Frequency: daily; Duration (mo): } \\
\text { 12; Dose (mg): 10; Co-intervention(s): micronutrient powder } \\
\text { Group 2: no zinc } \\
\text { Placebo not given; Co-intervention(s): micronutrient powder }\end{array}$} \\
\hline Outcomes & \multicolumn{2}{|c|}{$\begin{array}{l}\text { All-cause mortality,incidence of all-cause diarrhoea, incidence of severe diarrhoea, preva- } \\
\text { lence of all-cause diarrhoea, incidence of persistent diarrhoea, incidence of LRTI, preva- } \\
\text { lence of LRTI, hospitalisation due to LRTI, prevalence of anaemia, serum ferritin, serum } \\
\text { zinc, blood haemoglobin, prevalence of stunting } \\
\text { Time point (wk): } 52\end{array}$} \\
\hline \multicolumn{3}{|l|}{ Notes } \\
\hline \multicolumn{3}{|l|}{ Risk of bias } \\
\hline Bias & Authors' judgement & Support for judgement \\
\hline $\begin{array}{l}\text { Random sequence generation (selection } \\
\text { bias) }\end{array}$ & Low risk & $\begin{array}{l}\text { Quote: "randomly allocated within urban } \\
\text { and rural strata using computer-generated } \\
\text { random numbers" }\end{array}$ \\
\hline Allocation concealment (selection bias) & Low risk & $\begin{array}{l}\text { Quote: "MNPs were packaged in individ- } \\
\text { ual daily dose sachets which were identical } \\
\text { apart from their colour (Group B=Brown, } \\
\text { Group C=Green). The colour coding used } \\
\text { was known only to the Manager, Genera } \\
\text { Pharmaceuticals, Islamabad and the Chair } \\
\text { of the trial's Data Monitoring Committee } \\
\text { (DMC)“ }\end{array}$ \\
\hline
\end{tabular}

Blinding of participants (performance Low risk bias)

Quote: "The investigators, field and supervisory staff were blinded to the composition of the MNP preparations until after the results of the trial had been presented to the independent DMC.“

Blinding of personnel (performance bias) Low risk All outcomes

Quote: "The investigators, field and supervisory staff were blinded to the composition of the MNP preparations until after the results of the trial had been presented to the independent DMC.“

Blinding of outcome assessment (detection Low risk bias)

Quote: "“All data collectors were provided with refresher training at 6 monthly intervals and rotated between clusters to avoid All outcomes differential interviewer bias across clusters. 
Soofi 2013 (Continued)

\begin{tabular}{l|ll}
$\begin{array}{l}\text { Incomplete outcome data (attrition bias) } \\
\text { All outcomes }\end{array}$ & Low risk & $\begin{array}{l}\text { Quote: "Between } 18 \text { and } 23.9 \text { months of } \\
\text { age there did not appear to be any link } \\
\text { between treatment allocation and missing- } \\
\text { ness. There was evidence to suggest that } \\
\text { children with a high proportion of observed } \\
\text { days with diarrhoea tended to have fewer } \\
\text { days of completed follow-up." } \\
\text { Comment: } 18.6 \% \text { missing, but no differ- } \\
\text { ence between groups }\end{array}$ \\
\hline Selective reporting (reporting bias) & Low risk & $\begin{array}{l}\text { Quote: protocol also includes "serum zinc, } \\
\text { serum retinol, hair zinc, CRP and some im- } \\
\text { mune response parameters" } \\
\text { Comment: key clinical outcomes reported }\end{array}$ \\
\hline Other bias & Low risk & \begin{tabular}{l} 
Comment: appears to be free of other bias \\
\hline
\end{tabular} \\
\hline
\end{tabular}

Tielsch 2006

Methods

CRCT?: CRCT; Cross-over?: non-cross-over

Participants

Country: Nepal; Setting: Sarlahi District in southern Nepal; Urbanicity: rural

Inclusion criteria: N/A

Exclusion criteria: N/A

Baseline characteristics

Avg age (mo): N/A; Min age (mo): 1; Max age (mo): 35; \% Female: 49

Avg HAZ: N/A; Stunting: both - separate data not given; Avg height (cm): N/A; Avg zinc concentration $(\mu \mathrm{g} / \mathrm{dL})$ : N/A

Total N: 49,205; Group 1 N: 16,426; Group 2 N: 15,700; Group 3 N: 8951; Group 4 N: 8128

Total clusters: 425; Group 1 clusters: 107; Group 2 clusters: 106; Group 3 clusters: 107; Group 4 clusters: 105

Interventions

Group 1: zinc

Formulation: pill/tablet; Compound: sulfate; Frequency: daily; Duration (mo): N/A; Dose (mg): $5 \mathrm{mg}$ to children < 1 year old; $10 \mathrm{mg}$ to children 1 year of age or older; Cointervention(s): N/A

Group 2: no zinc

Placebo given; Co-intervention(s): N/A

Group 3: zinc

Co-intervention(s): $6.25 \mathrm{mg}$ iron and $25 \mu \mathrm{g}$ folic acid to children $<1$ year old; $12.5 \mathrm{mg}$ iron and $50 \mu \mathrm{g}$ folic acid to children 1 year of age or older

Group 4: no zinc

Placebo given; Co-intervention(s): $6.25 \mathrm{mg}$ iron and $25 \mu \mathrm{g}$ folic acid to children $<1$ year old; $12.5 \mathrm{mg}$ iron and $50 \mu \mathrm{g}$ folic acid to children 1 year of age or older

Zinc supplementation for preventing mortality, morbidity, and growth failure in children aged 6 months to 12 years of age (Review) 
Tielsch 2006 (Continued)

Outcomes

All-cause mortality, serum or plasma zinc concentration, prevalence of zinc deficiency, serum or plasma copper concentration, prevalence of copper deficiency

Time point (wk): 52 (biochemical outcomes)

Notes

- Greater than 50\% of participants analysed in the Tielsch et al Lancet 2006; 367: 14452 article are within the eligible age range for this review. So, baseline demographic data and most outcome data from this trial report are included in this review. However, this Tielsch et al 2006 trial report provides some outcome data for subsets of participants that potentially are not eligible for this review based on age; these data for potentially ineligible participant subsets are not included in this review. Less than $51 \%$ of participants analysed in the Tielsch et al Lancet 2007; 370: 1230-39 article are within the eligible age range for this review. However, this Tielsch et al 2007 trial report provides data on some outcomes for subsets of participants that are eligible for this review based on age; these data for eligible participant subsets are included in this review

- "On the basis of recommendations from the data and safety monitoring board, the arms of the trial in which children were given iron and folic acid were stopped in November, 2003, and children in those sectors were randomly reassigned to either placebo or zinc." The Tielsch et al 2007 trial report analyses a "merged set" of data, including: (a) children originally assigned to zinc or placebo, and (b) those who originally received iron/folic $\mathrm{acid} / \mathrm{zinc}$ or iron/folic acid, and were then reassigned to zinc or placebo. To avoid a unit of analysis error, data from (a) the iron/folic acid/zinc and iron/folic acid groups reported in Tielsch et al 2006, and (b) the zinc and placebo groups reported in Tielsch et al 2007, are not included in the same meta-analysis

- The numbers of participants listed in this table as being randomised to the zinc and placebo groups: (a) Do not include those from the iron/folic acid/zinc and iron/folic acid groups who were switched to zinc or placebo, but (b) Do include "7432 children from sectors originally assigned to iron and folic acid or to iron and folic acid with zinc who were not eligible for the original allocation, but were subsequently randomly assigned to either placebo or zinc."

- Though some trial reports of this study report that 426 sectors were randomised, the Tielsch et al 2007 trial report, which is the only trial report that provides data on the number of sectors randomised to each study group, states that 425 sectors were randomised

- "All children older than 6 months also received vitamin A as part of a national programme or, if missed, by study staff: those aged 12 months or older were given 200000 IU of vitamin A every 6 months and those aged 6-12 months were given 100000 IU.”

- "Children were discharged from the study when they reached 36 months of age", and most children were less than 24 months of age at baseline; the duration of supplementation seemed to be at least 12 months for most participants

Risk of bias

Bias

Authors' judgement

Support for judgement

Random sequence generation (selection Low risk bias)

Quote: "Sectors were randomly assigned to treatment groups in blocks of four...All possible orders of the four treatment groups were written on...paper slips, with roughly

Zinc supplementation for preventing mortality, morbidity, and growth failure in children aged 6 months to 12 years of age (Review) 
Tielsch 2006 (Continued)

equal numbers of slips for each order. One slip was randomly drawn to assign treatment codes to four sectors within a VDC. This continued until all sectors were assigned."

Comment: seems likely to have used a truly random method to generate an allocation sequence

Allocation concealment (selection bias) Low risk
Quote: "One slip was randomly drawn to assign treatment codes to...sectors...This continued until all sectors were assigned. " "The Department of Child and Adolescent Health and Development at WHO, Geneva, Switzerland, kept the treatment assignment codes."

Comment: sufficient allocation concealment seems likely

Blinding of participants (performance Low risk bias)

All outcomes

Blinding of personnel (performance bias) Low risk All outcomes bias)

All outcomes

Incomplete outcome data (attrition bias) Low risk All outcomes trial...Investigators, study staff...were un-
Quote: "We did a...double-masked... trial...participants were unaware of assigned treatments."

Comment: sufficient blinding seems likely

Quote: "We did a...double-masked... aware of assigned treatments."

Comment: sufficient blinding seems likely

Quote: "We did a...double-masked... trial...Investigators, study staff...were unaware of assigned treatments."

Comment: sufficient blinding seems likely

\% Missing: 16

Reasons/details: besides the " 7432 children from sectors originally assigned to iron and folic acid or to iron and folic acid with zinc who were not eligible for the original allocation, but were subsequently randomly assigned to either placebo or zinc", there were 12,133 participants originally assigned to the placebo group, and 12,885 participants originally assigned to the zinc group. Among these 12,133 placebo group participants: 595 refused, 917 were lost or moved, and 224 died. Among these 12,885 zinc group participants: 947 refused, 916 were lost or moved, and 225 died. Among 
Tielsch 2006 (Continued)

\begin{tabular}{|c|c|c|}
\hline & & $\begin{array}{l}\text { the } 8128 \text { participants assigned to the iron + } \\
\text { folic acid group: } 952 \text { refused, } 347 \text { moved, } \\
\text { and } 112 \text { died before this group was stopped } \\
\text { in November } 2003 \text {. Among the } 8951 \text { par- } \\
\text { ticipants assigned to the iron + folic acid + } \\
\text { zinc group: } 1186 \text { refused, } 354 \text { moved, and } \\
119 \text { died before this group was stopped in } \\
\text { November } 2003 \\
\text { Comment: reasons for, and amount of, } \\
\text { missing data were similar between the } \\
\text { placebo and zinc groups. Reasons for, and } \\
\text { amount of, missing data were similar be- } \\
\text { tween the iron + folic acid and zinc + iron } \\
+ \text { folic acid groups }\end{array}$ \\
\hline Selective reporting (reporting bias) & Unclear risk & $\begin{array}{l}\text { Comment: serum zinc, blood haemoglo- } \\
\text { bin, serum ferritin, and serum copper } \\
\text { concentrations; prevalence of zinc, iron, } \\
\text { and copper deficiency; and prevalence of } \\
\text { anaemia were reported, but were not pre- } \\
\text { specified in the trial protocol. However all } \\
\text { of these were stated to be secondary, not } \\
\text { primary, outcomes in the trial reports } \\
\text { Protocol identifier: NCT00109551 }\end{array}$ \\
\hline Other bias & Low risk & Comment: appears to be free of other bias \\
\hline
\end{tabular}

Tielsch 2006 (2)

Methods

Participants

Interventions

Outcomes Mortality due to all-cause diarrhoea, mortality due to LRTI, blood haemoglobin concentration, prevalence of anaemia, serum or plasma ferritin concentration, prevalence of iron deficiency

Notes As Tielsch 2006 above

Tupe 2009

Methods

CRCT?: CRCT; Cross-over?: non-cross-over

Participants

Country: India; Setting: Pune City, Maharashtra State, Western India; Urbanicity: urban Inclusion criteria: N/A

Exclusion criteria: current illness such as fever or respiratory or gastrointestinal infection; taking medical treatment; suffered from any illness in the recent past; taking multivitamin

Zinc supplementation for preventing mortality, morbidity, and growth failure in children aged 6 months to 12 years of age (Review)

Copyright (c) 2014 The Cochrane Collaboration. Published by John Wiley \& Sons, Ltd. 
Tupe 2009 (Continued)

mineral supplements

Baseline characteristics

Avg age (mo): 144; Min age (mo): 120; Max age (mo): 155; \% Female: 100

Avg HAZ: -1.3; Stunting: both - separate data not given; Avg height (cm): 142; Avg zinc concentration $(\mu \mathrm{g} / \mathrm{dL}): 59$

Total N: 88; Group 1 N: 44; Group 2 N: 44

Total clusters: 2; Group 1 clusters: 1; Group 2 clusters: 1

Interventions

Group 1: zinc

Formulation: pill/tablet; Compound: unclear; Frequency: 6 days/wk; Duration (mo): 2. 5; Dose (mg): 16.6; Co-intervention(s): N/A

Group 2: no zinc

Placebo not given; Co-intervention(s): N/A

Outcomes

Height, weight, serum or plasma zinc concentration, prevalence of zinc deficiency, blood haemoglobin concentration, prevalence of anaemia, serum or plasma ferritin concentration

Time point (wk): 10

Notes

- In addition to the study groups mentioned in this table, there was a group of participants who received "zinc- and micronutrient-rich food supplements." Baseline characteristics reported in this table are weighted averages of all groups except the "zinc- and micronutrient-rich food supplements" group, since this group is not included in any meta-analyses in this review

- This trial included some participants who were 13 years of age and older at baseline. However, baseline characteristics reported in this table were calculated based on data from participants less than 13 years of age. Data on all outcomes (except for prevalence of zinc deficiency and prevalence of anaemia) were also calculated based on data from participants less than 13 years of age. Even though zinc deficiency and anaemia prevalence are partially based on data from participants older than 13 years, the average age of participants analysed for these outcomes is less than 13 years

- "Ayurvedic zinc tablet (jasad bhasma) was chosen as a natural elemental zinc supplement... Tablets containing $20 \mathrm{mg}$ of jasad bhasma of a standard ayurvedic company were procured. Analysis of the jasad tablet in our laboratory indicated that each tablet contained $16.6 \mathrm{mg}$ elemental zinc, $0.74 \mathrm{mg}$ iron, and the remaining part as starch." We deemed the $0.74 \mathrm{mg}$ iron to be too insignificant to have any effect on outcomes in this trial

Risk of bias

Bias

Authors' judgement

Support for judgement

Random sequence generation (selection Low risk bias)

Quote: In response to a request for further details on sequence generation, an author of this study explained that, "Three classes of 7 th standard girls from the schools were randomly assigned to either of the two intervention groups or control group by the statistician", and that a "Lottery method

Zinc supplementation for preventing mortality, morbidity, and growth failure in children aged 6 months to 12 years of age (Review)

Copyright @ 2014 The Cochrane Collaboration. Published by John Wiley \& Sons, Ltd. 
Tupe 2009 (Continued)

\begin{tabular}{|c|c|c|}
\hline & & $\begin{array}{l}\text { was used to allocate a class to any one of } \\
\text { the three treatments." } \\
\text { Comment: it seems likely that the alloca- } \\
\text { tion sequence was generated using a truly } \\
\text { random method }\end{array}$ \\
\hline Allocation concealment (selection bias) & Unclear risk & $\begin{array}{l}\text { Quote: N/A } \\
\text { Comment: insufficient details available to } \\
\text { make a judgement }\end{array}$ \\
\hline $\begin{array}{l}\text { Blinding of participants (performance } \\
\text { bias) } \\
\text { All outcomes }\end{array}$ & Unclear risk & $\begin{array}{l}\text { Quote: "Control group did not receive } \\
\text { placebo but was unaware of the supple- } \\
\text { mented group." } \\
\text { Comment: it is unclear how measured out- } \\
\text { comes might be influenced by a lack of } \\
\text { placebo }\end{array}$ \\
\hline $\begin{array}{l}\text { Blinding of personnel (performance bias) } \\
\text { All outcomes }\end{array}$ & Unclear risk & $\begin{array}{l}\text { Quote: "Control group did not receive } \\
\text { placebo but was unaware of the supple- } \\
\text { mented group." } \\
\text { Comment: it is unclear how measured out- } \\
\text { comes might be influenced by a lack of } \\
\text { placebo }\end{array}$ \\
\hline $\begin{array}{l}\text { Blinding of outcome assessment (detection } \\
\text { bias) } \\
\text { All outcomes }\end{array}$ & Low risk & $\begin{array}{l}\text { Quote: "The measurement team (both } \\
\text { pretest and posttest observations) was } \\
\text { blinded as to whether each girl was a mem- } \\
\text { ber of one of the intervention groups or the } \\
\text { control group." } \\
\text { Comment: sufficient blinding seems likely }\end{array}$ \\
\hline $\begin{array}{l}\text { Incomplete outcome data (attrition bias) } \\
\text { All outcomes }\end{array}$ & Low risk & $\begin{array}{l}\text { \% Missing: } 6 \\
\text { Reasons/details: in the zinc group: } 1 \text { par- } \\
\text { ticipant was "excluded because of religious } \\
\text { fasting" that she observed during the study } \\
\text { period. In the control group: } 4 \text { participants } \\
\text { were excluded because they were absent on } \\
\text { the day of outcome measurement } \\
\text { Comment: } 6 \% \text { of the randomised partici- } \\
\text { pants eligible for our review had data miss- } \\
\text { ing; this } 6 \% \text { missing figure includes all } \\
\text { groups except the "zinc- and micronutri- } \\
\text { ent-rich food supplements" group, since } \\
\text { this group is not included in any meta-anal- } \\
\text { yses in this review. In addition, this } 6 \% \\
\text { missing figure only includes participants } \\
\text { who were less than } 13 \text { years of age at base- } \\
\text { line. Though it is unclear whether being } \\
\text { absent on the day of testing might bias re- }\end{array}$ \\
\hline
\end{tabular}

Zinc supplementation for preventing mortality, morbidity, and growth failure in children aged 6 months to 12 years of age (Review) 
Tupe 2009 (Continued)

sults, the amount of missing data seems too minimal to impact results

Selective reporting (reporting bias) Unclear risk
Comment: prevalence of zinc deficiency and prevalence of anaemia were reported, but were not pre-specified in the protocol for this study; though the related outcomes of plasma zinc concentration and haemoglobin concentration were pre-specified in the protocol for this study

Other bias

Low risk

Comment: appears to be free of other bias

Uckardes 2009

Methods

Participants
CRCT?: IRCT; Cross-over?: non-cross-over

Country: Turkey; Setting: Ankara; Urbanicity: urban

Inclusion criteria: 3rd grade student

Exclusion criteria: any chronic systemic disease which could affect their neuropsychological performance and zinc metabolism

Baseline characteristics

Avg age (mo): 102; Min age (mo): 89; Max age (mo): 140; \% Female: 50.5

Avg HAZ: N/A; Stunting: unclear; Avg height (cm): 127.45; Avg zinc concentration $(\mu \mathrm{g} / \mathrm{dL}): 119.7$

Total N: 226; Group 1 N: 113; Group 2 N: 113

Interventions

Group 1: zinc

Formulation: solution; Compound: sulfate; Frequency: 5 days/wk; Duration (mo): 2.5;

Dose (mg): 15; Co-intervention(s): N/A

Group 2: no zinc

Placebo given; Co-intervention(s): N/A

Outcomes

Serum or plasma zinc concentration, prevalence of zinc deficiency

Time point (wk): 10

Notes

Risk of bias

\begin{tabular}{|c|c|c|}
\hline Bias & Authors' judgement & Support for judgement \\
\hline $\begin{array}{l}\text { Random sequence generation (selection } \\
\text { bias) }\end{array}$ & Unclear risk & $\begin{array}{l}\text { Quote: "Children in each class were ran- } \\
\text { domized to one of the research groups." } \\
\text { "Randomization was made simply by di- } \\
\text { viding the class student list into two as } \\
\text { study and control groups." } \\
\text { Comment: insufficient details available to }\end{array}$ \\
\hline
\end{tabular}


Uckardes 2009 (Continued)

make a judgement as to whether or not an allocation sequence was generated using a truly random method

Allocation concealment (selection bias) Unclear risk

Blinding of participants (performance Low risk bias)

All outcomes
Quote: N/A

Comment: insufficient details available to make a judgement

Quote:

"Dou-

ble-blind...placebo controlled trial." "The placebo was also manufactured by the company with same appearance."

Comment: sufficient blinding seems likely

Blinding of personnel (performance bias) Low risk All outcomes

Quote:

"Double-blind... placebo controlled trial...The investigators and teachers were blind until the end of the analysis." " Zinc and placebo syrups were given by the teachers at school..." So, the teachers were the providers of the syrups. ) "The placebo was also manufactured by the company with same appearance."

Comment: sufficient blinding seems likely

Blinding of outcome assessment (detection Low risk bias)

All outcomes

Quote:

"Double-blind... placebo controlled trial... The investigators. ..were blind until the end of the analysis. " "The placebo was also manufactured by the company with same appearance."

Comment: sufficient blinding seems likely

\% Missing: 4

Reasons/details: "Four children from the zinc group and four from the placebo group left the study because family moved to another district $(\mathrm{n}=4)$, school absenteeism $(\mathrm{n}=2)$ and vomiting $(\mathrm{n}=2)$."

Comment: missing data seem too minimal to impact results

Selective reporting (reporting bias)

Unclear risk
Comment: though side effects "were monitored by teachers daily at school", "side effects were not collected numerically from all subjects" and "only the teachers' of 2 classes (45 case, 45 placebo) had documented data." No trial protocol referenced by the study 
Uckardes 2009 (Continued)

Other bias

Unclear risk
Comment: "Serum zinc level was measured...Caloric spectrophotometery was used instead of atomic absorption spectrophotometer due to the limited budget of the study. This method may not be as sensitive as atomic absorption spectrophotometery for measuring serum zinc levels or there may be a systematic error in our chemical methodology. Although we could not detect any children with zinc deficiency in our participants most probably due to the methodology, other studies from our region demonstrate a prevalence of zinc deficiency around $20 \%$." Thus, an insensitive instrument for measuring prevalence of zinc deficiency may have been used, and this could have lead to an under-estimation of the number of participants with zinc deficiency and/or the effect of zinc supplementation on zinc deficiency prevalence

Udomkesmalee 1992

Methods

Participants
CRCT?: IRCT; Cross-over?: non-cross-over

Country: Thailand; Setting: Pana District, Ubon Province, Northeast Thailand; Urbanicity: rural

Inclusion criteria: serum concentration of retinol $<1.05 \mu \mathrm{mol} / \mathrm{L}$; serum concentration of zinc $<12.2 \mu \mathrm{mol} / \mathrm{L}$

Exclusion criteria: N/A

Baseline characteristics

Avg age (mo): 112; Min age (mo): 72; Max age (mo): 156; \% Female: 42

Avg HAZ: N/A; Stunting: both - separate data not given; Avg height $(\mathrm{cm}):$ N/A; Avg zinc concentration $(\mu \mathrm{g} / \mathrm{dL}): 85.8$

Total N: 133; Group 1 N: 33; Group 2 N: 35; Group 3 N: 32; Group 4 N: 33
Group 1: zinc

Formulation: capsule; Compound: gluconate; Frequency: 5 days/wk; Duration (mo): 6; Dose (mg): 25; Co-intervention(s): N/A

Group 2: no zinc

Placebo given; Co-intervention(s): N/A

Group 3: zinc

Co-intervention(s): $1500 \mathrm{RE}$ vitamin A per day

Group 4: no zinc

Placebo given; Co-intervention(s): 1500 RE vitamin A per day 
Udomkesmalee 1992 (Continued)

Notes

Risk of bias

\begin{tabular}{lll}
\hline Bias & Authors' judgement & Support for judgement \\
\hline $\begin{array}{l}\text { Random sequence generation (selection } \\
\text { bias) }\end{array}$ & Unclear risk & $\begin{array}{l}\text { Quote: “They were then randomly as- } \\
\text { signed...” } \\
\text { Comment: insufficient details available to } \\
\text { make a judgement as to whether or not an } \\
\text { allocation sequence was generated using a } \\
\text { truly random method }\end{array}$ \\
\hline
\end{tabular}

Allocation concealment (selection bias) Unclear risk

Quote: "The capsule code was revealed after all analyses were completed."

Comment: despite this statement, the method of allocation concealment is not described in sufficient detail to allow a definite judgement

Blinding of participants (performance Low risk bias)

Quote: “...double-blind study...All supplementary capsules were similar in appear-

All outcomes ance... The capsule code was revealed after all analyses were completed."

Comment: sufficient blinding seems likely

Blinding of personnel (performance bias) Low risk All outcomes

Quote: “...double-blind study...All supplementary capsules were similar in appearance... The capsule code was revealed after all analyses were completed."

Comment: sufficient blinding seems likely

Blinding of outcome assessment (detection Low risk bias)

All outcomes

Quote: “...double-blind study...All supplementary capsules were similar in appearance... The capsule code was revealed after all analyses were completed."

Comment: sufficient blinding seems likely

Incomplete outcome data (attrition bias) Low risk

\% Missing: 5

All outcomes

Reasons/details: "One subject withdrew toward the end of study period; six subjects were identified with thalassemia according to abnormal blood cell morphology."

Comment: missing data seem too minimal to impact results 
Udomkesmalee 1992 (Continued)

\begin{tabular}{l|l|l}
\hline Selective reporting (reporting bias) & High risk & $\begin{array}{l}\text { Comment: height and weight were mea- } \\
\text { sured, but are not reported in a way that can } \\
\text { be meta-analysed. Prevalence of anaemia } \\
\text { may have been measured as an outcome, } \\
\text { but is not reported in a way that can be } \\
\text { meta-analysed }\end{array}$ \\
\hline Other bias & Low risk & Comment: appears to be free of other bias \\
\hline
\end{tabular}

Udomkesmalee 1992 (2)

\begin{tabular}{l|l}
\hline Methods & \\
\hline Participants & \\
\hline Interventions & \\
\hline Outcomes & Serum or plasma zinc concentration \\
\hline Notes & As Udomkesmalee 1992 above \\
\hline
\end{tabular}

Umeta 2000

\begin{tabular}{|c|c|}
\hline Methods & CRCT?: IRCT; Cross-over?: non-cross-over \\
\hline Participants & $\begin{array}{l}\text { Country: Ethiopia; Setting: Dodota Sire district, Arsi zone, central Ethiopia; Urbanicity: } \\
\text { rural } \\
\text { Inclusion criteria: apparently healthy; looked well; exclusively breastfed for the first } 4 \\
\text { months of life; free from intestinal parasites } \\
\text { Exclusion criteria: N/A } \\
\text { Baseline characteristics } \\
\text { Avg age (mo): } 9.4 \text {; Min age (mo): 6; Max age (mo): 12; \% Female: } 50 \\
\text { Avg HAZ: }-1.7 \text {; Stunting: both - separate data given; Avg height }(\mathrm{cm}): 67.2 \text {; Avg zinc } \\
\text { concentration ( } \mu \mathrm{g} / \mathrm{dL}) \text { : N/A } \\
\text { Total N: } 200 \text {; Group } 1 \mathrm{~N}: 100 \text {; Group } 2 \mathrm{~N}: 100\end{array}$ \\
\hline Interventions & $\begin{array}{l}\text { Group 1: zinc } \\
\text { Formulation: solution; Compound: sulfate; Frequency: } 6 \text { days/wk; Duration (mo): 6; } \\
\text { Dose (mg): } 10 \text {; Co-intervention(s): N/A } \\
\text { Group 2: no zinc } \\
\text { Placebo given; Co-intervention(s): N/A }\end{array}$ \\
\hline Outcomes & $\begin{array}{l}\text { Incidence of all-cause diarrhoea, height, weight, weight-to-height ratio, serum or plasma } \\
\text { zinc concentration } \\
\text { Time point (wk): } 24\end{array}$ \\
\hline
\end{tabular}

Notes

Zinc supplementation for preventing mortality, morbidity, and growth failure in children aged 6 months to 12 years of age (Review) 
Umeta 2000 (Continued)

Risk of bias

\begin{tabular}{|c|c|c|}
\hline Bias & Authors' judgement & Support for judgement \\
\hline $\begin{array}{l}\text { Random sequence generation (selection } \\
\text { bias) }\end{array}$ & Unclear risk & $\begin{array}{l}\text { Quote: Participants were "randomly as- } \\
\text { signed to receive the zinc supplement or } \\
\text { placebo." } \\
\text { Comment: insufficient details available to } \\
\text { make a judgement as to whether or not an } \\
\text { allocation sequence was generated using a } \\
\text { truly random method }\end{array}$ \\
\hline Allocation concealment (selection bias) & Unclear risk & $\begin{array}{l}\text { Quote: N/A } \\
\text { Comment: insufficient details available to } \\
\text { make a judgement }\end{array}$ \\
\hline $\begin{array}{l}\text { Blinding of participants (performance } \\
\text { bias) } \\
\text { All outcomes }\end{array}$ & Low risk & $\begin{array}{l}\text { Quote: “...double-blind, placebo-con- } \\
\text { trolled trial...The supplement and placebo } \\
\text { were indistinguishable in colour and the } \\
\text { slight metallic taste of the supplement was } \\
\text { acceptable to the infants." } \\
\text { Comment: the "slight metallic taste of the } \\
\text { supplement" does not seem likely to influ- } \\
\text { ence outcomes. Sufficient blinding seems } \\
\text { likely }\end{array}$ \\
\hline $\begin{array}{l}\text { Blinding of personnel (performance bias) } \\
\text { All outcomes }\end{array}$ & Low risk & $\begin{array}{l}\text { Quote: “...double-blind, placebo-con- } \\
\text { trolled trial... The supplement and placebo } \\
\text { were indistinguishable in colour and the } \\
\text { slight metallic taste of the supplement was } \\
\text { acceptable to the infants...Neither the field } \\
\text { assistants nor the investigator knew the } \\
\text { codes. The codes were revealed only after } \\
\text { the study was completed and the data anal- } \\
\text { ysis was finalised." } \\
\text { Comment: sufficient blinding seems likely }\end{array}$ \\
\hline $\begin{array}{l}\text { Blinding of outcome assessment (detection } \\
\text { bias) } \\
\text { All outcomes }\end{array}$ & Low risk & $\begin{array}{l}\text { Quote: "...double-blind, placebo-con- } \\
\text { trolled trial...The supplement and placebo } \\
\text { were indistinguishable in colour and the } \\
\text { slight metallic taste of the supplement was } \\
\text { acceptable to the infants...Neither the field } \\
\text { assistants nor the investigator knew the } \\
\text { codes. The codes were revealed only after } \\
\text { the study was completed and the data anal- } \\
\text { ysis was finalised." } \\
\text { Comment: sufficient blinding seems likely }\end{array}$ \\
\hline
\end{tabular}

Zinc supplementation for preventing mortality, morbidity, and growth failure in children aged 6 months to 12 years of age (Review) 
Umeta 2000 (Continued)

\begin{tabular}{|c|c|c|}
\hline $\begin{array}{l}\text { Incomplete outcome data (attrition bias) } \\
\text { All outcomes }\end{array}$ & Low risk & $\begin{array}{l}\text { \% Missing: } 8 \\
\text { Reasons/details: N/A } \\
\text { Comment: no reasons for dropout were re- } \\
\text { ported. However, the same amount of data } \\
\text { was missing from the zinc group and the } \\
\text { placebo group, and missing data seem too } \\
\text { minimal to impact results }\end{array}$ \\
\hline Selective reporting (reporting bias) & Unclear risk & $\begin{array}{l}\text { Comment: no trial protocol referenced by } \\
\text { the study }\end{array}$ \\
\hline Other bias & Low risk & Comment: appears to be free of other bias \\
\hline
\end{tabular}

\section{Vakili 2009}

Methods

CRCT?: IRCT; Cross-over?: non-cross-over

Participants peri-urban

Inclusion criteria: free of chronic diseases, such as sickle cell disease or protein-energy malnutrition

Exclusion criteria: N/A

Baseline characteristics

Avg age (mo): 93.4; Min age (mo): 78; Max age (mo): 120; \% Female: 50

Avg HAZ: N/A; Stunting: unclear; Avg height $(\mathrm{cm})$ : N/A; Avg zinc concentration $(\mu \mathrm{g} /$ $\mathrm{dL}): \mathrm{N} / \mathrm{A}$

Total N: 200; Group 1 N: 100; Group 2 N: 100

Interventions Group 1: zinc

Formulation: pill/tablet; Compound: sulfate; Frequency: 6 days/wk; Duration (mo): 5;

Dose (mg): 10; Co-intervention(s): N/A

Group 2: no zinc

Placebo given; Co-intervention(s): N/A

No outcomes of interest reported in a way that can be meta-analysed

Notes

Risk of bias

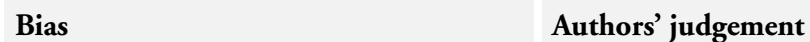

Random sequence generation (selection Unclear risk bias)

\section{Support for judgement}

Quote: "The study was a randomized...intervention trial...A total of 200 children...were randomly assigned..." Comment: insufficient details available to make a judgement as to whether or not an allocation sequence was generated using a 
truly random method

\begin{tabular}{|c|c|c|}
\hline Allocation concealment (selection bias) & Unclear risk & $\begin{array}{l}\text { Quote: N/A } \\
\text { Comment: insufficient details available to } \\
\text { make a judgement }\end{array}$ \\
\hline $\begin{array}{l}\text { Blinding of participants (performance } \\
\text { bias) } \\
\text { All outcomes }\end{array}$ & Unclear risk & $\begin{array}{l}\text { Quote: "The study was a...double- } \\
\text { blind...intervention trial..." } \\
\text { Comment: insufficient details available to } \\
\text { make a judgement }\end{array}$ \\
\hline $\begin{array}{l}\text { Blinding of personnel (performance bias) } \\
\text { All outcomes }\end{array}$ & Unclear risk & $\begin{array}{l}\text { Quote: "The study was a...double- } \\
\text { blind...intervention trial..." } \\
\text { Comment: insufficient details available to } \\
\text { make a judgement }\end{array}$ \\
\hline $\begin{array}{l}\text { Blinding of outcome assessment (detection } \\
\text { bias) } \\
\text { All outcomes }\end{array}$ & Unclear risk & $\begin{array}{l}\text { Quote: "The study was a...double- } \\
\text { blind...intervention trial..." } \\
\text { Comment: insufficient details available to } \\
\text { make a judgement }\end{array}$ \\
\hline $\begin{array}{l}\text { Incomplete outcome data (attrition bias) } \\
\text { All outcomes }\end{array}$ & Low risk & $\begin{array}{l}\text { \% Missing: } 0 \\
\text { Reasons/details: N/A } \\
\text { Comment: N/A }\end{array}$ \\
\hline Selective reporting (reporting bias) & Unclear risk & $\begin{array}{l}\text { Comment: no trial protocol referenced by } \\
\text { the study }\end{array}$ \\
\hline Other bias & Low risk & Comment: appears to be free of other bias \\
\hline
\end{tabular}

Veenemans 2011

\begin{tabular}{ll}
\hline Methods & CRCT?: IRCT; Cross-over?: non-cross-over \\
\hline Participants & $\begin{array}{l}\text { Country: Tanzania; Setting: Segera and Kwedizinga wards in Handeni District of North- } \\
\text { ern Tanzania; Urbanicity: rural } \\
\text { Inclusion criteria: N/A }\end{array}$ \\
$\begin{array}{l}\text { Exclusion criteria: height-for-age z-score > -1.5 SD; weight-for-height z-score <-3 SD; } \\
\text { haemoglobin concentration < 70 g/L; unlikely to remain permanently resident or comply } \\
\text { with interventions; signs of severe or chronic disease } \\
\text { Baseline characteristics } \\
\text { Avg age (mo): 32.5; Min age (mo): 6; Max age (mo): 60; \% Female:51 } \\
\text { Avg HAZ: -2.43; Stunting: both - separate data not given; Avg height (cm): N/A; Avg } \\
\text { zinc concentration ( } \mu \text { g/dL): N/A } \\
\text { Total N: 612; Group 1 N: 153; Group 2 N: 153; Group 3 N: 151; Group 4 N: 155 }\end{array}$ \\
\hline $\begin{array}{l}\text { Group 1: zinc } \\
\text { Formulation: capsule; Compound: gluconate; Frequency: daily; Duration (mo): } 11 ; \text { Dose }\end{array}$
\end{tabular}


Veenemans 2011 (Continued)

(mg): 10; Co-intervention(s): N/A

Group 2: no zinc

Placebo given; Co-intervention(s): N/A

Group 3: zinc

Co-intervention(s): multi-nutrients (including iron)

Group 4: no zinc

Placebo given; Co-intervention(s): multi-nutrients (including iron)

Outcomes

All-cause mortality, all-cause hospitalisation, incidence of all-cause diarrhoea, incidence of LRTI, incidence of malaria, serum or plasma zinc concentration, prevalence of zinc deficiency, blood haemoglobin concentration, prevalence of anaemia, serum or plasma ferritin concentration, prevalence of iron deficiency

Time point (wk): 36 (biochemical outcomes), 47.3 (morbidity and mortality outcomes)

Notes

- Participants were enrolled between February and August 2008, and "Supplementation and follow-up continued for all children until 12 March 2009, when the trial was stopped.

"The primary analysis of malaria episodes had a median follow-up duration of 331 days

- "Those with Plasmodium infection at baseline were treated with artemether-lumefantrine."

\section{Risk of bias}

Bias

Random sequence generation (selection Low risk bias)
Authors' judgement
Support for judgement

Quote: "We used stratified block randomisation to allocate interventions. A colleague not otherwise involved in the trial used tables with random numbers to generate the allocation sequence consisting of randomly permuted blocks with random size (4 or 8) within each of six strata defined by Plasmodium infection (yes/no infected) and age class (6-17 months, 18-35 months, and 36-60 months)."

Comment: N/A

Quote: "A colleague not otherwise involved in the trial used tables with random numbers to generate the allocation sequence... Interventions were indicated by colour code on paper slips in opaque, consecutively numbered envelopes that were prepared in advance, in excess of the expected number required... This code was not revealed to researchers, field staff, or participants, who therefore did not know who received what intervention...At the end of each screening day, when eligibility had been fully established, children 
Veenemans 2011 (Continued)

\begin{tabular}{|l|l|} 
& were individually allocated in order of their \\
screening number to intervention groups \\
by drawing successive envelopes from a box \\
corresponding to the infection- and age- \\
specific stratum for that child. The number \\
of the envelope was then recorded on a list \\
before the envelope was opened." \\
Comment: indicates central randomisation \\
(i.e. randomisation by someone not in- \\
volved with enrolling patients) and sequen- \\
tially numbered, opaque, sealed envelopes \\
to conceal allocation
\end{tabular}

Blinding of participants (performance Low risk bias)

All outcomes
Quote: "Intervention group was indicated by colour code, but neither participants...knew who received what intervention...This code was not revealed to...participants, who therefore did not know who received what intervention...All types of powder had similar appearance, smell, and taste...The randomisation code was not revealed to...participants until data collection was completed and the database had been finalised and sent to the Trial Oversight Committee."

Comment: sufficient blinding seems likely

Blinding of personnel (performance bias) Low risk

All outcomes

Quote: “Intervention group was indicated by colour code, but neither...nor field staff knew who received what intervention... This code was not revealed to...field staff... who therefore did not know who received what intervention...All types of powder had similar appearance, smell, and taste...The randomisation code was not revealed to...field workers...until data collection was completed and the database had been finalised and sent to the Trial Oversight Committee."

Comment: sufficient blinding seems likely

Blinding of outcome assessment (detection Low risk bias)

All outcomes
Quote: “Intervention group was indicated by colour code, but neither... researchers, nor... knew who received what intervention...This code was not revealed to researchers..., who therefore did not know who received what intervention...All types of powder had similar appearance, smell, and taste...The randomisation code was 
Veenemans 2011 (Continued)

not revealed to researchers... until data collection was completed and the database had been finalised and sent to the Trial Oversight Committee... It should be noted also that the clinical outcome assessors were blinded to what intervention had been assigned to individual children."

Comment: sufficient blinding seems likely

Incomplete outcome data (attrition bias) Low risk All outcomes

\section{\% Missing: 3}

Reasons/details: in the zinc group: 5 participants emigrated from the study area, and 1 was "withdrawn by parents." In the placebo group: 4 participants emigrated from the study area. In the multi-nutrients with zinc group, 3 participants emigrated from the study area, 1 was "withdrawn by parents", and 1 died. In the multi-nutrients without zinc group, 3 participants emigrated from the study area and 2 died

Comment: reasons for, and amount of, missing data were similar between study groups. Migration was the most common reason for missing data, and this reason is unlikely to bias results. Missing data seem too minimal to impact results

Comment: anthropometric indices, including height-for-age z-score, were prespecified as a secondary outcome in the protocol for this study and were measured, but are not reported as outcomes. Hospitalisations due to malaria were measured, but were not pre-specified in the protocol for this study, and are not reported in a way that can be meta-analysed. Malaria prevalence and LRTI incidence were reported, but were not pre-specified in the protocol for this study

Protocol identifier: NCT00623857

Online web appendix obtained from http: //www.plosmedicine.org/article/ info\%3Adoi\%2F10.1371\%2Fjournal. pmed. 1001125 
Veenemans 2011 (2)

Methods

Participants

Interventions

Outcomes All-cause mortality, all-cause hospitalisation, incidence of all-cause diarrhoea, incidence of LRTI, incidence of malaria, serum or plasma zinc concentration, prevalence of zinc deficiency, blood haemoglobin concentration, prevalence of anaemia, serum or plasma ferritin concentration, prevalence of iron deficiency

Notes As Veenemans 2011 above

Walravens 1983

Methods

Participants
CRCT?: IRCT; Cross-over?: non-cross-over

Country: United States of America; Setting: Denver, Colorado; Urbanicity: urban Inclusion criteria: height-for-age below the 10th percentile on the National Center for Health Statistics grids; nutritional or biochemical evidence of zinc deficiency; products of term pregnancies; birth measurements appropriate for gestation age; 2 or more of the following: calculated dietary zinc intake $<2 / 3$ of the Recommended Dietary Allowance, plasma zinc $<68 \mu \mathrm{g} / \mathrm{dL}$ or hair zinc $<105 \mu \mathrm{g} / \mathrm{g}$

Exclusion criteria: detectable medical reasons for poor growth

Baseline characteristics

Avg age (mo): 50; Min age (mo): 24; Max age (mo): 72; \% Female: 35

Avg HAZ: -2.07; Stunting: both - separate data not given; Avg height (cm): N/A; Avg zinc concentration $(\mu \mathrm{g} / \mathrm{dL}): 72$

Total N: 57; Group 1 N: N/A; Group 2 N: N/A

\begin{tabular}{ll} 
Interventions & $\begin{array}{l}\text { Group 1: zinc } \\
\text { Formulation: solution; Compound: sulfate; Frequency: Twice daily; Duration (mo): } 12 ; \\
\text { Dose (mg): 5; Co-intervention(s): N/A } \\
\text { Group 2: no zinc } \\
\text { Placebo given; Co-intervention(s): N/A }\end{array}$ \\
\hline Outcomes & $\begin{array}{l}\text { Height, weight, weight-to-height ratio, serum or plasma zinc concentration, serum or } \\
\text { plasma copper concentration } \\
\text { Time point (wk): } 52\end{array}$ \\
\hline Notes & $\begin{array}{l}\text { This was a "pair-matched" study, and at the end of the study, 20 participants remained } \\
\text { in the zinc group and } 20 \text { participants in the placebo group. So, there might have been } \\
\text { approximately equal numbers of participants randomised to the zinc group and the } \\
\text { placebo group, but the exact number of participants randomised to each group was not } \\
\text { reported }\end{array}$
\end{tabular}

Risk of bias

Bias

Authors' judgement

Support for judgement 
Walravens 1983 (Continued)

\begin{tabular}{|c|c|c|}
\hline $\begin{array}{l}\text { Random sequence generation (selection } \\
\text { bias) }\end{array}$ & Unclear risk & $\begin{array}{l}\text { Quote: "These subjects were pair-matched } \\
\text { as closely as possible...The first member of } \\
\text { a pair was assigned randomly to either the } \\
\text { zinc supplement or a placebo." } \\
\text { Comment: insufficient details available to } \\
\text { make a judgement as to whether or not an } \\
\text { allocation sequence was generated using a } \\
\text { truly random method }\end{array}$ \\
\hline
\end{tabular}

Allocation concealment (selection bias) Low risk

Quote: "These subjects were pair-matched as closely as possible...by one of the investigators who was not involved with the clinical management of the children, and had no knowledge of the progress of the participants during the course of treatment period. The first member of a pair was assigned randomly to either the zinc supplement or a placebo."

Comment: indicates central randomisation (i.e. randomisation by someone not involved with enrolling patients) to conceal allocation

Blinding of participants (performance Low risk bias)

All outcomes

Quote: “...double blind...study...The two syrups were indistinguishable in appearance and were prepared at the pharmacy of the University of Colorado Medical Center, where the code was kept...Test or control assignment was unknown to the children and their families..."

Comment: sufficient blinding seems likely

Blinding of personnel (performance bias) Low risk

All outcomes

Quote: “...double blind...study...The two syrups were indistinguishable in appearance and were prepared at the pharmacy of the University of Colorado Medical Center, where the code was kept...Test or control assignment was unknown to... the members of the investigating team who were responsible for clinical care, anthropometry, diet, or laboratory analysis."

Comment: sufficient blinding seems likely

Blinding of outcome assessment (detection Low risk bias)

All outcomes

Quote: “...double blind...study...The two syrups were indistinguishable in appearance and were prepared at the pharmacy of the University of Colorado Medical Center, where the code was kept...Test or control assignment was unknown to... 
the members of the investigating team who were responsible for clinical care, anthropometry, diet, or laboratory analysis."

Comment: sufficient blinding seems likely

\begin{tabular}{l|l}
$\begin{array}{l}\text { Incomplete outcome data (attrition bias) } \\
\text { All outcomes }\end{array}$ & Unclear risk \\
& $\begin{array}{l}\text { \% Missing: } 30 \\
\text { Reasons/details: "Of the } 17(30 \%) \text { who } \\
\text { failed to complete the study, } 11 \text { moved } \\
\text { from the area and six withdrew." } \\
\text { Comment: a large proportion of the data } \\
\text { is missing and the amount of missing data } \\
\text { was not reported separately for each study } \\
\text { group }\end{array}$
\end{tabular}

\begin{tabular}{l|ll}
\hline Selective reporting (reporting bias) & Unclear risk & $\begin{array}{l}\text { Comment: no trial protocol referenced by } \\
\text { the study }\end{array}$ \\
\hline Other bias & Low risk & Comment: appears to be free of other bias \\
\hline
\end{tabular}

Walravens 1989

\begin{tabular}{|c|c|}
\hline Methods & CRCT?: IRCT; Cross-over?: non-cross-over \\
\hline Participants & $\begin{array}{l}\text { Country: United States of America; Setting: Denver, Colorado; Urbanicity: urban } \\
\text { Inclusion criteria: for children whose initial growth was not in the } 10 \text { lower percentiles: } \\
\text { documented decline of } 20 \text { or more percentiles in weight-for-age resulting in a weight } \\
\text { below the 10th percentile. For children whose initial growth was in the } 10 \text { lower per- } \\
\text { centiles: a decline in weight percentiles; documented decline of } 20 \text { or more percentiles } \\
\text { in weight for height } \\
\text { Exclusion criteria: malabsorption, chronic infections, other known causes of growth } \\
\text { failure, families with previous problems of neglect, disturbed family dynamics, language } \\
\text { barriers precluding adequate communication } \\
\text { Baseline characteristics } \\
\text { Avg age (mo): } 15.2 \text {; Min age (mo): } 8 \text {; Max age (mo): } 27 \text {; } \% \text { Female: } 48 \\
\text { Avg HAZ: }-1.35 \text {; Stunting: unclear; Avg height (cm): } 74.61 \text {; Avg zinc concentration } \\
\text { ( } \mu \text { g/dL): } 70 \\
\text { Total N: N/A; Group } 1 \mathrm{~N} \text { : N/A; Group } 2 \text { N: N/A }\end{array}$ \\
\hline Interventions & $\begin{array}{l}\text { Group 1: zinc } \\
\text { Formulation: solution; Compound: sulfate; Frequency: unclear; Duration (mo): 6; Dose } \\
\text { (mg): 25; Co-intervention(s): N/A } \\
\text { Group 2: no zinc } \\
\text { Placebo given; Co-intervention(s): N/A }\end{array}$ \\
\hline
\end{tabular}

Outcomes

Height, weight, serum or plasma zinc concentration

Time point (wk): 24 
Notes

Risk of bias
Number of participants randomised to each study group was not reported. Instead, the following was reported: " 87 families were approached regarding the zinc supplementation study. The families of 30 infants either refused participation after the introductory screening or refused to continue in the study after starting it. The remaining 57 infants completed the supplementation project...The final matching included 13 male and 12 female pairs and seven unmatched infants." It is unclear how many of the 87 infants approached were randomised to each study group, because it is unclear how many of the 30 infants who refused did so before randomisation versus after randomisation

\begin{tabular}{|c|c|c|}
\hline Bias & Authors' judgement & Support for judgement \\
\hline $\begin{array}{l}\text { Random sequence generation (selection } \\
\text { bias) }\end{array}$ & Unclear risk & $\begin{array}{l}\text { Quote: "Pair matching was done by an in- } \\
\text { vestigator (K.M.H.) not involved in the } \\
\text { clinical management of the children...The } \\
\text { first member of a pair was randomly as- } \\
\text { signed to receive either the zinc supplement } \\
\text { or the placebo." } \\
\text { Comment: insufficient details available to } \\
\text { make a judgement as to whether or not an } \\
\text { allocation sequence was generated using a } \\
\text { truly random method }\end{array}$ \\
\hline Allocation concealment (selection bias) & Unclear risk & $\begin{array}{l}\text { Quote: N/A } \\
\text { Comment: insufficient details available to } \\
\text { make a judgement }\end{array}$ \\
\hline $\begin{array}{l}\text { Blinding of participants (performance } \\
\text { bias) } \\
\text { All outcomes }\end{array}$ & Low risk & $\begin{array}{l}\text { Quote: “...double- } \\
\text { blind, controlled study...The two syrups } \\
\text { were indistinguishable in appearance...Test } \\
\text { or control assignment was unknown to the } \\
\text { families..." } \\
\text { Comment: sufficient blinding seems likely }\end{array}$ \\
\hline $\begin{array}{l}\text { Blinding of personnel (performance bias) } \\
\text { All outcomes }\end{array}$ & Low risk & $\begin{array}{l}\text { Quote: “...double- } \\
\text { blind, controlled study... The two syrups } \\
\text { were indistinguishable in appearance... Test } \\
\text { or control assignment was unknown to the. } \\
\text {..investigators involved in clinical care, an- } \\
\text { thropometry, or dietary analysis." } \\
\text { Comment: sufficient blinding seems likely }\end{array}$ \\
\hline $\begin{array}{l}\text { Blinding of outcome assessment (detection } \\
\text { bias) } \\
\text { All outcomes }\end{array}$ & Low risk & $\begin{array}{l}\text { Quote: “...double- } \\
\text { blind, controlled study...The two syrups } \\
\text { were indistinguishable in appearance... Test } \\
\text { or control assignment was unknown to the. } \\
\text {..investigators involved in clinical care, an- }\end{array}$ \\
\hline
\end{tabular}


Walravens 1989 (Continued)

thropometry, or dietary analysis.”

Comment: sufficient blinding seems likely

\begin{tabular}{|c|c|c|}
\hline $\begin{array}{l}\text { Incomplete outcome data (attrition bias) } \\
\text { All outcomes }\end{array}$ & Unclear risk & $\begin{array}{l}\text { \% Missing: N/A } \\
\text { Reasons/details: "The families of } 30 \text { infants } \\
\text { either refused participation after the intro- } \\
\text { ductory screening or refused to continue in } \\
\text { the study after starting it." } \\
\text { Comment: the following were not re- } \\
\text { ported: number of participants ran- } \\
\text { domised, number of participants ran- } \\
\text { domised to each group, amount of missing } \\
\text { data for each group }\end{array}$ \\
\hline
\end{tabular}

\begin{tabular}{l|l|l}
\hline Selective reporting (reporting bias) Unclear risk & Comment: no trial protocol referenced by
\end{tabular} the study

Other bias

Low risk

Comment: appears to be free of other bias

\section{Wessells 2012b}

Methods CRCT?: IRCT; Cross-over?: non-cross-over

Participants

Country: Burkina Faso; Setting: the catchment area of the governmental health clinic located in Toussiana; Urbanicity: rural

Inclusion criteria: currently breastfeeding; haemoglobin level $\geq 60 \mathrm{~g} / \mathrm{L}$; no fever or diarrhoea ( $>3$ liquid or semi-liquid stools in a 24-hour period) reported in the past week Exclusion criteria: currently consuming vitamin or mineral supplements or zinc-fortified infant formulas; demonstrated bipedal oedema or other serious medical conditions; had a twin enrolled in the study

Baseline characteristics

Avg age (mo): 13.7; Min age (mo): 6; Max age (mo): 23; \% Female: 49

Avg HAZ: -1.5; Stunting: unclear; Avg height $(\mathrm{cm})$ : 72.5; Avg zinc concentration $(\mu \mathrm{g} /$ dL): 62.9

Total N: 451; Group 1 N: 300; Group 2 N: 151

Interventions Group 1: zinc

Formulation: solution or dispersible tablets; Compound: sulfate; Frequency: daily; Duration (mo): 0.75; Dose (mg): 5; Co-intervention(s): N/A

Group 2: no zinc

Placebo given; Co-intervention(s): N/A

Outcomes

Serum or plasma zinc concentration, prevalence of zinc deficiency, serum or plasma copper concentration

Time point (wk): 3

Zinc supplementation for preventing mortality, morbidity, and growth failure in children aged 6 months to 12 years of age (Review) 
Wessells 2012b (Continued)

Notes

150 participants were randomised to receive dispersible zinc tablets, 150 participants were randomised to receive liquid zinc supplements, and 151 participants were randomised to receive liquid placebo supplements

\section{Risk of bias}

\begin{tabular}{lll} 
Bias & Authors' judgement & Support for judgement \\
\hline $\begin{array}{l}\text { Random sequence generation (selection } \\
\text { bias) }\end{array}$ & Low risk & $\begin{array}{l}\text { Quote: "Eligible study participants were } \\
\text { randomly assigned to } 1 \text { of } 3 \text { treatment } \\
\text { groups by using an independently gener- } \\
\text { ated block randomization scheme, with a } \\
\text { varied block length of } 3 \text { or } 6 \ldots \text { Tables of ran- } \\
\text { dom permutation..." } \\
\text { Comment: N/A }\end{array}$ \\
\hline
\end{tabular}

Allocation concealment (selection bias) Low risk

Quote: "Eligible study participants were randomly assigned to 1 of 3 treatment groups by using an independently generated block randomization scheme..."

Comment: indicates central randomisation (i.e. randomisation by someone not involved with enrolling patients) to conceal allocation

Blinding of participants (performance Unclear risk bias)

Quote: “...partially-masked, placebo-controlled trial...Zn and placebo syrups were indistinguishable in appearance, flavor, and packaging...Treatment groups remained masked until all statistical analyses were completed."

Comment: though the zinc and placebo syrups were indistinguishable, there was no placebo for the zinc tablets that some participants received. Thus, people involved in the study would not have been blind to the group assignment of the zinc tablet group

Blinding of personnel (performance bias) Unclear risk All outcomes

Quote: “...partially-masked, placebo-controlled trial...Zn and placebo syrups were indistinguishable in appearance, flavor, and packaging...Treatment groups remained masked until all statistical analyses were completed."

Comment: though the zinc and placebo syrups were indistinguishable, there was no placebo for the zinc tablets that some participants received. Thus, people involved in

Zinc supplementation for preventing mortality, morbidity, and growth failure in children aged 6 months to I2 years of age (Review) 
Wessells 2012b (Continued)

the study would not have been blind to the group assignment of the zinc tablet group

Blinding of outcome assessment (detection Unclear risk bias)

All outcomes
Quote: “...partially-masked, placebo-controlled trial...Zn and placebo syrups were indistinguishable in appearance, flavor, and packaging...Treatment groups remained masked until all statistical analyses were completed."

Comment: though the zinc and placebo syrups were indistinguishable, there was no placebo for the zinc tablets that some participants received. Thus, people involved in the study would not have been blind to the group assignment of the zinc tablet group

\% Missing: 4

Reasons/details: in the zinc group (comprised of participants who received liquid zinc supplements and participants who received zinc tablets): 11 withdrew consent, 3 moved from the study area, and 2 withdrew due to illness. In the placebo group: 3 withdrew consent and 1 withdrew due to illness. In addition, there were 5 blood draw failures in the zinc group

Comment: reasons for missing data were similar between study groups. Missing data seem too minimal to impact results
Selective reporting (reporting bias) Unclear risk

Comment: prevalence of LRTI was measured, but is not reported. Prevalence of diarrhoea was measured, but is not reported in a way that can be meta-analysed. Neither LRTI nor diarrhoea prevalence was pre-specified in the protocol for this study. However, based on email contact with an author of this study, it seems likely that there was probably not sufficient time to allow for detectable differences in morbidity and that morbidity outcomes were included in the measurements simply to control for any baseline differences or possible confounding

Protocol identifier: NCT00944853

Other bias Low risk
Comment: appears to be free of other bias 
Methods

Participants
CRCT?: IRCT; Cross-over?: non-cross-over

Country: Ecuador; Setting: El Carmen, a small town in the coastal plains, and the communities surrounding it; Latacunga, a medium-sized town in the Andean highlands, and several surrounding rural communities; and 2 shantytowns in the hills adjacent to the capital city of Quito, also in the Andean highlands; Urbanicity: multiple

Inclusion criteria: $\mathrm{LAZ}<-1.3$ for children 12 to 20 mo old and $<-1.5$ for children 21 to 29 mo old, assessed by comparison with the WHO/NCHS international reference data; haemoglobin $\geq 10.5 \mathrm{~g} / \mathrm{dL}$, adjusted for altitude; absence of chronic disease or congenital defects that restrict normal growth

Exclusion criteria: N/A

Baseline characteristics

Avg age (mo): 20.9; Min age (mo): 12; Max age (mo): 30; \% Female: 46.9

Avg HAZ: -2.3; Stunting: both - separate data not given; Avg height (cm): 77.3; Avg zinc concentration $(\mu \mathrm{g} / \mathrm{dL}): 71.9$

Total N: 503; Group 1 N: 376; Group 2 N: 127

\section{Group 1: zinc}

Formulation: solution; Compound: sulfate; Frequency: daily; Duration (mo): 6; Dose $(\mathrm{mg})$ : 6.7 on average (among participants who received 3, 7, or $10 \mathrm{mg} /$ day of zinc); Cointervention(s): N/A

Group 2: no zinc

Placebo given; Co-intervention(s): N/A

Outcomes

Incidence of all-cause diarrhoea, height, weight, weight-to-height ratio, serum or plasma zinc concentration, blood haemoglobin concentration, serum or plasma ferritin concentration, serum or plasma copper concentration

Time point (wk): 24

Notes

$127,124,126,126$, and 128 participants were randomised to receive placebo, $3 \mathrm{mg}$ zinc/day, $7 \mathrm{mg}$ zinc/day, $10 \mathrm{mg}$ zinc/day, and $10 \mathrm{mg}$ zinc/day $+0.5 \mathrm{mg}$ copper/day, respectively. Baseline characteristics reported in this table are weighted averages of all groups except the zinc + copper group, since the zinc + copper group is not included in any meta-analyses in this review

\section{Risk of bias}

Bias

Random sequence generation (selection Low risk bias)

\section{Authors' judgement}

\section{Support for judgement}

Quote: "The randomization lists...were generated... by using a fixed block randomization procedure." "Participants were assigned a study number... The numbers were previously assigned to one of the five study groups by computer randomization by the study's statistician."

Comment: N/A 
Wuehler 2008 (Continued)

Allocation concealment (selection bias) Low risk

Quote: "The randomization lists...were generated independently..."

Comment: indicates central randomisation (i.e. randomisation by someone not involved with enrolling patients) to conceal allocation

Blinding of participants (performance Low risk bias)

All outcomes

(1)

Quote: “...double-masked intervention trial...blinding of...participants to treatment group..." "There was no color or other method of distinguishing between supplements... The flavor of the zinc and copper were masked by the preservative that was added to all syrups."

Comment: sufficient blinding seems likely

Blinding of personnel (performance bias) Low risk All outcomes
Quote: “...double-masked intervention trial...blinding of investigators...to treatment group..." "There was no color or other method of distinguishing between supplements... The flavor of the zinc and copper were masked by the preservative that was added to all syrups."

Comment: sufficient blinding seems likely
Blinding of outcome assessment (detection Low risk bias)

All outcomes

Quote: “...double-masked intervention trial...blinding of investigators...to treatment group..." "There was no color or other method of distinguishing between supplements... The flavor of the zinc and copper were masked by the preservative that was added to all syrups."

Comment: sufficient blinding seems likely

Incomplete outcome data (attrition bias) Low risk All outcomes
\% Missing: 10.7

Reasons/details: participants "moved out of the study area", "refused to continue supplement consumption", "refused blood draws", or "withdrew consent without a specified reason". "Moved out of the study area" was the most common reason for missing data

Comment: $10.7 \%$ of the randomised participants eligible for our review had data missing; this $10.7 \%$ missing figure includes all groups except the zinc + copper group, since the zinc + copper group is not included in any meta-analyses in this re- 


\begin{tabular}{|c|c|c|}
\hline & & $\begin{array}{l}\text { view. "There were no significant differences } \\
\text { in rates of attrition by treatment group... } \\
\text { nor any significant differences between the } \\
\text { baseline characteristics of the children who } \\
\text { left the study prematurely and those of chil- } \\
\text { dren who completed the full 6-mo inter- } \\
\text { vention." Migration was the most common } \\
\text { reason for missing data and this reason is } \\
\text { unlikely to bias results }\end{array}$ \\
\hline Selective reporting (reporting bias) & High risk & $\begin{array}{l}\text { Comment: diarrhoea prevalence and LRTI } \\
\text { prevalence were measured, but are not re- } \\
\text { ported in a way that can be meta-analysed }\end{array}$ \\
\hline Other bias & Low risk & Comment: appears to be free of other bias \\
\hline
\end{tabular}

What follows is an explanation of what is meant by the various abbreviations in the Characteristics of included studies, Characteristics of studies awaiting classification, and Characteristics of ongoing studies tables.

- Unclear: it is not clear how this study should be classified for this characteristic; N/A: data not available (i.e. not reported) or not applicable.

- CRCT?: is this study cluster-randomised (i.e. a CRCT) or individually randomised (i.e. an IRCT)?

- Cross-over?: is this study a non-cross-over trial or a cross-over trial?

- Urbanicity: was the study conducted in a rural, urban, or peri-urban area? "Multiple" means that the study was conducted in more than one such area (e.g. in both urban and rural areas).

- Avg: average; (mo): months; Min: minimum; Max: maximum; HAZ: height-for-age z-score.

- Stunting: 'Stunted' means that all study participants were stunted. 'Non-stunted' means that none of the study participants were stunted. 'Both' means that some of the study participants were stunted, and some were non-stunted. 'Separate data given' means that the trial reported at least some data separately for stunted participants or non-stunted participants.

- N: sample size; Clusters: number of clusters in a CRCT study or study group.

- Dose: the actual dose of zinc given at each administration of the supplement, not a daily dose equivalent.

- Co-intervention(s): co-interventions administered along with zinc or placebo. The frequency and duration of co-intervention administration is the same as that of zinc or placebo unless stated otherwise.

- Placebo (not) given: whether or not a placebo substitute for zinc was administered.

- Time point (wk): how long (in weeks) after randomisation were reported outcomes observed?

- \% Missing: approximate $\%$ of study participants with missing data for non-mortality outcomes.

\section{Other abbreviations}

d: day; GH: growth hormone; IFA: iron + folic acid; IU: international units; LAZ: length-for-age z score; LRTI: lower respiratory tract infection; LTFU: lost to follow-up; MM: micronutrient mix; MV: multivitamin; NCHS: National Center for Health Statistics; SD: standard deviation; wk: week; WLZ: weight-for-length z score 
Characteristics of excluded studies [ordered by study ID]

\begin{tabular}{|c|c|}
\hline Study & Reason for exclusion \\
\hline Ahmed 2009b & Non-RCT. \\
\hline Bates 1993 & Non-RCT. \\
\hline Behrens 1990 & Therapeutic supplementation. \\
\hline Berger 2006 & Wrong age range. \\
\hline Bobat 2005 & Condition of HIV. \\
\hline Brooks 2005 & Wrong age range. \\
\hline Campos 2004 & Non-RCT. \\
\hline Cuevas 2002 & No eligible comparison. \\
\hline Duggan 2003 & Fortification/sprinkles. \\
\hline Fahmida 2007 & Wrong age range. \\
\hline Hashemipour 2009 & Condition of obesity. \\
\hline Heinig 2006 & Wrong age range. \\
\hline Hess 2011 & Acceptability study randomising order of administration. \\
\hline Imamoglu 2005 & Non-RCT. \\
\hline Kordas 2005 & Therapeutic supplementation. \\
\hline Osendarp 2002 & Wrong age range. \\
\hline Payne-Robinson 1991 & Severe protein-energy malnutrition. \\
\hline Perrone 1999 & No eligible comparison. \\
\hline Ronaghy 1969 & Wrong age range. \\
\hline Ronaghy 1974 & Wrong age range. \\
\hline Roxas 1980 & Non-RCT. \\
\hline Shingwekar 1979 & Non-RCT. \\
\hline
\end{tabular}


(Continued)

\begin{tabular}{ll}
\hline Shrivastava 1993 & Non-RCT. \\
\hline Walravens 1992 & Wrong age range. \\
\hline Wasantwisut 2006 & Wrong age range. \\
\hline Yanfeng 1997 & No eligible comparison. \\
\hline Zeba 2008 & No eligible comparison. \\
\hline Zimmermann 2013 & Intervention not eligible (LifeStraw with or without zinc). \\
\hline
\end{tabular}

RCT: randomised controlled trial

Characteristics of studies awaiting assessment [ordered by study ID]

\section{Arabaci 2010}

\begin{tabular}{|c|c|}
\hline Methods & CRCT?: N/A; Cross-over?: N/A \\
\hline Participants & $\begin{array}{l}\text { Country: N/A; Setting: N/A; Urbanicity: N/A } \\
\text { Inclusion criteria: haemoglobin }<11 \mathrm{~g} / \mathrm{dL} \text { and ferritin }<12 \mathrm{ng} / \mathrm{mL} \\
\text { Exclusion criteria: N/A } \\
\text { Baseline characteristics } \\
\text { Avg age (mo): N/A; Min age (mo): 6; Max age (mo): 72; \% Female: N/A } \\
\text { Avg HAZ: N/A; Stunting: N/A; Avg height (cm): N/A; Avg zinc concentration ( } \mu \mathrm{g} / \mathrm{dL}): \text { N/A } \\
\text { Total N: 53; Group } 1 \mathrm{~N}: 27 \text {; Group } 2 \mathrm{~N}: 26\end{array}$ \\
\hline Interventions & $\begin{array}{l}\text { Group 1: zinc } \\
\text { Formulation: N/A; Compound: N/A; Frequency: N/A; Duration (mo): 3; Dose (mg): N/A; Co-intervention(s): N/ } \\
\text { A } \\
\text { Group 2: no zinc } \\
\text { Unclear whether or not placebo given; Co-intervention(s): N/A }\end{array}$ \\
\hline Outcomes & Time point (wk): N/A \\
\hline Notes & A full-text trial report exists for this study, but could not be obtained \\
\hline
\end{tabular}


Chicourel 2001

Methods CRCT?: N/A; Cross-over?: N/A

Participants Country: Brazil; Setting: municipality of Juiz de Fora; Urbanicity: unclear

Inclusion criteria: N/A

Exclusion criteria: N/A

Baseline characteristics

Avg age (mo): N/A; Min age (mo): 49; Max age (mo): 82; \% Female: N/A

Avg HAZ: N/A; Stunting: unclear; Avg height (cm): N/A; Avg zinc concentration $(\mu \mathrm{g} / \mathrm{dL})$ : N/A

Total N: 59; Group 1 N: 30; Group 2 N: 29

Interventions Group 1: zinc

Formulation: N/A; Compound: N/A; Frequency: N/A; Duration (mo): unclear; Dose (mg): 10; Co-intervention(s)

: N/A

Group 2: no zinc

Placebo given; Co-intervention(s): N/A

Outcomes Time point (wk): N/A

Notes In addition to the study groups mentioned in this table, there was a group of 31 participants who received iron supplementation $(30 \mathrm{mg})$

A full-text trial report exists for this study, but could not be obtained

\section{Jimenez 2000}

Methods CRCT?: N/A; Cross-over?: N/A

Participants Country: N/A; Setting: N/A; Urbanicity: N/A

Inclusion criteria: recently recovered from persistent diarrhoea

Exclusion criteria: N/A

Baseline characteristics

Avg age (mo): N/A; Min age (mo): N/A; Max age (mo): N/A; \% Female: N/A

Avg HAZ: N/A; Stunting: N/A; Avg height (cm): N/A; Avg zinc concentration ( $\mu \mathrm{g} / \mathrm{dL})$ : N/A

Total N: N/A; Group 1 N: N/A; Group 2 N: N/A

Interventions Group 1: zinc

Formulation: N/A; Compound: sulfate; Frequency: N/A; Duration (mo): N/A; Dose (mg): 10 mg/day; Co-intervention(s): N/A

Group 2: no zinc

Placebo given; Co-intervention(s): N/A

Outcomes Height, weight, blood haemoglobin concentration

Time point (wk): N/A

Notes

Not enough information was available in the trial report to determine study eligibility (e.g. that participants met the age criteria for this review) 
Methods CRCT?: IRCT; Cross-over?: non-cross-over

Participants Country: Brazil; Setting: a favela in northeast Brazil; Urbanicity: urban

Inclusion criteria: below median height-for-age z-score

Exclusion criteria: N/A

Baseline characteristics

Avg age (mo): N/A; Min age (mo): N/A; Max age (mo): N/A; \% Female: N/A

Avg HAZ: N/A; Stunting: unclear; Avg height (cm): N/A; Avg zinc concentration $(\mu \mathrm{g} / \mathrm{dL})$ : N/A

Total N: 213; Group 1 N: N/A; Group 2 N: N/A; Group 3 N: N/A; Group 4 N: N/A; Group 5 N: N/A; Group 6

N: N/A; Group 7 N: N/A; Group 8 N: N/A

Interventions Group 1: zinc

Formulation: unclear; Compound: unclear; Frequency: 2 days/wk; Duration (mo): 12; Dose (mg): 40; Co-intervention(s): N/A

Group 2: no zinc

Unclear whether or not placebo given; Co-intervention(s): N/A

Group 3: zinc

Formulation: unclear; Compound: unclear; Frequency: 2 days/wk; Duration (mo): 12; Dose (mg): 40; Co-intervention(s): 200,000 IU retinol every 4 months

Group 4: no zinc

Unclear whether or not placebo given; Co-intervention(s): 200,000 IU retinol every 4 months

Group 5: zinc

Formulation: unclear; Compound: unclear; Frequency: 2 days/wk; Duration (mo): 12; Dose (mg): 40; Co-intervention(s): $16 \mathrm{~g}$ of glutamine for 10 days

Group 6: no zinc

Unclear whether or not placebo given; Co-intervention(s): $16 \mathrm{~g}$ of glutamine for 10 days

Group 7: zinc

Formulation: unclear; Compound: unclear; Frequency: 2 days/wk; Duration (mo): 12; Dose (mg): 40; Co-intervention(s): 200,000 IU retinol every 4 months; $16 \mathrm{~g}$ of glutamine for 10 days

Group 8: no zinc

Unclear whether or not placebo given; Co-intervention(s): 200,000 IU retinol every 4 months; 16 g of glutamine for 10 days

Outcomes Time point (wk): N/A

Notes Not enough information was available in the trial report to determine study eligibility (e.g. that participants met the age criteria for this review)

Smith 1985

Methods CRCT?: IRCT; Cross-over?: non-cross-over

Participants Country: Australia; Setting: 5 communities in the Kimberley region of Western Australia; Urbanicity: unclear Inclusion criteria: N/A

Exclusion criteria: N/A

Baseline characteristics

Avg age (mo): N/A; Min age (mo): 60; Max age (mo): 180; \% Female: N/A

Avg HAZ: N/A; Stunting: unclear; Avg height $(\mathrm{cm})$ : N/A; Avg zinc concentration $(\mu \mathrm{g} / \mathrm{dL})$ : N/A

Total N: N/A; Group 1 N: N/A; Group 2 N: N/A

Zinc supplementation for preventing mortality, morbidity, and growth failure in children aged 6 months to 12 years of age (Review) 


\section{Smith 1985 (Continued)}

\begin{tabular}{ll} 
Interventions & $\begin{array}{l}\text { Group 1: zinc } \\
\text { Formulation: unclear; Compound: acetate; Frequency: } 5 \text { days/wk; Duration (mo): N/A; Dose (mg): } 20 \mathrm{mg} \text { to children } \\
\text { aged } 5 \text { to } 8 \text { years, } 40 \mathrm{mg} \text { to children aged } 9 \text { to } 15 \text { years; Co-intervention(s): N/A } \\
\text { Group 2: no zinc } \\
\text { Placebo given; Co-intervention(s): N/A }\end{array}$ \\
\hline Outcomes & $\begin{array}{l}\text { Serum or plasma zinc concentration } \\
\text { Time point (wk): N/A }\end{array}$ \\
\hline Notes & $\begin{array}{l}\text { It was reported that, "Pairs of children... were randomised to receive oral zinc or placebo", and that "102 } \\
\text { pairs...completed the trial." However, number of children randomised was not reported } \\
\text { Not enough information was available in the trial report to determine study eligibility (e.g. that participants met the } \\
\text { age criteria for this review) }\end{array}$
\end{tabular}

Avg: average; CRCT: cluster-randomised controlled trial; HAZ: height-for-age z-score; IRCT: individually randomised controlled trial;

IU: international units; mo: month; wk: week

\section{Characteristics of ongoing studies [ordered by study ID]}

\section{CTRI/2010/091/001417}

\begin{tabular}{|c|c|}
\hline Trial name or title & $\begin{array}{l}\text { 'A clinical trial to study the effect of zinc sulfate in reducing the incidence of diarrhea, acute respiratory tract } \\
\text { infections and in promoting growth in infants of 6-11 months of age' }\end{array}$ \\
\hline Methods & CRCT?: N/A; Cross-over?: N/A \\
\hline Participants & $\begin{array}{l}\text { Country: India; Setting: N/A; Urbanicity: unclear } \\
\text { Inclusion criteria: apparently healthy } \\
\text { Exclusion criteria: receiving zinc supplement currently or in past } 3 \text { months; child who is severely malnourished, } \\
\text { immunodeficient or on steroid therapy, severely ill requiring hospitalisation; children of families who are not } \\
\text { likely to stay in the study area until completion of the study } \\
\text { Baseline characteristics } \\
\text { Avg age (mo): N/A; Min age (mo): 6; Max age (mo): } 11 \text {; \% Female: N/A } \\
\text { Avg HAZ: N/A; Stunting: N/A; Avg height (cm): N/A; Avg zinc concentration ( } \mu \mathrm{g} / \mathrm{dL}): \text { N/A } \\
\text { Total N: } 220 \text { (target sample size); Group } 1 \mathrm{~N} \text { : N/A; Group } 2 \text { N: N/A }\end{array}$ \\
\hline Interventions & $\begin{array}{l}\text { Group 1: zinc } \\
\text { Formulation: solution; Compound: sulfate; Frequency: daily; Duration (mo): 0.5; Dose (mg): 20; Co-inter- } \\
\text { vention(s): N/A } \\
\text { Group 2: no zinc } \\
\text { Placebo given; Co-intervention(s): N/A }\end{array}$ \\
\hline
\end{tabular}

Outcomes

Primary outcomes: incidence of diarrhoea, acute respiratory tract infections, height, weight Secondary outcomes: "Nil"

Time point (wk): 20 


\section{CTRI/2010/091/001417 (Continued)}

Starting date

Contact information Akash Malik (drakashmalik28@gmail.com). EMW emailed 30 January 2013

Notes COMPLETED

NCT00133406

Trial name or title 'Long-term Impact and Intervention for Diarrhea in Brazil'

\begin{tabular}{|c|c|}
\hline Methods & CRCT?: N/A; Cross-over?: N/A \\
\hline Participants & $\begin{array}{l}\text { Country: Brazil; Setting: a favela; Urbanicity: urban } \\
\text { Inclusion criteria: height-for-age Z-score (HAZ) less than the median for the Parque Universitario community; } \\
\text { resident in Brazilian favela } \\
\text { Exclusion criteria: exclusively breastfed; participated in the "hospital study" or any other study with in the } \\
\text { past } 2 \text { years; fever at time of screening; systemic disease at the time of screening including but not limited to: } \\
\text { shock, meningitis, sepsis, pneumonia, tuberculosis, varicella; on antibiotics during screening; siblings from } \\
\text { the same household enrolled in this study } \\
\text { Baseline characteristics } \\
\text { Avg age (mo): N/A; Min age (mo): } 2 \text {; Max age (mo): 8; \% Female: N/A } \\
\text { Avg HAZ: N/A; Stunting: N/A; Avg height }(\mathrm{cm}) \text { : N/A; Avg zinc concentration ( } \mu \mathrm{g} / \mathrm{dL}) \text { : N/A } \\
\text { Total N: } 280 \text { or } 321 \text { (target sample size); Group } 1 \mathrm{~N} \text { : N/A; Group } 2 \mathrm{~N} \text { : N/A; Group } 3 \mathrm{~N} \text { : N/A; Group } 4 \mathrm{~N} \text { : } \\
\text { N/A }\end{array}$ \\
\hline
\end{tabular}

Interventions Group 1: zinc

Formulation: N/A; Compound: N/A; Frequency: 2 days/wk; Duration (mo): 12; Dose (mg): 40; Co-intervention(s): N/A

Group 2: no zinc

Placebo given; Co-intervention(s): N/A

Group 3: zinc

Formulation: N/A; Compound: N/A; Frequency: 2 days/wk; Duration (mo): 12; Dose (mg): 40; Co-intervention(s): 100,000 IU vitamin A for children under 12 months of age, 200,000 IU for children at least 12 months of age, "both q months for 1 year at 0,4 and 8 months"

Group 4: no zinc

Placebo given; Co-intervention(s): 100,000 IU vitamin A for children under 12 months of age, 200,000 IU for children at least 12 months of age, "both q months for 1 year at 0, 4 and 8 months"

Outcomes

Number of episodes of diarrhoea, number of days of diarrhoea, height-for-age Z Score (HAZ), blood zinc level

Time point (wk): 144

Starting date

June 2006 (date of first enrolment)

Contact information Richard Guerrant (rlg9a@virginia.edu). EMW emailed 20 January 2013

Zinc supplementation for preventing mortality, morbidity, and growth failure in children aged 6 months to 12 years of age (Review) 


\section{NCT00133406 (Continued)}

Notes

There is also a sub-study to determine if 10 days of glutamine delivered as an oral bolus improves the health of the digestive system

\section{NCT00228254}

Trial name or title 'Vitamin A and zinc: Prevention of Pneumonia (VAZPOP) Study'

Methods CRCT?: N/A; Cross-over?: N/A

Participants Country: Ecuador; Setting: Quito; Urbanicity: urban

Inclusion criteria: residence of 1 year or longer in the neighbourhood

Exclusion criteria: recent vitamin or micronutrient use; clinical evidence of zinc or vitamin A deficiency; severe malnutrition such as weight $<$ or $=$ to $60 \%$ of expected weight

Baseline characteristics

Avg age (mo): N/A; Min age (mo): 6; Max age (mo): 36; \% Female: N/A

Avg HAZ: N/A; Stunting: N/A; Avg height (cm): N/A; Avg zinc concentration ( $\mu \mathrm{g} / \mathrm{dL})$ : N/A

Total N: 2,582; Group 1 N: N/A; Group 2 N: N/A; Group 3 N: N/A; Group 4 N: N/A

Interventions

Group 1: zinc

Formulation: N/A; Compound: N/A; Frequency: N/A; Duration (mo): N/A; Dose (mg): 12.5; Co-intervention(s): 10,000 IU per week

Group 2: no zinc

Placebo given; Co-intervention(s): 10,000 IU per week

Outcomes Primary outcomes: incidence of acute lower respiratory infection (pneumonia), growth

Secondary outcomes: incidence of diarrhoeal disease, incidence of other respiratory infections

Time point (wk): N/A

Starting date January 2000

Contact information Jeffrey K Griffiths (jeffrey.griffiths@tufts.edu). EMW emailed 20 January 2013

Notes

\section{NCT00374023}

Trial name or title 'A Study on Immunological Effect of Vitamin A and Zinc in a Placebo Controlled 4 Cell Trial'

Methods

Participants

Interventions

Outcomes

Starting date

Zinc supplementation for preventing mortality, morbidity, and growth failure in children aged 6 months to 12 years of age (Review)

Copyright @ 2014 The Cochrane Collaboration. Published by John Wiley \& Sons, Ltd. 


\section{NCT00374023 (Continued)}

\begin{tabular}{ll} 
Contact information & Swapan K Roy \\
\hline Notes & Estimated completion 1995
\end{tabular}

\section{NCT00421668}

Trial name or title

Methods

Participants

Interventions

Outcomes

Starting date

Contact information Christopher Duggan (christopher.duggan@childrens.harvard.edu). EMW emailed 21 January 2013

Notes COMPLETED

\section{NCT00589264}

\begin{tabular}{ll} 
Trial name or title & 'Zinc and Biobehavioral Development in Early Childhood' \\
\hline Methods & CRCT?: N/A; Cross-over?: N/A \\
\hline Participants & $\begin{array}{l}\text { Country: Peru; Setting: Lima; Urbanicity: N/A } \\
\text { Inclusion criteria: born at term of non-low birth weight; free of major malformations, genetic abnormalities, } \\
\text { or health problems associated with developmental delays; planning to remain in study area for } 1 \text { year; in good } \\
\text { general health }\end{array}$ \\
$\begin{array}{l}\text { Exclusion criteria: low birth weight; non-term delivery; vision or hearing problems; anaemia } \\
\text { Baseline characteristics } \\
\text { Avg age (mo): 6; Min age (mo): 6; Max age (mo): 6; \% Female: N/A } \\
\text { Avg HAZ: N/A; Stunting: N/A; Avg height (cm): N/A; Avg zinc concentration }(\mu \mathrm{g} / \mathrm{dL}): \text { N/A } \\
\text { Total N: N/A; Group } 1 \text { N: N/A; Group 2 N: N/A }\end{array}$ \\
\hline
\end{tabular}

\section{Interventions Group 1: zinc}

Formulation: N/A; Compound: N/A; Frequency: daily; Duration (mo): 6; Dose (mg): 10; Co-intervention (s): $10 \mathrm{mg}$ iron and $1 / 2 \mathrm{mg}$ copper

Group 2: no zinc

Placebo given; Co-intervention(s): $10 \mathrm{mg}$ iron and 1/2 mg copper

\begin{tabular}{ll}
\hline Outcomes & Growth \\
& Time point (wk): N/A
\end{tabular}




\section{NCT00589264 (Continued)}

\begin{tabular}{ll}
\hline Starting date & July 2004 \\
\hline Contact information & Laura E Caulfield (lcaulfie@jhsph.edu). EMW emailed 21 January 2013 \\
\hline Notes & COMPLETED \\
\hline
\end{tabular}

NCT00944359

Trial name or title 'Impact of Preventive and Therapeutic Zinc Supplementation Programs Among Young Children'

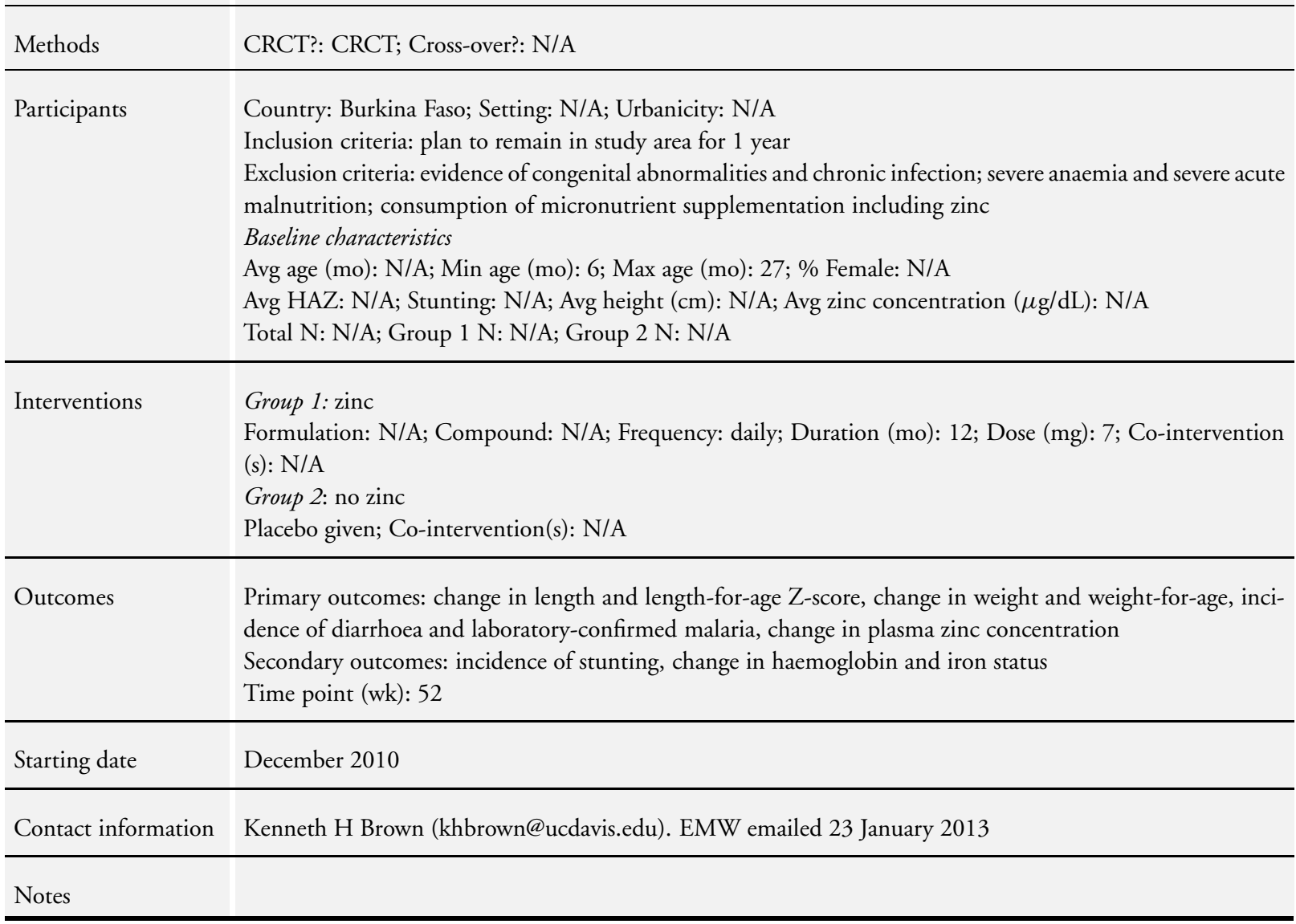

\section{NCT00967551}

Trial name or title Micronutrient Sprinkles in a Daycare Center

\section{Methods}

Participants

Interventions

Zinc supplementation for preventing mortality, morbidity, and growth failure in children aged 6 months to 12 years of age (Review) 


\section{NCT00967551 (Continued)}

Outcomes

Starting date

Contact information Conrad Cole (Conrad.Cole@cchmc.org). EMW emailed 30 January 2013

Notes COMPLETED

\section{NCT00980421}

\begin{tabular}{|c|c|}
\hline Trial name or title & 'Safety of Various Mode of Delivery of Iron Supplement on Iron Toxicity Markers in Preschool Children' \\
\hline Methods & CRCT?: N/A; Cross-over?: N/A \\
\hline Participants & $\begin{array}{l}\text { Country: India; Setting: Sangam Vihar, Delhi; Urbanicity: N/A } \\
\text { Inclusion criteria: willing to stay in the study area for } 6 \text { months } \\
\text { Exclusion criteria: severely malnourished or ill requiring hospitalisation } \\
\text { Baseline characteristics } \\
\text { Avg age (mo): N/A; Min age (mo): } 24 ; \text { Max age }(\mathrm{mo}): 36 ; \% \text { Female: N/A } \\
\text { Avg HAZ: N/A; Stunting: N/A; Avg height }(\mathrm{cm}): \text { N/A; Avg zinc concentration }(\mu \mathrm{g} / \mathrm{dL}): \mathrm{N} / \mathrm{A} \\
\text { Total N: } 120 \text {; Group } 1 \mathrm{~N}: 120 \text {; Group } 2 \mathrm{~N}: 120\end{array}$ \\
\hline Interventions & $\begin{array}{l}\text { Group 1: zinc } \\
\text { Formulation: pill/tablet; Compound: sulfate; Frequency: daily; Duration (mo): 6; Dose }(\mathrm{mg}) \text { : 10; Co-inter- } \\
\text { vention(s): } 12.5 \mathrm{mg} / \text { day of iron } \\
\text { Group 2: no zinc } \\
\text { Placebo given; Co-intervention(s): } 12.5 \mathrm{mg} / \text { day of iron }\end{array}$ \\
\hline Outcomes & $\begin{array}{l}\text { Mortality, incidence of disease requiring hospitalisation, iron status } \\
\text { Time point (wk): } 24\end{array}$ \\
\hline Starting date & October 2009 \\
\hline Contact information & $\begin{array}{l}\text { Venugopal P Menon (biocmr@sify.com) and Jitender Kumar (cmrdelhi@airtelmail.in). EMW emailed } 21 \\
\text { January } 2013\end{array}$ \\
\hline Notes & $\begin{array}{l}\text { In addition to the study groups mentioned in this table, there is a group of } 60 \text { participants that receives } \\
\text { biscuits fortified with iron (IB), and a group of } 60 \text { participants that receives placebo tablets }\end{array}$ \\
\hline
\end{tabular}

\section{NCT01306097}

Trial name or title 'Zinc Supplementation and Severe and Recurrent Diarrhea'

Methods

Participants

Zinc supplementation for preventing mortality, morbidity, and growth failure in children aged 6 months to 12 years of age (Review) 


\section{NCT01306097 (Continued)}

Interventions

Outcomes

Starting date

Contact information Bandar Abbas, Hormozgan, Iran

Notes COMPLETED

\section{NCT01616693}

Trial name or title

'Zinc and/or Probiotic Supplementation of Rotavirus and Oral Polio Virus Vaccines'

Methods

Participants

Interventions

Outcomes

Starting date

Contact information Gagandeep Kang (gkang@cmcvellore.ac.in) and Jacob John (jacob@cmcsph.org)

Notes Currently recruiting

Avg: average; CRCT: cluster-randomised controlled trial; HAZ: height-for-age z-score; IU: international units; mo: month; wk: week 
DATA AND ANALYSES

Comparison 1. Zinc versus no zinc

\begin{tabular}{|c|c|c|c|c|}
\hline Outcome or subgroup title & $\begin{array}{l}\text { No. of } \\
\text { studies }\end{array}$ & $\begin{array}{c}\text { No. of } \\
\text { participants }\end{array}$ & Statistical method & Effect size \\
\hline 1 All-cause mortality & 14 & 138302 & Risk Ratio (Fixed, 95\% CI) & $0.95[0.86,1.05]$ \\
\hline $\begin{array}{l}2 \text { Mortality due to all-cause } \\
\text { diarrhoea }\end{array}$ & 4 & 132321 & Risk Ratio (Fixed, 95\% CI) & $0.95[0.69,1.31]$ \\
\hline 3 Mortality due to LRTI & 3 & 132063 & Risk Ratio (Fixed, 95\% CI) & $0.86[0.64,1.15]$ \\
\hline 4 Mortality due to malaria & 2 & 42818 & Risk Ratio (Fixed, 95\% CI) & $0.90[0.77,1.06]$ \\
\hline 5 All-cause hospitalisation & 9 & 92872 & Risk Ratio (Fixed, 95\% CI) & $1.04[0.97,1.11]$ \\
\hline 6 Incidence of all-cause diarrhoea & 35 & 15042 & Risk Ratio (Fixed, 95\% CI) & $0.87[0.85,0.89]$ \\
\hline 7 Prevalence of all-cause diarrhoea & 15 & 8519 & Risk Ratio (Fixed, 95\% CI) & $0.88[0.86,0.90]$ \\
\hline $\begin{array}{l}8 \text { Hospitalisation due to all-cause } \\
\text { diarrhoea }\end{array}$ & 5 & 74039 & Risk Ratio (Fixed, 95\% CI) & $1.03[0.87,1.22]$ \\
\hline 9 Incidence of severe diarrhoea & 7 & 4982 & Risk Ratio (Fixed, 95\% CI) & $0.89[0.84,0.95]$ \\
\hline $\begin{array}{l}10 \text { Incidence of persistent } \\
\text { diarrhoea }\end{array}$ & 9 & 6216 & Risk Ratio (Fixed, 95\% CI) & $0.73[0.62,0.85]$ \\
\hline $\begin{array}{l}11 \text { Prevalence of persistent } \\
\text { diarrhoea }\end{array}$ & 2 & 665 & Risk Ratio (Fixed, 95\% CI) & $0.70[0.64,0.76]$ \\
\hline 12 Incidence of LRTI & 18 & 9610 & Risk Ratio (Fixed, 95\% CI) & $1.00[0.94,1.07]$ \\
\hline 13 Prevalence of LRTI & 4 & 1955 & Risk Ratio (Fixed, 95\% CI) & $1.20[1.10,1.30]$ \\
\hline 14 Hospitalisation due to LRTI & 4 & 74743 & Risk Ratio (Fixed, 95\% CI) & $1.10[0.93,1.30]$ \\
\hline 15 Incidence of malaria & 6 & 2407 & Risk Ratio (Fixed, 95\% CI) & $1.05[0.95,1.15]$ \\
\hline 16 Prevalence of malaria & 1 & 661 & Risk Ratio (M-H, Fixed, 95\% CI) & $0.88[0.47,1.64]$ \\
\hline 17 Height & 59 & 13669 & Std. Mean Difference (Fixed, 95\% CI) & $-0.09[-0.13,-0.06]$ \\
\hline 18 Weight & 52 & 12305 & Std. Mean Difference (Fixed, 95\% CI) & $-0.10[-0.14,-0.07]$ \\
\hline 19 Weight-to-height ratio & 29 & 7901 & Std. Mean Difference (IV, Fixed, 95\% CI) & $-0.05[-0.10,-0.01]$ \\
\hline 20 Prevalence of stunting & 9 & 3838 & Risk Ratio (Fixed, 95\% CI) & $0.94[0.86,1.02]$ \\
\hline $\begin{array}{l}21 \text { Serum or plasma zinc } \\
\text { concentration }\end{array}$ & 56 & 9810 & Std. Mean Difference (Fixed, 95\% CI) & $-0.62[-0.67,-0.58]$ \\
\hline 22 Prevalence of zinc deficiency & 21 & 5434 & Risk Ratio (Fixed, 95\% CI) & $0.49[0.45,0.53]$ \\
\hline 23 Study withdrawal & 6 & 4263 & Risk Ratio (M-H, Fixed, 95\% CI) & $1.75[0.93,3.32]$ \\
\hline 24 Participants with $\geq 1$ side effect & 3 & 850 & Risk Ratio (M-H, Fixed, 95\% CI) & $1.13[1.00,1.27]$ \\
\hline 25 Vomiting episodes & 6 & 4095 & Risk Ratio (Fixed, 95\% CI) & $1.68[1.61,1.75]$ \\
\hline $\begin{array}{l}26 \text { Participants with } \geq 1 \text { vomiting } \\
\quad \text { episode }\end{array}$ & 5 & 35192 & Risk Ratio (Fixed, 95\% CI) & $1.29[1.14,1.46]$ \\
\hline $\begin{array}{l}27 \text { Blood haemoglobin } \\
\text { concentration }\end{array}$ & 36 & 6024 & Std. Mean Difference (Fixed, 95\% CI) & $0.05[-0.00,0.10]$ \\
\hline 28 Prevalence of anaemia & 19 & 4287 & Risk Ratio (Fixed, 95\% CI) & $1.00[0.95,1.06]$ \\
\hline $\begin{array}{l}29 \text { Serum or plasma ferritin } \\
\text { concentration }\end{array}$ & 25 & 4474 & Std. Mean Difference (Fixed, 95\% CI) & $-0.07[-0.13,-0.00]$ \\
\hline 30 Prevalence of iron deficiency & 15 & 3149 & Risk Ratio (Fixed, 95\% CI) & $0.99[0.89,1.10]$ \\
\hline $\begin{array}{l}31 \text { Serum or plasma copper } \\
\text { concentration }\end{array}$ & 13 & 3071 & Std. Mean Difference (Fixed, 95\% CI) & $0.22[0.14,0.29]$ \\
\hline 32 Prevalence of copper deficiency & 3 & 1337 & Risk Ratio (Fixed, 95\% CI) & $2.64[1.28,5.42]$ \\
\hline
\end{tabular}

Zinc supplementation for preventing mortality, morbidity, and growth failure in children aged 6 months to 12 years of age (Review)

Copyright @ 2014 The Cochrane Collaboration. Published by John Wiley \& Sons, Ltd. 


\begin{tabular}{|c|c|c|c|c|}
\hline Outcome or subgroup title & $\begin{array}{l}\text { No. of } \\
\text { studies }\end{array}$ & $\begin{array}{c}\text { No. of } \\
\text { participants }\end{array}$ & Statistical method & Effect size \\
\hline 1 All-cause mortality & 1 & 323 & Risk Ratio (Fixed, 95\% CI) & $0.33[0.01,8.39]$ \\
\hline 2 All-cause hospitalisation & 1 & 399 & Risk Ratio (Fixed, 95\% CI) & $0.92[0.45,1.89]$ \\
\hline 3 Incidence of all-cause diarrhoea & 5 & 1530 & Risk Ratio (Fixed, 95\% CI) & $1.10[1.03,1.18]$ \\
\hline 4 Prevalence of all-cause diarrhoea & 1 & 399 & Risk Ratio (Fixed, 95\% CI) & $0.90[0.76,1.06]$ \\
\hline 5 Incidence of severe diarrhoea & 1 & 323 & Risk Ratio (Fixed, 95\% CI) & $0.78[0.59,1.04]$ \\
\hline $\begin{array}{l}6 \text { Hospitalisation due to all-cause } \\
\text { diarrhoea }\end{array}$ & 1 & 399 & Risk Ratio (M-H, Fixed, 95\% CI) & $0.99[0.25,3.88]$ \\
\hline 7 Incidence of LRTI & 3 & 1065 & Risk Ratio (Fixed, 95\% CI) & $0.93[0.83,1.04]$ \\
\hline 8 Incidence of malaria & 1 & 419 & Risk Ratio (Fixed, 95\% CI) & $0.86[0.59,1.24]$ \\
\hline 9 Height & 5 & 1517 & Std. Mean Difference (IV, Fixed, 95\% CI) & $0.06[-0.04,0.16]$ \\
\hline 10 Weight & 4 & 910 & Std. Mean Difference (IV, Fixed, 95\% CI) & $0.12[-0.01,0.25]$ \\
\hline 11 Weight-to-height ratio & 4 & 933 & Std. Mean Difference (IV, Fixed, 95\% CI) & $0.06[-0.07,0.19]$ \\
\hline 12 Prevalence of stunting & 2 & 462 & Risk Ratio (M-H, Fixed, 95\% CI) & $0.92[0.85,0.99]$ \\
\hline $\begin{array}{l}13 \text { Serum or plasma zinc } \\
\text { concentration }\end{array}$ & 8 & 1337 & Std. Mean Difference (IV, Fixed, 95\% CI) & $0.16[0.05,0.27]$ \\
\hline 14 Prevalence of zinc deficiency & 3 & 350 & Risk Ratio (M-H, Fixed, 95\% CI) & $1.42[0.75,2.68]$ \\
\hline 15 Study withdrawal & 2 & 557 & Risk Ratio (M-H, Fixed, 95\% CI) & $1.41[0.91,2.18]$ \\
\hline $\begin{array}{l}16 \text { Blood haemoglobin } \\
\text { concentration }\end{array}$ & 8 & 1341 & Std. Mean Difference (IV, Fixed, 95\% CI) & $-0.23[-0.34,-0.12]$ \\
\hline $\begin{array}{l}17 \text { Serum or plasma ferritin } \\
\text { concentration }\end{array}$ & 6 & 945 & Std. Mean Difference (IV, Fixed, 95\% CI) & $-1.78[-1.99,-1.56]$ \\
\hline 18 Prevalence of iron deficiency & 2 & 248 & Risk Ratio (M-H, Fixed, 95\% CI) & $0.12[0.04,0.32]$ \\
\hline 19 Prevalence of anaemia & 3 & 482 & Risk Ratio (M-H, Fixed, 95\% CI) & $0.78[0.67,0.92]$ \\
\hline $\begin{array}{l}20 \text { Serum or plasma copper } \\
\text { concentration }\end{array}$ & 2 & 353 & Std. Mean Difference (IV, Fixed, 95\% CI) & $0.06[-0.15,0.27]$ \\
\hline
\end{tabular}

Comparison 3. Zinc versus no zinc: subgroup analyses

\begin{tabular}{|c|c|c|c|c|}
\hline Outcome or subgroup title & $\begin{array}{l}\text { No. of } \\
\text { studies }\end{array}$ & $\begin{array}{c}\text { No. of } \\
\text { participants }\end{array}$ & Statistical method & Effect size \\
\hline $\begin{array}{l}1 \text { All-cause mortality: age } \\
\text { subgroup analysis }\end{array}$ & 15 & 155782 & Risk Ratio (Fixed, 95\% CI) & $0.93[0.85,1.02]$ \\
\hline 1.16 months to $<1$ year & 6 & 29879 & Risk Ratio (Fixed, 95\% CI) & $1.06[0.88,1.27]$ \\
\hline 1.21 to $<5$ years & 10 & 125903 & Risk Ratio (Fixed, 95\% CI) & $0.89[0.80,0.99]$ \\
\hline $\begin{array}{l}2 \text { All-cause mortality: dose } \\
\text { subgroup analysis }\end{array}$ & 17 & 156372 & Risk Ratio (Fixed, 95\% CI) & $0.93[0.84,1.02]$ \\
\hline 2.10 to $<5 \mathrm{mg}$ & 2 & 717 & Risk Ratio (Fixed, 95\% CI) & $0.72[0.08,6.47]$ \\
\hline 2.25 to $<10 \mathrm{mg}$ & 1 & 274 & Risk Ratio (Fixed, 95\% CI) & $3.04[0.32,28.90]$ \\
\hline 2.310 to $<15 \mathrm{mg}$ & 11 & 152062 & Risk Ratio (Fixed, 95\% CI) & $0.93[0.84,1.02]$ \\
\hline $2.420 \mathrm{mg}$ or more & 3 & 3319 & Risk Ratio (Fixed, 95\% CI) & $0.14[0.01,2.78]$ \\
\hline $\begin{array}{l}3 \text { All-cause mortality: duration } \\
\text { subgroup analysis }\end{array}$ & 15 & 155517 & Risk Ratio (Fixed, 95\% CI) & $0.93[0.84,1.02]$ \\
\hline
\end{tabular}

Zinc supplementation for preventing mortality, morbidity, and growth failure in children aged 6 months to 12 years of age (Review) 
3.10 to $<6$ months

3.26 to $<12$ months

3.312 months or more

4 All-cause mortality: iron co-

interventions subgroup analysis

4.1 Iron co-intervention

4.2 No iron co-intervention

5 All-cause mortality: formulation subgroup analysis

5.1 Solution

5.2 Pill/Tablet

5.3 Capsule

5.4 Powder

6 Incidence of all-cause diarrhoea:

age subgroup analysis

6.16 months to $<1$ year

6.21 to $<5$ years

6.35 to $<13$ years

7 Incidence of all-cause diarrhoea:

dose subgroup analysis

7.10 to $<5 \mathrm{mg}$

7.25 to $<10 \mathrm{mg}$

7.310 to $<15 \mathrm{mg}$

7.415 to $<20 \mathrm{mg}$

$7.520 \mathrm{mg}$ or more

8 Incidence of all-cause diarrhoea: duration subgroup analysis

8.10 to $<6$ months

8.26 to $<12$ months

8.312 months or more

9 Incidence of all-cause diarrhoea:

iron co-interventions subgroup analysis

9.1 Iron co-intervention

9.2 No iron co-intervention

10 Incidence of all-cause diarrhoea:

formulation subgroup analysis

10.1 Solution

10.2 Pill/tablet

10.3 Capsule

10.4 Powder

11 Prevalence of all-cause

diarrhoea: age subgroup

analysis

11.16 months to $<1$ year

11.21 to $<5$ years

12 Prevalence of all-cause

diarrhoea: dose subgroup

analysis

$$
\begin{aligned}
& 12.10 \text { to }<5 \mathrm{mg} \\
& 12.25 \text { to }<10 \mathrm{mg} \\
& 12.310 \text { to }<15 \mathrm{mg}
\end{aligned}
$$

Risk Ratio (Fixed, 95\% CI)

Risk Ratio (Fixed, 95\% CI)

Risk Ratio (Fixed, 95\% CI)

Risk Ratio (Fixed, 95\% CI)

Risk Ratio (Fixed, 95\% CI)

Risk Ratio (Fixed, 95\% CI)

Risk Ratio (Fixed, 95\% CI)

Risk Ratio (Fixed, 95\% CI)

Risk Ratio (Fixed, 95\% CI)

Risk Ratio (Fixed, 95\% CI)

Risk Ratio (Fixed, 95\% CI)

Risk Ratio (Fixed, 95\% CI)

Risk Ratio (Fixed, 95\% CI)

Risk Ratio (Fixed, 95\% CI)

Risk Ratio (Fixed, 95\% CI)

Risk Ratio (Fixed, 95\% CI)

Risk Ratio (Fixed, 95\% CI)

Risk Ratio (Fixed, 95\% CI)

Risk Ratio (Fixed, 95\% CI)

Risk Ratio (Fixed, 95\% CI)

Risk Ratio (Fixed, 95\% CI)

Risk Ratio (Fixed, 95\% CI)

Risk Ratio (Fixed, 95\% CI)

Risk Ratio (Fixed, 95\% CI)

Risk Ratio (Fixed, 95\% CI)

Risk Ratio (Fixed, 95\% CI)

Risk Ratio (Fixed, 95\% CI)

Risk Ratio (Fixed, 95\% CI)

Risk Ratio (Fixed, 95\% CI)

Risk Ratio (Fixed, 95\% CI)

Risk Ratio (Fixed, 95\% CI)

Risk Ratio (Fixed, 95\% CI)

Risk Ratio (Fixed, 95\% CI)

Risk Ratio (Fixed, 95\% CI)

Risk Ratio (Fixed, 95\% CI)

Risk Ratio (Fixed, 95\% CI)

Risk Ratio (Fixed, 95\% CI)
$0.59[0.07,5.15]$

$0.68[0.37,1.25]$

$0.93[0.85,1.03]$

$0.93[0.85,1.02]$

$0.99[0.86,1.15]$

$0.89[0.79,1.00]$

0.93 [0.84, 1.02]

$0.99[0.25,3.91]$

$0.93[0.85,1.02]$

$0.51[0.05,5.60]$

$0.71[0.27,1.86]$

0.87 [0.86, 0.89]

$0.88[0.85,0.90]$

0.87 [0.84, 0.90]

0.90 [0.81, 0.98]

0.87 [0.85, 0.89]

$0.95[0.89,1.01]$

0.73 [0.64, 0.83]

0.96 [0.92, 0.99]

$0.61[0.58,0.65]$

$0.90[0.87,0.94]$

0.87 [0.85, 0.89]

$0.89[0.85,0.93]$

0.86 [0.84, 0.89]

0.88 [0.82, 0.95$]$

0.87 [0.85, 0.89]

$1.00[0.96,1.05]$

0.82 [0.80, 0.84]

0.87 [0.85, 0.89]

0.84 [0.82, 0.86$]$

$0.90[0.81,0.99]$

$0.78[0.60,1.01]$

1.04 [0.98, 1.09]

0.88 [0.86, 0.90]

$0.96[0.93,1.00]$

0.85 [0.83, 0.87]

$0.88[0.86,0.90]$

$1.00[0.92,1.08]$

1.17 [0.60, 2.28]

$0.93[0.90,0.96]$ 
12.415 to $<20 \mathrm{mg}$

$12.520 \mathrm{mg}$ or more

13 Prevalence of all-cause

diarrhoea: duration subgroup

analysis

$$
13.10 \text { to }<6 \text { months }
$$

13.26 to $<12$ months

13.312 months or more

14 Prevalence of all-cause

diarrhoea: iron co-interventions

subgroup analysis

14.1 Iron co-intervention

14.2 No iron co-intervention

15 Prevalence of all-cause

diarrhoea: formulation

subgroup analysis

15.1 Solution

15.2 Pill/tablet

15.3 Powder

16 Incidence of LRTI: age

subgroup analysis

16.16 months to $<1$ year

16.21 to $<5$ years

16.35 to $<13$ years

17 Incidence of LRTI: dose

subgroup analysis

17.10 to $<5 \mathrm{mg}$

17.210 to $<15 \mathrm{mg}$

$17.320 \mathrm{mg}$ or more

18 Incidence of LRTI: duration

subgroup analysis

18.10 to $<6$ months

18.26 to $<12$ months

18.312 months or more

19 Incidence of LRTI: iron co-

interventions subgroup analysis

19.1 Iron co-intervention

19.2 No iron co-intervention

20 Incidence of LRTI: formulation

subgroup analysis

20.1 Solution

20.2 Pill/tablet

20.3 Capsule

20.4 Powder

21 Height: country income level subgroup analysis

21.1 Low- or middle-income

21.2 High-income

22 Height: age subgroup analysis

22.16 months to $<1$ year

22.21 to $<5$ years

22.35 to $<13$ years
Risk Ratio (Fixed, 95\% CI)

Risk Ratio (Fixed, 95\% CI)

Risk Ratio (Fixed, 95\% CI)

Risk Ratio (Fixed, 95\% CI)

Risk Ratio (Fixed, 95\% CI)

Risk Ratio (Fixed, 95\% CI)

Risk Ratio (Fixed, 95\% CI)

Risk Ratio (Fixed, 95\% CI)

Risk Ratio (Fixed, 95\% CI)

Risk Ratio (Fixed, 95\% CI)
Risk Ratio (Fixed, 95\% CI) Risk Ratio (Fixed, 95\% CI) Risk Ratio (Fixed, 95\% CI) Risk Ratio (Fixed, 95\% CI)

Risk Ratio (Fixed, 95\% CI) Risk Ratio (Fixed, 95\% CI) Risk Ratio (Fixed, 95\% CI) Risk Ratio (Fixed, 95\% CI)

Risk Ratio (Fixed, 95\% CI) Risk Ratio (Fixed, 95\% CI) Risk Ratio (Fixed, 95\% CI) Risk Ratio (Fixed, 95\% CI)

Risk Ratio (Fixed, 95\% CI) Risk Ratio (Fixed, 95\% CI) Risk Ratio (Fixed, 95\% CI) Risk Ratio (Fixed, 95\% CI)

Risk Ratio (Fixed, 95\% CI) Risk Ratio (Fixed, 95\% CI)

Risk Ratio (Fixed, 95\% CI)

Risk Ratio (Fixed, 95\% CI)

Risk Ratio (Fixed, 95\% CI)

Risk Ratio (Fixed, 95\% CI)

Risk Ratio (Fixed, 95\% CI)

Std. Mean Difference (Fixed, 95\% CI)

Std. Mean Difference (Fixed, 95\% CI) Std. Mean Difference (Fixed, 95\% CI) Std. Mean Difference (Fixed, 95\% CI) Std. Mean Difference (Fixed, 95\% CI) Std. Mean Difference (Fixed, 95\% CI) Std. Mean Difference (Fixed, 95\% CI)
$0.61[0.54,0.69]$

$0.85[0.82,0.87]$

$0.88[0.86,0.90]$

$0.85[0.82,0.87]$

$0.92[0.89,0.95]$

$0.88[0.74,1.03]$

$0.88[0.86,0.90]$

$0.96[0.88,1.05]$

$0.88[0.86,0.90]$

$0.88[0.86,0.90]$

$0.88[0.85,0.90]$

$0.86[0.81,0.92]$

$1.03[0.95,1.12]$

$1.01[0.95,1.08]$

$0.97[0.88,1.07]$

$1.05[0.96,1.16]$

$1.00[0.72,1.40]$

$1.00[0.94,1.07]$

$0.94[0.78,1.13]$

$1.00[0.91,1.10]$

1.02 [0.92, 1.13]

$1.00[0.94,1.07]$

$1.03[0.92,1.14]$

$0.98[0.90,1.06]$

$1.08[0.83,1.42]$

1.00 [0.94, 1.07]

$0.99[0.87,1.12]$

$1.01[0.93,1.08]$

1.00 [0.94, 1.07]

$0.98[0.91,1.05]$

$1.19[0.93,1.51]$

$1.12[0.84,1.51]$

$1.25[0.75,2.09]$

$-0.09[-0.13,-0.06]$

$-0.09[-0.13,-0.06]$

$-0.17[-0.40,0.06]$

$-0.03[-0.06,0.00]$

$0.26[0.19,0.33]$

$-0.09[-0.14,-0.04]$

$-0.25[-0.32,-0.18]$ 
23 Height: stunting subgroup analysis

23.1 Stunted

23.2 Non-stunted

24 Height: dose subgroup analysis

24.10 to $<5 \mathrm{mg}$

24.25 to $<10 \mathrm{mg}$

24.310 to $<15 \mathrm{mg}$

24.415 to $<20 \mathrm{mg}$

$24.520 \mathrm{mg}$ or more

25 Height: duration subgroup

analysis

25.10 to $<6$ months

25.26 to $<12$ months

25.312 months or more

26 Height: iron co-interventions subgroup analysis

26.1 Iron co-intervention

26.2 No iron co-intervention

27 Height: formulation subgroup analysis

27.1 Solution

27.2 Pill/tablet

27.3 Capsule

28 Weight: country income level subgroup analysis

28.1 Low- or middle-income

28.2 High-income

29 Weight: age subgroup analysis

29.16 months to $<1$ year

29.21 to $<5$ years

29.35 to $<13$ years

30 Weight: stunting subgroup

analysis

30.1 Stunted

30.2 Non-stunted

31 Weight: dose subgroup analysis

31.10 to $<5 \mathrm{mg}$

31.25 to $<10 \mathrm{mg}$

31.310 to $<15 \mathrm{mg}$

31.415 to $<20 \mathrm{mg}$

$31.520 \mathrm{mg}$ or more

32 Weight: duration subgroup analysis

32.10 to $<6$ months

32.26 to $<12$ months

32.312 months or more

33 Weight: iron co-interventions

subgroup analysis

33.1 Iron co-intervention

33.2 No iron co-intervention
Std. Mean Difference (Fixed, 95\% CI)

Std. Mean Difference (Fixed, 95\% CI)

Std. Mean Difference (Fixed, 95\% CI)

Std. Mean Difference (Fixed, 95\% CI)

Std. Mean Difference (Fixed, 95\% CI)

Std. Mean Difference (Fixed, 95\% CI)

Std. Mean Difference (Fixed, 95\% CI)

Std. Mean Difference (Fixed, 95\% CI)

Std. Mean Difference (Fixed, 95\% CI)

Std. Mean Difference (Fixed, 95\% CI)

4475

6479

2715

13439

2929

10510

13220

9030

3868

322

12305

12034
Std. Mean Difference (Fixed, 95\% CI) Std. Mean Difference (Fixed, 95\% CI) Std. Mean Difference (Fixed, 95\% CI) Std. Mean Difference (Fixed, 95\% CI)

Std. Mean Difference (Fixed, 95\% CI) Std. Mean Difference (Fixed, 95\% CI)

Std. Mean Difference (Fixed, 95\% CI)

Std. Mean Difference (Fixed, 95\% CI) Std. Mean Difference (Fixed, 95\% CI) Std. Mean Difference (Fixed, 95\% CI) Std. Mean Difference (Fixed, 95\% CI)

Std. Mean Difference (Fixed, 95\% CI) Std. Mean Difference (Fixed, 95\% CI) Std. Mean Difference (Fixed, 95\% CI) Std. Mean Difference (Fixed, 95\% CI) Std. Mean Difference (Fixed, 95\% CI) Std. Mean Difference (Fixed, 95\% CI) Std. Mean Difference (Fixed, 95\% CI)

Std. Mean Difference (Fixed, 95\% CI) Std. Mean Difference (Fixed, 95\% CI) Std. Mean Difference (Fixed, 95\% CI) Std. Mean Difference (Fixed, 95\% CI) Std. Mean Difference (Fixed, 95\% CI) Std. Mean Difference (Fixed, 95\% CI) Std. Mean Difference (Fixed, 95\% CI) Std. Mean Difference (Fixed, 95\% CI) Std. Mean Difference (Fixed, 95\% CI)

Std. Mean Difference (Fixed, 95\% CI) Std. Mean Difference (Fixed, 95\% CI) Std. Mean Difference (Fixed, 95\% CI) Std. Mean Difference (Fixed, 95\% CI)

Std. Mean Difference (Fixed, 95\% CI) Std. Mean Difference (Fixed, 95\% CI)
$-0.21[-0.34,-0.08]$

$-0.25[-0.40,-0.10]$ $-0.09[-0.36,0.17]$ $-0.08[-0.11,-0.05]$ $-0.02[-0.13,0.10]$ $-0.29[-0.37,-0.22]$ $-0.06[-0.12,-0.00]$ $0.01[-0.24,0.26]$ $0.01[-0.05,0.07]$ $-0.09[-0.13,-0.06]$

$0.01[-0.04,0.07]$

$-0.17[-0.22,-0.12]$ $-0.10[-0.17,-0.02]$ $-0.09[-0.13,-0.06]$

$-0.01[-0.08,0.07]$

$-0.12[-0.16,-0.08]$

$-0.09[-0.13,-0.06]$

$-0.12[-0.16,-0.07]$ $-0.02[-0.09,0.04]$ $-0.31[-0.59,-0.03]$ $-0.10[-0.14,-0.07]$

$-0.10[-0.14,-0.07]$ $-0.16[-0.40,0.07]$ $0.01[-0.03,0.04]$ $0.31[0.25,0.38]$ $-0.06[-0.11,-0.01]$ $-0.28[-0.36,-0.20]$ $-0.19[-0.32,-0.05]$

$-0.25[-0.40,-0.09]$ $-0.01[-0.27,0.26]$

$-0.10[-0.13,-0.06]$ $-0.00[-0.12,0.11]$ $-0.27[-0.35,-0.20]$ $-0.11[-0.17,-0.04]$ $0.20[-0.06,0.45]$ $-0.01[-0.08,0.05]$ $-0.10[-0.14,-0.07]$

$-0.05[-0.11,0.00]$

$-0.20[-0.26,-0.15]$

$0.01[-0.07,0.09]$

$-0.10[-0.14,-0.07]$

$-0.06[-0.14,0.02]$

$-0.12[-0.16,-0.08]$ 
34 Weight: formulation subgroup analysis

34.1 Solution

34.2 Pill/tablet

34.3 Capsule

35 Weight-to-height ratio: country income level subgroup analysis 35.1 Low- or middle-income 35.2 High-income

36 Weight-to-height ratio: age subgroup analysis

36.16 months to $<1$ year

36.21 to $<5$ years

36.35 to $<13$ years

37 Weight-to-height ratio: dose subgroup analysis

37.10 to $<5 \mathrm{mg}$

37.25 to $<10 \mathrm{mg}$

37.310 to $<15 \mathrm{mg}$

37.415 to $<20 \mathrm{mg}$

$37.520 \mathrm{mg}$ or more

38 Weight-to-height ratio: duration subgroup analysis

38.10 to $<6$ months

38.26 to $<12$ months

38.312 months or more

39 Weight-to-height ratio: iron cointerventions subgroup analysis 39.1 Iron co-intervention 39.2 No iron co-intervention

40 Weight-to-height ratio:

formulation subgroup analysis

40.1 Solution

40.2 Pill/tablet

41 Serum or plasma zinc

concentration: country income

level subgroup analysis

41.1 Low- or middle-income

41.2 High-income

42 Serum or plasma zinc

concentration: age subgroup

analysis

42.16 months to $<1$ year

42.21 to $<5$ years

42.35 to $<13$ years

43 Serum or plasma zinc

concentration: dose subgroup analysis

43.10 to $<5 \mathrm{mg}$
43.25 to $<10 \mathrm{mg}$
43.310 to $<15 \mathrm{mg}$
43.415 to $<20 \mathrm{mg}$

Std. Mean Difference (Fixed, 95\% CI)

Std. Mean Difference (Fixed, 95\% CI)

Std. Mean Difference (Fixed, 95\% CI)

Std. Mean Difference (Fixed, 95\% CI)

Std. Mean Difference (IV, Fixed, 95\% CI)

Std. Mean Difference (IV, Fixed, 95\% CI) Std. Mean Difference (IV, Fixed, 95\% CI) Std. Mean Difference (IV, Fixed, 95\% CI)

Std. Mean Difference (IV, Fixed, 95\% CI) Std. Mean Difference (IV, Fixed, 95\% CI) Std. Mean Difference (IV, Fixed, 95\% CI) Std. Mean Difference (IV, Fixed, 95\% CI)

Std. Mean Difference (IV, Fixed, 95\% CI) Std. Mean Difference (IV, Fixed, 95\% CI) Std. Mean Difference (IV, Fixed, 95\% CI) Std. Mean Difference (IV, Fixed, 95\% CI) Std. Mean Difference (IV, Fixed, 95\% CI) Std. Mean Difference (IV, Fixed, 95\% CI)

Std. Mean Difference (IV, Fixed, 95\% CI) Std. Mean Difference (IV, Fixed, 95\% CI) Std. Mean Difference (IV, Fixed, 95\% CI) Std. Mean Difference (IV, Fixed, 95\% CI)

Std. Mean Difference (IV, Fixed, 95\% CI) Std. Mean Difference (IV, Fixed, 95\% CI) Std. Mean Difference (IV, Fixed, 95\% CI)

Std. Mean Difference (IV, Fixed, 95\% CI) Std. Mean Difference (IV, Fixed, 95\% CI) Std. Mean Difference (Fixed, 95\% CI)

Std. Mean Difference (Fixed, 95\% CI) Std. Mean Difference (Fixed, 95\% CI) Std. Mean Difference (Fixed, 95\% CI)

Std. Mean Difference (Fixed, 95\% CI) Std. Mean Difference (Fixed, 95\% CI) Std. Mean Difference (Fixed, 95\% CI) Std. Mean Difference (Fixed, 95\% CI)

Std. Mean Difference (Fixed, 95\% CI) Std. Mean Difference (Fixed, 95\% CI) Std. Mean Difference (Fixed, 95\% CI) Std. Mean Difference (Fixed, 95\% CI)
$-0.11[-0.14,-0.07]$

$-0.14[-0.19,-0.10]$

$-0.01[-0.08,0.06]$

$-0.41[-0.71,-0.12]$

$-0.05[-0.10,-0.01]$

$-0.05[-0.09,-0.01]$

$-0.14[-0.53,0.25]$

$-0.03[-0.07,0.02]$

$-0.03[-0.11,0.04]$

$-0.02[-0.08,0.05]$

$-0.07[-0.20,0.06]$

$-0.05[-0.10,-0.01]$

$-0.07[-0.22,0.08]$

$-0.01[-0.12,0.10]$

$-0.08[-0.16,0.01]$

$0.22[-0.06,0.50]$

$-0.06[-0.13,0.00]$

$-0.05[-0.10,-0.01]$

$-0.07[-0.14,-0.00]$

$-0.05[-0.11,0.01]$

$0.10[-0.11,0.31]$

$-0.05[-0.09,-0.00]$

$-0.14[-0.24,-0.03]$

$-0.03[-0.08,0.02]$

$-0.05[-0.09,-0.00]$

$-0.06[-0.12,-0.01]$ $0.01[-0.08,0.11]$

$-0.62[-0.67,-0.58]$

$-0.63[-0.68,-0.59]$

$-0.23[-0.49,0.03]$

$-0.61[-0.65,-0.57]$

$-0.46[-0.55,-0.37]$

$-0.75[-0.81,-0.69]$

$-0.47[-0.55,-0.38]$

$-0.62[-0.67,-0.58]$

$-0.35[-0.49,-0.21]$

$-0.49[-0.59,-0.40]$

$-0.62[-0.68,-0.56]$

$-0.76[-0.94,-0.58]$ 
$43.520 \mathrm{mg}$ or more

44 Serum or plasma zinc

concentration: duration

subgroup analysis

44.10 to $<6$ months

44.26 to $<12$ months

44.312 months or more

45 Serum or plasma zinc

concentration: iron co-

interventions subgroup analysis

45.1 Iron co-intervention

45.2 No iron co-intervention

46 Serum or plasma zinc

concentration: Formulation

subgroup analysis

46.1 Solution

46.2 Pill/tablet

46.3 Capsule

46.4 Powder

47 Prevalence of zinc deficiency:

age subgroup analysis

47.16 months to $<1$ year

47.21 to $<5$ years

47.35 to $<13$ years

48 Prevalence of zinc deficiency:

dose subgroup analysis

48.15 to $<10 \mathrm{mg}$

48.210 to $<15 \mathrm{mg}$

48.315 to $<20 \mathrm{mg}$

$48.420 \mathrm{mg}$ or more

49 Prevalence of zinc deficiency:

duration subgroup analysis

49.10 to $<6$ months

49.26 to $<12$ months

49.312 months or more

50 Prevalence of zinc deficiency:

iron co-interventions subgroup

analysis

50.1 Iron co-intervention

50.2 No iron co-intervention

51 Prevalence of zinc deficiency:

formulation subgroup analysis

51.1 Solution

51.2 Pill/tablet

51.3 Capsule

52 Blood haemoglobin

concentration: age subgroup

analysis

52.16 months to $<1$ year

52.21 to $<5$ years

52.35 to $<13$ years
Std. Mean Difference (Fixed, 95\% CI)

Std. Mean Difference (Fixed, 95\% CI)
Std. Mean Difference (Fixed, 95\% CI) Std. Mean Difference (Fixed, 95\% CI) Std. Mean Difference (Fixed, 95\% CI) Std. Mean Difference (Fixed, 95\% CI)

Std. Mean Difference (Fixed, 95\% CI) Std. Mean Difference (Fixed, 95\% CI) Std. Mean Difference (Fixed, 95\% CI)

Std. Mean Difference (Fixed, 95\% CI) Std. Mean Difference (Fixed, 95\% CI) Std. Mean Difference (Fixed, 95\% CI) Std. Mean Difference (Fixed, 95\% CI) Risk Ratio (Fixed, 95\% CI)

Risk Ratio (Fixed, 95\% CI)

Risk Ratio (Fixed, 95\% CI)

Risk Ratio (Fixed, 95\% CI)

Risk Ratio (Fixed, 95\% CI)

Risk Ratio (Fixed, 95\% CI)

Risk Ratio (Fixed, 95\% CI)

Risk Ratio (Fixed, 95\% CI)

Risk Ratio (Fixed, 95\% CI)

Risk Ratio (Fixed, 95\% CI)

Risk Ratio (Fixed, 95\% CI)

Risk Ratio (Fixed, 95\% CI)

Risk Ratio (Fixed, 95\% CI)

Risk Ratio (Fixed, 95\% CI)

Risk Ratio (Fixed, 95\% CI)

Risk Ratio (Fixed, 95\% CI)

Risk Ratio (Fixed, 95\% CI)

Risk Ratio (Fixed, 95\% CI)

Risk Ratio (Fixed, 95\% CI)

Risk Ratio (Fixed, 95\% CI)

Std. Mean Difference (Fixed, 95\% CI)

Std. Mean Difference (Fixed, 95\% CI) Std. Mean Difference (Fixed, 95\% CI) Std. Mean Difference (Fixed, 95\% CI)
$-0.88[-0.98,-0.78]$

$-0.62[-0.67,-0.58]$

$-0.81[-0.88,-0.73]$

$-0.52[-0.58,-0.46]$

$-0.59[-0.67,-0.50]$

$-0.62[-0.67,-0.58]$

$-0.47[-0.54,-0.39]$

$-0.70[-0.75,-0.65]$

$-0.64[-0.68,-0.59]$

$-0.78[-0.84,-0.72]$

$-0.42[-0.49,-0.35]$

$-1.07[-1.21,-0.94]$

$0.06[-0.14,0.25]$

$0.49[0.45,0.53]$

$0.62[0.54,0.70]$

$0.41[0.37,0.47]$

$0.31[0.20,0.49]$

$0.49[0.45,0.53]$

$0.34[0.27,0.44]$

0.57 [0.52, 0.63]

$0.46[0.24,0.89]$

0.14 [0.10, 0.19]

$0.49[0.45,0.53]$

$0.22[0.18,0.27]$

$0.59[0.53,0.67]$

$0.55[0.48,0.64]$

$0.49[0.45,0.53]$

$0.62[0.55,0.69]$

0.37 [0.33, 0.42]

$0.49[0.45,0.53]$

$0.49[0.44,0.54]$

$0.59[0.50,0.68]$

0.29 [0.23, 0.37]

$-0.00[-0.06,0.05]$

$0.04[-0.05,0.12]$

$-0.04[-0.12,0.04]$

$-0.01[-0.13,0.11]$

Zinc supplementation for preventing mortality, morbidity, and growth failure in children aged 6 months to 12 years of age (Review) 
53 Blood haemoglobin

concentration: dose subgroup

analysis

53.10 to $<5 \mathrm{mg}$

53.25 to $<10 \mathrm{mg}$

53.310 to $<15 \mathrm{mg}$

53.415 to $<20 \mathrm{mg}$

$53.520 \mathrm{mg}$ or more

54 Blood haemoglobin

concentration: duration

subgroup analysis

54.10 to $<6$ months

54.26 to $<12$ months

54.312 months or more

55 Blood haemoglobin

concentration: iron co-

interventions subgroup analysis

55.1 Iron co-intervention

55.2 No iron co-intervention

56 Blood haemoglobin

concentration: formulation

subgroup analysis

56.1 Solution

56.2 Pill/tablet

56.3 Capsule

56.4 Powder

57 Prevalence of anaemia: age

subgroup analysis

57.16 months to $<1$ year

57.21 to $<5$ years

57.35 to $<13$ years

58 Prevalence of anaemia: dose

subgroup analysis

58.10 to $<5 \mathrm{mg}$

58.25 to $<10 \mathrm{mg}$

58.310 to $<15 \mathrm{mg}$

58.415 to $<20 \mathrm{mg}$

$58.520 \mathrm{mg}$ or more

59 Prevalence of anaemia: duration subgroup analysis

59.10 to $<6$ months

59.26 to $<12$ months

59.312 months or more

60 Prevalence of anaemia: iron co-

interventions subgroup analysis

60.1 Iron co-intervention

60.2 No iron co-intervention

61 Prevalence of anaemia:

formulation subgroup analysis

61.1 Solution

61.2 Pill/tablet

61.3 Capsule
Std. Mean Difference (Fixed, 95\% CI) Std. Mean Difference (Fixed, 95\% CI) Std. Mean Difference (Fixed, 95\% CI) Std. Mean Difference (Fixed, 95\% CI) Std. Mean Difference (Fixed, 95\% CI) Std. Mean Difference (Fixed, 95\% CI)

Std. Mean Difference (Fixed, 95\% CI) Std. Mean Difference (Fixed, 95\% CI) Std. Mean Difference (Fixed, 95\% CI) Std. Mean Difference (Fixed, 95\% CI)

Std. Mean Difference (Fixed, 95\% CI) Std. Mean Difference (Fixed, 95\% CI) Std. Mean Difference (Fixed, 95\% CI)

Std. Mean Difference (Fixed, 95\% CI) Std. Mean Difference (Fixed, 95\% CI) Std. Mean Difference (Fixed, 95\% CI) Std. Mean Difference (Fixed, 95\% CI) Risk Ratio (Fixed, 95\% CI)

Risk Ratio (Fixed, 95\% CI)

Risk Ratio (Fixed, 95\% CI)

Risk Ratio (Fixed, 95\% CI)

Risk Ratio (Fixed, 95\% CI)

Risk Ratio (Fixed, 95\% CI)

Risk Ratio (Fixed, 95\% CI)

Risk Ratio (Fixed, 95\% CI)

Risk Ratio (Fixed, 95\% CI)

Risk Ratio (Fixed, 95\% CI)

Risk Ratio (Fixed, 95\% CI)

Risk Ratio (Fixed, 95\% CI)

Risk Ratio (Fixed, 95\% CI)

Risk Ratio (Fixed, 95\% CI)

Risk Ratio (Fixed, 95\% CI)

Risk Ratio (Fixed, 95\% CI)

Risk Ratio (Fixed, 95\% CI)

Risk Ratio (Fixed, 95\% CI)

Risk Ratio (Fixed, 95\% CI)

Risk Ratio (Fixed, 95\% CI)

Risk Ratio (Fixed, 95\% CI)
$-0.01[-0.14,0.12]$

$0.01[-0.21,0.23]$

$-0.01[-0.08,0.06]$

$0.04[-0.17,0.24]$

$-0.10[-0.22,0.02]$

$-0.01[-0.07,0.04]$

$-0.17[-0.33,-0.01]$

$0.01[-0.06,0.08]$

$-0.01[-0.11,0.09]$

$-0.01[-0.07,0.04]$

$0.01[-0.07,0.08]$

$-0.04[-0.11,0.04]$

$-0.01[-0.07,0.04]$

$-0.01[-0.08,0.06]$

$-0.01[-0.12,0.09]$

$-0.07[-0.20,0.06]$

$0.07[-0.12,0.26]$

$1.00[0.95,1.06]$

$1.01[0.95,1.08]$

$0.99[0.88,1.12]$

$0.73[0.47,1.12]$

$1.00[0.95,1.06]$

$1.01[0.94,1.09]$

0.94 [0.47, 1.87]

$1.01[0.92,1.11]$

$0.76[0.40,1.46]$

0.17 [0.06, 0.46]

$1.00[0.95,1.06]$

$0.18[0.06,0.48]$

1.01 [0.94, 1.08]

$1.00[0.90,1.12]$

$1.00[0.95,1.06]$

$1.00[0.91,1.09]$

$1.00[0.93,1.08]$

$1.00[0.95,1.06]$

$0.90[0.78,1.04]$

$1.00[0.88,1.13]$
$1.02[0.95,1.10]$ 
61.4 Powder

62 Serum or plasma ferritin

concentration: country income

level subgroup analysis

62.1 Low- or middle-income

62.2 High-income

63 Serum or plasma ferritin

concentration: age subgroup

analysis

63.16 months to $<1$ year

63.21 to $<5$ years

63.35 to $<13$ years

64 Serum or plasma ferritin

concentration: dose subgroup analysis

64.10 to $<5 \mathrm{mg}$

64.25 to $<10 \mathrm{mg}$

64.310 to $<15 \mathrm{mg}$

64.415 to $<20 \mathrm{mg}$

$64.520 \mathrm{mg}$ or more

65 Serum or plasma ferritin

concentration: duration

subgroup analysis

65.10 to $<6$ months

65.26 to $<12$ months

65.312 months or more

66 Serum or plasma ferritin concentration: iron co-

interventions subgroup analysis

66.1 Iron co-intervention

66.2 No iron co-intervention

67 Serum or plasma ferritin

concentration: formulation

subgroup analysis

67.1 Solution

67.2 Pill/tablet

67.3 Capsule

67.4 Powder

68 Prevalence of iron deficiency:

age subgroup analysis

68.16 months to $<1$ year

68.21 to $<5$ years

68.35 to $<13$ years

69 Prevalence of iron deficiency: dose subgroup analysis

69.10 to $<5 \mathrm{mg}$

69.210 to $<15 \mathrm{mg}$

69.315 to $<20 \mathrm{mg}$

$69.420 \mathrm{mg}$ or more

70 Prevalence of iron deficiency:

Duration subgroup analysis

70.10 to $<6$ months
Risk Ratio (Fixed, 95\% CI)

Std. Mean Difference (Fixed, 95\% CI)

$1.19[0.81,1.73]$

$0.13[0.07,0.19]$

24

1

24

6
4427

47

4416

1166

2716

534

4586

Std. Mean Difference (Fixed, 95\% CI) Std. Mean Difference (Fixed, 95\% CI)

Std. Mean Difference (Fixed, 95\% CI)

Std. Mean Difference (Fixed, 95\% CI) Std. Mean Difference (Fixed, 95\% CI) Std. Mean Difference (Fixed, 95\% CI) Std. Mean Difference (Fixed, 95\% CI)

Std. Mean Difference (Fixed, 95\% CI) Std. Mean Difference (Fixed, 95\% CI) Std. Mean Difference (Fixed, 95\% CI) Std. Mean Difference (Fixed, 95\% CI) Std. Mean Difference (Fixed, 95\% CI) Std. Mean Difference (Fixed, 95\% CI)

Std. Mean Difference (Fixed, 95\% CI) Std. Mean Difference (Fixed, 95\% CI) Std. Mean Difference (Fixed, 95\% CI) Std. Mean Difference (Fixed, 95\% CI)

Std. Mean Difference (Fixed, 95\% CI) Std. Mean Difference (Fixed, 95\% CI) Std. Mean Difference (Fixed, 95\% CI)
Std. Mean Difference (Fixed, 95\% CI) Std. Mean Difference (Fixed, 95\% CI) Std. Mean Difference (Fixed, 95\% CI) Std. Mean Difference (Fixed, 95\% CI) Risk Ratio (Fixed, 95\% CI)

Risk Ratio (Fixed, 95\% CI)

Risk Ratio (Fixed, 95\% CI)

Risk Ratio (Fixed, 95\% CI)

Risk Ratio (Fixed, 95\% CI)

Risk Ratio (Fixed, 95\% CI)

Risk Ratio (Fixed, 95\% CI)

Risk Ratio (Fixed, 95\% CI)

Risk Ratio (Fixed, 95\% CI)

Risk Ratio (Fixed, 95\% CI)

Risk Ratio (Fixed, 95\% CI)
$0.12[0.06,0.19]$

$0.88[0.29,1.47]$

$0.14[0.08,0.20]$

$0.14[0.03,0.26]$

$0.16[0.08,0.24]$

$0.05[-0.15,0.24]$

0.13 [0.07, 0.19]

$0.07[-0.14,0.28]$

$0.15[-0.34,0.63]$

$0.20[0.13,0.28]$

$0.14[-0.08,0.36]$

$-0.17[-0.33,-0.02]$

$0.14[0.08,0.20]$

$-0.06[-0.20,0.07]$

$0.07[-0.03,0.17]$

$0.34[0.24,0.45]$

0.13 [0.07, 0.19]

$0.05[-0.02,0.13]$

$0.27[0.17,0.38]$

$0.13[0.07,0.20]$

$-0.01[-0.10,0.08]$

$0.16[0.04,0.29]$

0.54 [0.38, 0.69]

$0.18[-0.04,0.40]$

$0.99[0.89,1.10]$

$0.92[0.82,1.05]$

$1.16[0.94,1.44]$

1.12 [0.61, 2.04]

0.99 [0.89, 1.10]

$0.78[0.61,1.00]$

$1.03[0.91,1.16]$

1.07 [0.52, 2.18]

$2.16[0.72,6.44]$

$0.99[0.89,1.10]$

$2.16[0.72,6.44]$ 
70.26 to $<12$ months

70.312 months or more

71 Prevalence of iron deficiency: Iron co-interventions subgroup analysis

71.1 Iron co-intervention

71.2 No iron co-intervention

72 Prevalence of iron deficiency: formulation subgroup analysis

72.1 Solution

72.2 Pill/tablet

72.3 Capsule

73 Serum or plasma copper

concentration: country income

level subgroup analysis

73.1 Low- or middle-income

73.2 High-income

74 Serum or plasma copper

concentration: age subgroup

analysis

74.16 months to $<1$ year

74.21 to $<5$ years

75 Serum or plasma copper

concentration: dose subgroup analysis

75.10 to $<5 \mathrm{mg}$

75.25 to $<10 \mathrm{mg}$

75.310 to $<15 \mathrm{mg}$

$75.420 \mathrm{mg}$ or more

76 Serum or plasma copper

concentration: duration

subgroup analysis

76.10 to $<6$ months

76.26 to $<12$ months

76.312 months or more

77 Serum or plasma copper concentration: iron cointerventions subgroup analysis 77.1 Iron co-intervention

77.2 No iron co-intervention

78 Serum or plasma copper concentration: Formulation subgroup analysis

78.1 Solution

78.2 Pill/Tablet
5

Std. Mean Difference (Fixed, 95\% CI) Std. Mean Difference (Fixed, 95\% CI) Std. Mean Difference (Fixed, 95\% CI) Std. Mean Difference (Fixed, 95\% CI) Std. Mean Difference (Fixed, 95\% CI)

Std. Mean Difference (Fixed, 95\% CI) Std. Mean Difference (Fixed, 95\% CI) Std. Mean Difference (Fixed, 95\% CI) Std. Mean Difference (Fixed, 95\% CI)

Std. Mean Difference (Fixed, 95\% CI) Std. Mean Difference (Fixed, 95\% CI) Std. Mean Difference (Fixed, 95\% CI) 439

Risk Ratio (Fixed, 95\% CI)
$0.88[0.73,1.05]$

$1.04[0.91,1.18]$

$0.99[0.89,1.10]$

$1.02[0.89,1.17]$

$0.94[0.79,1.11]$

$0.99[0.89,1.10]$

$0.90[0.75,1.08]$

$1.05[0.91,1.20]$

0.88 [0.56, 1.37]

0.22 [0.14, 0.29]

$0.22[0.15,0.30]$

$-0.38[-0.99,0.23]$

0.22 [0.14, 0.29]

$0.11[-0.02,0.24]$

$0.26[0.17,0.35]$

$0.20[0.13,0.27]$

$0.08[-0.12,0.27]$

$0.31[0.13,0.49]$

$0.01[-0.10,0.12]$

0.46 [0.33, 0.59]

$0.22[0.14,0.29]$

$0.44[0.33,0.55]$

$0.08[-0.04,0.20]$

$-0.06[-0.24,0.11]$

0.22 [0.14, 0.29]

$0.10[-0.05,0.25]$

$0.25[0.17,0.33]$

$0.46[0.38,0.53]$

$0.37[0.29,0.46]$ $0.83[0.65,1.01]$ 


\section{CONTRIBUTIONSOFAUTHORS}

JJ, EMW, AI, SD, and ZB contributed to the background. EMW and JJ were primarily responsible for the methods. JJ, EMW, and AI developed the search strategy with Margaret Anderson. JJ executed the first literature search, and EMW and AI executed the update. JJ, EMW, AI, EC, and AI reviewed citations for inclusion. Disagreements were resolved through consultation with a third author. JJ, EMW, AI, SD, XHC, and AJ extracted data. JJ and EMW entered outcome data into RevMan, analysed the data, and made the tables. EMW, JJ, and AI wrote the results and discussion. EMW and AI drafted the 'Summary of findings' table, which was agreed on by all authors. $\mathrm{ZB}$ contributed to the writing and interpretation of findings.

\section{DECLARATIONSOF INTEREST}

Evan Mayo-Wilson - none known.

Jean Junior - none known.

Aamer Imdad has published previous reviews about zinc.

Sohni Dean - none known.

Xin Hui Chan - none known.

Evelyn Chan - none known.

Aneil Jaswal - none known.

Zulfiqar A Bhutta was involved in some of the included trials. Zulfiqar was not involved in data extraction of these studies. Zulfiqar has published previous reviews about zinc.

\section{SOURCES OF SUPPORT}

\section{Internal sources}

- Aga Khan University, Pakistan.

Aamer Imdad, Sohni Dean, and Zulfiqar A Bhutta are supported by Aga Khan University, Karachi, Pakistan

- The Centre for Evidence-Based Intervention, UK.

Jean Junior and Evan Mayo-Wilson are supported by the Centre for Evidence-Based Intervention, University of Oxford

\section{External sources}

- No sources of support supplied

\section{DIFFERENCES BETWEEN PROTOCOLANDREVIEW}

1. We eliminated hospitalisation due to severe diarrhoea and hospitalisation due to persistent diarrhoea as outcomes. (Studies only reported hospitalisation due to all-cause diarrhoea, undifferentiated by level of severity or persistence. However, if a child was hospitalised for a diarrhoea episode, this episode would likely be severe and/or persistent.)

2. We re-specified the "Side effects (for example, abdominal pain, nausea, vomiting, diarrhoea)" outcome to be: Study withdrawal, participants with one or more side effect, vomiting episodes, and participants with one or more vomiting episode. Participants with one or more vomiting episode is included in the 'Summary of findings' table.

3. We did not include incidence of severe diarrhoea and incidence of persistent diarrhoea in the 'Summary of findings' table.

4. Given the large number of excluded studies, we did not search all excluded study reference lists to identify additional studies.

5. We changed the age subgroup analysis from, "children six months to under five years versus five years to 13 years" to "children six months to under one year, versus one to under five years, versus five years to under 13 years."

Zinc supplementation for preventing mortality, morbidity, and growth failure in children aged 6 months to 12 years of age (Review)

Copyright () 2014 The Cochrane Collaboration. Published by John Wiley \& Sons, Ltd. 
6. We clarified the exclusion of mixed micronutrients and added "powder" as a category to the subgroup analysis for formulation.

7. We added an additional comparison to include zinc versus zinc plus iron.

8. We did not undertake a sensitivity analysis excluding studies from the primary analysis for risk of bias due to incomplete outcome data. Effects were more likely to be underestimated than overestimated as a result of dropout, so we consider the primary result to be a conservative estimate. 